University of Texas at El Paso

\title{
DigitalCommons@UTEP
}

Open Access Theses \& Dissertations

2013-01-01

\section{Nanocomposite and Mechanically Alloyed Reactive Materials as Energetic Additives in Chemical Oxygen Generators}

Marco Antonio Machado

University of Texas at El Paso, mamachado@miners.utep.edu

Follow this and additional works at: https://digitalcommons.utep.edu/open_etd

Part of the Mechanical Engineering Commons

\section{Recommended Citation}

Machado, Marco Antonio, "Nanocomposite and Mechanically Alloyed Reactive Materials as Energetic Additives in Chemical Oxygen Generators" (2013). Open Access Theses \& Dissertations. 1665.

https://digitalcommons.utep.edu/open_etd/1665 


\title{
NANOCOMPOSITE AND MECHANICALLY ALLOYED REACTIVE MATERIALS AS ENERGETIC ADDITIVES IN CHEMICAL OXYGEN GENERATORS
}

\author{
MARCO ANTONIO MACHADO
}

Department of Mechanical Engineering

\section{APPROVED:}

Evgeny Shafirovich, Ph.D., Chair

Norman D. Love, Ph.D.

David A. Roberson, Ph.D.

Benjamin C. Flores, Ph.D.

Dean of the Graduate School 


\section{Copyright (C)}

by

Marco Antonio Machado

2013 


\section{DEDICATION}

A Dios, por llenar mi vida de bendiciones y oportunidades para ser mejor, por darme la fuerza para terminar mi tesis. A mi tía Socorro Ochoa, mis tíos Arturo y Luz Elena Machado, a Carlos y María Zacarías, a mi tía Amparo, a mi tía Martha, y a mis tíos Jorge y Ludy Armenta por brindarme todo su apoyo y un lugar en su sus hogares para poder seguir asistiendo a la escuela. A mi tía Tere, a quien admiro tanto y de quien he aprendido muchísimo. A mi tío Chutoño, que siempre estuvo al pendiente de mí cuando necesite ayuda. Al Padre Machado que igualmente siempre estuvo al pendiente de mí familia. A todos mis amigos y compañeros en el servicio que siempre me dieron dolores de cabeza, y me los quitaron con risas. Finalmente dedico esta tesis a mis padres, mis hermanas, y a toda mi familia, que son los que me han aguantado toda la vida. Muchas gracias a todos ustedes que hicieron posible que hoy llegara hasta este punto en mi vida. 


\title{
NANOCOMPOSITE AND MECHANICALLY ALLOYED REACTIVE MATERIALS AS ENERGETIC ADDITIVES IN CHEMICAL OXYGEN GENERATORS
}

\author{
by \\ MARCO ANTONIO MACHADO
}

\begin{abstract}
THESIS
Presented to the Faculty of the Graduate School of The University of Texas at El Paso in Partial Fulfillment of the Requirements for the Degree of

MASTER OF SCIENCE

Department of Mechanical Engineering THE UNIVERSITY OF TEXAS AT EL PASO
\end{abstract}

December 2013 


\section{ACKNOWLEDGements}

I would like to thank my advisor and mentor Dr. Evgeny Shafirovich for giving me the opportunity to participate in his research in energetic materials and for all his instruction and advice during all the time while working toward my Master of Science degree. I also want to thank Dr. Edward Dreizin of the New Jersey Institute of Technology, his colleague Dr. Mirko Schoenitz, and his PhD student Yasmine Aly for providing their reactive materials for this research and for useful discussions.

I want to thank the U.S. Department of Defense, Grant Officer's Representative (GOR) Dr. Ralph Anthenien of ARO and Co-GOR Dr. Clifford Bedford of ONR for support through Grant W911NF-12-1-0056 because without this grant this research project would have not been possible.

I specially thank my teammates Daniel Rodriguez, Ashvin Kumar Narayana Swamy, and Armando Delgado with whom I have had the pleasure to work since 2012. Also, I want to thank my teammates Israel Lopez, Andres Contreras and Mohammad Shafiul Alam for their assistance while working on my project.

Finally, I want to thank Dr. Ahsan Choudhuri, Nathaniel Robinson, Laura Barnum, and all

student members of the Center for Space Exploration Technology Research in the Department of Mechanical Engineering for all their support. 


\begin{abstract}
Chemical oxygen generators are widely used for aircraft, spacecraft, submarines, and mine rescue. Oxygen-generating compositions typically include alkali metal chlorate or perchlorate that decomposes at increased temperatures, a transition-metal oxide as a decomposition catalyst, and a metal fuel that reacts with part of the produced oxygen to provide heat for a self-sustained propagation of the decomposition/combustion wave. To increase the oxygen yield per unit mass, it is of interest to minimize the amount of metal fuel, but decreasing its content leads to pulsating combustion and undesired fluctuations of the oxygen flow rate. This work explores the feasibility of replacing iron and tin, currently used in oxygen generators, with reactive materials, produced by arrested reactive milling and by mechanical alloying. Because of their high energy density, easy ignition, and good storability, these materials have the potential to improve the performance characteristics of oxygen generators. Thermodynamic calculations for combustion of sodium chlorate mixed with various reactive materials identified the most attractive additives providing high temperatures and high oxygen yield. Experiments on combustion of sodium chlorate-based mixtures with nanoscale cobalt oxide catalyst and the most promising energetic additives were conducted in an argon environment, using laser ignition. Infrared video recording was used to investigate the thermal wave propagation over the mixture pellet. The experiments have shown that mechanically alloyed $\mathrm{Al} / \mathrm{Mg}$ (1:1 mass ratio) material is a promising alternative to iron and tin, because significantly smaller amounts of this additive are needed for a steady propagation of the combustion wave.
\end{abstract}




\section{TABle OF CONTENTS}

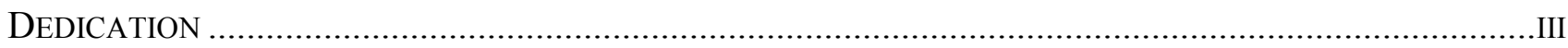

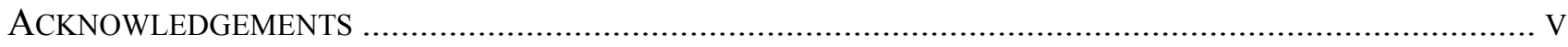

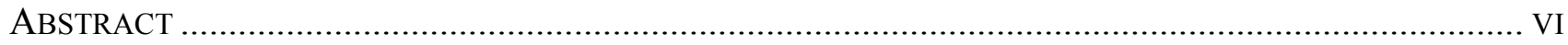

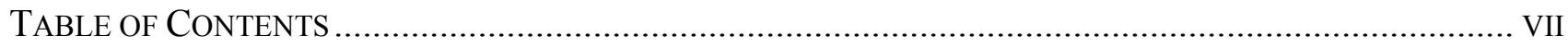

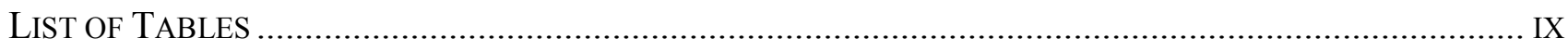

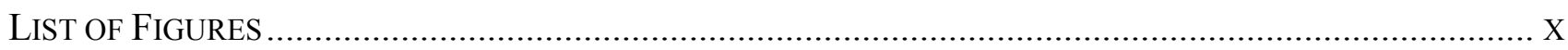

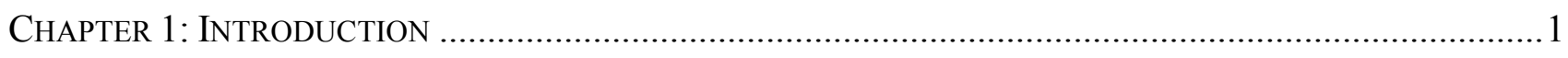

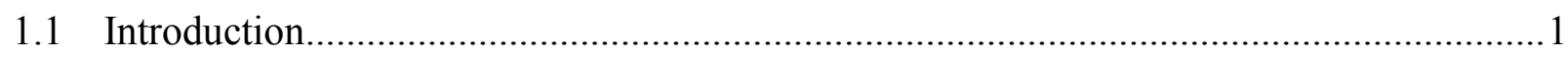

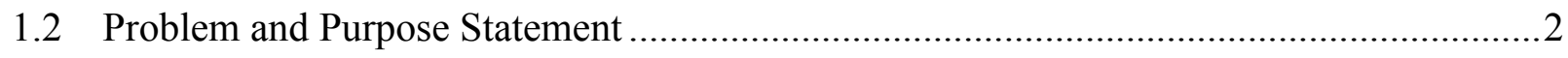

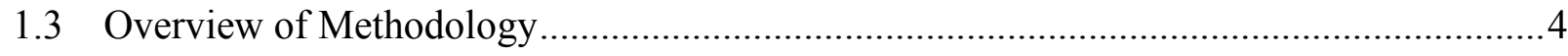

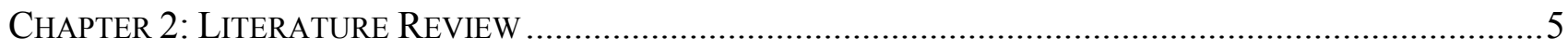

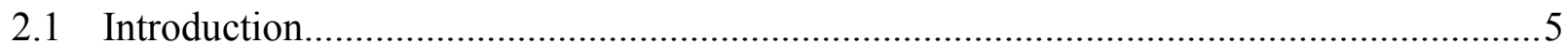

2.2 Oxygen source compound selection ......................................................................... 5

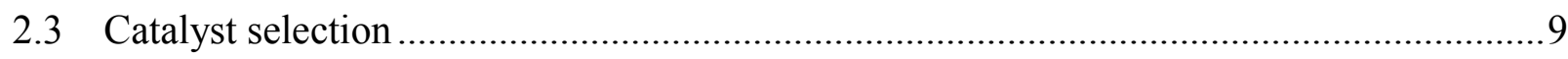

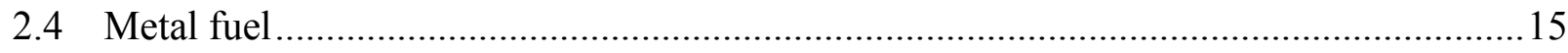

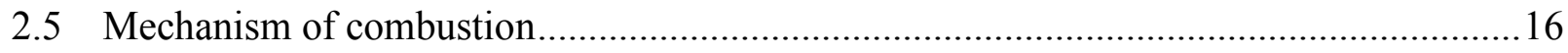

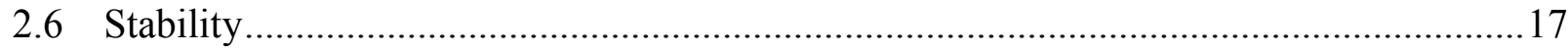

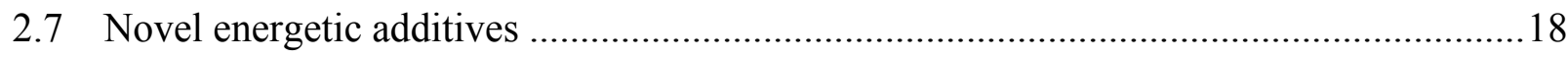

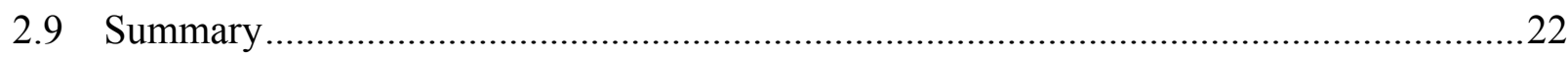

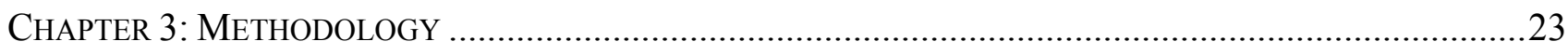

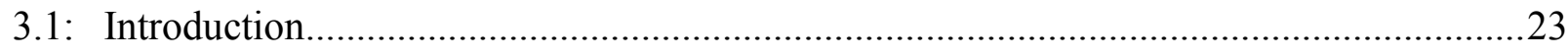

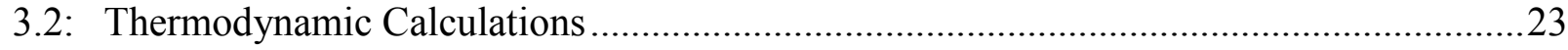

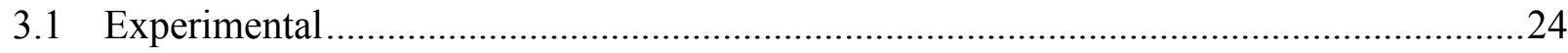

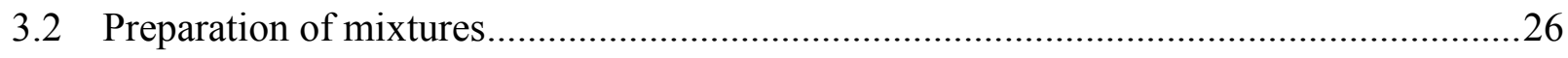

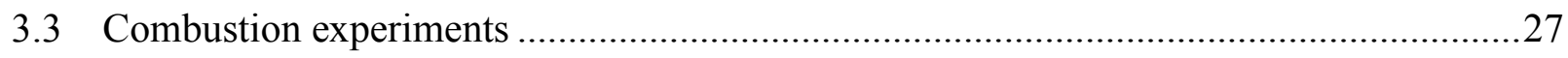

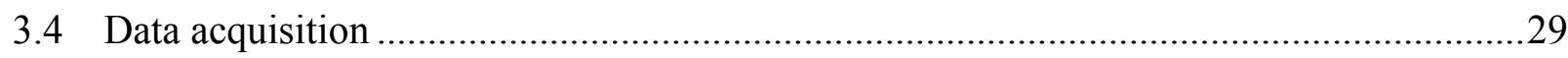

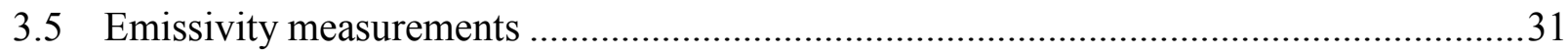

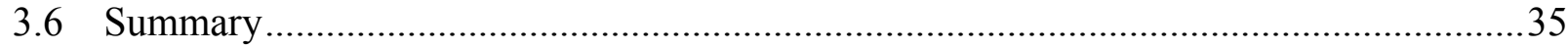




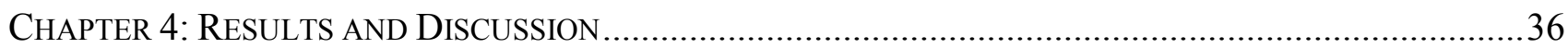

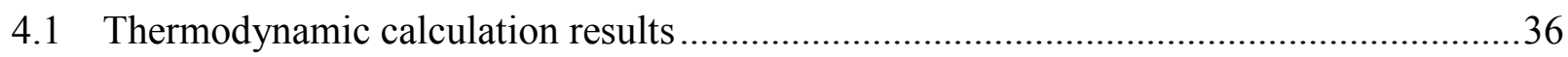

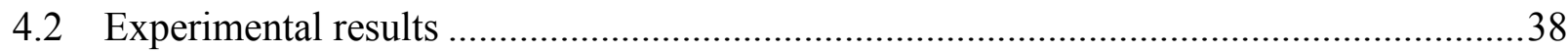

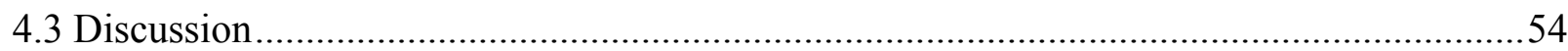

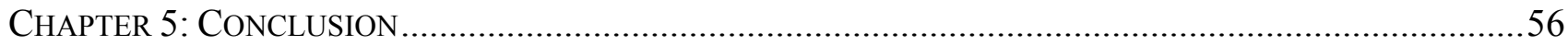

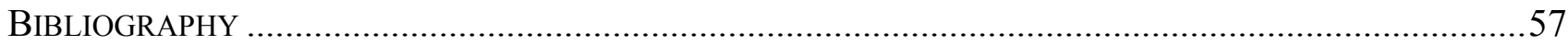

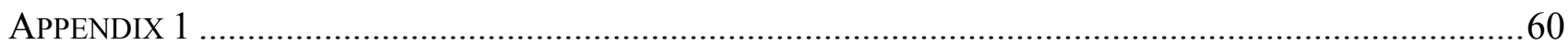

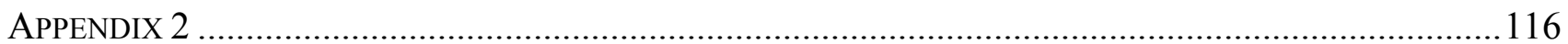

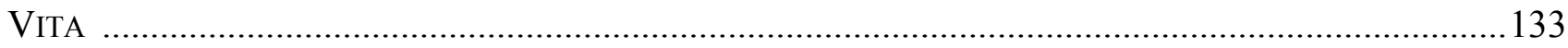




\section{LIST OF TABLES}

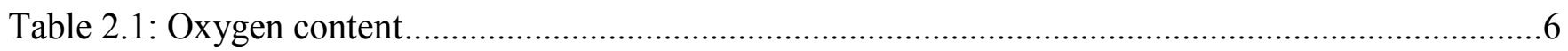

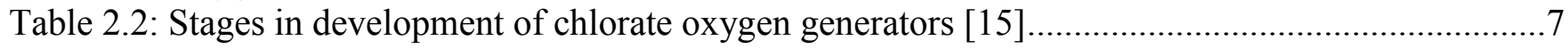

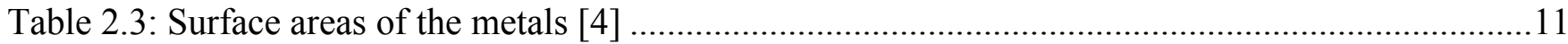

Table 2.4: Reactive nanomaterials prepared at NJIT by ARM to date [13] ..................................21

Table 4.1: Calculated amounts of additives to sodium chlorate that provide adiabatic flame temperatures of 600,700 , and $800{ }^{\circ} \mathrm{C}$ and respective mass fractions of molecular oxygen in the products. ................37

Table 4.2: Combustibility of mixtures with $5 \mathrm{wt} \%$ energetic additive..............................................40 


\section{LIST OF FigURES}

Fig. 1.1: Picture of actual chemical oxygen generators...............................................................

Fig. 1.2: Schematic of a typical chemical oxygen generator......................................................2

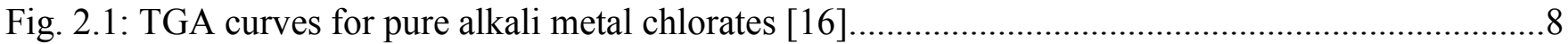

Fig. 2.2: TG curves of $\mathrm{NaClO}_{3}$ catalyzed by metal oxides with different surface areas [4]. .................10

Fig. 2.3: TG curves of $\mathrm{NaClO}_{3}$ catalyzed by metal oxides with high, comparable surface areas [4]......10

Fig. 2.4: TG curves of $\mathrm{NaClO}_{3}$ catalyzed by metal oxides with comparable surface areas [4]. ..............10

Fig. 2.5: TG curves of $\mathrm{NaClO}_{3}$ catalyzed by non-oxide additives [19] ..............................................12

Fig. 2.6: TG curves of $\mathrm{NaClO}_{3}$ catalyzed by copper compounds [19]............................................12

Fig. 2.7: $\mathrm{TG}$ curves of $\mathrm{NaClO}_{3}$ catalyzed by cobalt compounds and manganese compounds [19].........12

Fig. 2.8: Thermal decomposition of some non-oxide metal compounds [19]...................................13

Fig. 2.9: Thermograms of pure $\mathrm{NaClO} 3$ and binary mixtures of $\mathrm{NaClO} 3$ with micron-scale and nano-

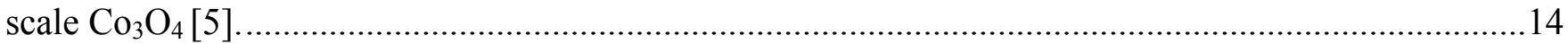

Fig. 2.10: TGA curves for $80 \% \mathrm{NaClO}_{3} / 20 \%$ Metal mixtures in Ar flow [10]. .................................15

Fig. 2.11: TGA curves of $\mathrm{Al}, \mathrm{Fe}, \mathrm{Co}, \mathrm{Ni}$, and $\mathrm{Sn}$ powders in $\mathrm{O}_{2}$ flow [10]......................................16

Fig. 2.12: A backscattered SEM image of the boron titanium nanocomposite powder, where the light

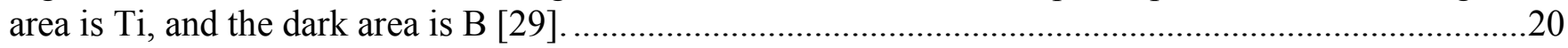

Fig. 2.13: Backscattered SEM images of the $\mathrm{AlNaNO}_{3}, \mathrm{MgNaNO}_{3}, \mathrm{Al}_{0.5} \mathrm{Mg}_{0.5} \mathrm{NaNO}_{3}$ composites [30].

Fig. 3.1: Typical appearance of produced pellets. ........................................................................2

Fig. 3.2: Schematic diagram of the experimental setup for laser ignition of the pellets. ........................28

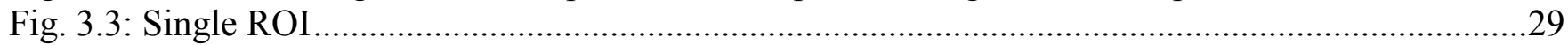

Fig. 3.4: Pellet with 115 ROIs aligned as used in the analysis of the combustion................................30

Fig. 3.5: Schematic of the experiment for measuring the pellet emissivity. ........................................32

Fig. 3.6: Infrared image of the black-body model heated on a hot plate. The scale shows temperature in

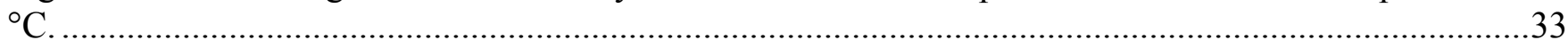

Fig. 3.7: An infrared image of melting pieces of the mixture heated on a hot plate and the temperature

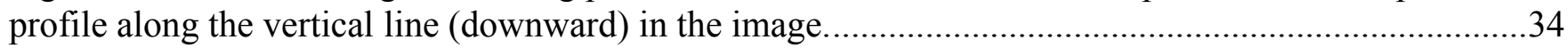

Fig. 4.1: Combustion products of a pellet that broke and separated during combustion. .......................38

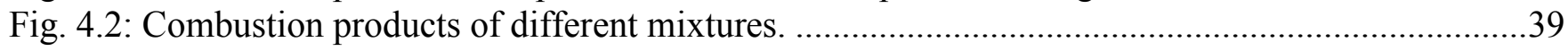

Fig. 4.3: Typical time variation of pressure during steady combustion and cooling; the mixture with 5 $\mathrm{wt} \% \mathrm{Al} / \mathrm{Mg}$ (4.7:5.3 mole ratio). Time zero was selected arbitrarily....................................................39

Fig. 4.4: Infrared images of combustion propagation over the pellet with $5 \mathrm{wt} \% \mathrm{Fe}$.........................41 Fig. 4.5: Temperature-distance profiles at different instants of time $1 \mathrm{~s}$ apart for the pellet with $5 \mathrm{wt} \%$

Fe. The labels indicate time (s) from the start of propagation.....................................................42

Fig. 4.6: Time variation of the maximum temperature in the combustion wave and the distance traveled

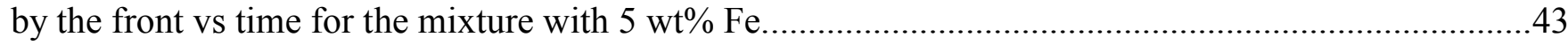

Fig. 4.7: Time variation of the maximum temperature in the combustion wave and the distance traveled

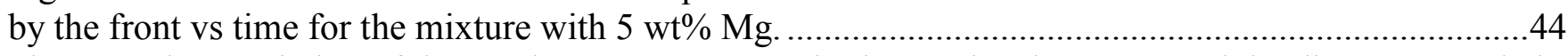

Fig. 4.8: Time variation of the maximum temperature in the combustion wave and the distance traveled by the front vs time for the mixture with $2 \mathrm{wt} \% \mathrm{Mg}$.............................................................4

Fig. 4.9: Time variation of the maximum temperature in the combustion wave and the distance traveled

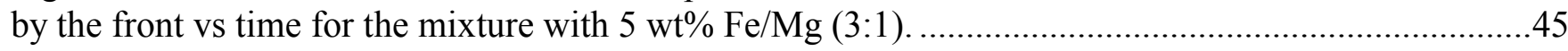

Fig. 4.10: Combustion of mixture with $5 \mathrm{wt} \% \mathrm{~B} / \mathrm{Ti}$ additive ...................................................46

Fig. 4.11: Time variation of the maximum temperature in the combustion wave and the distance traveled

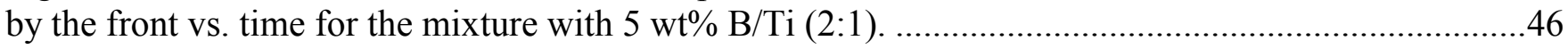


Fig. 4.12: Time variation of the maximum temperature in the combustion wave and the distance traveled by the front vs. time for the mixture with $5 \mathrm{wt} \% \mathrm{Al} / \mathrm{Mg}(4.7: 5.3)$.

Fig. 4.13: Time variation of the maximum temperature in the combustion wave and the distance traveled by the front vs. time for the mixture with $3 \mathrm{wt} \% \mathrm{Al} / \mathrm{Mg}(4.7: 5.3)$.

Fig. 4.14: Time variation of the maximum temperature in the combustion wave and the distance traveled by the front vs. time for the mixture with $3 \mathrm{wt} \% \mathrm{Al} / \mathrm{Mg}(4.7: 5.3)$.

Fig. 4.15: Infrared images of combustion propagation over the pellet with $5 \mathrm{wt} \% \mathrm{Al} / \mathrm{Mg}(4.7: 5.3$ mole ratio).

Fig. 4.16: Temperature-distance profiles at different instants of time $1 \mathrm{~s}$ apart for the pellet with $5 \mathrm{wt} \%$ of $\mathrm{Al} / \mathrm{Mg}$ (4.7:5.3 mole ratio). The labels indicate time (s) from the start of propagation.

Fig. 4.17: Temperature-distance profiles at different instants of time $1 \mathrm{~s}$ apart for the pellet with $3 \mathrm{wt} \%$ of $\mathrm{Al} / \mathrm{Mg}$ (4.7:5.3 mole ratio). The labels indicate time (s) from the start of propagation.

Fig. 4.18: Combustion front velocities of $\mathrm{NaClO}_{3}$-based mixtures with different energetic additives.....51

Fig. 4.19: Maximum temperatures in the combustion front, measured at the pellet surface, for $\mathrm{NaClO}_{3}$ based mixtures with different energetic additives.

Fig. 4.20: Time variation of pressure during combustion of the pellets with $5 \mathrm{wt} \% \mathrm{Fe}$ and $3 \mathrm{wt} \% \mathrm{Al} / \mathrm{Mg}$.

Time zero was selected arbitrarily.

Fig. 4.21: XRD pattern of the combustion products of the mixture with $5 \mathrm{wt} \% \mathrm{Al} / \mathrm{Mg}$ (4.7:5.3 mole ratio) after removing $\mathrm{NaCl}$. 


\section{CHAPTER 1: INTRODUCTION}

\subsection{Introduction}

Chemical oxygen generators, also called self-contained oxygen generators (SCOG) and oxygen candles, are widely used for military and civilian applications, including aircraft, spacecraft, submarines, and mine rescue [1]. Commercial airplanes, for example, use chemical oxygen generators to provide oxygen to the passengers in case of depressurization of the cabin.

Producing oxygen in a chemical manner provides multiple advantages over compressed oxygen systems, given the fact that chemical gas generators are substantially lighter. Installation is easier owing to the reduced number of components, and also allows for easier reconfiguration in case of need to change its location. An oxygen generator is safer than compressed oxygen systems due to the lack of high-pressure oxygen; note that oxygen is produced only when it is needed. In contrast with compressed gas systems where oxygen pressure levels and leakages need to be constantly monitored, chemical oxygen generators do no need maintenance. These advantages make chemical oxygen generators very attractive when compared to high pressure oxygen storage systems [2]. Figure 1.1 shows a photograph of oxygen generators for aircraft; the length of these devices varies from 6 to $8 \mathrm{~cm}$. Figure 1.2 shows the schematic of a typical oxygen candle.

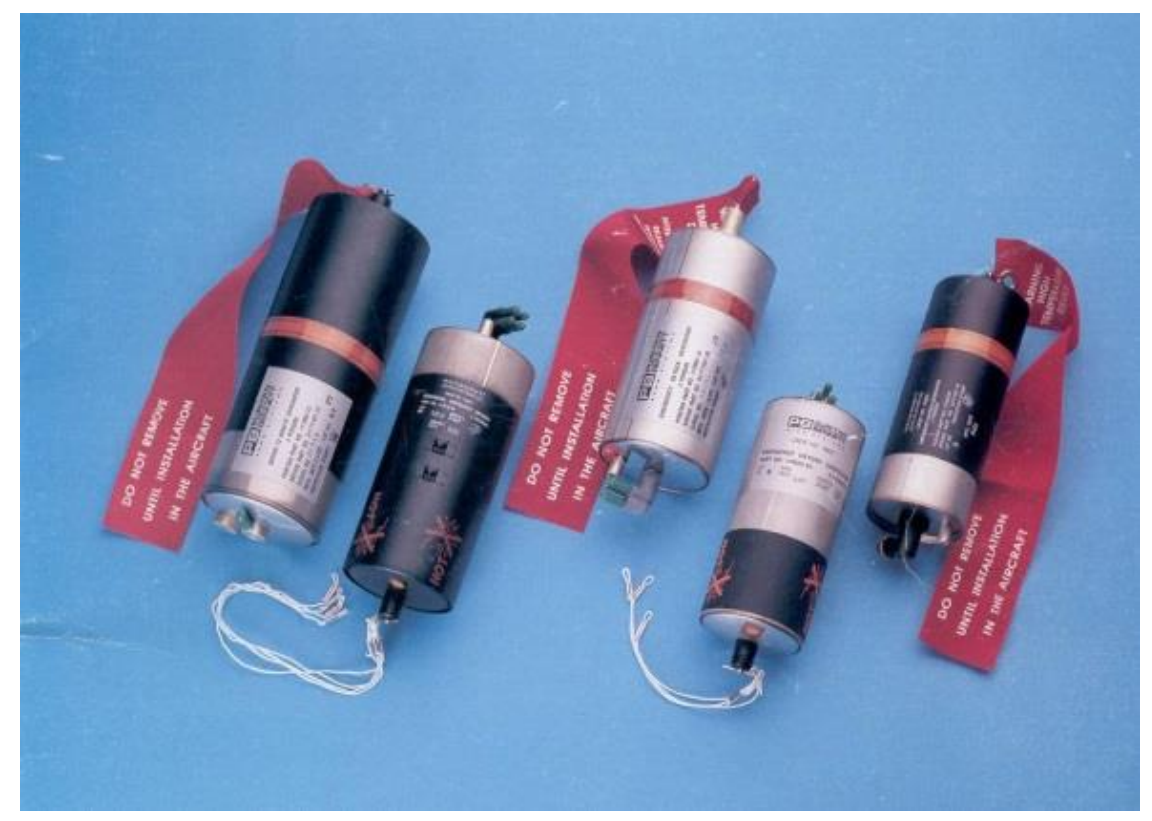

Fig. 1.1: Photograph of chemical oxygen generators for aircraft. 


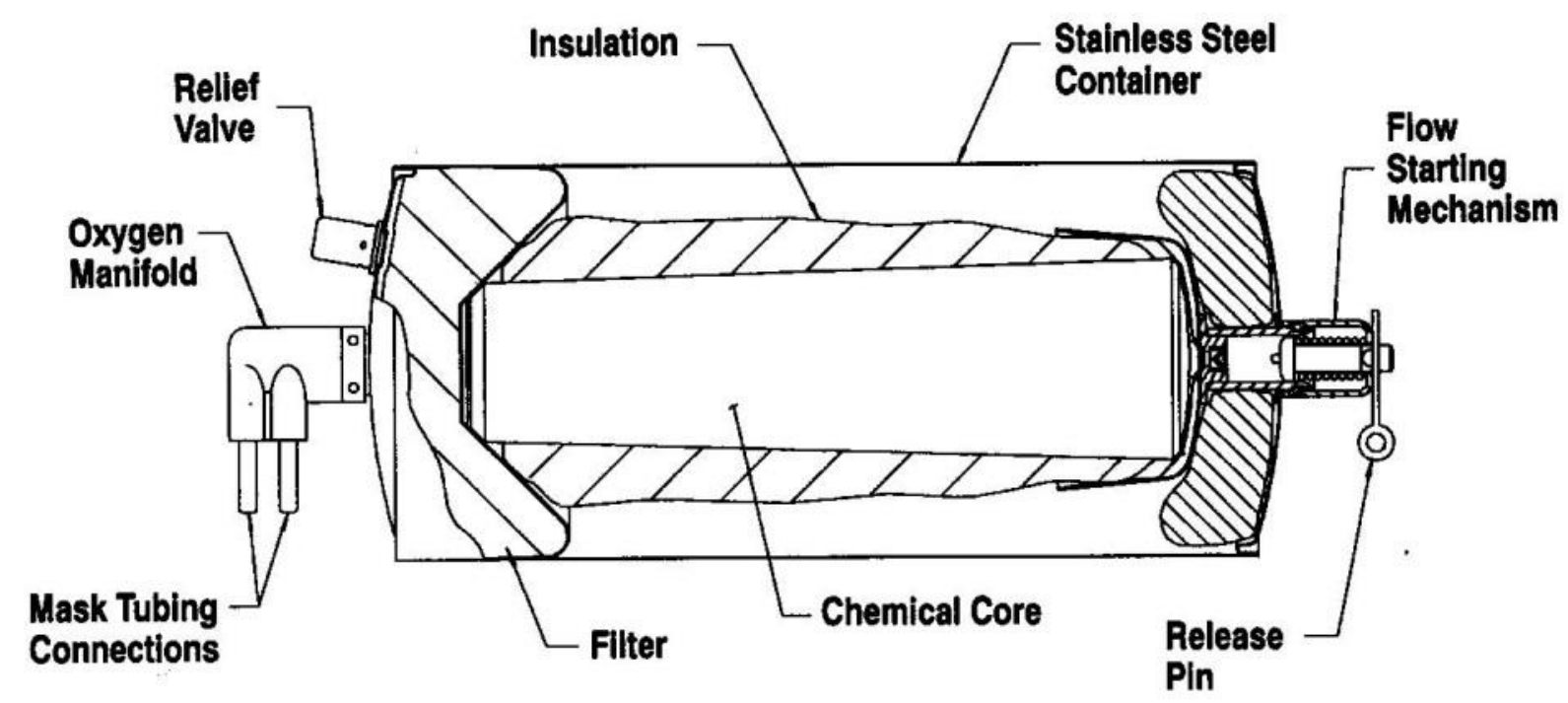

\section{Cross-section View of a Chemical Oxygen Generator}

Fig. 1.2: Schematic of a typical chemical oxygen generator for aircraft.

Oxygen-generating compositions typically include alkali metal chlorate or perchlorate (e.g., sodium chlorate, $\mathrm{NaClO}_{3}$ ) that decomposes at increased temperatures with release of oxygen. Increased temperatures are achieved by an exothermic reaction between an added metal fuel (e.g., iron or tin) and part of the product oxygen. The compositions also include a transition-metal oxide catalyst (e.g., cobalt oxide, $\left.\mathrm{Co}_{3} \mathrm{O}_{4}\right)$ that significantly decreases the decomposition temperature of the oxygen source $[3,4,5]$. As a result, oxygen is generated through a self-sustained propagation of the decomposition/combustion wave over the generator's chemical core $[6,7,8]$.

\subsection{Problem and Purpose Statement}

Despite the fact that $\mathrm{NaClO}_{3}$ has a negative formation enthalpy, $-365.8 \mathrm{~kJ} / \mathrm{mol}$ [9] and its decomposition to $\mathrm{NaCl}$ and $\mathrm{O}_{2}$ releases heat, it is not able to maintain a self-sustained combustion due to heat losses; consequently, energetic additives need to be added. To guarantee a self-sustained combustion, a significant amount of energetic additive is included; however, this may create deterioration in the generator's effectiveness $[6,7,8,10,11,5]$. The metal fuel typically consumes about 
$5 \%$ of the produced oxygen and provides combustion temperatures between $500-750{ }^{\circ} \mathrm{C}$ [12]. If the amount of metal fuel is decreased, a higher oxygen yield can be achieved; therefore, it is important to reduce the metal fuel content for increasing the efficiency of the oxygen candles. With decreasing the energetic additive content, however, combustion instability phenomena such as auto-oscillations, pulsating and/or spin combustion may occur [6]. These phenomena prove that combustion is at its limit and it might cease at any moment; needless to say, a chemical oxygen generator that does not provide the expected amount of oxygen, or that stops burning all of a sudden, is not reliable.

To have an efficient and reliable oxygen generator is extremely important because in case of an emergency, human lives depend on an oxygen generator. A key feature to provide a higher oxygen yield is to find a better energetic additive. For this project, sodium chlorate and cobalt oxide (II, III) are fixed as the oxygen source component and catalyst, respectively. The selection of the best energetic additives is based on the advantages of recent developments in the preparation of nanocomposite and mechanically alloyed reactive materials at the New Jersey Institute of Technology (NJIT).

The energetic additives include metal-metal, metal-metalloid, and metal-oxide (thermite) reactive nanocomposites as well as mechanically alloyed materials [13]. These new energetic materials could replace the metal fuel commonly used in oxygen gas generators. It was hypothesized that with these materials, due to the uniform mixing of components at the nano-scale level, oxygen generators will exhibit improved effectiveness, process stability, and fire safety. Testing this hypothesis involves the measurements of the energetic additive amount needed for self-sustained propagation of the combustion wave, combustion temperature, and the combustion front velocity as well as the identification of unstable phenomena (e.g. combustion pulsations and/or auto-oscillations). Comparison of the combustion characteristics and behaviors for oxygen-generating mixtures with different energetic additives allows one to assess the potential effect of the substitution of commonly used metal fuels by the novel reactive materials. 


\subsection{Overview of Methodology}

Preliminary selection of the best energetic additive candidates was based on thermodynamic calculations of the adiabatic combustion temperatures and product compositions. All compounds that require an amount of additive larger than what is used with iron or tin are automatically discarded. Once the best candidates are identified, experiments with them can be conducted.

The first step in the experimental procedure is to set a standard condition with iron, for example, how much iron is needed for a self-sustained combustion (e.g. weight percent additive, wt $\%$ ). The second step is to characterize the combustion of iron - sodium chlorate mixture by measuring the combustion characteristics (front velocity and combustion temperature) and investigating the combustion behavior (steady vs pulsating combustion). The same standard is then applied to NJIT energetic material candidates.

Combustion experiments are conducted with a pellet composed of sodium chlorate, cobalt oxide and an energetic additive. The pellet is ignited by a $\mathrm{CO}_{2}$ laser. Diagnostics are provided by an infrared video camera that makes possible the measurements of the temperature and front velocity, and, in addition, allows for the visualization of the combustion wave propagation. A conventional video camera is used to confirm the combustion velocity. The pressure increase is measured with a pressure transducer, which allows one to calculate (using the ideal gas equation) the mass of produced oxygen, which is then compared with the mass change of the pellet. 


\section{CHAPTER 2: LiterATURE REVIEW}

\subsection{Introduction}

Chemical oxygen generators consist mainly of an oxygen source compound (e.g. alkali metal chlorate of perchlorate). Alkali metal chlorates and perchlorates exhibit an exothermic decomposition; however, their exothermicity is not sufficiently high to maintain a self-sustained combustion. For this reason, the composition includes some amount of metal fuel (e.g., iron or tin). Oxidation of the metal by a portion of the produced oxygen liberates additional heat, which ensures the combustion front propagation. The typical mass fraction of metal fuel in oxygen generators is about $5 \mathrm{wt} \%$ [4]. The reactant mixture usually includes a transition-metal oxide as a decomposition catalyst and an alkaline compound which traps traces of chlorine $[5,6]$. These ingredients are mixed uniformly. Sometimes a small concentration of a binder, like water, is used. If water was used, the mixture is dried at about $130{ }^{\circ} \mathrm{C}$ [14]. The mixture is then compacted into a pellet. Chapter 2 gives a description of the limitations with oxygen generators, and the options as to what are the most effective oxygen source compounds, catalytic compounds for sodium chlorate, and potential alternatives for metal fuel produced by mechanical alloying and arrested reactive milling.

\subsection{Oxygen source compound selection}

Alkali metal chlorates and perchlorates as the main compound in chemical oxygen generators have been under investigation for several decades. This selection becomes understandable when a close look is given to the high oxygen content of these compounds. Among the alkali metals, lithium, sodium, and potassium, relatively light elements, are used in chlorate candles, while rubidium, cesium, francium and strontium are too heavy, leading to a significant decrease in the oxygen yield per unit mass of the compound. Table 2.1 shows the oxygen content in chlorates and perchlorates of lithium, sodium and potassium . Lithium perchlorate is the compound that carries the most oxygen by unit mass. 
Table 2.1: Oxygen content

\begin{tabular}{|c|c|}
\hline Compound & $\begin{array}{c}\text { Oxygen } \\
\text { Content (\%) }\end{array}$ \\
\hline $\mathrm{LiClO}_{4}$ & 58.69 \\
\hline $\mathrm{NaClO}_{4}$ & 52.27 \\
$\mathrm{KClO}_{4}$ & 46.19 \\
$\mathrm{LiClO}_{3}$ & 53.01 \\
\hline $\mathrm{NaClO}_{3}$ & 45.1 \\
$\mathrm{KClO}_{3}$ & 39.17 \\
\hline
\end{tabular}

Chemical oxygen generators increased in popularity during World War II [14]. Table 2.2 shows the initial composition, properties, and some product gases of the oxygen candles produced at that time. The varying number of components in the oxygen candles reflects the experimental trials regarding selection of the best components, especially noticeable with the catalysts. It is worth noticing that the maximum oxygen yield at that time was about 34\% [15] of the initial mass of the mixture. Sodium chlorate and potassium perchlorate, reported in the Table 2.2, remain the most popular oxygen source compounds used in chemical oxygen generators even 60 years after publication [15]. 
Table 2.2: Stages in development of chlorate oxygen generators [15]

\begin{tabular}{|c|c|c|c|c|c|c|c|}
\hline & $\begin{array}{c}\text { German } \\
\text { "Naszogen" } \\
(1930)\end{array}$ & French & $\begin{array}{l}\text { Japanese Aircraft } \\
\text { (In Military } \\
\text { Service } 1941 \text { - 42) }\end{array}$ & $\begin{array}{l}\text { British I } \\
(1942)\end{array}$ & $\begin{array}{l}\text { Oldbury } \\
\text { Co. (for } \\
\text { N.R.L } 1942 \\
-43 \text { ) }\end{array}$ & $\begin{array}{c}\text { British II (1943) } \\
\text { Trial Service in } \\
\text { Submarines, } 1944\end{array}$ & $\begin{array}{l}\text { Naval Research } \\
\text { Laboratory }{ }^{a}, \\
\text { Fused and Cast } \\
(1944-45)\end{array}$ \\
\hline \multicolumn{8}{|c|}{ Composition, Weight \% } \\
\hline \multicolumn{8}{|l|}{$\mathrm{O}_{2}$ Source } \\
\hline $\mathrm{kClO}_{4}$ & & 40 & $\ldots$ & $\ldots$ & $\ldots$ & $\ldots$ & $\ldots$ \\
\hline $\mathrm{kClO}_{3}$ & $?$ & 40 & $75-76$ & 72.5 & $\ldots$ & $\ldots$ & $\ldots$ \\
\hline $\mathrm{NaClO}_{3}$ & & $\ldots$ & $\ldots$ & $\ldots$ & 74 & 79 & 80 \\
\hline \multicolumn{8}{|l|}{ Supplementary heat } \\
\hline $\mathrm{C}$ & .. & 2 & $0.4^{b}$ & Traces & $<0.005^{b}$ & Traces & $<0.001^{b}$ \\
\hline $\mathrm{Fe}$ & 10 & $\ldots$ & $0-2.0$ & 12.5 & 10 & 5.5 & 10 \\
\hline \multicolumn{8}{|l|}{ Binder } \\
\hline Asbestos fiber & & $\ldots$ & $0-3.9$ & 12.1 & $\ldots$ & 12.6 & $\ldots$ \\
\hline Infusorial earth & & 15 & $\ldots$ & $\ldots$ & $\ldots$ & $\ldots$ & $\ldots$ \\
\hline Siliceous filler & ? & $\ldots$ & $0-5.3$ & $\ldots$ & $\ldots$ & $\ldots$ & $\ldots$ \\
\hline Fiberglass & & $\ldots$ & $\ldots$ & $\ldots$ & 12 & $\ldots$ & 6 \\
\hline \multicolumn{8}{|l|}{ Other ingredients } \\
\hline Iron oxides & & 3 & $15,6-19.2$ & $\ldots$ & $\ldots$ & $\ldots$ & $\ldots$ \\
\hline Cu powder & & $\ldots$ & $\ldots$ & 0.8 & $\ldots$ & 0.8 & $\ldots$ \\
\hline $\mathrm{NiCO}_{3}$ & ? & $\ldots$ & $\ldots$ & 0.1 & $\ldots$ & 0.1 & $\ldots$ \\
\hline $\mathrm{MnO}_{2}$ & & $\ldots$ & $0-0.6$ & $\ldots$ & $\ldots$ & $\ldots$ & $\ldots$ \\
\hline $\mathrm{BaO}_{2}$ & & $\ldots$ & $\ldots$ & 2 & 4 & 2 & 4 \\
\hline \multicolumn{8}{|c|}{ Properties } \\
\hline Density, $\mathrm{g} / \mathrm{ml}$ & & & 1.8 & 1.8 & 2 & 1.7 & 2.45 \\
\hline Oxygen yield, wt. \% & & & 27.5 & $25.2^{b}$ & 30.5 & $34.0^{b}$ & 34.1 \\
\hline \multicolumn{8}{|l|}{ Heat of reaction } \\
\hline Cal./g. material & & & $210^{b}$ & $250^{b}$ & $215,226^{b}$ & $185^{b}$ & $201,198^{b}$ \\
\hline Cal./liter $\mathrm{O}_{2}$ & & & $1100^{b}$ & $1420^{b}$ & 1060 & 730 & 835 \\
\hline \multicolumn{8}{|c|}{ composition of evolved gas } \\
\hline $\mathrm{O}_{2}$ & & & $96 \pm 1$ & $\ldots$ & 99 & $\ldots$ & $99.5+$ \\
\hline $\mathrm{CO}_{2}$ & & & $3.5 \pm 1$ & $\ldots$ & $<1$ & $\ldots$ & $<0.05$ \\
\hline $\mathrm{Cl}_{2}$ & & & $\begin{array}{l}\text { Present but } \\
\text { absorbed in filter }\end{array}$ & 0.001 & 0 & $\cdots$ & 0 \\
\hline $\mathrm{CO}$ & & & 0.1 & 0.08 & 0.03 & $\ldots$ & 0.007 \\
\hline \multicolumn{8}{|c|}{${ }^{a}$ Now being produced by Mine Safety Appliances Company } \\
\hline${ }^{\mathrm{b}}$ Calculated Values & & & & & & & \\
\hline
\end{tabular}

In 1964, Markowitz [16] stated that alkali metal perchlorates possess a higher thermal stability when compared with the corresponding chlorate. If a compound is thermally stable, higher operating temperatures are needed in the chemical oxygen generator, and for that reason, this thermal stability is an undesired property. Chlorates are preferred instead of perchlorates due to decomposition at lower 
temperatures. A differential thermal analysis (DTA) study was performed over pure alkali metal chlorates (e.g. no catalyst or metal fuel was added for this study) [16]. Figure 2.1 shows that the heavier the alkali metal, the more thermally stable the compound is. The first compound to start decomposing is $\mathrm{LiClO}_{3}$, while the last compound is $\mathrm{CsClO}_{3}$. The onset temperature of rapid decomposition is $367{ }^{\circ} \mathrm{C}$ for $\mathrm{LiClO}_{3}, 465{ }^{\circ} \mathrm{C}$ for $\mathrm{NaClO}_{3}$, and $472{ }^{\circ} \mathrm{C}$ for $\mathrm{KClO}_{3}$. For the remaining components, the oxygen yield decreased substantially and the decomposition temperature increased very little.

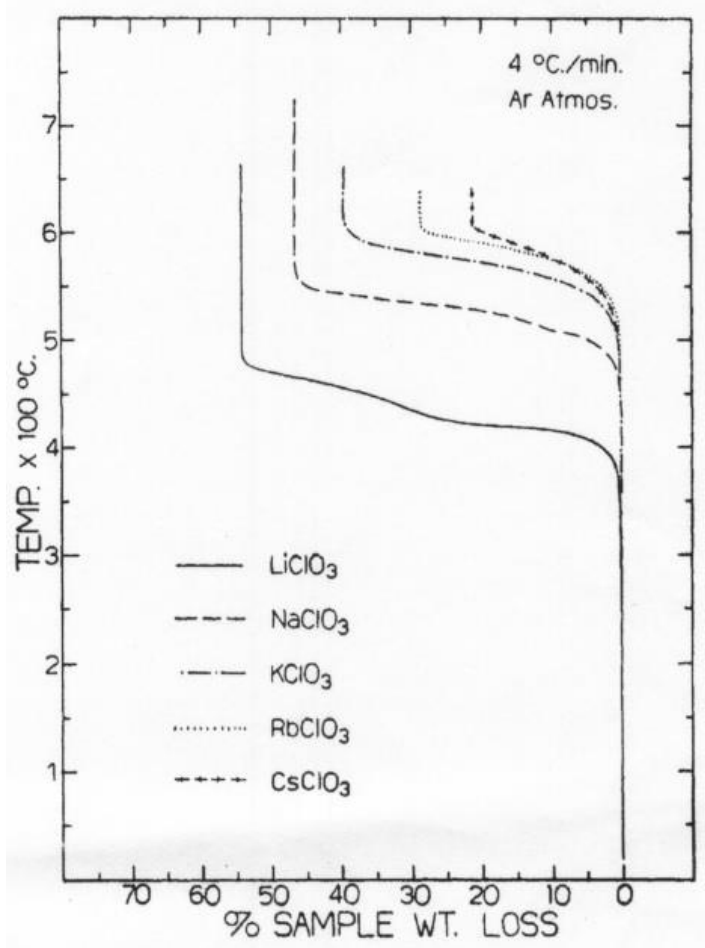

Fig. 2.1: TGA curves for pure alkali metal chlorates [16].

When deciding what compound to use as a source of oxygen for chemical oxygen generators, some aspects need to be taken into account. A high oxygen yield of the compound, a low decomposition temperature, a high rate of decomposition, a minimal released of chlorine gas (highly toxic), and handling conditions. The compounds with the lowest decomposition temperature and high oxygen yield are $\mathrm{LiClO}_{3}, \mathrm{NaClO}_{3}$, and $\mathrm{KClO}_{3}$. Lithium chlorate, however, is undesired because it has an extremely hygroscopic nature when is in anhydrous state. Markowitz et al. [16] stated that $\mathrm{LiClO}_{3}$ has to be stored in $\mathrm{P}_{2} \mathrm{O}_{5}$ and only handled in a dry box under a dry inert atmosphere. In addition to handling problems, 
$\mathrm{LiClO}_{3}$ produces considerably more chlorine gas when compared with $\mathrm{NaClO}_{3}$ (no chlorine gas was found in any other chlorate). If the small amount of chlorine produced in $\mathrm{NaClO}_{3}$ is removed, making the produced oxygen breathable, then $\mathrm{NaClO}_{3}$ becomes a more desirable compound than $\mathrm{KClO}_{3}$. In fact, due to the advantages of high weight/volume efficiency, low decomposition temperature, and low cost, Kshirsagar [17] states that sodium chlorate is the best source of oxygen for chemical oxygen generators. In the present project, sodium chlorate is the source of oxygen used for all the experiments.

\subsection{Catalyst selection}

A catalyst effectively lowers the decomposition temperature of the chlorate compound. In 1922, Mellor [18] noticed that some metallic oxides are good catalysts for chlorates and perchlorates. These compounds include manganese dioxide, cupric oxide, ferric oxide, cobaltic oxide, nickelic oxide, and the oxides of vanadium, uranium, and tungsten. In 1993, Zhang [4] conducted several experiments to find the best catalyst for $\mathrm{NaClO}_{3}$. Initial experiments compared the catalytic effect of metal oxide compounds on the thermal decomposition of sodium chlorate. In this study, $\mathrm{NaClO}_{3}$ was mixed with the catalysts in a ratio of $24: 1$. It was concluded that the catalytic activity of a metal oxide toward the decomposition of sodium chlorate is determined by the electron configuration of the metal cation rather than the electronic properties of the oxide. Metal cations with partially filled $d$-orbitals are very active $\left(\mathrm{MnO}_{2}, \mathrm{Fe}_{2} \mathrm{O}_{3}, \mathrm{Co}_{3} \mathrm{O}_{4}, \mathrm{CuO}_{2}, \mathrm{NiO}\right)$, transition metal cations with empty $d$-orbitals configurations are moderately active $\left(\mathrm{ZrO}_{2}, \mathrm{La}_{2} \mathrm{O}_{3}, \mathrm{CeO}_{2}\right)$, and metal cations with filled $d$-orbital or noble gas configuration have only minimal activities $\left(\mathrm{MgO}, \mathrm{CaO}, \mathrm{SiO}_{2}, \mathrm{ZnO}\right.$ and $\left.\mathrm{SnO}_{2}\right) \cdot \mathrm{Cr}^{6+}$ has completely empty $d$-orbitals and accordingly shows a moderate activity similar to the activities of $\mathrm{ZrO}_{2}, \mathrm{La}_{2} \mathrm{O}_{3}$, $\mathrm{CeO}_{2}$. Figures 2.2 to 2.4 compare the decomposition of $\mathrm{NaClO}_{3}$ with different catalysts. In addition, Table 2.3 shows the specific surface area for each of the catalytic compounds used. 


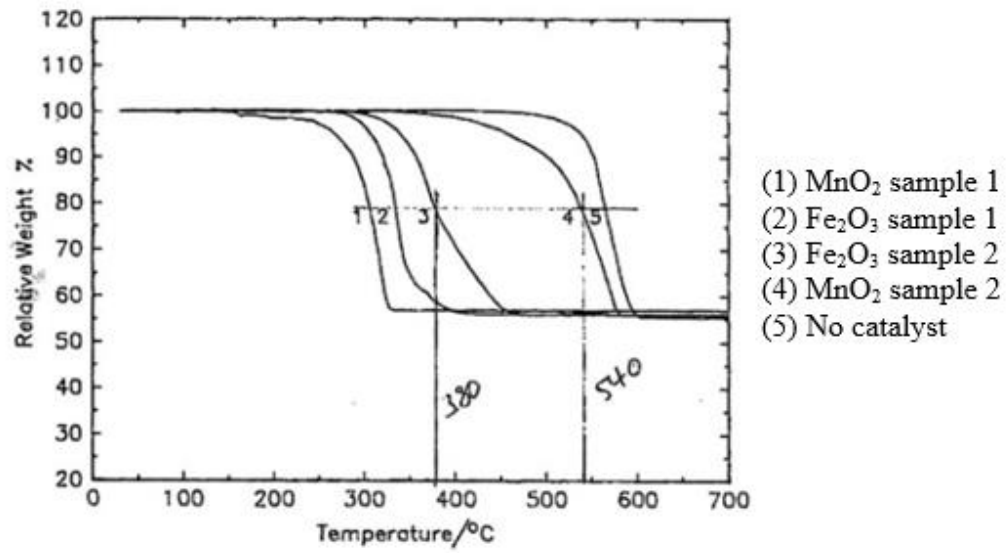

Fig. 2.2: TG curves of $\mathrm{NaClO}_{3}$ catalyzed by metal oxides with different surface areas [4].

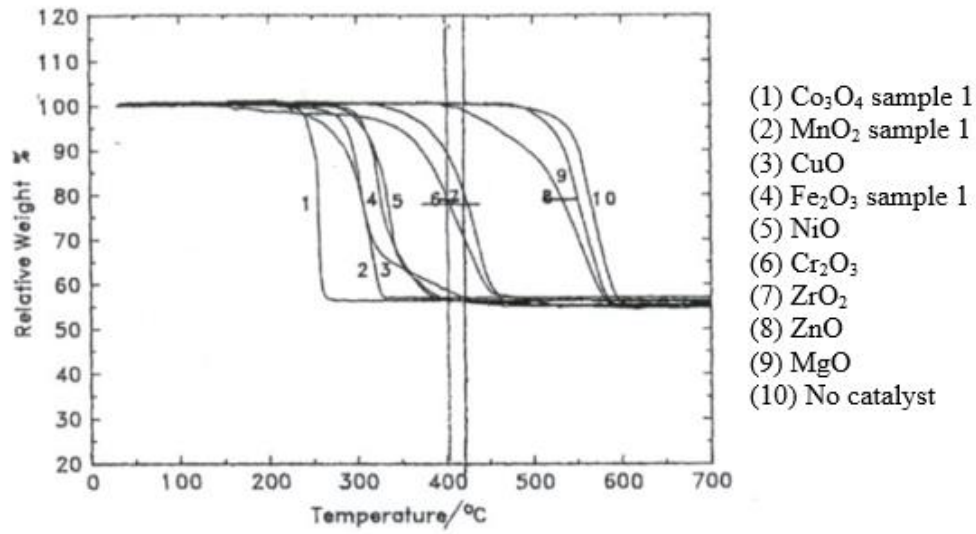

Fig. 2.3: TG curves of $\mathrm{NaClO}_{3}$ catalyzed by metal oxides with high, comparable surface areas [4].

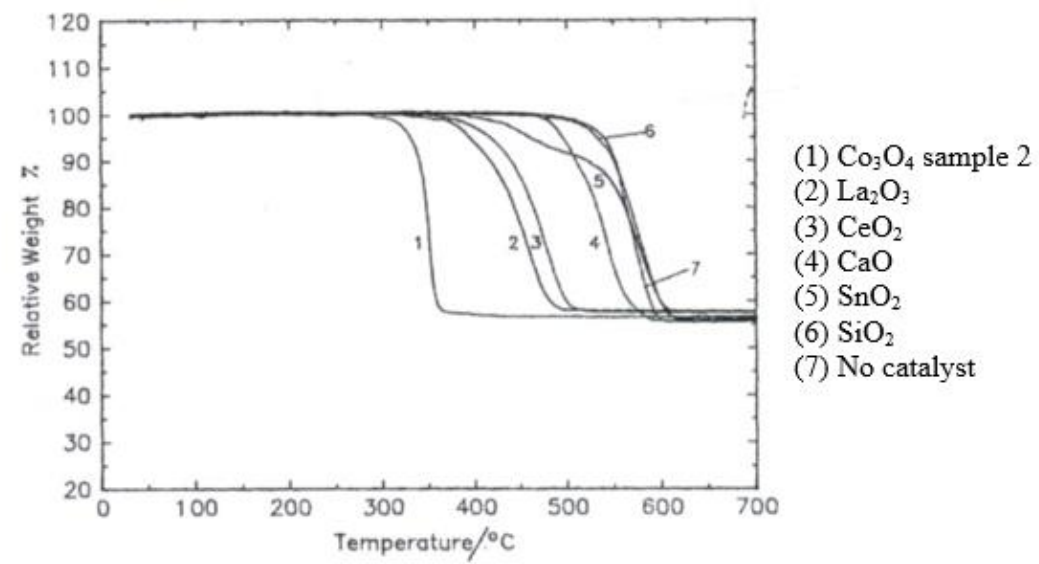

Fig. 2.4: TG curves of $\mathrm{NaClO}_{3}$ catalyzed by metal oxides with comparable surface areas [4]. 
Table 2.3: Surface areas of the metals [4]

\begin{tabular}{|c|c|c|c|}
\hline Compound & $\begin{array}{c}\text { Surface } \\
\text { area } \mathrm{m}^{2} \mathrm{~g}^{-1}\end{array}$ & Compound & $\begin{array}{c}\text { Surface area } \\
\mathrm{m}^{2} \mathrm{~g}^{-1}\end{array}$ \\
\hline $\mathrm{MgO}$ & 67 & $\mathrm{MnO}_{2}(2)$ & 0.5 \\
\hline $\mathrm{MnO}_{2}(1)$ & 58 & $\mathrm{Fe}_{2} \mathrm{O}_{3}(2)$ & 8 \\
\hline $\mathrm{Fe}_{2} \mathrm{O}_{3}(1)$ & 59 & $\mathrm{CeO}_{2}$ & 6 \\
\hline $\mathrm{Co}_{3} \mathrm{O}_{4}(1)$ & 61 & $\mathrm{CaO}$ & 7 \\
\hline $\mathrm{NiO}$ & 62 & $\mathrm{SiO}_{2}$ & 6 \\
\hline $\mathrm{CuO}$ & 63 & $\mathrm{SnO}_{2}$ & 6 \\
\hline $\mathrm{ZnO}$ & 68 & $\mathrm{Co}_{3} \mathrm{O}_{4}(2)$ & 5 \\
\hline $\mathrm{ZrO}_{2}$ & 68 & $\mathrm{La}_{2} \mathrm{O}_{3}$ & 5 \\
\hline $\mathrm{Cr}_{2} \mathrm{O}_{3}$ & 41 & & \\
\hline
\end{tabular}

In a similar study, sodium chlorate was mixed with non-oxide compounds at a mole ratio of 24:1 [19]. This second study followed a similar approach by selecting compounds with partially filled $d$ orbitals, empty $d$-orbital, and noble gas configuration cation in non-metal oxides. The first group included transition metal cations with partially filled $d$-orbitals and showed a high catalytic activity for thermal decomposition of sodium chlorate. First group included: $\mathrm{MnCO}_{3}, \mathrm{MnCl}_{2}-4 \mathrm{H}_{2} \mathrm{O}, \mathrm{MnO}_{2}, \mathrm{MnCo}_{3}$, $\mathrm{FeCl}_{3}-6 \mathrm{H}_{2} \mathrm{O}, \mathrm{CoCl}_{2}-6 \mathrm{H}_{2} \mathrm{O}, \mathrm{Co}_{3} \mathrm{O}_{4}, \mathrm{CoF}_{3}, \mathrm{CuCl}_{2}-2 \mathrm{H}_{2} \mathrm{O}, \mathrm{NiSO}_{4}-7 \mathrm{H}_{2} \mathrm{O}, \mathrm{CuO}, \mathrm{CuSO}_{4}-5 \mathrm{H}_{2} \mathrm{O}$. The second group catalysts included moderately active compounds containing transition metal cations with completely empty orbitals such as $\mathrm{La}(\mathrm{OH})_{3}$, and $\mathrm{Na}_{2} \mathrm{Cr}_{2} \mathrm{O}_{7}-2 \mathrm{H}_{2} \mathrm{O}$. The third group included metal cations with noble gas configurations such as $\mathrm{Li}_{2} \mathrm{SiO}_{3}, \mathrm{NaSnO}_{3}-3 \mathrm{H}_{2} \mathrm{O}, \mathrm{Ca}(\mathrm{OH})_{2}$. Compounds in this third group showed low catalytic activity. Figures 2.5 to 2.8 compares TGA analysis of these compositions where it can be observed that the best catalyst appears to be $\mathrm{CoCl}_{2}-6 \mathrm{H}_{2} \mathrm{O}$, which decomposes completely at $245^{\circ} \mathrm{C}$, and the second active catalyst is $\mathrm{Co}_{3} \mathrm{O}_{4}$, decomposing completely at about $255{ }^{\circ} \mathrm{C}$. Unfortunately, the specific surface area of tested catalysts was not reported. It can be concluded in that $\mathrm{CoCl}_{2}$ lowers the decomposition temperature of sodium chlorate more effectively than the other catalysts tested in this study. 


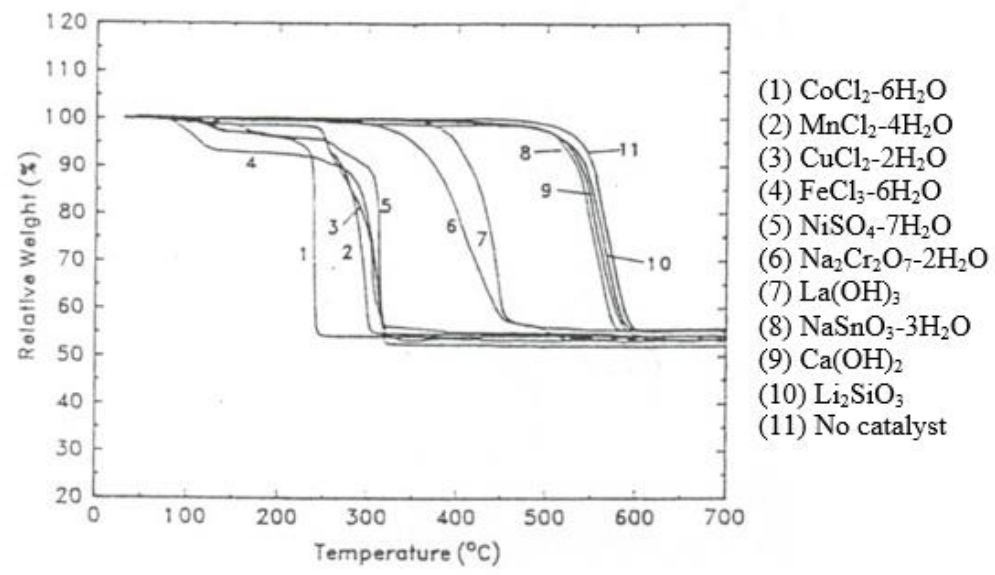

Fig. 2.5: TG curves of $\mathrm{NaClO}_{3}$ catalyzed by non-oxide additives [19].

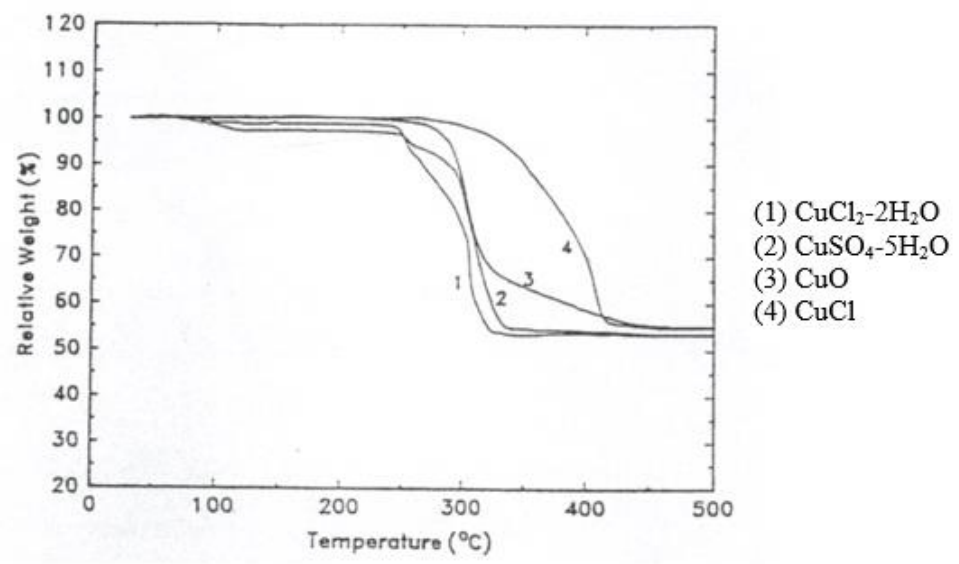

Fig. 2.6: TG curves of $\mathrm{NaClO}_{3}$ catalyzed by copper compounds [19].

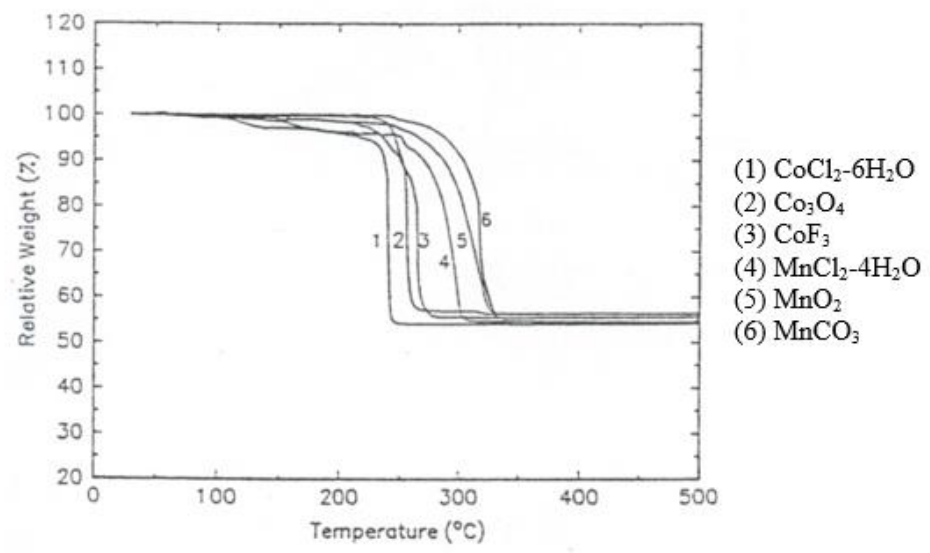

Fig. 2.7: TG curves of $\mathrm{NaClO}_{3}$ catalyzed by cobalt compounds and manganese compounds [19]. 


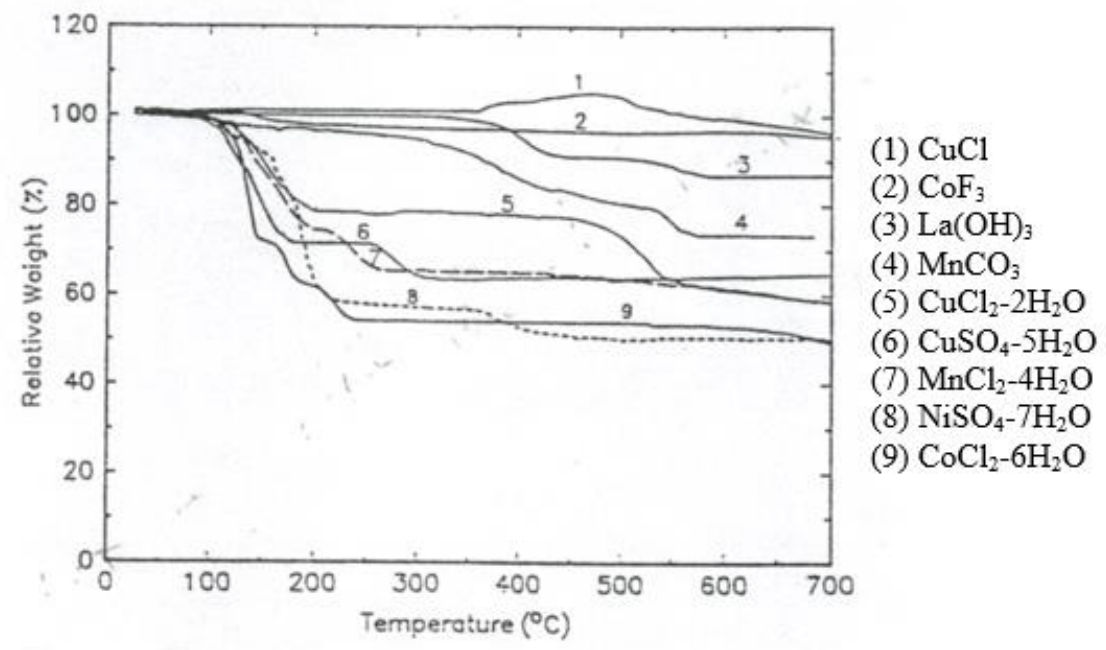

Fig. 2.8: Thermal decomposition of some non-oxide metal compounds [19].

Further, Malich [20] stated in a study about catalyzed sodium chlorate candles that cobalt oxide is used more often because cobalt chloride is difficult to dry. In addition, $\mathrm{Co}_{3} \mathrm{O}_{4}$ is preferred over $\mathrm{CoCl}_{2}$ as a catalyst for oxygen generator due to the possibility of chlorine liberation by the latter after oxidation [17]. If, on the other hand, iron (III) oxide (another very good catalyst as shown by Zhang [Ref]) is compared on a mole basis with cobalt (II, III) oxide with a similar specific surface area, it is clear that cobalt (II, III) oxide is a better catalyst. Comparing these two compounds on a mass basis is difficult, since in Figures 2.3 and 2.4 more cobalt (II, III) oxide is being used than iron (III) oxide by a factor of about 1.5. However, iron (III) oxide Sample 1 has about 7.6 times more surface area than iron (III) oxide Sample 2, and the decomposition temperature of sodium chlorate in both cases remains similar. It can be concluded that increasing the contact area of sodium chlorate with iron (III) oxide, by either adding more iron (III) oxide or increasing its specific surface area, would not provide any significant improvement in the decomposition temperature of sodium chlorate. This sets $\mathrm{Co}_{3} \mathrm{O}_{4}$ as the best catalyst for $\mathrm{NaClO}_{3}$. 


\subsubsection{Cobalt oxide particle size}

The decomposition temperature effectively decreases when a finer catalyst is used because of the increase in the contact area. Shafirovich et al. [5] compared the decomposition temperatures for sodium chlorate mixed with two different cobalt oxide powders (Fig. 2.9). It is seen that nanoscale $\mathrm{Co}_{3} \mathrm{O}_{4}$ (with a specific surface area of $29.61 \mathrm{~m}^{2} / \mathrm{g}$ ) decreases the decomposition temperature more significantly than the micron-scale powder (with a specific surface area of $0.84 \mathrm{~m}^{2} / \mathrm{g}$ ). It is remarkable that the onset temperature decreases by more than $300{ }^{\circ} \mathrm{C}$ with nanoscale $\mathrm{Co}_{3} \mathrm{O}_{4}$ as compared with pure $\mathrm{NaClO}_{3}$. Further, the decomposition interval (the difference between the final and onset temperatures) for nanoscale $\mathrm{Co}_{3} \mathrm{O}_{4}$ is much narrower as compared with the micron-scale $\mathrm{Co}_{3} \mathrm{O}_{4}$. Note that with the nanoscale catalyst, significant decomposition occurs when $\mathrm{NaClO}_{3}$ is still solid (the melting point is $248{ }^{\circ} \mathrm{C}$ ). The authors have shown that adding a higher portion than $3 \mathrm{wt} \%$ of $\mathrm{Co}_{3} \mathrm{O}_{4}$ to the mixture does not have any significant effect. In addition, it can be concluded that increasing the specific surface area from 29.61 to $61 \mathrm{~m}^{2} / \mathrm{g}$ [4] does not provide any significant reduction in the decomposition temperature.

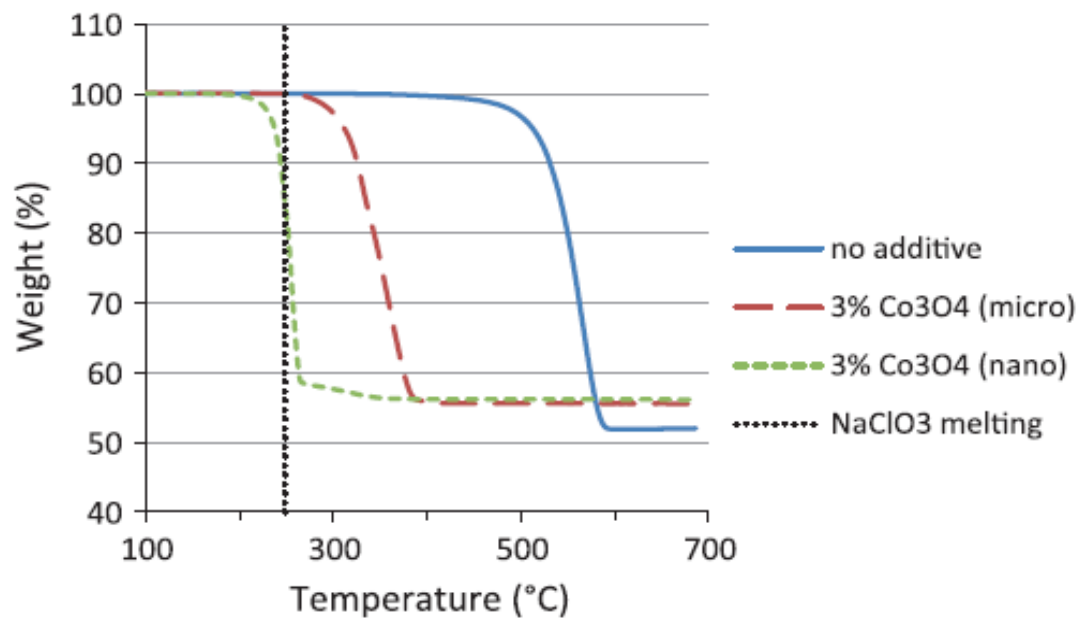

Fig. 2.9: Thermograms of pure $\mathrm{NaClO}_{3}$ and binary mixtures of $\mathrm{NaClO}_{3}$ with micron-scale and nano-scale $\mathrm{Co}_{3} \mathrm{O}_{4}[5]$. 


\section{$2.4 \quad$ Metal fuel}

As stated in the introduction to this chapter, oxidation of metal fuels is needed to provide heat for a self-sustained propagation of the combustion wave. In the previous section, it was discussed that transition metal oxides with partially $d$-orbitals provided the most catalytic effect; therefore, the use of transition metals as fuels may produce metal oxides that exhibit a catalytic activity. If transition metals can serve simultaneously as fuels and catalysts, the number of components in oxygen generators can be decreased.

To study the catalytic effects of $\mathrm{Al}, \mathrm{Fe}, \mathrm{Co}, \mathrm{Ni}$, and $\mathrm{Sn}$ on decomposition of sodium chlorate, Shafirovich et al. [10] conducted a thermal analysis of binary mixtures, $80 \mathrm{wt} \% \mathrm{NaClO}_{3}$ and $20 \mathrm{wt} \%$ metal fuel, in an argon flow. Experiments with $\mathrm{NaClO}_{3} / \mathrm{Sn}$ and $\mathrm{NaClO}_{3} / \mathrm{Co}$ mixtures in oxygen atmosphere were also conducted. Figure 2.10 is a TGA study where it is shown that the largest catalytic effect observed was for Co, where decomposition starts at $250{ }^{\circ} \mathrm{C}$ and is complete at $400{ }^{\circ} \mathrm{C}$. In Fig. 2.10 all powders are -325 mesh, with exception of $\mathrm{Sn} 2$ which size is $1-3 \mu \mathrm{m}$, and $\mathrm{NaClO}_{3}$ is -100 mesh. ( $\mathrm{Sn} 1$ and Sn2 were two different tin powders.) The study concluded that catalytic effects of metals on sodium chlorate decomposition range from negligible for aluminum and tin to significant for cobalt and nickel, while iron exhibits moderate catalytic activity.

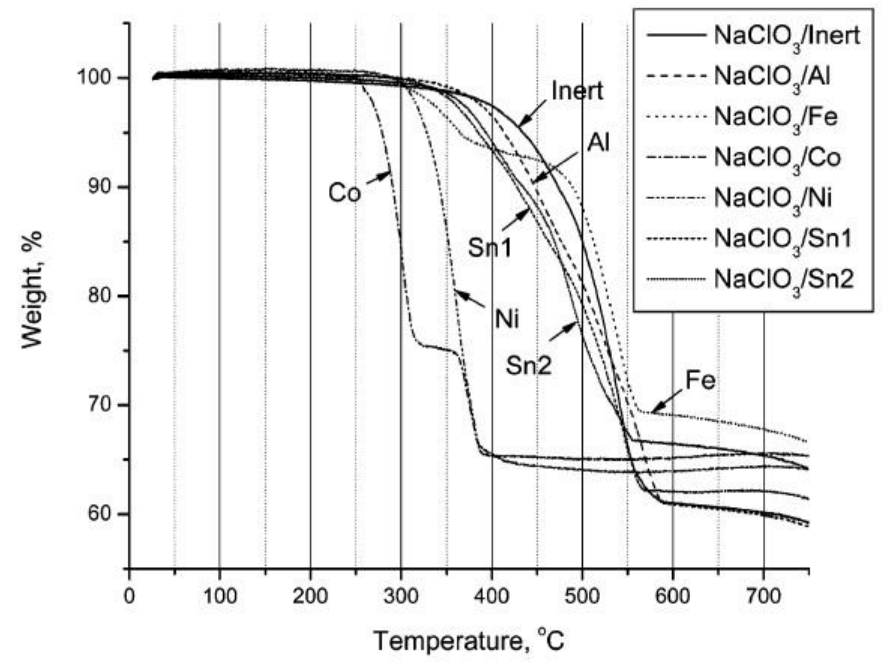

Fig. 2.10: TGA curves for $80 \% \mathrm{NaClO}_{3} / 20 \%$ Metal mixtures in Ar flow [10]. 
Also in the same study [10], thermal analysis for oxidation of metal powders in $\mathrm{O}_{2}$ gas flow was made as shown in Fig. 2.11. To study the oxidation temperature of the metal fuel is important because high oxidation temperatures of the metal fuel may create instabilities during combustion. Among the studied metals, iron and cobalt are the metals that oxidize at the lowest temperatures. In order to select a better metal fuel, the formation enthalpies of the combustion products $\mathrm{Fe}_{2} \mathrm{O}_{3}(-7.34 \mathrm{~kJ} / \mathrm{g})$ and $\mathrm{Co}_{3} \mathrm{O}_{4}$ $(-5.01 \mathrm{~kJ} / \mathrm{g})$ are compared. It is clear that iron is a more suitable metal fuel because it oxidizes at lower temperatures and provides more energy per unit mass than cobalt.

(a)

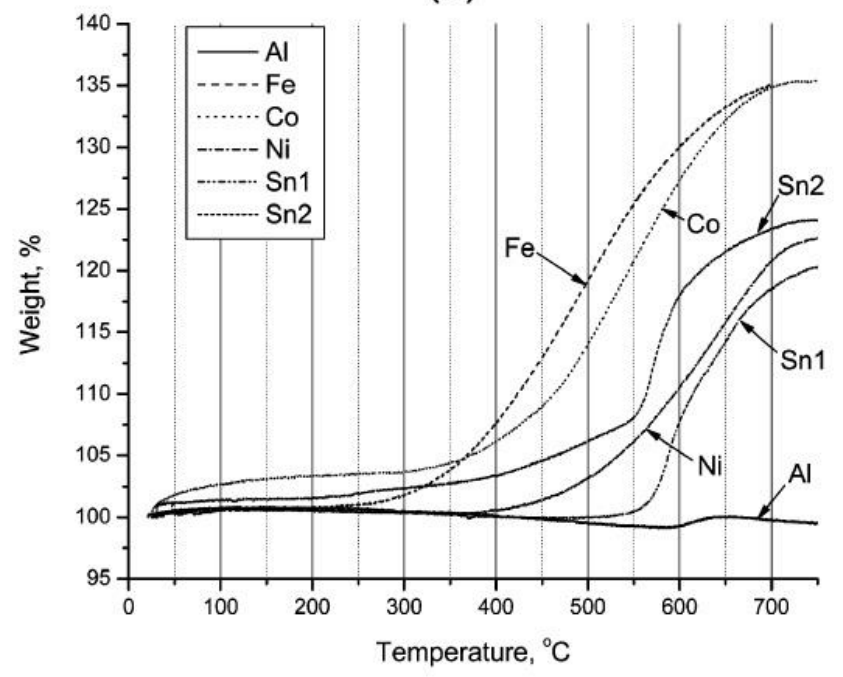

Fig. 2.11: TGA curves of $\mathrm{Al}, \mathrm{Fe}, \mathrm{Co}, \mathrm{Ni}$, and $\mathrm{Sn}$ powders in $\mathrm{O}_{2}$ flow [10].

The metal fuels that are most commonly used in current oxygen generators are iron and tin [6]. Tin has a lower energetic effect, but it has an important advantage. Some carbon is always present in iron powders, leading to generation of carbon monoxide during the operation. Tin powders do not contain any carbon so that the production of carbon monoxide is evaded by using tin as a metal fuel.

\subsection{Mechanism of combustion}

In chemical oxygen generators, the combustion wave propagates because of two interconnected reactions where sodium chlorate decomposes producing oxygen (Eq. 1) and using the heat generated by the metal oxidation (Eq. 2). The oxygen that reacts with the metal fuel (Eq. 2) comes from the chlorate decomposition (Eq. 1). It is important that, on one hand, the metal oxidation reaction (Eq. 2) needs 
oxygen formed in the decomposition reaction (Eq. 1), while, on the other hand, combustion wave propagation is impossible without the heat of reaction (Eq. 2). Additionally, the decomposition of sodium chlorate may include several reaction steps (Eqs. 3-7) [Ref].

$$
\begin{aligned}
& \mathrm{NaClO}_{3} \rightarrow \mathrm{NaCl}+\frac{3}{2} \mathrm{O}_{2} \\
& \mathrm{M}_{\mathrm{X}}+\frac{\mathrm{Y}}{2} \mathrm{O}_{2} \rightarrow \mathrm{M}_{\mathrm{X}} \mathrm{O}_{\mathrm{Y}} \\
& \mathrm{NaClO}_{3} \rightarrow \frac{3}{4} \mathrm{NaClO}_{4}+\frac{1}{4} \mathrm{NaCl} \\
& \mathrm{NaClO}_{4} \rightarrow \mathrm{NaClO}_{3}+\frac{1}{2} \mathrm{O}_{2} \\
& \mathrm{NaClO}_{3} \rightarrow \mathrm{NaClO}_{2}+\frac{1}{2} \mathrm{O}_{2} \\
& \mathrm{NaClO}_{2} \rightarrow \mathrm{NaClO}+\mathrm{O}_{2} \\
& \mathrm{NaClO}_{2} \rightarrow \frac{2}{3} \mathrm{NaClO}_{3}+\frac{1}{3} \mathrm{NaCl}
\end{aligned}
$$

\subsection{Stability}

Decomposition of sodium chlorate in solid state may create a problem. The oxygen produced from the decomposition can build up pressure and force its way out of the mixture block, resulting in an irregular oxygen evolution. In addition, pressure buildup inside a candle block can result in cracks, which would cause irregular reaction front propagation and thus erratic reaction rate. Decomposing in liquid phase does not have those problems and thus has smoother oxygen generation [14]. On the other hand, it has been shown that low-temperature reactant melting stimulates pulsations in combustion front propagation while the high-temperature melting of reaction products stabilizes the combustion wave [8].

Combustion temperatures in oxygen generators are in usually in range from 400 to $800{ }^{\circ} \mathrm{C}$. The lower limit is related to the decomposition of sodium chlorate, while the upper temperature limit is the melting point of sodium chloride byproduct, $801{ }^{\circ} \mathrm{C}$. The melting of $\mathrm{NaCl}$ and the simultaneous evolution of oxygen cause violent ebullition and splattering of the molten material [15]. In actual generators, the combustion temperature is selected to provide the required rate of oxygen generation. 


\subsection{Novel energetic additives}

Metals such as $\mathrm{Al}$ and $\mathrm{Mg}$ have high combustion enthalpies and they are widely used as additives in energetic materials for propellants, explosives, and pyrotechnics. However, the high ignition temperature of $\mathrm{Al}$ and the aging problems of $\mathrm{Mg}$ prevent their use in chemical oxygen generators. As a result, metals with a low exothermicity but with low ignition temperatures and acceptable storage/handling properties such Fe and Sn are currently used. Recent advances in the development of nanocomposite and mechanically alloyed reactive materials indicate that such materials are highly exothermic, ignite at relatively low temperatures, and can be stored for a long time [Refs].

These materials may provide advantages over single metal particles as components of energetic and gas-generating materials. Micron-sized metal particles ignite after a fairly long delay as compared to the initiation of monomolecular energetic compounds; such delays are usually controlled by relatively slow heterogeneous reactions leading up to the self-sustaining combustion of the metal particles. Ignition delays of metal particles are "usually associated with diffusion of oxidizer and/or fuel through the protective layers of metal oxide. Such layers always form on the surface of the metal oxidizing at a low temperature (prior to its ignition) so that the concentration of oxidizer outside the metal particle has only a limited effect on the rate of the critical diffusion processes" [Ref]. Ideally, the best energetic material would be monomolecular (highest possible specific surface area), enabling an exothermic reaction to occur very rapidly [13].

This naturally leads to the idea of using materials with high specific surface area, or materials divided down to the nanoscale to accelerate combustion of metals. An idealized metal-oxidizer system similar to the monomolecular energetic compound can be described as a metastable, homogeneous metal-oxidizer solution in which the components are not chemically bonded. The reaction rate would not be limited then by heterogeneous transport processes, as it is in micron sized metal particles.

Manufacturing and characterization of metal-based reactive nanomaterials including elemental metal nanopowders and various nanocomposite material systems is being researched currently. Because of the nanometer scale of the individual particles, or phase domains, and because of the very high enthalpy of reaction between components of the nanocomposite materials, the final phase compositions, morphology, and thermodynamic properties of the reactive nanocomposite materials may be different 
from those of their micron-scaled counterparts. The well-known high oxidation energies of metallic fuels can now be released very rapidly because of the very high reactive interface areas in such metalbased reactive nanomaterials [13].

In the present work, we used materials obtained by mechanical alloying and arrested reactive milling. These techniques are briefly described in Sections 2.7.1 and 2.7.2.

\subsubsection{Mechanical alloying}

Mechanical alloying (MA) is a dry, high energy ball milling process in which initial blend of powders is repeatedly kneaded together and re-fractured by the action of the ball-powder collisions. The mechanisms of MA include repeated cold welding and fracturing leading to ultrafine mixing and true alloying $[22,23]$. Usually about $1-5$ mass \% process control agents (PCA) are added to the power blend, e.g. stearic acid, hexane, and methanol, to avoid domination of cold welding and formation of large agglomerates.

Mechanical alloying produces highly metastable phases and supersaturated solid solutions [24, $25,26,27]$. These materials have high combustion enthalpies (typical of Al), and reduced ignition delays (i.e., alloys or composites of $\mathrm{Al} / \mathrm{Mg}, \mathrm{Al} / \mathrm{Ti}$, etc. [22]) For example, the tested alloy compositions including $\mathrm{Al}$ with $\mathrm{Mg}$ contents from 10 to $50 \mathrm{wt} \%$, the ignition temperatures varied from 1,170 to $1,020 \mathrm{~K}$ versus about $2,300 \mathrm{~K}$ for pure $\mathrm{Al}[21]$.

\subsubsection{Arrested Reactive Milling}

Nanocomposite reactive materials used in the present research were produced by arrested reactive milling (ARM). In this techiques, the starting materials are mixtures of regular metal, metalloid, and/or oxide powders and a PCA. The initial size is not critical, and starting with very fine or nano-sized material is in fact undesirable. The materials used are capable of reacting exothermically; usually a mixture of metals and metal oxides (thermites). The powders of the selected materials are mixed and ball-milled, but if the mixture is milled for too long, a self-sustained reaction is triggered. If the milling process is interrupted just before reaction starts, fully dense (near theoretical density) micron-sized composite particles with nanoscaled structural features can be produced. The produced particle consists of inclusions of one component, fully embedded into the matrix of the other element, as shown in Figs. 
2.12 and 2.13. Since one material is embedded into a matrix of another compound, aging conditions are improved [28], opening the possibility to use materials non-commonly used in oxygen generators, as it is the case with magnesium. Table 2.4 shows the compounds prepared to date by NJIT [13].

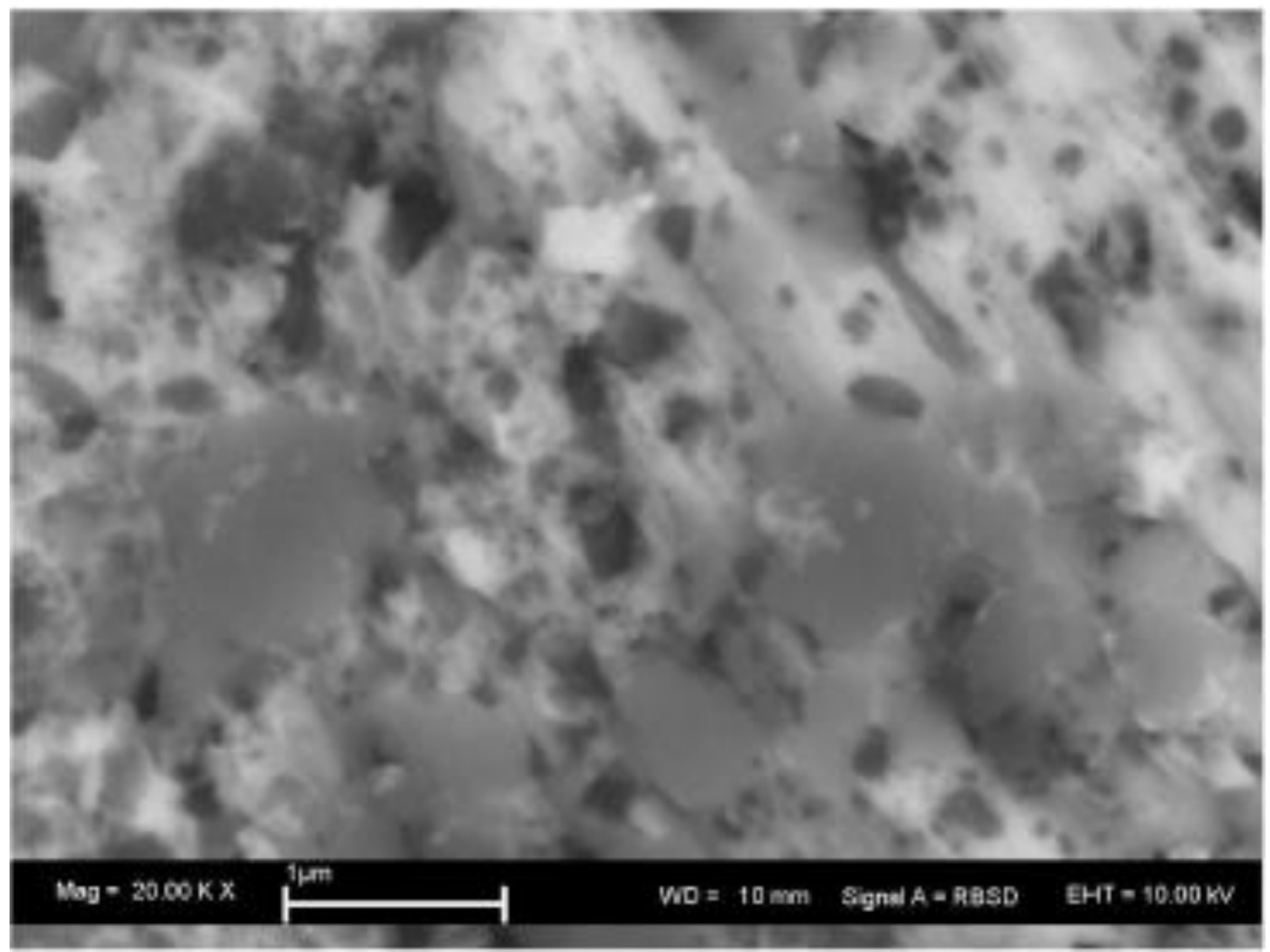

Fig. 2.12: A backscattered SEM image of the boron titanium nanocomposite powder, where the light area is Ti, and the dark area is B [29]. 


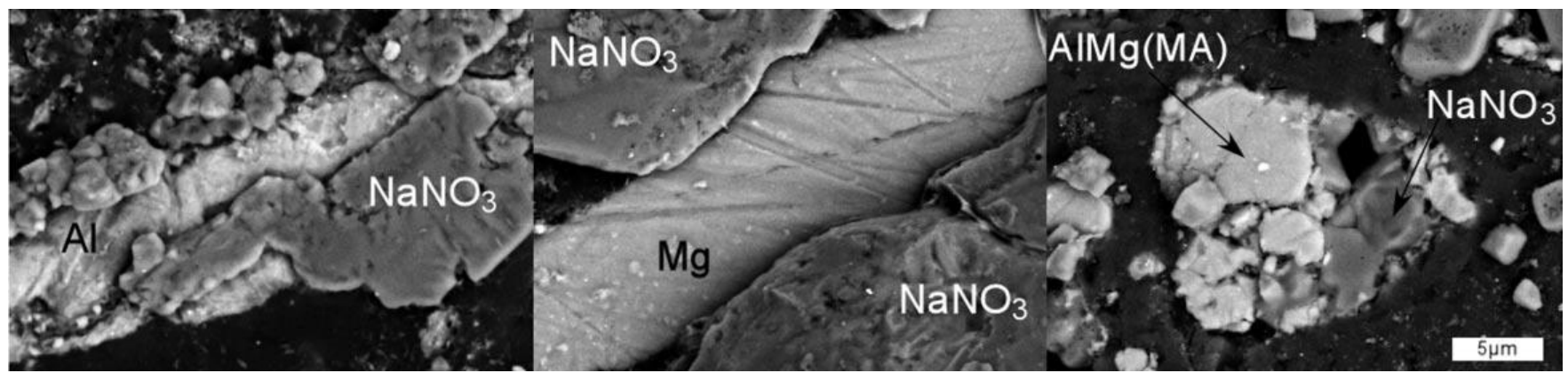

Fig. 2.13: Backscattered SEM images of the $\mathrm{AlNaNO}_{3}, \mathrm{MgNaNO}_{3}, \mathrm{Al}_{0.5} \mathrm{Mg}_{0.5} \mathrm{NaNO}_{3}$ composites [30].

Table 2.4: Reactive nanomaterials prepared at NJIT by ARM to date [13].

\begin{tabular}{|c|c|c|c|c|c|c|c|}
\hline \multicolumn{8}{|c|}{ Nanocomposite Thermites } \\
\hline \multirow[t]{2}{*}{ Fuel } & \multicolumn{7}{|c|}{ Oxidizer } \\
\hline & $\mathrm{Fe}_{2} \mathrm{O}_{3}$ & $\mathrm{MoO}_{3}$ & $\mathrm{CuO}$ & $\mathrm{Bi}_{2} \mathrm{O}_{3}$ & $\mathrm{WO}_{3}$ & $\mathrm{SrO}_{2}$ & $\mathrm{NaNO}_{3}$ \\
\hline Al & $\mathrm{x}$ & $x^{a}$ & $x^{a}$ & $x$ & $x$ & $x$ & $x^{b}$ \\
\hline $\mathrm{Mg}$ & & $x$ & $x$ & & & & $\mathrm{x}$ \\
\hline $\mathrm{Al}_{0.5} \mathrm{Mg}_{0.5}$ & & & & & & & $x$ \\
\hline $\mathrm{MgH}_{2}$ & & $x$ & $x$ & & & & \\
\hline Si & & $x$ & $x$ & $x$ & & & \\
\hline $\mathrm{Zr}$ & & $x$ & $x$ & $x$ & & & $x$ \\
\hline $2 \mathrm{~B}+\mathrm{Ti}^{\mathrm{C}}$ & & & & & & & $x^{b}$ \\
\hline $2 B+Z r^{c}$ & & & & & & & $x^{b}$ \\
\hline \multicolumn{8}{|c|}{ Reactive metal-metalloid composites } \\
\hline B & \multicolumn{7}{|c|}{ Reactive metals: $\mathrm{Ti}, \mathrm{Zr}, \mathrm{Hf}$} \\
\hline \multicolumn{8}{|c|}{ Nanostructured Al-based alloys } \\
\hline Al & \multicolumn{7}{|c|}{ Alloying components: $\mathrm{W}, \mathrm{Hf}, \mathrm{Mg}, \mathrm{MgH} 2, \mathrm{Ti}, \mathrm{Li}, \mathrm{Zr}, \mathrm{C}$} \\
\hline \multicolumn{8}{|c|}{${ }^{\mathrm{a}}$ Metal-rich nanocomposites also have been synthesized. } \\
\hline \multicolumn{8}{|c|}{${ }^{\mathrm{b}}$ Metal-lean nanocomposites also have been synthesized. } \\
\hline \multicolumn{8}{|c|}{${ }^{\mathrm{C}}$ Nanocomposite powder used as component for compound nanocomposite. } \\
\hline
\end{tabular}




\subsection{Summary}

The oxygen source compound that is most commonly used in chemical oxygen generators is sodium chlorate because it provides a high oxygen yield, has a relatively low decomposition temperature, decomposes in a single step, and is relatively inexpensive. The decomposition temperature of this compound can be further reduced with the addition of a catalyst. Previous studies revealed that transition metal cations with partially filled d-orbitals showed very high catalytic activity, with $\mathrm{Co}_{3} \mathrm{O}_{4}$ being the best catalyst. Increasing the surface areas of the reactants (reducing particle size of sodium chlorate and of cobalt (II, III) oxide) improves the combustion/decomposition of sodium chlorate. Use of a nano-scale cobalt (II, III) oxide with a specific surface area of $29.6 \mathrm{~m}^{2} / \mathrm{g}$ decreases the decomposition temperature by more than $300{ }^{\circ} \mathrm{C}$ as compared with the micron-scale cobalt (II, III) oxide $\left(0.84 \mathrm{~m}^{2} / \mathrm{g}\right)$.

Self-sustained propagation becomes possible if heat is provided to $\mathrm{NaClO}_{3}$. A metal fuel, such as iron or tin, is commonly used in oxygen generators. Iron releases a large amount of heat when is oxidized, and it is oxidized at relatively low temperatures. Larger amounts of energetic additive are needed if tin is used instead. A disadvantage of using metal fuels is that they consume part of the oxygen produced. The oxygen yield may increase if the metal fuels are substituted by better energetic additives.

Nanocomposite and mechanically alloyed reactive materials have the potential to improve the performance of oxygen generators. Mixing of materials in the nano-scale produces a surface area that accelerates ignition and improves storage conditions, opening the possibility for utilizing materials with high oxidation heats that are not used currently in chemical oxygen generators, such as aluminum and magnesium. Nanocomposite and mechanically alloyed reactive materials provide a more controllable heat release, and fewer amounts would be needed to provide a self-sustained combustion of the oxygen candle, thus increasing the oxygen yield. 


\section{ChAPTER 3: Methodology}

\section{1: Introduction}

The scientific approach selected in the present research is quite straightforward. First, thermodynamic calculations were completed for sodium chlorate with commonly used metal fuels and most of the nanocomposite and mechanically alloyed reactive materials already produced at NJIT. The best (thermodynamically) energetic additives were identified and tested experimentally. Oxygengenerating mixtures were prepared using $\mathrm{NaClO}_{3}, \mathrm{Co}_{3} \mathrm{O}_{4}$, and energetic additive. Combustion of the obtained mixture pellets was studied in an experimental facility equipped with laser ignition. All the pellets were prepared and tested under the same conditions. Since iron is a commonly used metal fuel and releases more heat than tin, iron was set as the baseline fuel for comparison with all other energetic materials. The standard for comparison was the smallest amount of iron that provided self-sustained propagation of the combustion wave. The combustibility limit for each tested energetic additive was then identified by decreasing the energetic additive content until self-sustained propagation of the combustion wave was impossible. Further, the combustion characteristics of the tested compositions at the identical amounts of energetic additives were compared.

\section{2: Thermodynamic Calculations}

Thermodynamic calculations of the adiabatic flame temperatures and combustion product compositions were conducted using THERMO (version 4.3) software, which is based on the Gibbs free energy minimization and contains a database of approximately 3,000 compounds [31]. Of specific importance is the capability of this code to handle both intermetallic and thermite reactions in addition to conventional gas-phase combustion reactions. Since the available THERMO database did not contain thermochemical properties of sodium chlorate, the formation enthalpy of this compound, $-365.8 \mathrm{~kJ} / \mathrm{mol}$ [9], was added to the database. Pressure was equal to $1 \mathrm{~atm}$ in all calculations.

Thermodynamic calculations were also conducted for several mixtures that included an additional $3 \mathrm{wt} \%$ of $\mathrm{Co}_{3} \mathrm{O}_{4}$, which was used as a catalyst in all experiments. Those calculations did not lead to a noticeable deviation from the data presented in Section 4.1 (Table 4.1). 


\subsection{Experimental}

\subsubsection{Energetic Materials}

Combustion experiments were conducted with the following reactive material additives:

- Pure metals: $\mathrm{Fe}$ and $\mathrm{Mg}$

- Mechanically alloyed powders: $\mathrm{Fe} / \mathrm{Mg}$ (3:1), $\mathrm{Al} / \mathrm{Mg}$ (4.7:5.3), $\mathrm{Al} / \mathrm{Mg}$ (7:3), $\mathrm{Al} / \mathrm{Mg}(4: 1)$, and $\mathrm{Al} / \mathrm{Mg}(9: 1)$

- Reactive metal-metal composites: $\mathrm{Al} / \mathrm{Ti}(4: 1)$

- Reactive metal-metalloid composites: $\mathrm{B} / \mathrm{Ti}(2: 1)$

- Nanocomposite thermites: $\mathrm{Al} / \mathrm{NaNO} 3$ (5:3), $\mathrm{Al} / \mathrm{NaNO} 3$ (2.1:1), and $\mathrm{Al} / \mathrm{MoO}_{3}(8: 1)$

Here, the mole ratios are indicated. Note that for $\mathrm{Al} / \mathrm{Mg}$, 4.7:5.3 mole ratio corresponds to 1:1 mass ratio.

For using as single metal additives, iron $(99.9 \%$ metal basis pure, $<10 \mu \mathrm{m})$ and magnesium ( $99.5 \%$ metal basis pure, -325 mesh) were purchased from Sigma Aldrich and used as is.

Nanocomposite and mechanically alloyed reactive materials were produced by Prof. Edward Dreizin's team at the New Jersey Institute of Technology as follows.

For preparation of $\mathrm{Fe} / \mathrm{Mg}$ powders, starting materials included elemental powders of Fe (AlfaAesar, 98\% metals basis, -325 mesh, reduced) and Mg (Alfa-Aesar, 99.8\% pure, -325 mesh). Powders were mechanically milled using a SPEX SamplePrep 8000 shaker mill with 50-ml flat-ended steel vials and steel milling media ( $9.5 \mathrm{~mm}$ diameter balls). Each vial was loaded in argon with a $5 \mathrm{~g}$ powder load and a ball-to-powder mass ratio (BPR) of 10. To inhibit cold-welding and prevent partial reactions during the milling process, $5 \mathrm{ml}$ of hexane $\left(\mathrm{C}_{6} \mathrm{H}_{14}\right)$ was added to each milling vial as a process control agent (PCA). The powders were milled for $6 \mathrm{~h}$.

The same shaker mill was used to prepare nanocomposite $\mathrm{Al} / \mathrm{MoO}_{3}$ powders. $5 \mathrm{~mm}$ diameter balls steel milling media and the charge ratio was 5 were used. $\mathrm{Al} / \mathrm{MoO}_{3}$ energetic material was prepared from powders of elemental aluminum (99\% pure, -325 mesh by Alfa Aesar) and molybdenum trioxide $\mathrm{MoO}_{3}(99.95 \%$ pure, by Alfa Aesar). Preparation was carried out in an argon environment using 
$5 \mathrm{~g}$ powder batches with different $\mathrm{Al} / \mathrm{MoO} 3$ ratios, and $4 \mathrm{ml}$ of hexane $\left(\mathrm{C}_{6} \mathrm{H}_{14}\right)$ was added as a PCA. Milling time was $60 \min [32,33]$.

All other materials prepared using ball milling employed a Retsch PM-400 MA planetary mill equipped with an air conditioner, which cools the milling compartment. The rotation speed was set at $350 \mathrm{rpm}$ and the rotation direction changed every $15 \mathrm{~min}$.

Starting materials used in the synthesis of the $\mathrm{Al} / \mathrm{Mg}$ alloys [34] included elemental powders of Al (Atlantic Equipment Engineers, 99.8\% pure, -325 mesh) and Mg (Alfa-Aesar, 99.8\% pure, -325 mesh). Mechanically alloyed powders were prepared following a two-stage procedure [22, 34]. Powders of $\mathrm{Al}$ and $\mathrm{Mg}$ and $9.5 \mathrm{~mm}$ diameter hardened steel balls were loaded in steel milling vials in argon. The powder charge was $30 \mathrm{~g}$ per vial and the BPR was $10.50 \mathrm{ml}$ of hexane was added to each milling vial as a PCA. Milling time was $120 \mathrm{~min}$. The rotation direction was changed every $15 \mathrm{~min}$.

The first stage produced a coarse, mechanically alloyed powder. The second stage of milling, aimed to reduce the particle size, involved the addition of a new PCA, iodine (I2, chips, Sigma Aldrich, $99 \%$ pure), at $4 \mathrm{wt} \%$ of the initial powder load. The $9.5 \mathrm{~mm}$ balls were removed and replaced with the same mass of $3 \mathrm{~mm}$ hardened steel balls. The duration of the second milling stage varied between 65 and $125 \mathrm{~min}$, depending on the effectiveness of the air-conditioner cooling the milling compartment which was affected by the air humidity.

Starting materials used in the synthesis of $\mathrm{Al} / \mathrm{Ti}$ alloys included elemental powders of $\mathrm{Al}$ (Atlantic Equipment Engineers, 99.8\% pure, -325 mesh) and Ti (Alfa-Aesar, 99\% metals basis, -325 mesh). Powders were loaded in steel milling vials in argon. $9.5 \mathrm{~mm}$ diameter hardened steel milling balls were used. The powder charge was $100 \mathrm{~g}$ per vial and the BPR was 3. Custom-made cooling fins were attached to each vial to aid in cooling. The initial milling time was set to $480 \mathrm{~min}$. Different PCAs were employed to achieve homogeneous mixing between Al and Ti and to avoid powder caking. For two different samples tested, stearic acid and paraffin wax were added as $2 \mathrm{wt} \%$ of the initial powder load. The second stage of milling involved the addition of another PCA to reduce particle sizes. For the sample prepared with stearic acid, $50 \mathrm{ml}$ of heptane were used. For the wax-prepared sample, iodoform $\left(\mathrm{CHI}_{3}\right)$ was added at $2 \mathrm{wt} \%$ of the initial powder load. 
Preparation of $\mathrm{B} / \mathrm{Ti}$ [29] composite powders started with amorphous powders of boron (nominal size $0.7 \mu \mathrm{m}, 98.5 \%$ pure, by SB Boron) and titanium (-325 mesh, 99.7\% pure, by Atlantic Equipment Engineers). The nanocomposite powders were prepared in this project using a sequence of two milling steps. In the first step, the powders were milled with a small amount of liquid process control agent (heptane) until the desired nanostructured refinement was achieved. In the second step, the amount of heptane was substantially increased and the resulting slurry was milled to minimize agglomeration and achieve the desired particle size distribution.

Preparation of $\mathrm{Al} / \mathrm{NaNO}_{3}$ started with blends of sodium nitrate (99\%, Alfa Aesar) and aluminum (99.9\%, -325 mesh, Atlantic Equipment Engineers [30]). Custom made steel jars suitable for high pressure applications (18 $\mathrm{mm}$ wall thickness) and $9.53 \mathrm{~mm}$ balls made of AISI/SAE 1013 low-carbon Steel were used. Synthesis was carried out in argon environment with $20 \mathrm{~g}$ batches and a BPR of 5 . For safety and ease of handling of the prepared reactive composites, $25 \mathrm{~mL}$ of hexane was added into each milling jar, also under argon. This was followed by a brief $5 \mathrm{~min}$ period of wet milling, which was intended to break loose agglomerates, and did not affect the structure of the prepared composites. To prevent slow reaction of the respective metal component with atmospheric oxygen, the samples were stored under hexane as well.

\subsection{Preparation of mixtures}

All tested compositions included $3 \mathrm{wt} \%$ of cobalt oxide $\left(\mathrm{Co}_{3} \mathrm{O}_{4}, 99.5 \%\right.$ metal basis pure, $<50$ $\mathrm{nm}$, Sigma Aldrich) and 3-5 wt $\%$ of a reactive material additive, with the balance of sodium chlorate (ACS reagent, 99.0\% pure, Sigma Aldrich) and with no binder. In some previous studies, water was used as a binder, and then moisture was removed by heating the pellets up to $130{ }^{\circ} \mathrm{C}$ in a furnace [Ref]. In the present work, water was not used to avoid its reaction with the energetic additives.

As stated in the literature review chapter, the influence of $\mathrm{NaClO}_{3}$ particle size on combustion of its mixtures was studied previously [6]. A decrease in the particle size from $420-590 \mu \mathrm{m}$ to $149-177$ $\mu \mathrm{m}$ increased the front velocity by about $30 \%$. In the present work, to decrease the particle size and thus make a more uniform mixture, sodium chlorate was milled in a roller mill (Labmill-8000) in portions of 
$25 \mathrm{~g}$ for $2 \mathrm{~h}$. The particle size distribution of the milled $\mathrm{NaClO}_{3}$ powder was characterized using a multilaser particle size analyzer (Microtrac Bluewave). The mean volume diameter was $97 \mu \mathrm{m}$.

The milled $\mathrm{NaClO}_{3}$ was mixed with $\mathrm{Co}_{3} \mathrm{O}_{4}$ and the reactive material additive during $1 \mathrm{~h}$ in a tumbler mixer (BioEngineering Inversina 2L). The mixtures were compacted into cylindrical pellets (diameter: $13 \mathrm{~mm}$, length: $20 \mathrm{~mm}$ ) using a uniaxial hydraulic press (Carver). The pressing force was equal to $19.6 \mathrm{kN}$ (pressure: $148 \mathrm{MPa}$ ). The relative density of the pellets was $0.80 \pm 0.01$. Figure 3.1 shows a typical pellet. The straight vertical line seen on the pellet surface was produced by a trapezoidal split sleeve pressing die (composed of three sleeves), which was used for compressing the mixture. The use of this die simplified the removal of the pellet and cleaning of the die components.

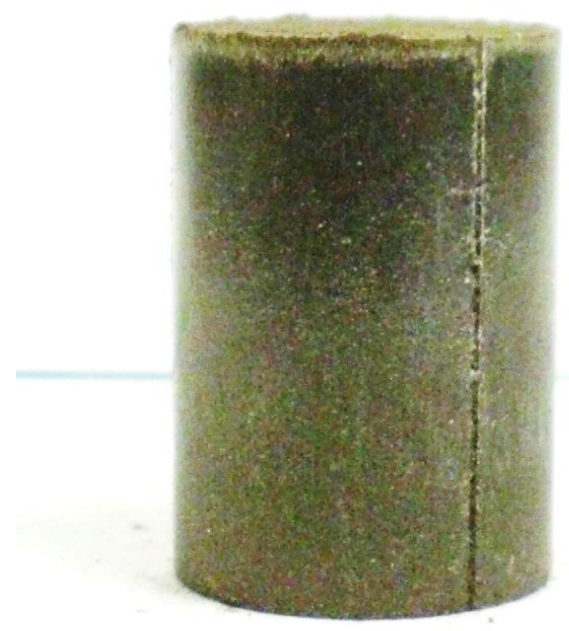

Fig. 3.1: Typical appearance of produced pellets.

\subsection{Combustion experiments}

Combustion of the obtained pellets was investigated using an experimental setup with laser ignition (Fig. 3.2). The setup includes a stainless steel chamber (volume: $11.35 \mathrm{~L}$ ), equipped with a door port, three windows for observation and video recording, a zinc selenide window for introducing the laser beam, a sapphire window that enabled infrared video recording, and a pressure transducer (Omegadyne PX-409-030AI). The pellet was installed vertically on a brass pedestal. 


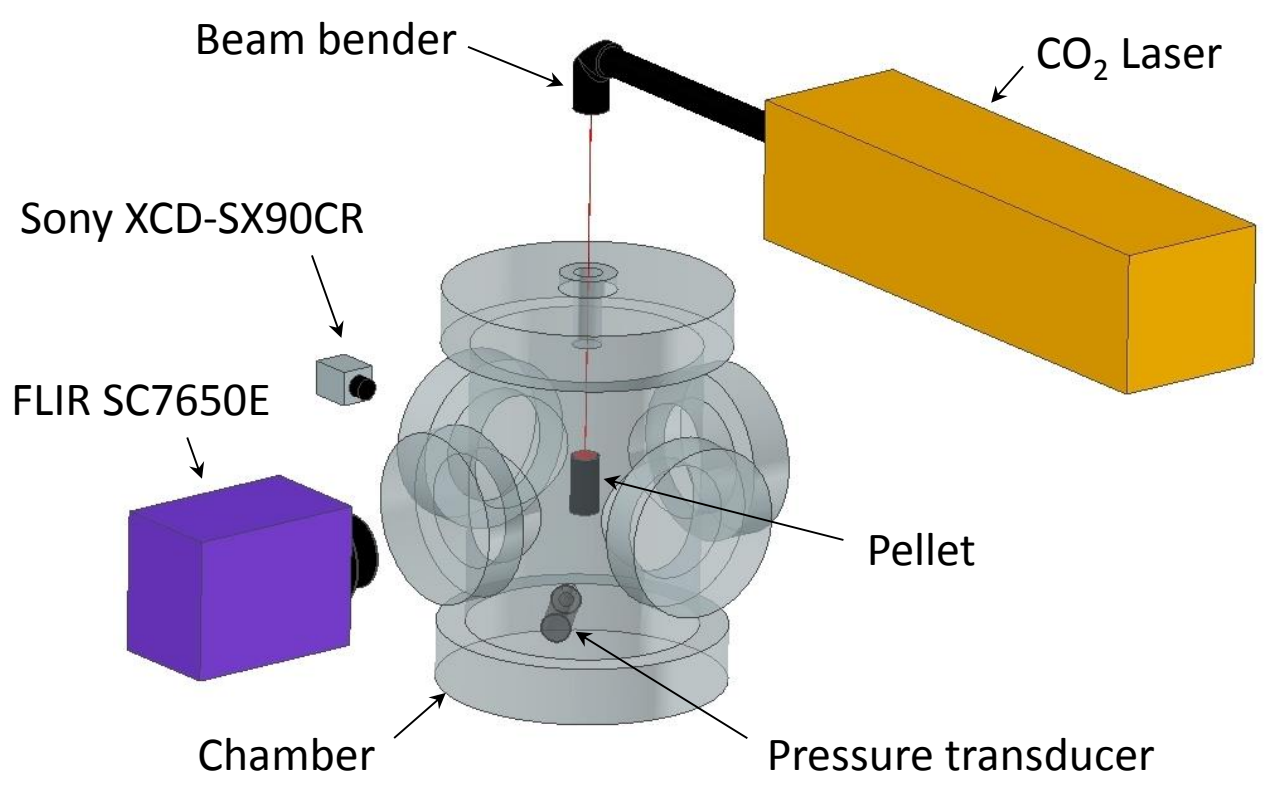

Fig. 3.2: Schematic diagram of the experimental setup for laser ignition of the pellets.

The leaks in the chamber were checked over a long period, and then the average leak was calculated. The pressure in the chamber was reduced to $0.5 \mathrm{kPa}$ (absolute) using a vacuum pump and turned off. When left for over a period of 30 hours, the chamber gained pressure at the rate of 4.48 $\mathrm{Pa} / \mathrm{min}$. To determine the loss of pressure the chamber was filled with argon at $101 \mathrm{kPa}$ (absolute), and left for over 30 hours. The loss of pressure was found to be at the rate of $0.848 \mathrm{~Pa} / \mathrm{min}$. Note the atmospheric pressure in El Paso is about $90 \mathrm{kPa}$, These leaks are minimal and did not lead to any noticeable error in the calculations of pressure increment, given the fact that a typical combustion time was about 3 minutes.

Before each experiment, the chamber was evacuated three times to a pressure of 1-2 $\mathrm{kPa}$ and filled with ultra-high purity argon (99.999\%) to a pressure of $1 \mathrm{~atm}$. An infrared beam (wavelength: 10.6 $\mu \mathrm{m}$, diameter: $2.0 \pm 0.3 \mathrm{~mm}$ ) of a $\mathrm{CO}_{2}$ laser (Synrad Firestar ti-60) was introduced into the chamber vertically through the $\mathrm{ZnSe}$ window, located at the chamber lid. The beam was directed to the top of the pellet. For alignment of the optical system, a laser diode (Synrad Diode Pointer) was used. The power of the beam after passing the beam delivery system and $\mathrm{ZnSe}$ window was measured with a powermeter (Synrad PW-250) and controlled using a laser controller (Synrad UC-2000), while the duration of the 
laser pulse was controlled using LabVIEW (National Instruments) software. In all reported experiments, the power and duration of the laser pulse were equal to $36 \mathrm{~W}$ and $10 \mathrm{~s}$, respectively.

\subsection{Data acquisition}

After ignition, the combustion front propagated downward through the sample. The propagation was monitored using a digital video camera (Sony XCD-SX90CR) and an infrared video camera (FLIR SC7650E). The infrared camera was calibrated by the manufacturer for measurements in three temperature ranges: $0-300{ }^{\circ} \mathrm{C}, 300-1500{ }^{\circ} \mathrm{C}$, and $1500-2500{ }^{\circ} \mathrm{C}$. In most experiments, the temperature remained lower than the melting point of $\mathrm{NaCl}\left(800.7^{\circ} \mathrm{C}\right)$. Thus only the first two calibration ranges were used in the present work.

The dynamics of temperature distribution over the pellet surface was investigated through the analysis of images obtained with the infrared camera (25 images per second). Using ExaminIR (FLIR) software, a dynamic temperature map was generated for each experiment. More specifically, on the image of the pellet, 115 regions of interest (ROI), served as temperature sensors, were selected along the vertical axis as shown in Fig. 3.3. Each ROI consisted of nine (i.e., 3 x 3) pixels as shown in Fig. 3.4. For each ROI, the temperature was determined as an average of the temperatures measured in the nine pixels. Playing the recorded video generated the temperature-time dependence for each square. The pixel size corresponded to $49 \mu \mathrm{m}$ on the pellet surface so that the distance between the centers of adjacent ROI was equal to $147 \mu \mathrm{m}$. The matrix with the temperature-time data was transformed into temperature-distance profiles at different instants of time so that the thermal wave propagation was visualized for each experiment. The maximum temperature in the front and its propagation velocity were used as combustion characteristics of the prepared mixtures. In some experiments, the front velocity was additionally determined using video recording with the Sony camera. 


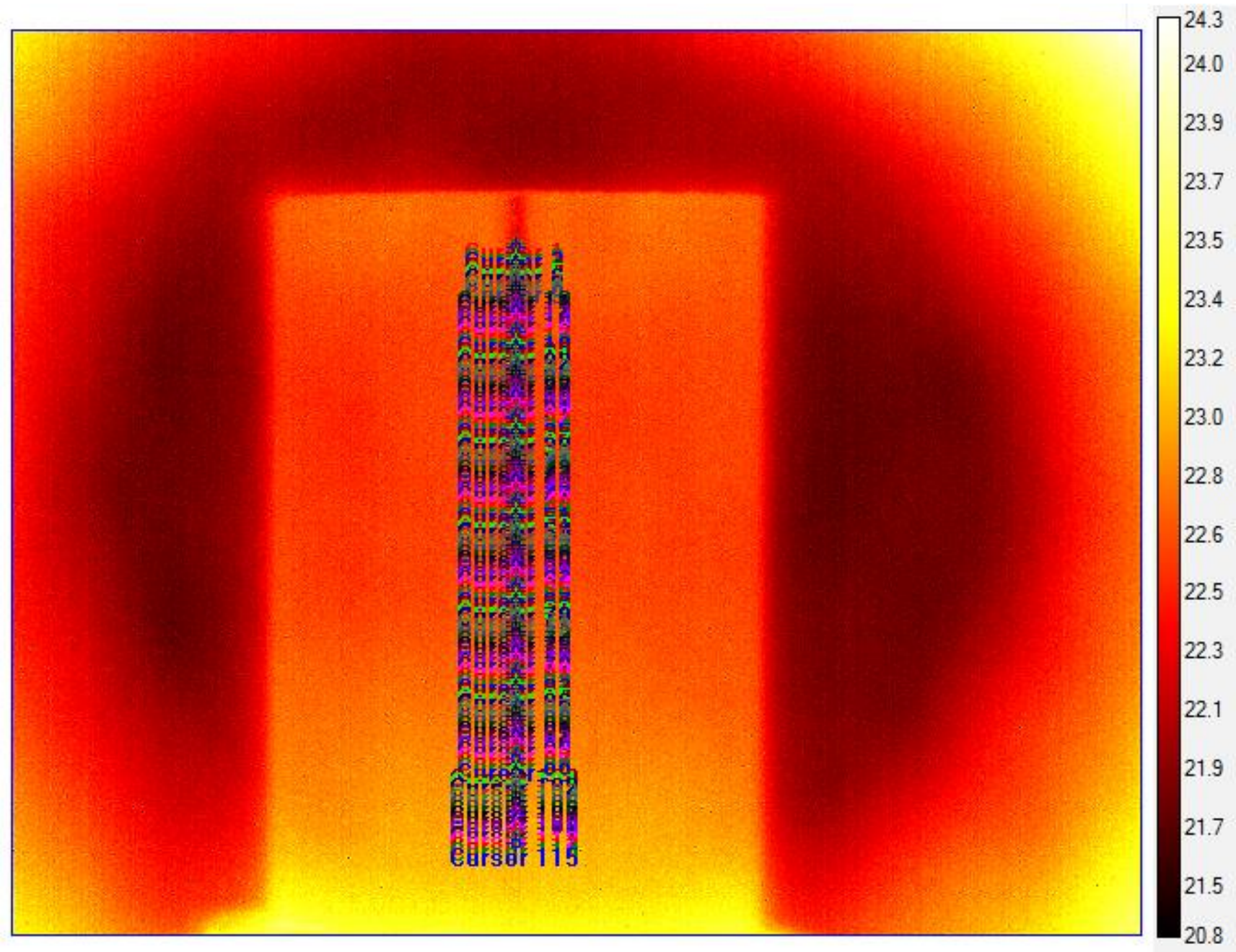

Fig. 3.3: Pellet with 115 ROIs aligned as used in the analysis of the combustion.

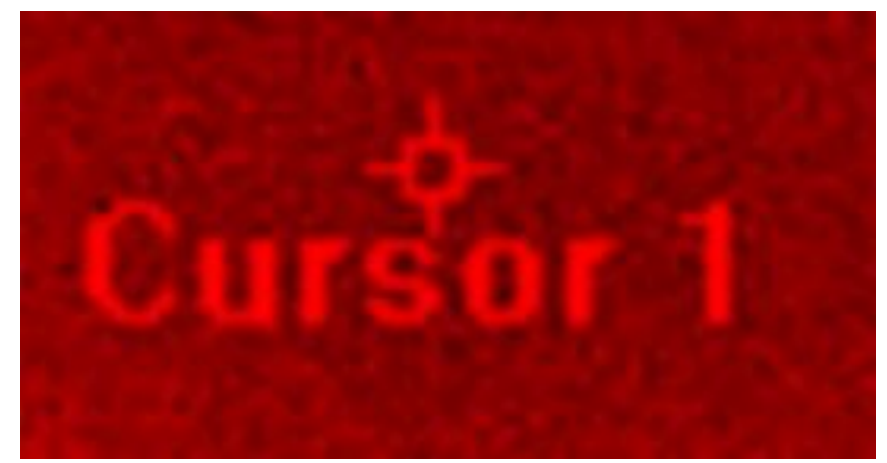

Fig. 3.4: Single ROI 
Combustion products were characterized using X-ray diffraction analysis (Bruker D8 Discover XRD). For better accuracy, before the analysis, sodium chloride was washed out of the products by dissolution in cold water. The remaining powder was then collected on a filter paper and dried at room temperature.

\subsection{Emissivity measurements}

For temperature measurements with the infrared camera, the pellet emissivity should be known. To determine the emissivities of the tested pellets, special experiments were conducted. Black-body models were fabricated for several tested materials.

For better accuracy, the black body model should be a lumped system where the heat conduction inside is much faster than the heat transfer from its surface to the surrounding air. This makes the determination of the emissivity from these experiments more accurate, since the temperature difference between the cavity and the external pellet surface is small. It is generally accepted to neglect the temperature distribution inside the heated body is the Biot number $(B i)$ is less than 0.1 [35]. The Biot number was estimated using the formula: $B i=L_{\mathrm{c}} \cdot h / k$ where $h$ is the heat transfer coefficient, $k$ is the thermal conductivity of the pellet, and $L_{\mathrm{c}}$ is the characteristic size. The specific heat of $\mathrm{NaClO}_{3}$ is $0.95 \mathrm{~J} / \mathrm{g} \cdot \mathrm{K}$ at $25{ }^{\circ} \mathrm{C}$ and $1.05 \mathrm{~J} / \mathrm{g} \cdot \mathrm{K}$ at $90{ }^{\circ} \mathrm{C}[36]$. The addition of 3 wt $\% \mathrm{Co}_{3} \mathrm{O}_{4}$ and 5 wt $\%$ of an energetic material only slightly influences the specific heat of the pellet. Using the average specific heat of $\mathrm{NaClO}_{3}, 1 \mathrm{~J} / \mathrm{g} \cdot \mathrm{K}$, the measured thermal diffusivity of $\mathrm{NaClO}_{3}$-based pellets, $0.3 \mathrm{~mm} / \mathrm{s}$ [8], and the pellet density, $1.8 \mathrm{~g} / \mathrm{cm}^{3}$, the thermal conductivity was estimated to be $0.564 \mathrm{~J} / \mathrm{m} \cdot \mathrm{K}$. The characteristic size, calculated as the volume-to surface ratio, where the cavity volume was subtracted from the pellet volume, was equal to $2.42 \mathrm{~mm}$. The heat transfer coefficient, with pellet surface temperature of $80{ }^{\circ} \mathrm{C}$ and air surrounding air being at $25^{\circ} \mathrm{C}$, was calculated using the formulas for natural convection around a horizontal cylinder [35], giving a value of $13.1 \mathrm{~W} / \mathrm{m} \cdot \mathrm{K}$. These values gave a Biot number equal to 0.563 , and the pellet could be treated then as a lumped system.

For each model, two identical pellets (diameter: $13 \mathrm{~mm}$, length: $13 \mathrm{~mm}$ ) were prepared and a hemispherical cavity (diameter: $9.5 \mathrm{~mm}$ ) was made using a ball nose end mill (by hand) in each of them. 
Then, the two pellets were attached to each other applying an adhesive tape over the cylindrical surface so that a spherical cavity was obtained inside the resulting composite body. A 1.2-mm diameter channel was drilled to connect one end of the composite pellet with the cavity, as shown in Fig. 3.5. The black body model was placed on a hot plate (Thermo Scientific HP2305B) and heated. The temperature at the center of the channel (i.e., the temperature of material at the inner surface of the cavity) was measured using the infrared camera and software, with the assumption that the emissivity is equal to 1 . At the selected power of the hot plate, the temperature in the cavity was stabilized at around $80{ }^{\circ} \mathrm{C}$. After that, the temperatures of the cavity and of the external pellet surface at its flat end near the channel were recorded and compared to each other.

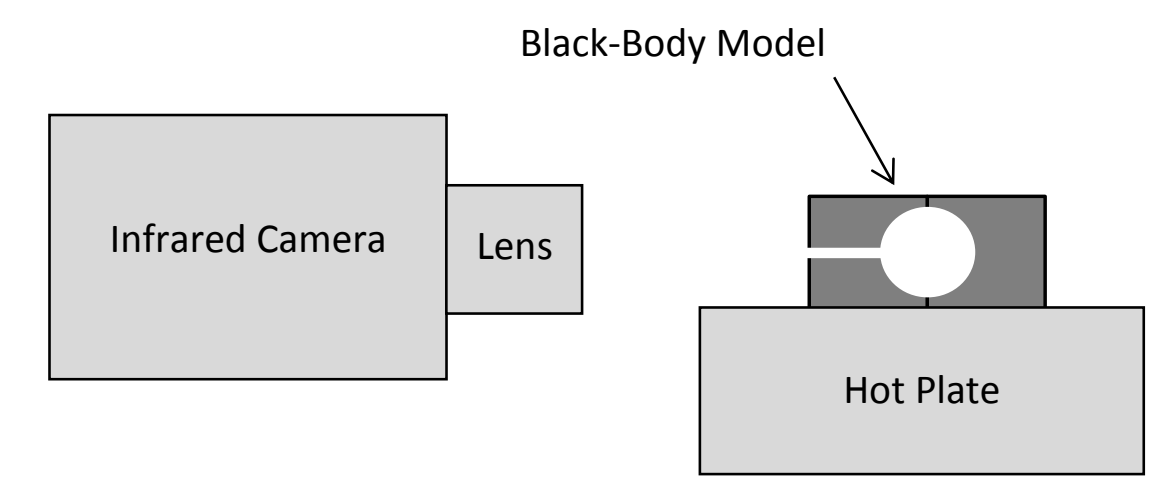

Fig. 3.5: Schematic of the experiment for measuring the pellet emissivity.

Placing the pellet on a hot plate means that heat is gained from the bottom of the pellet and it is lost form the top. This certainly creates a temperature gradient. However, the temperature of the pellet remains constant along the pellet length.

Since the temperature decreases with increasing the distance from the hot plate (Fig. 3.6), the measurements were conducted along an isothermal line that passed through the hole. Rectangular ROIs bigger than the 3 by 3 pixels ROIs described before were created in the channel (box 4 in Fig. 3.6) and along the isothermal line (boxes 3 and 5 in Fig. 3.6). The average temperature was determined for each region. The temperature of the flat surface along the isothermal line, measured with the assumption of the emissivity equal to 1 , was lower than that of the cavity by $8-10{ }^{\circ} \mathrm{C}$. In reality, due to the low Biot number of the tested pellets, the temperature difference between the internal surface of the cavity and 
the external surface of the pellet is negligible. Thus, the lower value of the measured temperature of the external surface is explained by the lower emissivity. Assuming that the emissivity of the "black-body" cavity is 1 , the emissivity of the pellet surface was calculated.

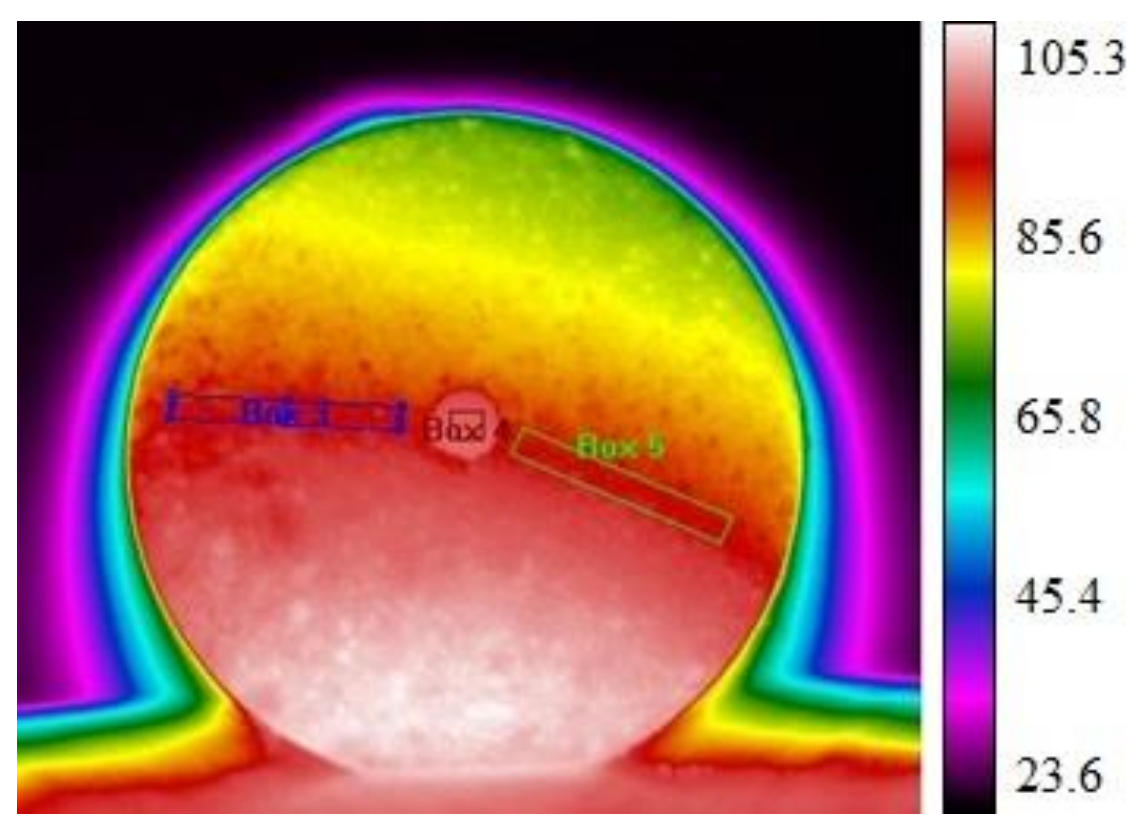

Fig. 3.6: Infrared image of the black-body model heated on a hot plate. The scale shows temperature in ${ }^{\circ} \mathrm{C}$.

The emissivities of five different pellet compositions (no additive, $3 \mathrm{wt} \% \mathrm{Al} / \mathrm{Mg}(7: 3), 5 \mathrm{wt} \%$ $\mathrm{Mg}, 4 \mathrm{wt} \% \mathrm{Fe} / \mathrm{Mg}$, and $5 \mathrm{wt} \% \mathrm{Fe} / \mathrm{Mg}$ ) were determined based on 30 measurements for each, taken at different times after the temperature stabilization. The scatter of data for each composition was larger than the change due to changing the composition, which is understandable because the compositions were similar (with 92-97 wt $\% \mathrm{NaClO}_{3}, 3 \mathrm{wt} \% \mathrm{Co}_{3} \mathrm{O}_{4}$, and $0-5 \mathrm{wt} \%$ of the energetic additive). Averaging all the values produced an emissivity of $0.80 \pm 0.05$.

In addition, the emissivity measurements were conducted using the melting point of sodium chlorate $\left(248{ }^{\circ} \mathrm{C}[8]\right)$. A pellet with $\mathrm{Al} / \mathrm{Mg}$ (7:3) additive was broken and several pieces were placed onto the hot plate and heated up to achieve melting of $\mathrm{NaClO}_{3}$. Figure 3.7 shows an infrared image of the heated pieces and the temperature profile along the vertical line in the image. The temperatures were measured in the range from 100 to $300{ }^{\circ} \mathrm{C}$, with the assumption that the emissivity is equal to 0.8 . The bottom of the image (where the temperature is lower than the maximum) corresponds to the hot plate 
and should be ignored. It is seen that the profile includes a distinct plateau at about $250{ }^{\circ} \mathrm{C}$, which clearly indicates melting. This remarkable agreement with the melting point of $\mathrm{NaClO}_{3}$ confirms that the emissivity of this pellet was very close to 0.8 .
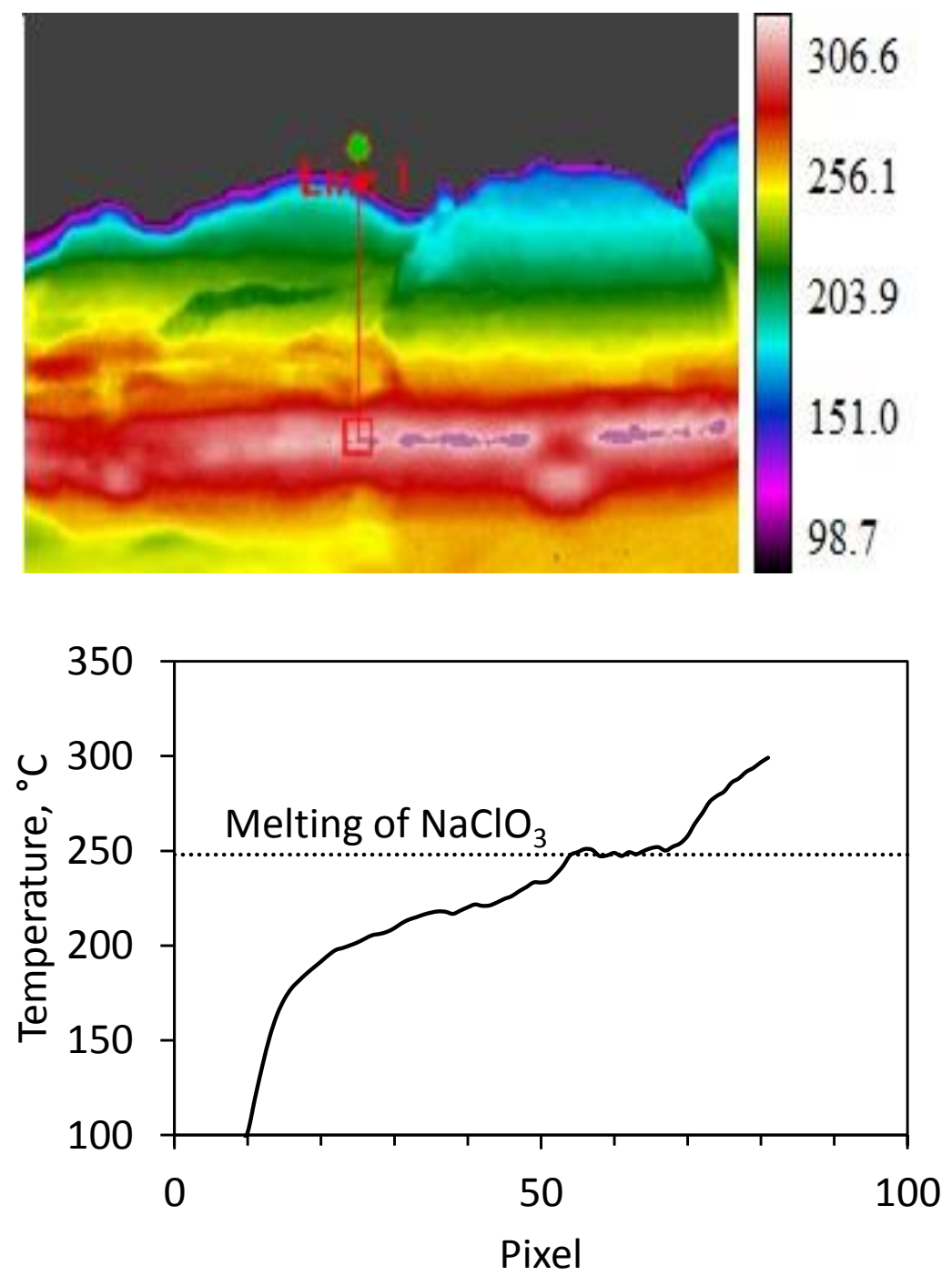

Fig. 3.7: An infrared image of melting pieces of the mixture heated on a hot plate and the temperature profile along the vertical line (downward) in the image.

Based on the emissivity measurements, in the analysis of combustion experiments, it was assumed that the emissivity of all the samples was 0.8 , independently of the pellet composition. It was also assumed that the emissivity remains constant for the range of temperatures observed in the experiments (typically less than $800{ }^{\circ} \mathrm{C}$ ). 


\subsection{Summary}

The first step to identify the best energetic additive was to perform thermodynamic calculations for combustion of sodium chlorate mixed with reactive materials prepared at NJIT. Once the amount required to provide a certain adiabatic flame temperature was obtained for all tested materials, a comparison with commonly used metal fuels iron and tin took place. The selection of the best candidates consists of 11 different energetic additives.

The combustion of the mixtures was made possible by compressing the compounds into a pellet of $13 \mathrm{~mm}$ in diameter and about $20 \mathrm{~mm}$ in height. The standard for comparison was iron given the fact that that this metal fuel is commonly used in oxygen generators and it provides more heat than tin. All the mixtures consisted of sodium chlorate, milled to a particle size of about $100 \mu \mathrm{m}$, nanoscale cobalt (II, III) oxide, and the energetic additive, which were mixed in portions of 25 grams for one hour in a tumbler mixer. Portions of about 5 grams were pressed with a 2 -ton force to produce the tested pellets.

The pellets were installed vertically in an $11.35 \mathrm{~L}$ stainless steel chamber. Ignition occurred using an infrared $\mathrm{CO}_{2}$ laser in a $1 \mathrm{~atm}$ argon atmosphere. A pressure transducer was used to record the increase in pressure. A conventional video camera was used for observations and an infrared video camera (FLIR SC7650E) was used to acquire a dynamic temperature map. This dynamic temperature map could be manipulated to produce graphs that showed the temperature of selected points as a function of time, temperature as a function of distance at different times, the maximum temperature as a function of time, and the combustion front position as a function of time, as described in the next Chapter.

The infrared camera required the user to input the emissivity of the object being recorded, in this case the pellet. The emissivity was determined with two different methods; each of them provided the same value: 0.8 . 


\section{CHAPTER 4: RESUlTS AND DisCUSSION}

\subsection{Thermodynamic calculation results}

Table 4.1 shows the amounts of 25 binary mixtures that need to be added to sodium chlorate to provide the adiabatic flame temperatures of 600,700 , and $800{ }^{\circ} \mathrm{C}$. Table 4.1 also shows the mass fraction of molecular oxygen $\left(\mathrm{O}_{2}\right)$ in the combustion products. For comparison, Table 4.1 also presents the values obtained for iron and tin, which are currently used in chemical oxygen generators. This allows one to readily select the mixtures that provide higher theoretical temperatures and $\mathrm{O}_{2}$ yield compared to the current formulations.

Further, the values obtained for pure aluminum and magnesium are presented. Aluminum is not used in chemical oxygen generators because it does not ignite at relatively low temperatures occurring in these generators and, in addition, does not show any catalytic effect on the decomposition of sodium chlorate [10]. Because of handling and stability problems (quick aging in oxidizing and moist environments and high fire hazard), magnesium is not used either. However, $\mathrm{Al} / \mathrm{Mg}$ materials obtained by mechanical alloying are promising additives because they ignite easier than $\mathrm{Al}$ and, at the same time, are expected to be substantially more stable and less hazardous than pure $\mathrm{Mg}$ [28].

In Table 4.1, the mixtures containing smaller overall weight percent of additive compared to the formulation with $\mathrm{Fe}$ (and shown above it) are most promising. Among the metal-metal and metalmetalloid reactive materials, $\mathrm{B} / \mathrm{Ti}$ and $\mathrm{Al} / \mathrm{Ti}$ mixtures provide the best results, while $\mathrm{Al} / \mathrm{NaNO}_{3}$ is the best among nanocomposite thermites. Although calculations were not performed for various $\mathrm{Al} / \mathrm{Mg}$ alloys, considering the results obtained for pure $\mathrm{Al}$ and $\mathrm{Mg}$, such alloys are expected to perform similarly to $\mathrm{B} / \mathrm{Ti}$ and $\mathrm{Al} / \mathrm{Ti}$ composites. Thermodynamically, all these additives are more efficient than iron or tin. More specifically, a lower concentration of the additive provides the same adiabatic combustion temperature and, simultaneously, a higher oxygen yield.

Note that the combustion products predicted to form by the thermodynamic calculations are fully oxidized. There are no metals or unoxidized compounds such as $\mathrm{TiB}_{2}$ and AlTi in the predicted products. At the same time, the idea of using reactive materials is based on the initial exothermic reactions between the additive's components that kick-start combustion. The generated intermetallic or 
other phases are expected to oxidize in the subsequent reaction with the produced oxygen. The calculated combustion products for all compositions are presented in Appendix 1.

Table 4.1: Calculated amounts of additives to sodium chlorate that provide adiabatic flame temperatures of 600,700 , and $800^{\circ} \mathrm{C}$ and respective mass fractions of molecular oxygen in the products.

\begin{tabular}{|c|c|c|c|c|c|c|c|}
\hline \multicolumn{2}{|c|}{ Additive Composition } & \multicolumn{2}{|c|}{$\begin{array}{c}\text { Composition for } 600 \\
{ }^{\circ} \mathrm{C}\end{array}$} & \multicolumn{2}{|c|}{$\begin{array}{c}\text { Composition for } 700 \\
{ }^{\circ} \mathrm{C}\end{array}$} & \multicolumn{2}{|c|}{$\begin{array}{c}\text { Composition for } 800 \\
{ }^{\circ} \mathrm{C}\end{array}$} \\
\hline $\begin{array}{l}\text { Components } \\
\qquad(\mathrm{X} / \mathrm{Y})\end{array}$ & $\begin{array}{c}\text { X-to-Y } \\
\text { Mole } \\
\text { Ratio }\end{array}$ & $\begin{array}{l}\text { Additive, } \\
\text { wt } \%\end{array}$ & $\begin{array}{l}\mathrm{O}_{2} \text { Mass } \\
\text { Fraction }\end{array}$ & $\begin{array}{l}\text { Additive, } \\
\text { wt } \%\end{array}$ & $\begin{array}{l}\mathrm{O}_{2} \text { Mass } \\
\text { Fraction }\end{array}$ & $\begin{array}{l}\text { Additive, } \\
\text { wt } \%\end{array}$ & $\begin{array}{l}\mathrm{O}_{2} \text { Mass } \\
\text { Fraction }\end{array}$ \\
\hline $\mathrm{Al}$ & - & 0.5 & 0.4442 & 0.8 & 0.4402 & 1.1 & 0.4362 \\
\hline $\mathrm{B} / \mathrm{Ti}$ & $2: 1$ & 0.5 & 0.4437 & 1.0 & 0.4368 & 1.4 & 0.4312 \\
\hline $\mathrm{Al} / \mathrm{Ti}$ & $1: 1$ & 0.5 & 0.4449 & 1.0 & 0.4389 & 1.5 & 0.4329 \\
\hline $\mathrm{Mg}$ & - & 0.6 & 0.4443 & 1.0 & 0.4398 & 1.6 & 0.4332 \\
\hline $\mathrm{B} / \mathrm{Zr}$ & $2: 1$ & 0.6 & 0.4438 & 1.1 & 0.4381 & 1.8 & 0.43 \\
\hline $\mathrm{Al} / \mathrm{Fe}$ & $1: 1$ & 1.0 & 0.4406 & 1.6 & 0.4344 & 2.5 & 0.4252 \\
\hline $\mathrm{Al} / \mathrm{Ni}$ & $1: 1$ & 0.9 & 0.4427 & 1.9 & 0.4335 & 3.0 & 0.4234 \\
\hline $\mathrm{B} / \mathrm{Hf}$ & $2: 1$ & 1.2 & 0.4405 & 2.0 & 0.4338 & 3.1 & 0.4245 \\
\hline $\mathrm{Al} / \mathrm{NaNO}_{3}$ & $2: 1$ & 1.2 & 0.4448 & 2.3 & 0.4392 & 3.6 & 0.4326 \\
\hline $\mathrm{MgH}_{2} / \mathrm{MoO}_{3}$ & $3: 1$ & 1.4 & 0.4386 & 2.3 & 0.4307 & 3.7 & 0.4183 \\
\hline $\mathrm{Mg} / \mathrm{NaNO}_{3}$ & $3: 1$ & 1.2 & 0.4422 & 2.5 & 0.4359 & 3.9 & 0.4284 \\
\hline $\mathrm{Mg} / \mathrm{MoO}_{3}$ & $3: 1$ & 1.7 & 0.4395 & 2.9 & 0.4314 & 4.5 & 0.4206 \\
\hline $\mathrm{Al} / \mathrm{MoO}_{3}$ & $2: 1$ & 1.9 & 0.4376 & 3.1 & 0.4291 & 4.9 & 0.4165 \\
\hline $\mathrm{Al} / \mathrm{Fe}_{2} \mathrm{O}_{3}$ & $2: 1$ & 2.0 & 0.4367 & 3.2 & 0.4293 & 5.0 & 0.4171 \\
\hline $\mathrm{Al} / \mathrm{SrO}_{2}$ & $4: 3$ & 1.6 & 0.4421 & 3.3 & 0.4327 & 5.3 & 0.4216 \\
\hline$F e$ & - & 2.1 & 0.4324 & 3.4 & 0.421 & 5.3 & 0.4043 \\
\hline $\mathrm{MgH}_{2} / \mathrm{CuO}$ & $1: 1$ & 1.8 & 0.4374 & 3.5 & 0.4246 & 5.4 & 0.4103 \\
\hline $\mathrm{Si} / \mathrm{MoO}_{3}$ & $3: 2$ & 2.2 & 0.4351 & 3.8 & 0.4237 & 5.8 & 0.4093 \\
\hline $\mathrm{Zr} / \mathrm{NaNO}_{3}$ & $3: 2$ & 1.9 & 0.4387 & 3.8 & 0.4298 & 6.0 & 0.4186 \\
\hline $\mathrm{Al} / \mathrm{WO}_{3}$ & $2: 1$ & 2.3 & 0.4367 & 4.1 & 0.4256 & 6.4 & 0.4113 \\
\hline $\mathrm{Al} / \mathrm{CuO}$ & $2: 3$ & 2.5 & 0.4356 & 4.3 & 0.4245 & 6.7 & 0.4097 \\
\hline $\mathrm{Mg} / \mathrm{CuO}$ & $1: 1$ & 2.4 & 0.4364 & 4.3 & 0.4249 & 6.7 & 0.4104 \\
\hline $\mathrm{Zr} / \mathrm{MoO}_{3}$ & $3: 2$ & 2.7 & 0.434 & 4.5 & 0.4227 & 6.9 & 0.4076 \\
\hline$S n$ & - & 2.7 & 0.4315 & 4.9 & 0.4156 & 7.5 & 0.3969 \\
\hline $\mathrm{Si} / \mathrm{CuO}$ & $1: 2$ & 2.8 & 0.4335 & 5.1 & 0.4192 & 8.0 & 0.4012 \\
\hline $\mathrm{Zr} / \mathrm{CuO}$ & $1: 2$ & 3.2 & 0.4324 & 5.6 & 0.4185 & 8.6 & 0.4012 \\
\hline $\mathrm{Al} / \mathrm{Bi}_{2} \mathrm{O}_{3}$ & $2: 1$ & 4.2 & 0.4281 & 7.4 & 0.4107 & $>10$ & $<0.4$ \\
\hline $\mathrm{Zr} / \mathrm{Bi}_{2} \mathrm{O}_{3}$ & $3: 2$ & 4.9 & 0.4249 & 8.6 & 0.4053 & $>10$ & $<0.4$ \\
\hline $\mathrm{Si} / \mathrm{Bi}_{2} \mathrm{O}_{3}$ & $3: 2$ & 5.0 & 0.4237 & 8.8 & 0.4029 & $>10$ & $<0.4$ \\
\hline
\end{tabular}




\subsection{Experimental results}

Most of the pellets broke and fell to the chamber floor during combustion as show in Fig.4.1. This can be explained by two phenomena. The first is the production of oxygen during solid state of sodium chlorate, which might produce irregular combustion front and cracks in the pellet as shown in Fig. 4.1 by the yellow oval. The second phenomenon is the displacement of the pellet during combustion produced by the melting of sodium chlorate. In addition, the pellet was not supported at the top so that nothing could prevent it from falling. Note that actual oxygen generators include a casing which prevents any displacement, but using such a casing for the combustion experiments would not allow any measurements with the infrared camera.

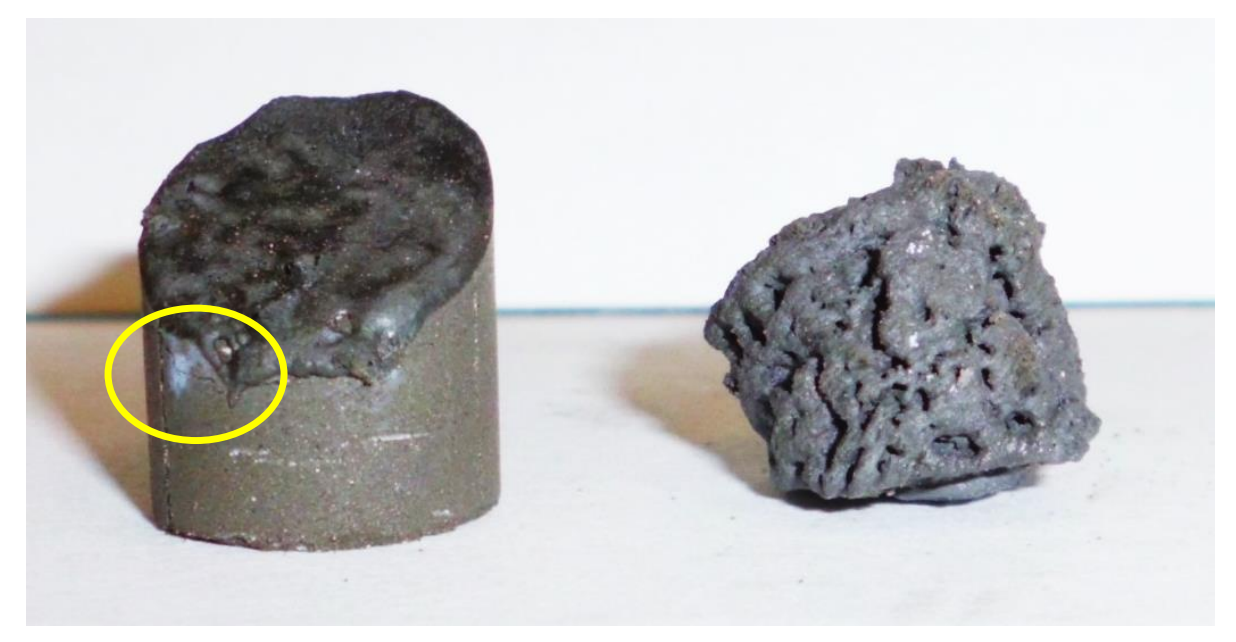

Fig. 4.1: Combustion products of a pellet that broke and separated during combustion.

All the pellets after combustion showed high porosity, this was expected due to the mass being gasified (Figs. 4.1 and 4.2). Figure 4.2 show different outcomes during combustion of the pellets. Mixtures that provided the most stable combustion characteristics produced similar products as the left pellet in Fig. 4.2, showing high porosity and being relatively strong when compared to combustion products with unstable combustion characteristics. The combusted pellet in the middle of Fig.4.2 is a typical pellet where the combustion was unstable, producing fragile products that would split to small pieces upon handling, weighting and storage. Touching these samples would practically destroy them. The combustion pellet in the right side of Fig.4.2 is a typical pellet of a composition that did not provided self-sustained propagation of the combustion wave (only the top part of the pellet reacted). 

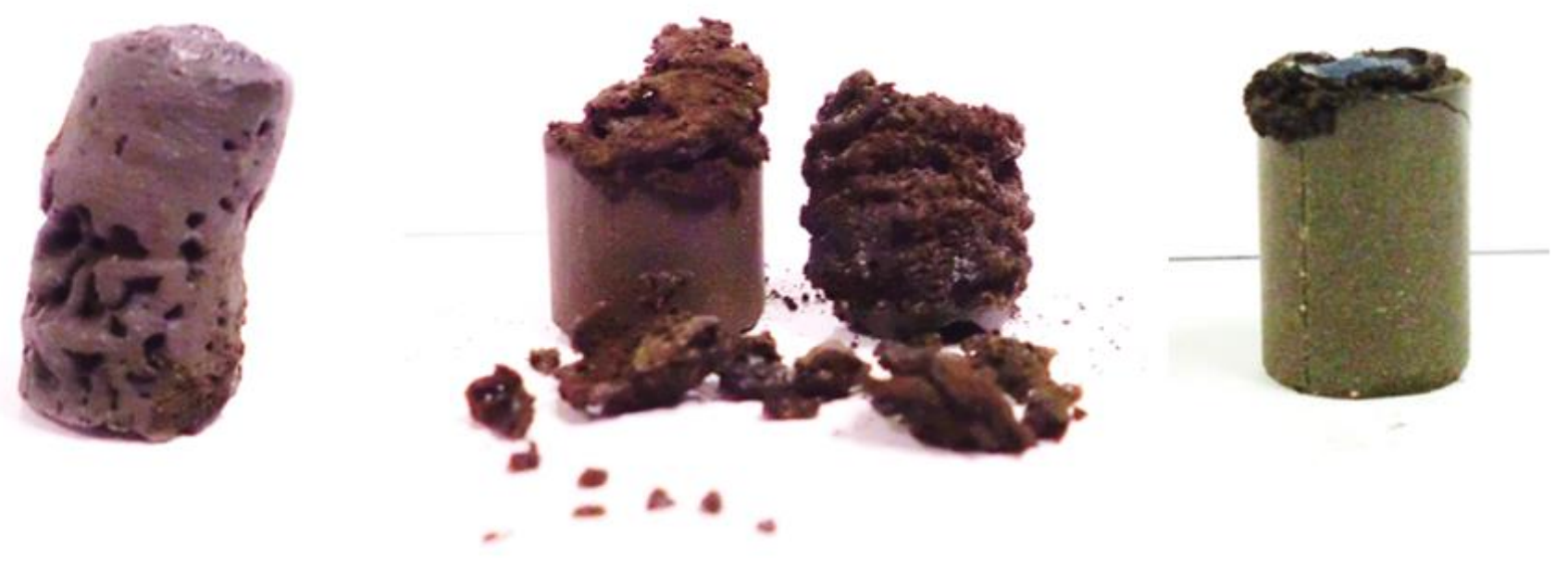

Fig. 4.2: Combustion products of different mixtures.

Figure 4.3 shows a typical pressure rise for an experiment where steady combustion occurred. The pressure gradually increases and then decreases to a stable value due to heat transfer to the chamber walls. Based on the pressure increase, the mass of the evolved oxygen was calculated for each experiment, assuming the ideal gas behavior. Also, the oxygen mass was calculated based on the mass of decomposed sodium chlorate, assuming that each mole of $\mathrm{NaClO}_{3}$ decomposes to $1 \mathrm{~mol}$ of $\mathrm{NaCl}$ and $1.5 \mathrm{~mol}$ of $\mathrm{O}_{2}$. On average, the mass of oxygen determined from the pressure rise was less by $2.95 \%$ than that determined from the pellet mass change. Taking into consideration that small pieces of the initial material were typically found in the chamber after experiments, the obtained results are in good agreement.

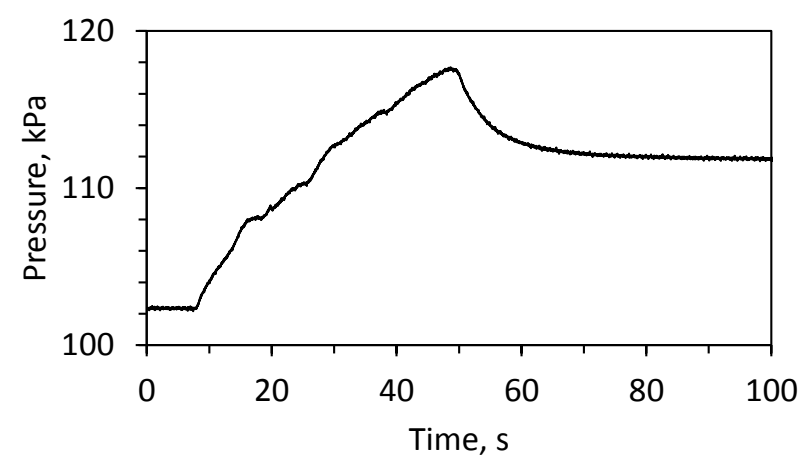

Fig. 4.3: Typical time variation of pressure during steady combustion and cooling; the mixture with $5 \mathrm{wt} \% \mathrm{Al} / \mathrm{Mg}$ (4.7:5.3 mole ratio). Time zero was selected arbitrarily. 
Multiple experiments were performed for each of the 12 different compositions (145 experiments in total). For iron, $5 \mathrm{wt} \% \mathrm{Fe}$ was needed for a self-sustained combustion. The front propagated with an average velocity of $0.22 \mathrm{~mm} / \mathrm{s}$, with a maximum combustion temperature of $700{ }^{\circ} \mathrm{C}$. For direct comparisons with iron, all the mixtures were tested for ignition with $5 \mathrm{wt} \%$ of the additive. Table 4.2 summarizes the results of these experiments. The column "Combustion" indicates whether the mixture exhibits a self-sustained propagation of the combustion front. The fact that significantly larger amounts of additives are required for achieving thermodynamically predicted combustion temperatures is explained by heat losses. In addition to experiments presented in Table 4.2, for selected materials, experiments were performed with lower amounts of additives.

Table 4.2: Combustibility of mixtures with $5 \mathrm{wt} \%$ energetic additive.

\begin{tabular}{|c|c|c|c|c|}
\hline Additive & Mole ratio & Combustion & $\begin{array}{c}\text { Front velocity, } \\
\mathbf{m m} / \mathbf{s}\end{array}$ & $\begin{array}{c}\text { Maximum } \\
\text { combustion } \\
\text { temperature, }{ }^{\circ} \mathbf{C}\end{array}$ \\
\hline $\mathrm{Fe}$ & - & yes & $0.22 \pm 0.03$ & $700 \pm 10$ \\
\hline $\mathrm{Mg}$ & - & yes & $0.55 \pm 0.02$ & $820 \pm 10$ \\
\hline $\mathrm{Fe} / \mathrm{Mg}$ & $3: 1$ & yes & $0.22 \pm 0.01$ & $695 \pm 19$ \\
\hline $\mathrm{B} / \mathrm{Ti}$ & $2: 1$ & yes & $0.24 \pm 0.05$ & $759 \pm 25$ \\
\hline $\mathrm{Al} / \mathrm{Mg}$ & $4.7: 5.3$ & yes & $0.41 \pm 0.08$ & $763 \pm 27$ \\
\hline $\mathrm{Al} / \mathrm{Mg}$ & $7: 3$ & yes & $0.31 \pm 0.05$ & $705 \pm 24$ \\
\hline $\mathrm{Al} / \mathrm{Mg}$ & $4: 1$ & no & - & - \\
\hline $\mathrm{Al} / \mathrm{Mg}$ & $9: 1$ & no & - & - \\
\hline $\mathrm{Al} / \mathrm{Ti}$ & $4: 1$ & no & - & - \\
\hline $\mathrm{Al} / \mathrm{NaNO} \mathrm{N}_{3}$ & $5: 3$ & no & - & - \\
\hline $\mathrm{Al} / \mathrm{NaNO} 3$ & $2.1: 1$ & no & - & - \\
\hline $\mathrm{Al} / \mathrm{MoO}_{3}$ & $8: 1$ & no & - & \\
\hline & & & & \\
\hline
\end{tabular}

Recalling that the combustibility limit of iron was found to be $5 \mathrm{wt} \%$ at the specified tested conditions, it was expected to observe unstable phenomena during the analysis of the combustion propagation wave. The images from Fig. 4.4 were obtained from an infrared video. It is seen that with the Fe additive, during the period from $46 \mathrm{~s}$ to $56 \mathrm{~s}$, the front virtually stands at a fixed position and the temperature of the products is decreasing; then, the front moves again and the temperature is increases. Also, the front shape is irregular. 


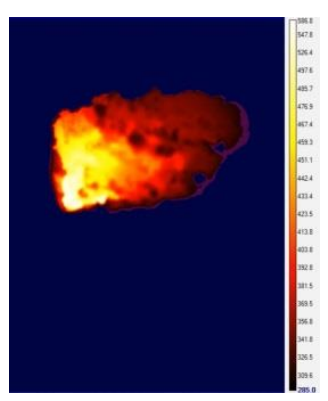

$30 \mathrm{~s}$

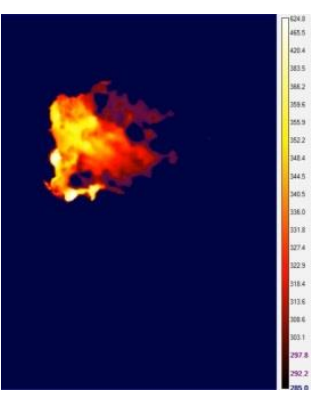

$40 \mathrm{~s}$

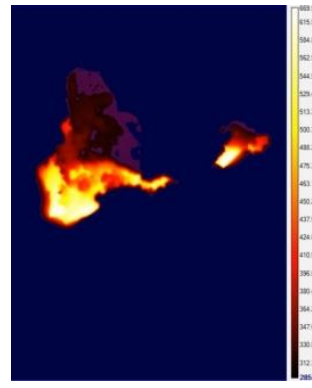

$50 \mathrm{~s}$

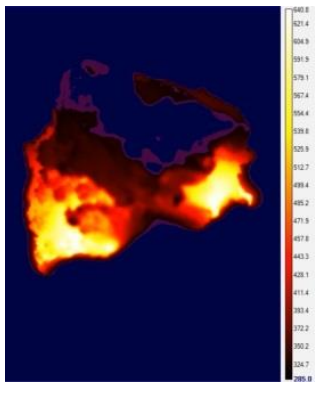

$60 \mathrm{~s}$

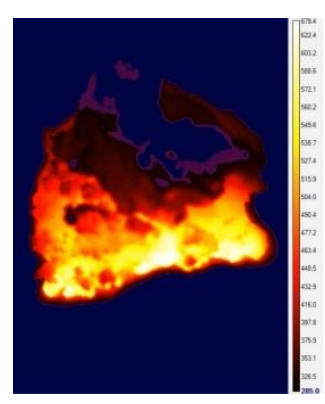

$70 \mathrm{~s}$

Fig. 4.4: Infrared images of combustion propagation over the pellet with 5 wt $\% \mathrm{Fe}$.

The pulsating and steady modes of the combustion front propagation are clearly reflected in the dynamics of temperature-distance profiles, obtained using infrared imaging. For example, Figure 4.5-a shows the thermal wave that propagates over a pellet that includes $5 \mathrm{wt} \% \mathrm{Fe}$ (not the same sample as in Figure 4.4). It is seen that significant pulsations in the front motion occur. For clarity, Figure 4.5-b presents a fragment of the plot shown in Figure 4.5-a, with time labels for all curves. Only temperature profiles for instants of time from $36 \mathrm{~s}$ through $47 \mathrm{~s}$ are shown in this plot. It is seen that for $4 \mathrm{~s}$ (from 37 $\mathrm{s}$ to $41 \mathrm{~s}$ ) the front almost does not move and the temperature decreases. Soon after that, the temperature increases and the front travels about $2 \mathrm{~mm} / \mathrm{s}$ for $2 \mathrm{~s}$ (from $41 \mathrm{~s}$ to $43 \mathrm{~s}$ ). Then, again, for $4 \mathrm{~s}$ (from $43 \mathrm{~s}$ to $47 \mathrm{~s})$ the front virtually stands in a fixed location. 

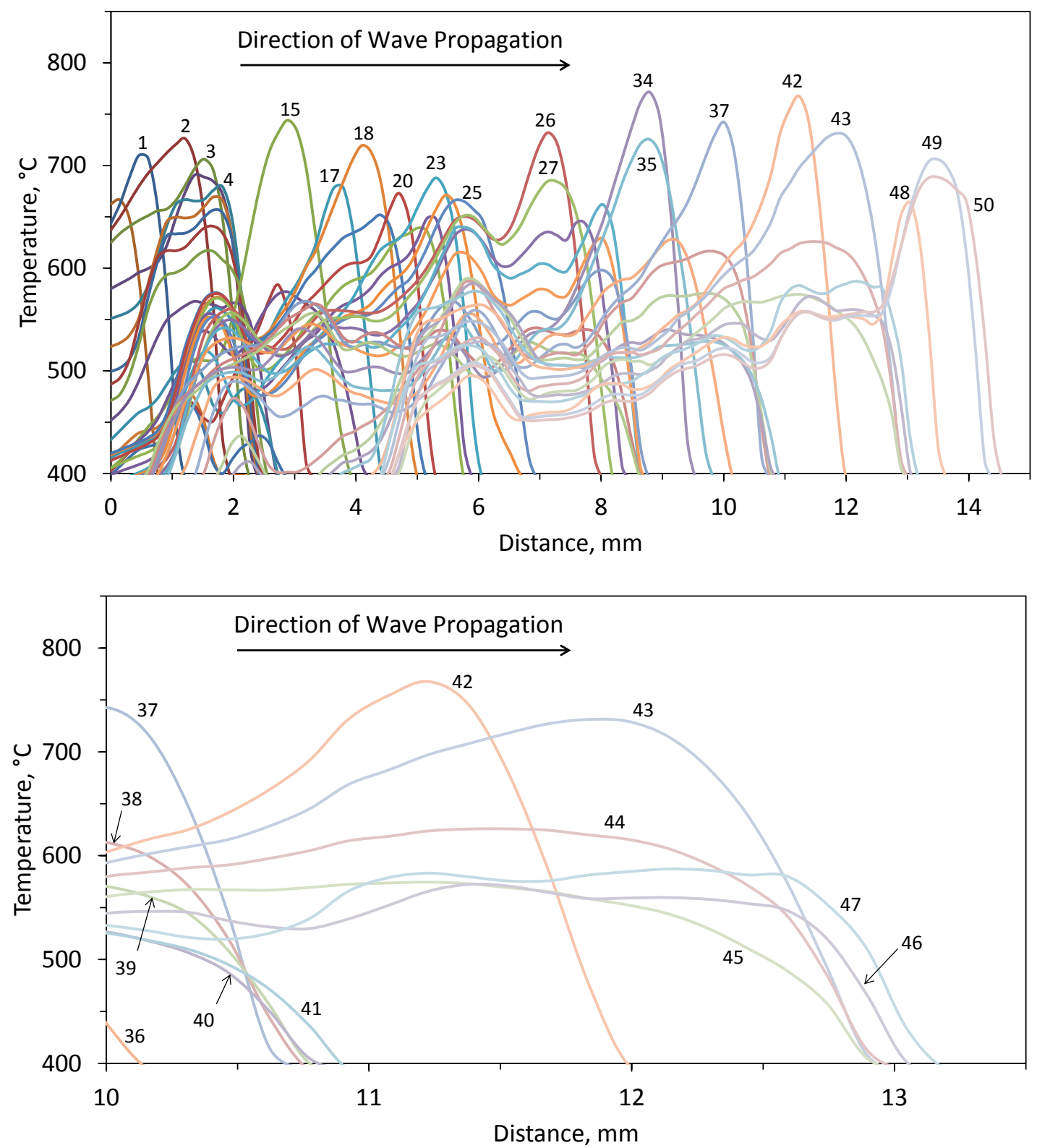

Fig. 4.5: Temperature-distance profiles at different instants of time $1 \mathrm{~s}$ apart for the pellet with 5 wt $\% \mathrm{Fe}$. The labels indicate time (s) from the start of propagation.

The temperature-distance plot might me difficult to read if the combustion front is similar to the one in Fig. 4.5. For clarity, Fig. 4.6 shows the time variation of the maximum temperature in the combustion wave and the distance traveled by the front as a function of time (a temperature of $400{ }^{\circ} \mathrm{C}$ in the front was taken to characterize its position). It is seen that the maximum temperature fluctuates from $450{ }^{\circ} \mathrm{C}$ to $770{ }^{\circ} \mathrm{C}$ and the front motion includes complete stops and rapid jumps forward. The stops correlate with the periods of temperature fall, while the jumps occur when the temperature rises. 


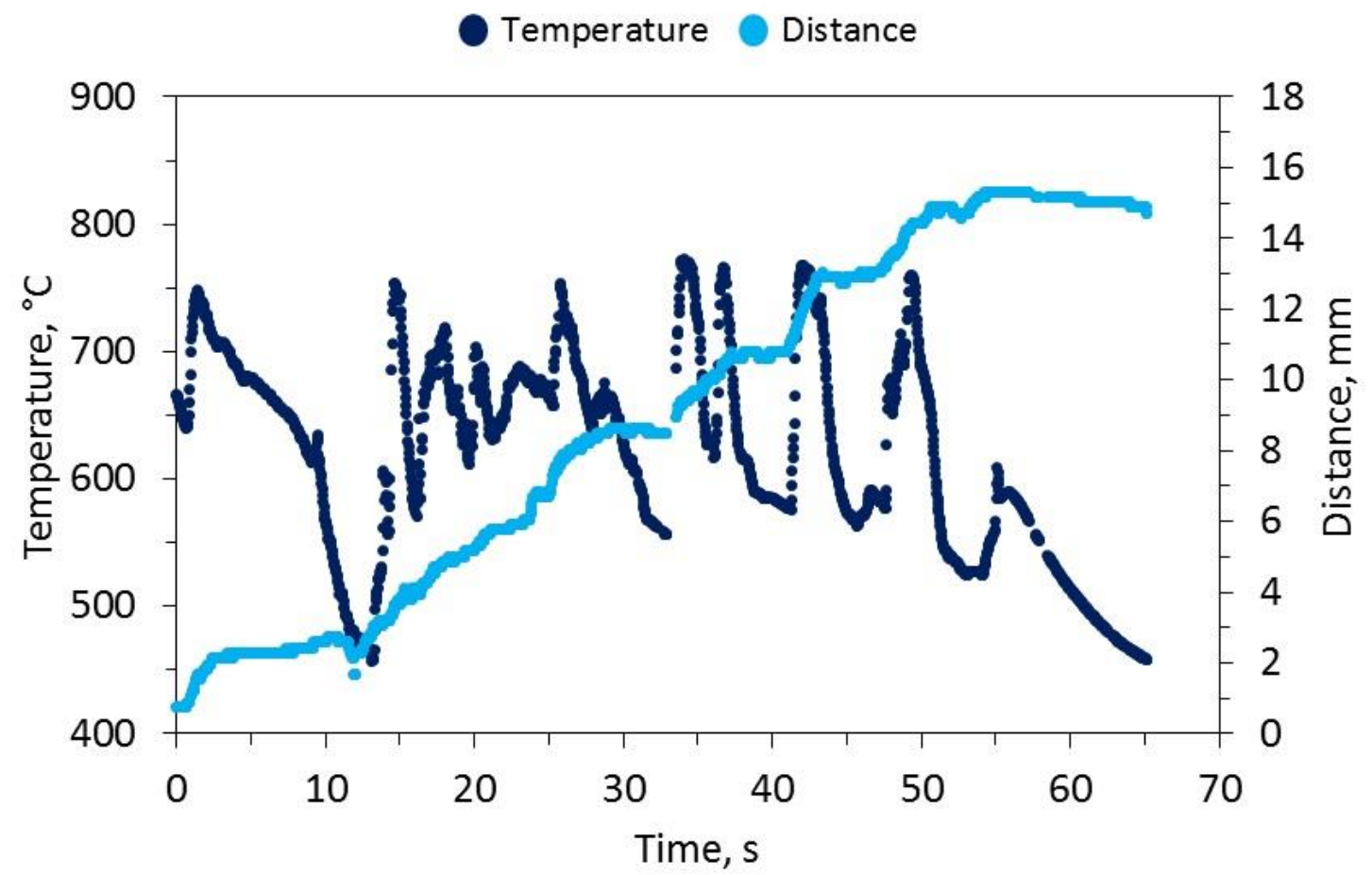

Fig. 4.6: Time variation of the maximum temperature in the combustion wave and the distance traveled by the front vs time for the mixture with $5 \mathrm{wt} \% \mathrm{Fe}$.

For Mg, smaller additives provided self-sustained propagation of the combustion wave. For 5 wt $\% \mathrm{Mg}$, both the average maximum temperature $\left(820^{\circ} \mathrm{C}\right)$ and the front velocity $(0.55 \mathrm{~m} / \mathrm{s})$ were significantly higher than for $\mathrm{Fe}$ at $5 \mathrm{wt} \%$. Figure 4.7 shows that at $5 \mathrm{wt} \% \mathrm{Mg}$, small variations of the maximum temperature occurred and the combustion front propagated in a steady manner with small instabilities. At $4 \mathrm{wt} \% \mathrm{Mg}$, the average combustion temperature was $803{ }^{\circ} \mathrm{C}$ and the front velocity was $0.45 \mathrm{~mm} / \mathrm{s}$. A decrease in $\mathrm{Mg}$ content to $3 \mathrm{wt} \%$ resulted in the front velocity and temperature of 0.44 $\mathrm{mm} / \mathrm{s}$ and $767{ }^{\circ} \mathrm{C}$, respectively. The mixture burned at only $2 \mathrm{wt} \% \mathrm{Mg}$ added, with the combustion characteristics of $0.24 \mathrm{~mm} / \mathrm{s}$ and $720^{\circ} \mathrm{C}$, which are similar to those for the mixture with $5 \mathrm{wt} \% \mathrm{Fe}$. The maximum temperature and combustion front varying with time are shown in Fig. 4.8. It can be observed that sometimes the combustion front moved back and the maximum temperature fluctuations took slightly longer time when compared with $5 \mathrm{wt} \% \mathrm{Fe}$. Additional maximum temperature and combustion front vs time graphs are reported in Appendix 2. 


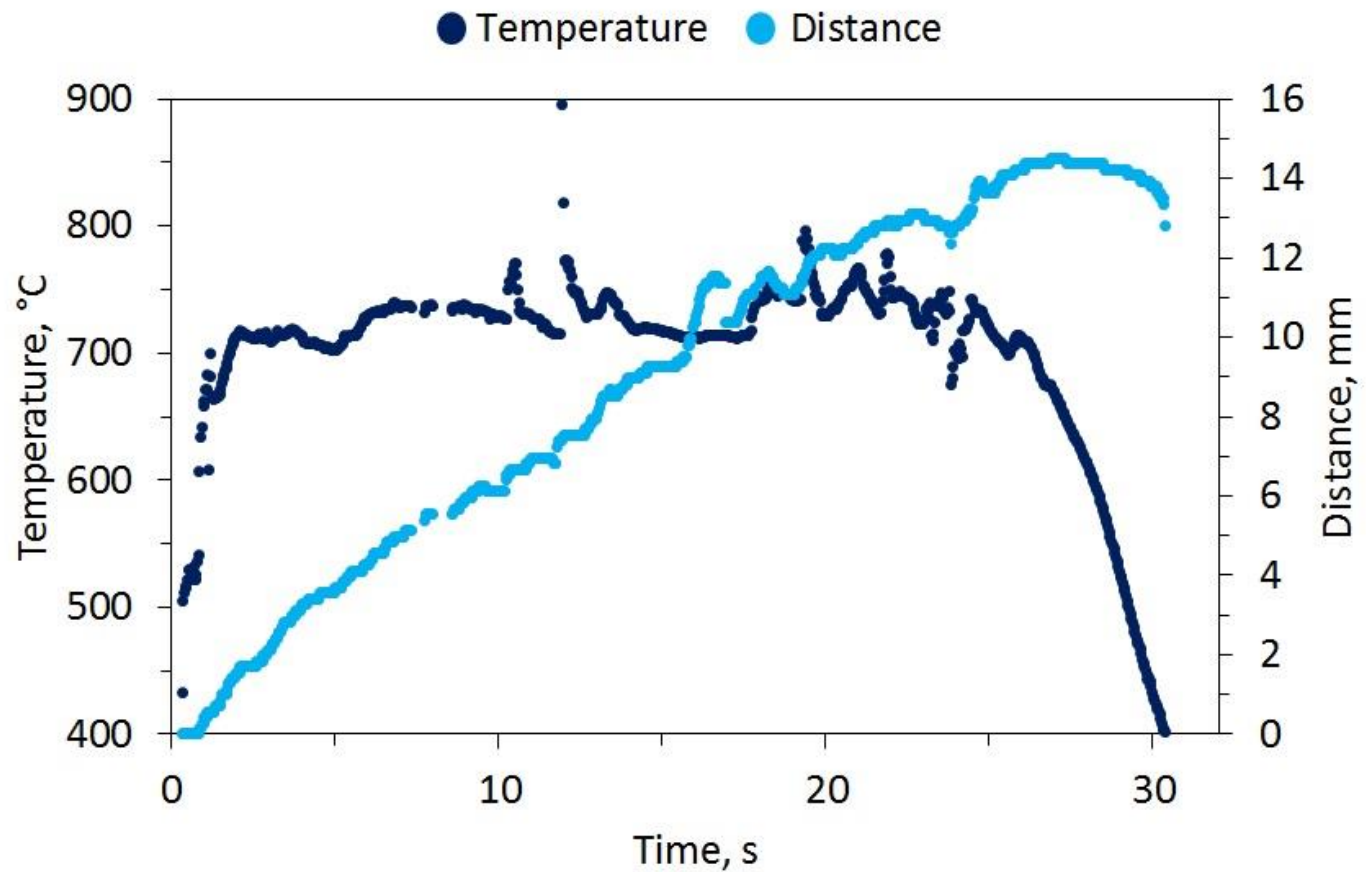

Fig. 4.7: Time variation of the maximum temperature in the combustion wave and the distance traveled by the front vs time for the mixture with $5 \mathrm{wt} \% \mathrm{Mg}$.

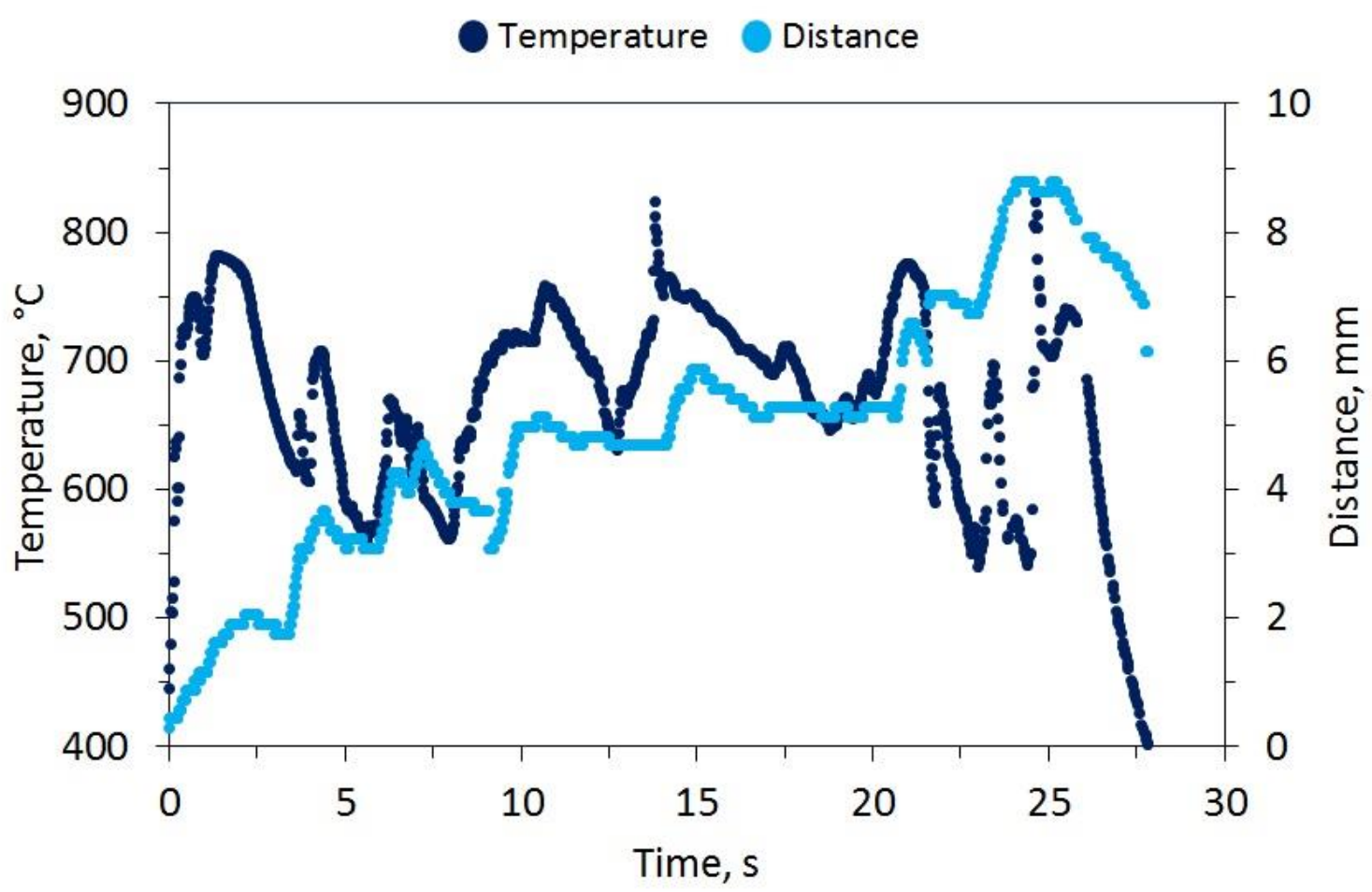

Fig. 4.8: Time variation of the maximum temperature in the combustion wave and the distance traveled by the front vs time for the mixture with $2 \mathrm{wt} \% \mathrm{Mg}$. 
For $\mathrm{Fe} / \mathrm{Mg}$, the combustion characteristics were similar to those obtained with $5 \mathrm{wt} \% \mathrm{Fe}$. Also, $5 \mathrm{wt} \%$ is the minimum required concentration for combustion of the mixture with $\mathrm{Fe} / \mathrm{Mg}$ additive. Thus, the addition of $\mathrm{Mg}$ to $\mathrm{Fe}$ (1:3 mole ratio) did not lead to any significant effect to the average combustion temperature $\left(695^{\circ} \mathrm{C}\right)$ and the combustion front velocity $(0.22 \mathrm{~m} / \mathrm{s})$. Nevertheless, it is remarkable that adding only a small fraction of $\mathrm{Mg}$ to $\mathrm{Fe}$ (mass ratio of 13:87) improves significantly the combustion fluctuations in the maximum temperature and the front displacement as shown in Fig. 4.9.

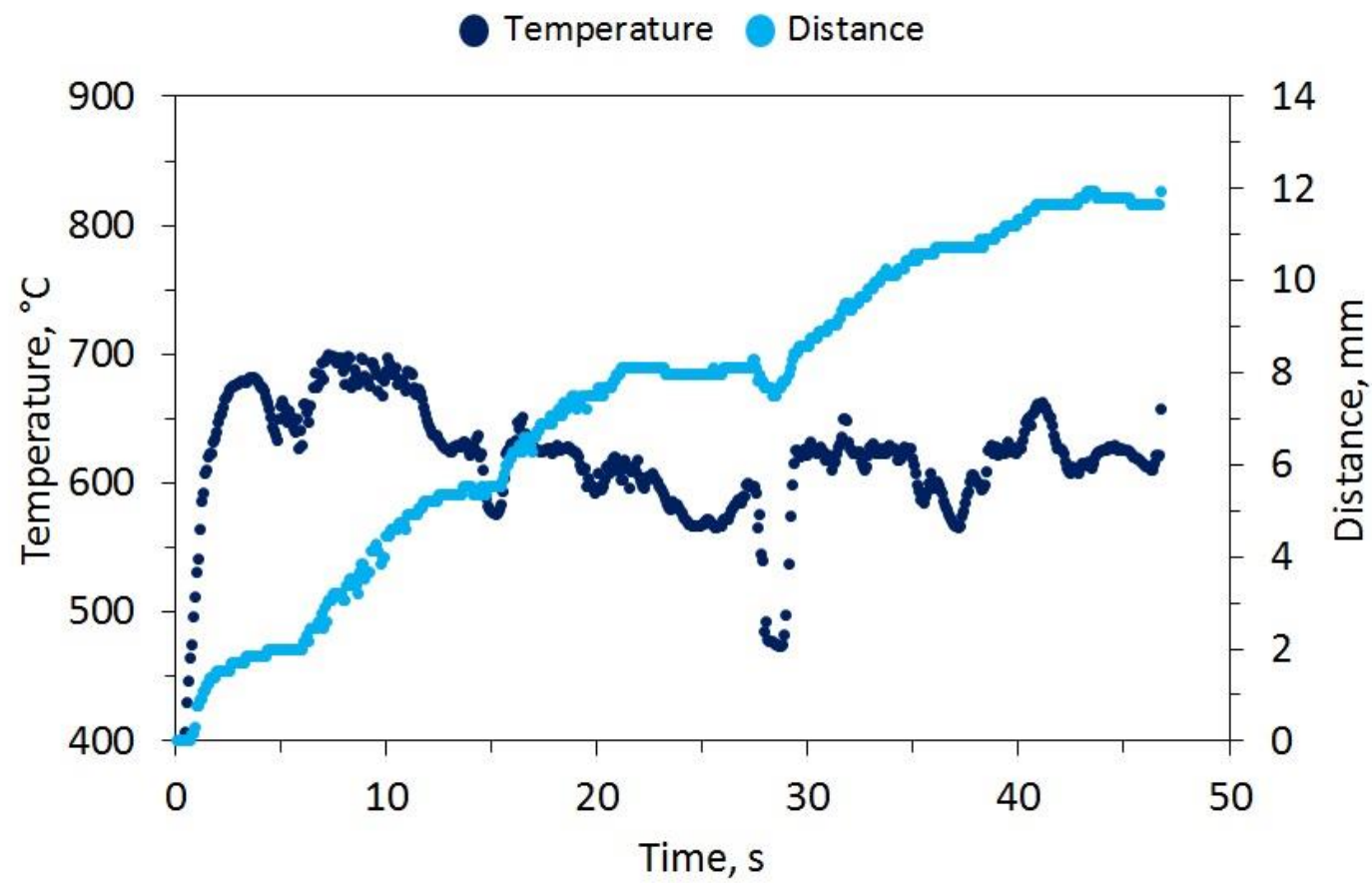

Fig. 4.9: Time variation of the maximum temperature in the combustion wave and the distance traveled by the front vs time for the mixture with $5 \mathrm{wt} \% \mathrm{Fe} / \mathrm{Mg}(3: 1)$.

For $\mathrm{B} / \mathrm{Ti}$, the average maximum temperature $\left(759^{\circ} \mathrm{C}\right)$ was significantly higher compared to $\mathrm{Fe}$, but the average front velocity $(0.24 \mathrm{~m} / \mathrm{s})$ was about the same. Numerous sparks were observed throughout the process as shown in Figure 4.10. Regardless of the higher temperature shown, fluctuations can be observed in the maximum temperature in Fig. 11. The propagation of the combustion wave is improved when compared with $5 \mathrm{wt} \% \mathrm{Fe}$. 

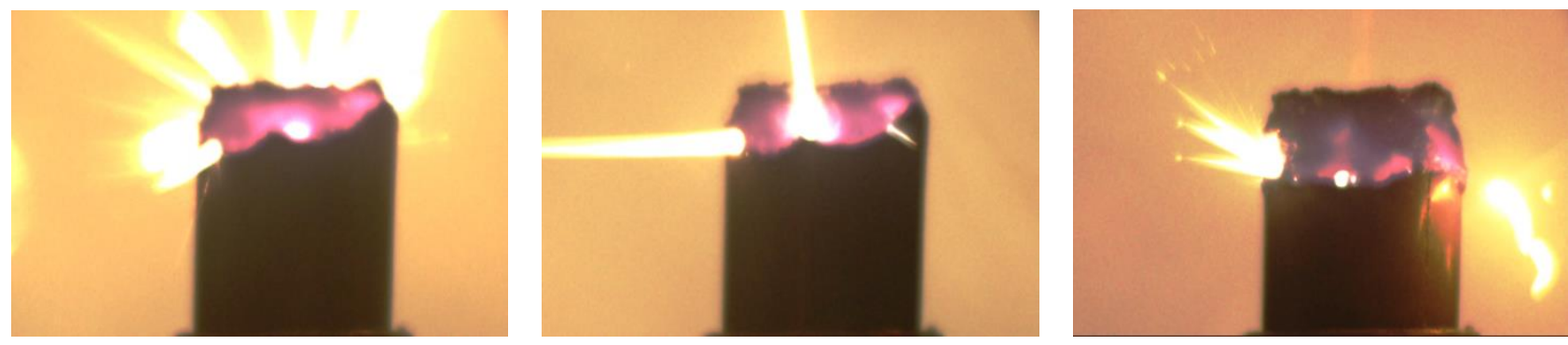

Fig. 4.10: Combustion of mixture with $5 \mathrm{wt} \% \mathrm{~B} / \mathrm{Ti}$ additive.

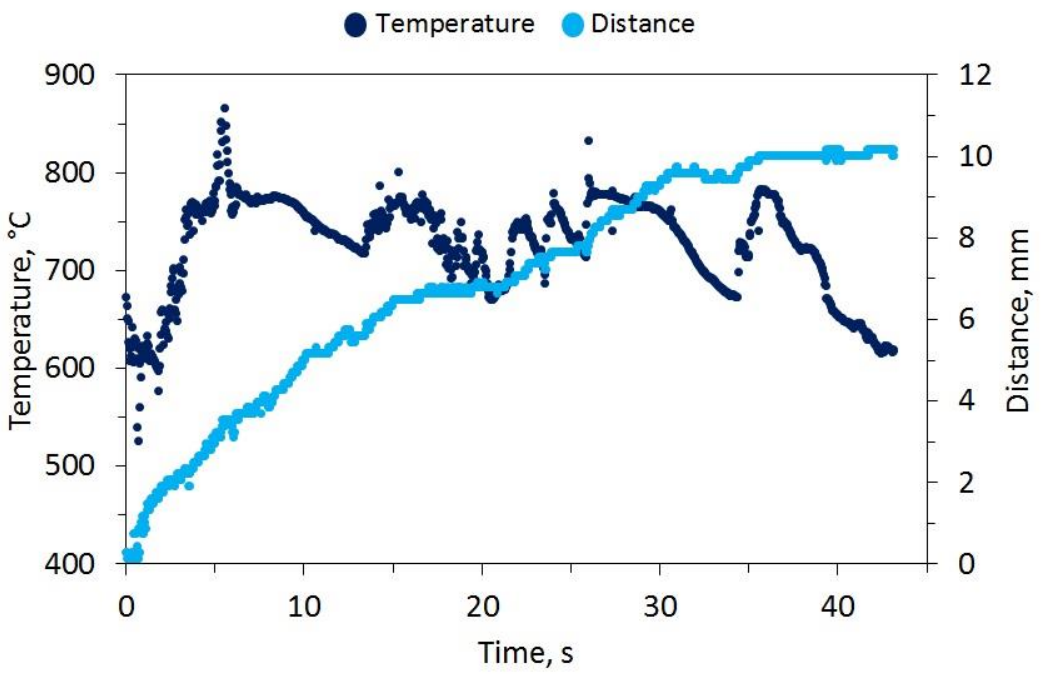

Fig. 4.11: Time variation of the maximum temperature in the combustion wave and the distance traveled by the front vs. time for the mixture with $5 \mathrm{wt} \% \mathrm{~B} / \mathrm{Ti}(2: 1)$.

For $\mathrm{Al} / \mathrm{Mg}$ (4.7:5.3), the average maximum temperature was significantly higher than for $\mathrm{Fe}$ (though lower than for $\mathrm{Mg}$ ) at $763{ }^{\circ} \mathrm{C}$, and the front velocity of $0.41 \mathrm{~mm} / \mathrm{s}$ was about twice the velocity for Fe. Figure 4.12 shows a very constant maximum average maximum temperature variation with time and a very smooth propagation of the combustion front vs. time. A concentration of $4 \mathrm{wt} \%$ enabled to reach the flame speed and temperature of $0.37 \mathrm{~mm} / \mathrm{s}$ and $767{ }^{\circ} \mathrm{C}$. The mixture with $3 \mathrm{wt} \%$ additive burned with the front velocity being equal to $0.24 \mathrm{~mm} / \mathrm{s}$, i.e., as fast as the mixture with $5 \mathrm{wt} \% \mathrm{Fe}$, and the measured temperature was equal to $685^{\circ} \mathrm{C}$. Figure 4.13 shows the varying maximum temperature with respect to time and the combustion front vs. time. It can be observed that $3 \mathrm{wt} \% \mathrm{Al} / \mathrm{Mg}$ (4.7:5.3) delivers very similar combustion characteristics to $5 \mathrm{wt} \% \mathrm{Fe}$. Further reduction of the additive $\mathrm{Al} / \mathrm{Mg}$ (4.7:5.3) did not provide self-sustained propagation of the combustion wave. 


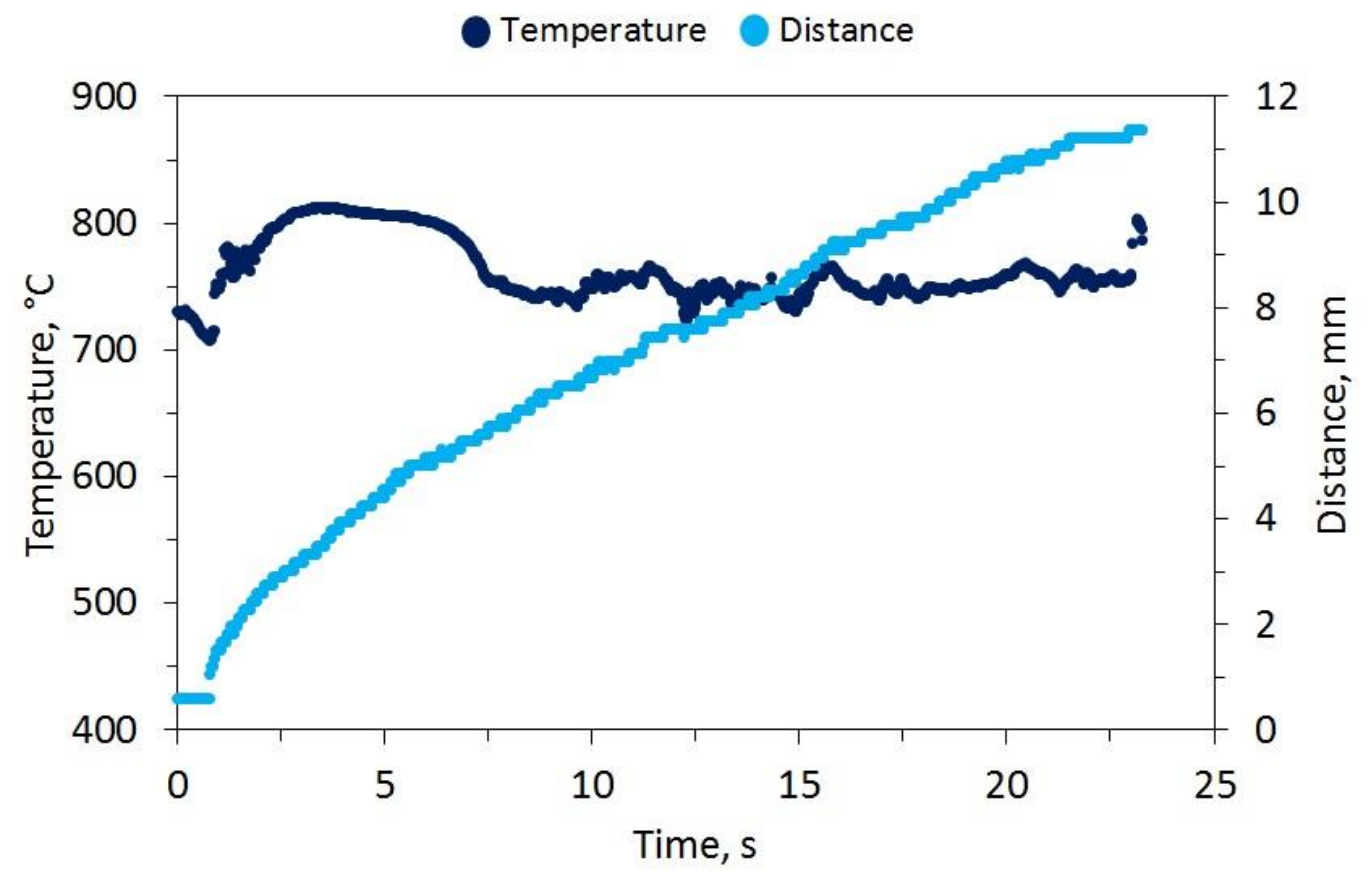

Fig. 4.12: Time variation of the maximum temperature in the combustion wave and the distance traveled by the front vs. time for the mixture with $5 \mathrm{wt} \% \mathrm{Al} / \mathrm{Mg}$ (4.7:5.3).

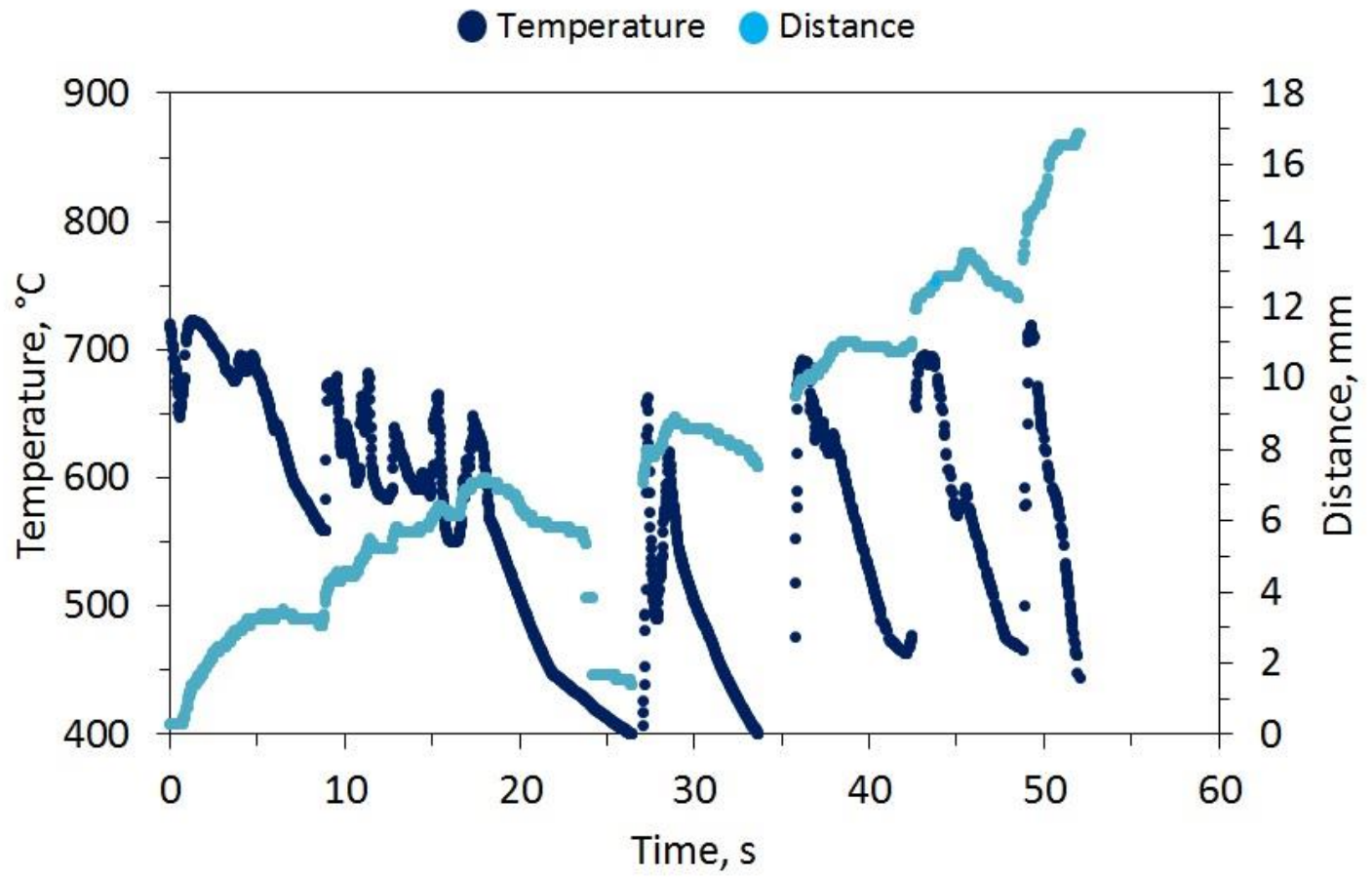

Fig. 4.13: Time variation of the maximum temperature in the combustion wave and the distance traveled by the front vs. time for the mixture with $3 \mathrm{wt} \% \mathrm{Al} / \mathrm{Mg}(4.7: 5.3)$. 
For $\mathrm{Al} / \mathrm{Mg}(7: 3)$, the mixture burned slightly better than that with $5 \mathrm{wt} \% \mathrm{Fe}$. Also, $5 \mathrm{wt} \% \mathrm{was}$ the minimum required concentration of the additive. Figure 4.14 shows the maximum temperature and combustion front vs. time. The addition of $5 \mathrm{wt} \% \mathrm{Al} / \mathrm{Mg}$ (7:3) produces very similar combustion characteristics as $5 \mathrm{wt} \% \mathrm{Fe}$ and $3 \mathrm{wt} \% \mathrm{Al} / \mathrm{Mg}$ (4.7:5.3). The additive $\mathrm{Al} / \mathrm{Mg}(7: 3)$ might not be better than Fe, however it is better than $\mathrm{Sn}$; however, and advantage of $\mathrm{Al} / \mathrm{Mg}(7: 3)$ is that no $\mathrm{CO}$ would be produced as it happens when using Fe as a metal fuel.

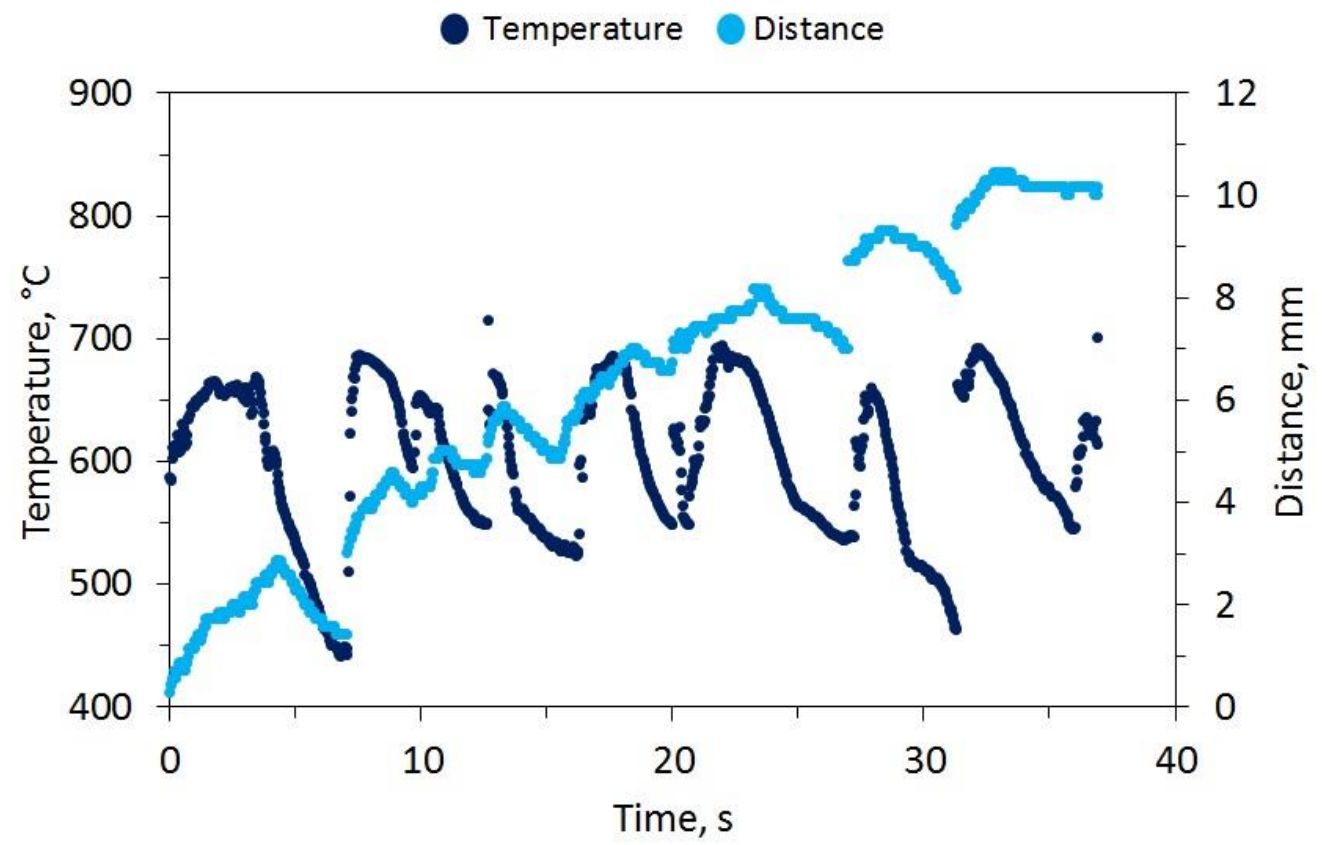

Fig. 4.14: Time variation of the maximum temperature in the combustion wave and the distance traveled by the front vs. time for the mixture with $3 \mathrm{wt} \% \mathrm{Al} / \mathrm{Mg}(4.7: 5.3)$.

No ignition was observed for the mixtures with $\mathrm{Al} / \mathrm{Mg}$ if the concentration of $\mathrm{Mg}$ was $20 \mathrm{~mol} \%$ or less. For $\mathrm{Al} / \mathrm{Ti}$ (4:1, both types of powder - prepared with stearic acid and with paraffin wax), $\mathrm{Al} / \mathrm{NaNO}_{3}$ (both mole ratios), and $\mathrm{Al} / \mathrm{MoO}_{3}$ (8:1). Additional graphs (Temperature vs. Time, Temperature vs Distance, and Maximum Temperature and Combustion front vs. Time) for all energetic additives that provided self-sustained propagation of the combustion wave are presented in Appendix 2.

Since Al/Mg (4.7:5.3) produced the best results from all the energetic additives tested, Fig. 15 shows the propagation of the combustion wave by infrared images (similar to Fig. 4.4). In contrast, with 
Fe additive, the front motion is rather uniform and the front is flatter. Also for comparison, Figure 4.16 shows the thermal wave that propagates over a pellet that includes $5 \mathrm{wt} \%$ of $\mathrm{Al} / \mathrm{Mg}(4.7: 5.3$ mole ratio). It is seen that, in contrast with the Fe-containing mixture (Fig. 4.5), the propagation in Fig. 4. 16 is very uniform. As noted above, a decrease in $\mathrm{Al} / \mathrm{Mg}$ concentration from $5 \mathrm{wt} \%$ to $3 \mathrm{wt} \%$ makes the combustion characteristics similar to those for the mixture with $5 \mathrm{wt} \% \mathrm{Fe}$. The combustion also becomes pulsating, as shown in Fig. 4.17.

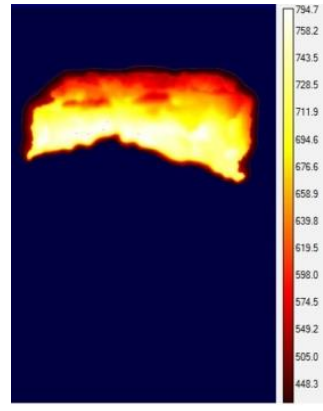

$31 \mathrm{~s}$

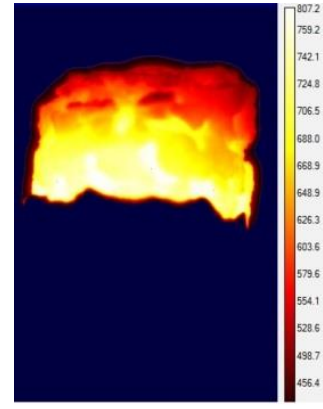

$40 \mathrm{~s}$

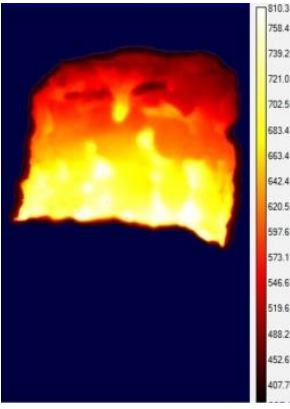

$49 \mathrm{~s}$

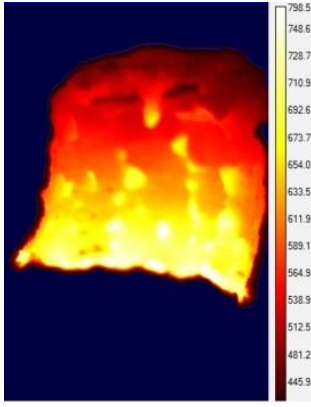

$58 \mathrm{~s}$

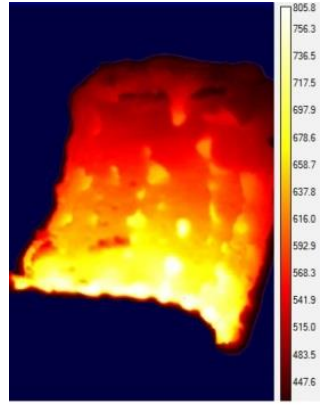

$65 \mathrm{~s}$

Fig. 4.15: Infrared images of combustion propagation over the pellet with $5 \mathrm{wt} \% \mathrm{Al} / \mathrm{Mg}$ (4.7:5.3 mole ratio).

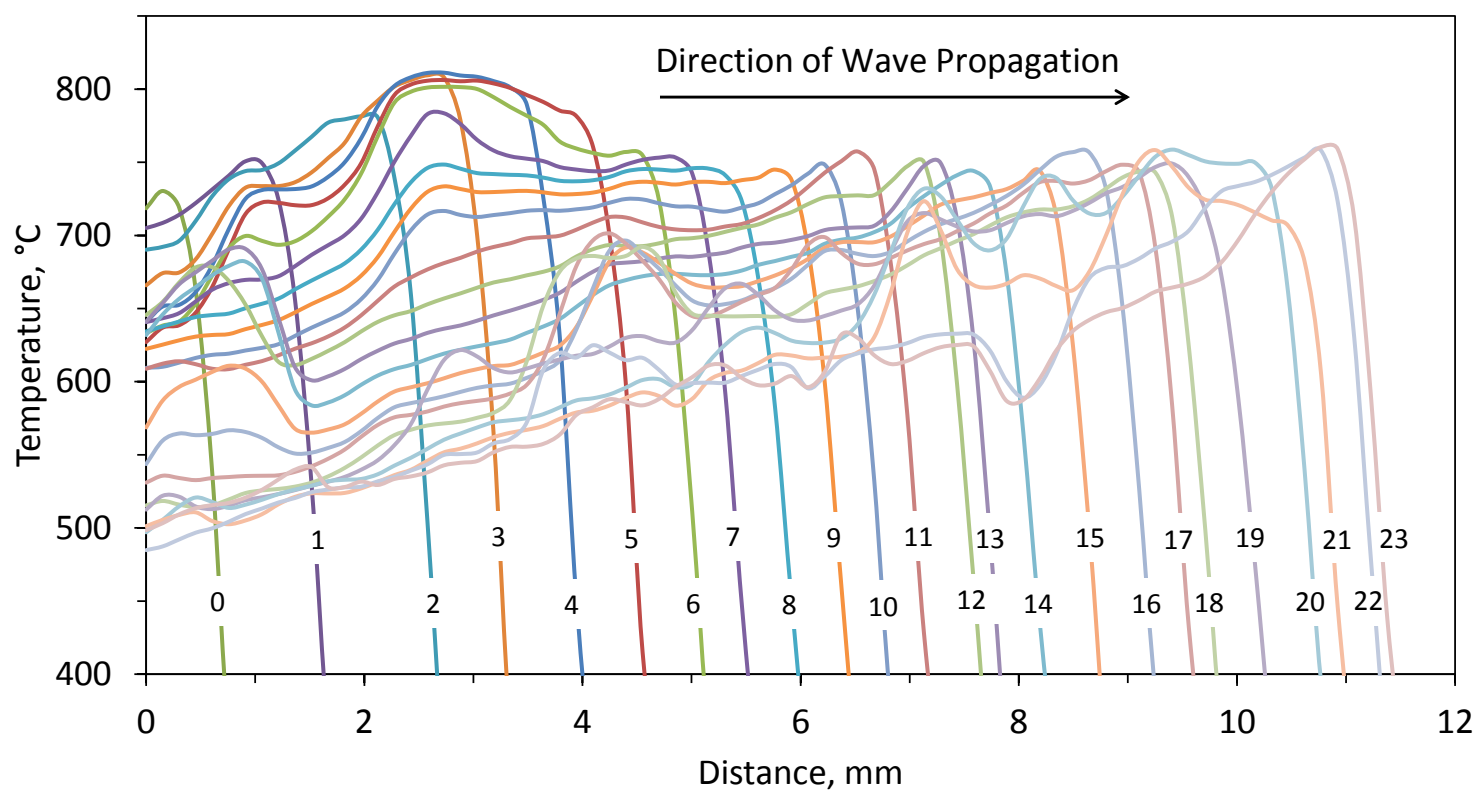


Fig. 4.16: Temperature-distance profiles at different instants of time $1 \mathrm{~s}$ apart for the pellet with $5 \mathrm{wt} \%$ of $\mathrm{Al} / \mathrm{Mg}$ (4.7:5.3 mole ratio). The labels indicate time (s) from the start of propagation.

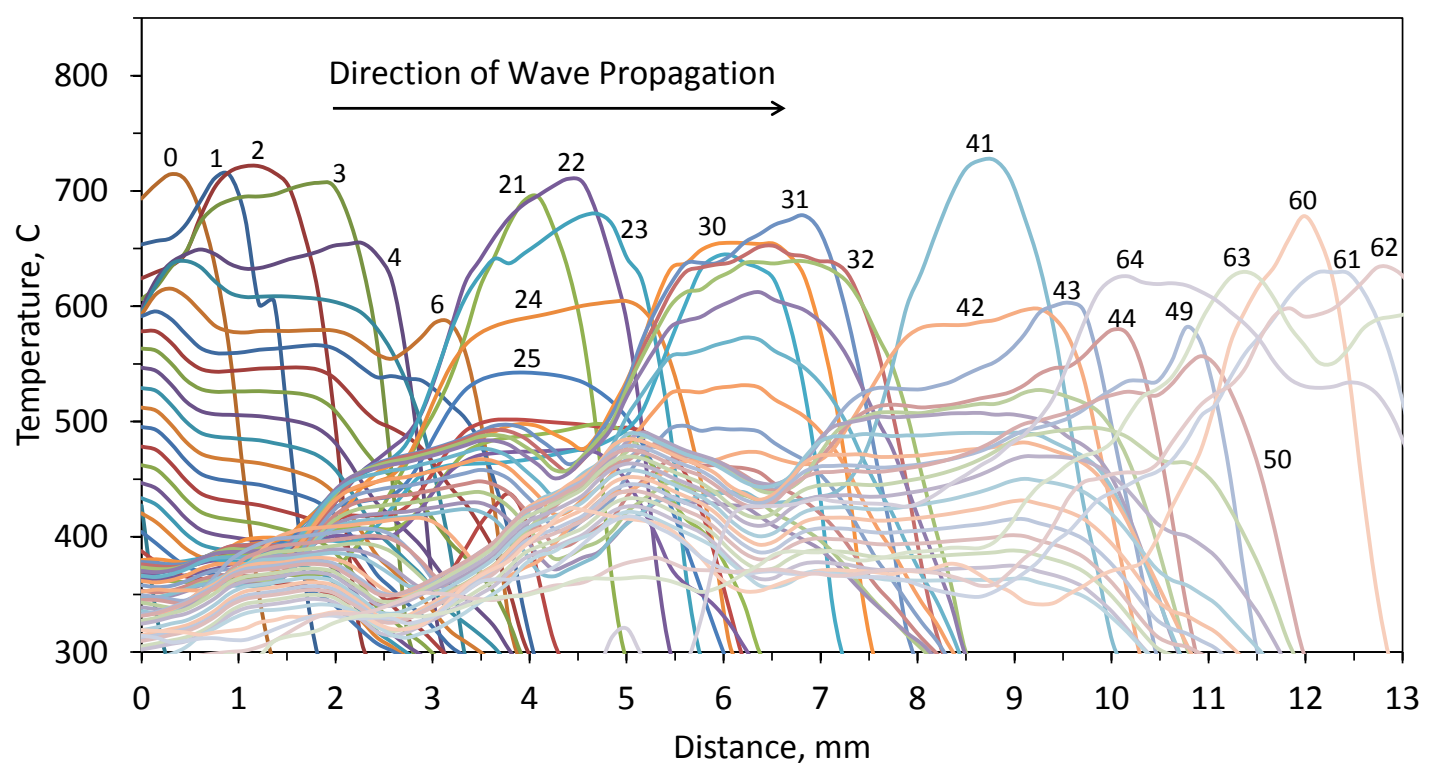

Fig. 4.17: Temperature-distance profiles at different instants of time $1 \mathrm{~s}$ apart for the pellet with $3 \mathrm{wt} \%$ of $\mathrm{Al} / \mathrm{Mg}$ (4.7:5.3 mole ratio). The labels indicate time (s) from the start of propagation.

Figures 4.18 and 4.19 summarize the combustion front velocities and maximum combustion temperatures for the mixtures with $\mathrm{Fe}, \mathrm{Mg}, \mathrm{Fe} / \mathrm{Mg}, \mathrm{B} / \mathrm{Ti}$, and two $\mathrm{Al} / \mathrm{Mg}$ additives. Analysis of the obtained experimental results shows that the replacement of Fe with the same or even smaller amount of $\mathrm{Al} / \mathrm{Mg}$ (4.7:5.3) material increases both the combustion front velocity and the maximum temperature. 


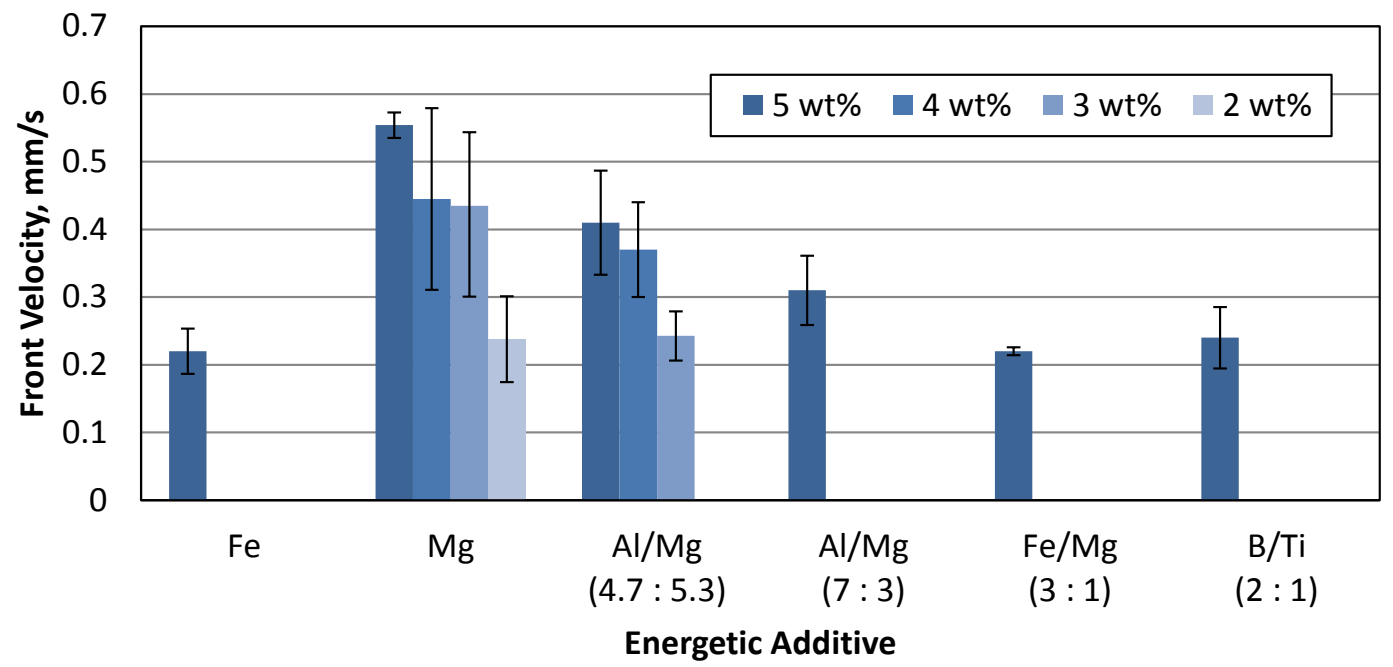

Fig. 4.18: Combustion front velocities of $\mathrm{NaClO}_{3}$-based mixtures with different energetic additives.

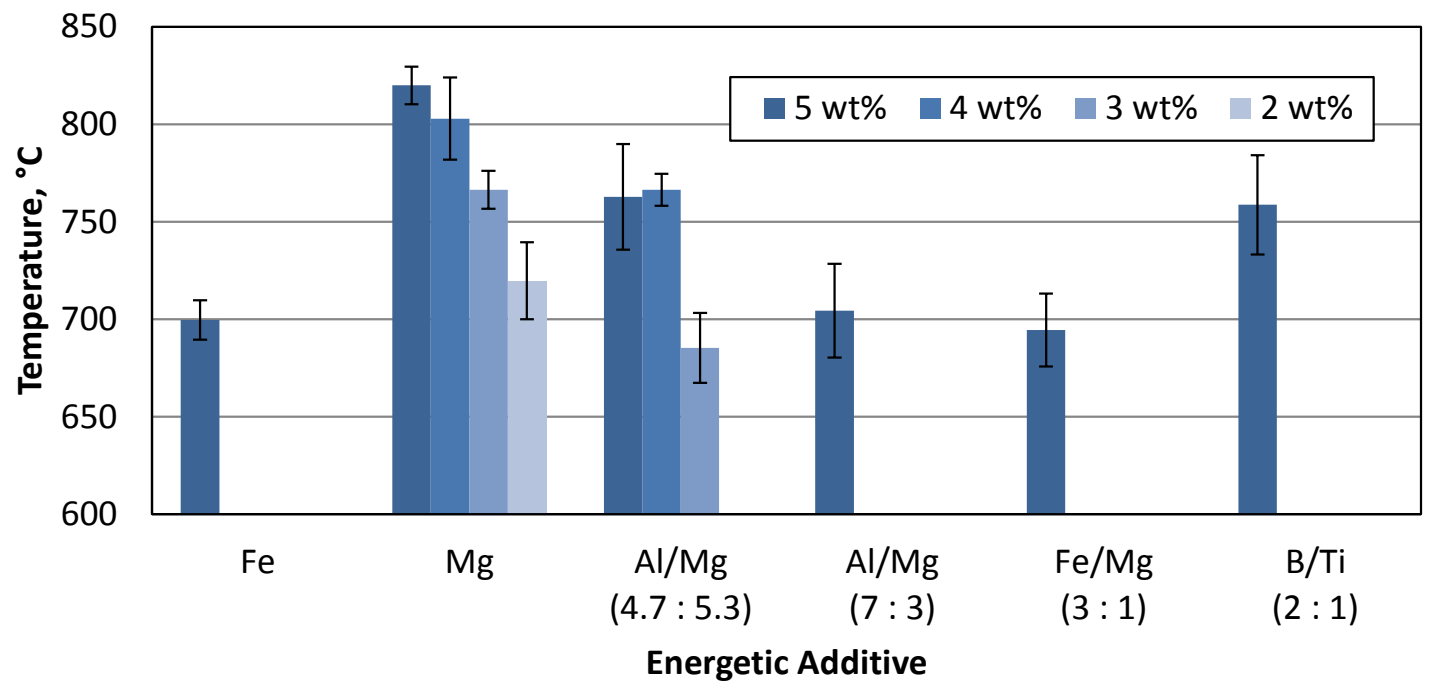

Fig. 4.19: Maximum temperatures in the combustion front, measured at the pellet surface, for $\mathrm{NaClO}_{3}$-based mixtures with different energetic additives.

The front pulsations, such as those observed at $5 \mathrm{wt} \% \mathrm{Fe}$ and $3 \mathrm{wt} \% \mathrm{Al} / \mathrm{Mg}$, lead to the fluctuations of the oxygen flow rate, which are highly undesired in emergency oxygen generators $[6,7$, 8]. In the present experiments, the flow rate fluctuations result in the fluctuations of pressure in the reaction chamber. For example, Figure 4.20 shows the time variation of pressure during combustion of 
pellets with $5 \mathrm{wt} \% \mathrm{Fe}$ and $3 \mathrm{wt} \% \mathrm{Al} / \mathrm{Mg}$. The pressure pulsations did not occur during uniform combustion of the mixtures with $5 \mathrm{wt} \% \mathrm{Al} / \mathrm{Mg}$ (see Figure 4.3).

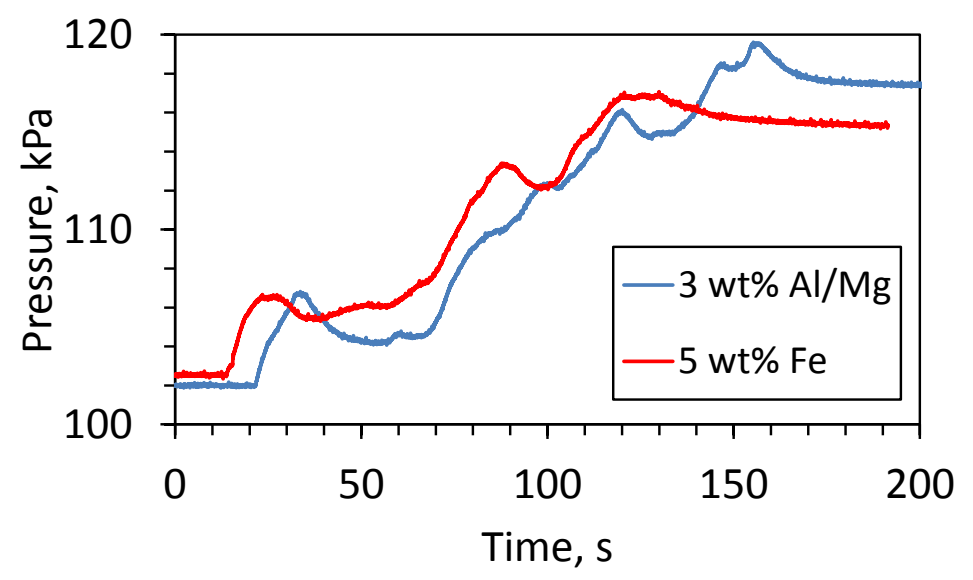

Fig. 4.20: Time variation of pressure during combustion of the pellets with $5 \mathrm{wt} \% \mathrm{Fe}$ and $3 \mathrm{wt} \%$ $\mathrm{Al} / \mathrm{Mg}$. Time zero was selected arbitrarily.

Figure 4.21 shows the XRD pattern of the combustion products of the mixture with $5 \mathrm{wt} \%$ $\mathrm{Al} / \mathrm{Mg}$ (4.7:5.3 mole ratio) after removing $\mathrm{NaCl}$. It is seen that the main peaks correspond to oxides of $\mathrm{Al}, \mathrm{Mg}$, and $\mathrm{Co}$. Note that the main lines for $\mathrm{Co}_{3} \mathrm{O}_{4}$ are the same as for $\mathrm{MgAl}_{2} \mathrm{O}_{4}\left(2 \Theta: 31^{\circ}, 37^{\circ}, 45^{\circ}, 59^{\circ}\right.$, and $65^{\circ}$ ), so that it is impossible to distinguish these two phases in the diffraction pattern. The obtained results are in agreement with the experiments on combustion of mechanically alloyed $\mathrm{Al} / \mathrm{Mg}$ particles in air, where $\mathrm{XRD}$ analysis showed $\mathrm{MgO}, \mathrm{Al}_{2} \mathrm{O}_{3}$, and $\mathrm{MgAl}_{2} \mathrm{O}_{4}$ in the products [33]. Also, the main lines for $\mathrm{Al}$ are at $39^{\circ}, 45^{\circ}, 65^{\circ}$, and $78^{\circ}$. The obtained diffraction pattern has a small peak at $39^{\circ}$, while three other lines overlap the peaks of other phases. Thus, it cannot be excluded that a small amount of free metallic $\mathrm{Al}$ is present in the products. 


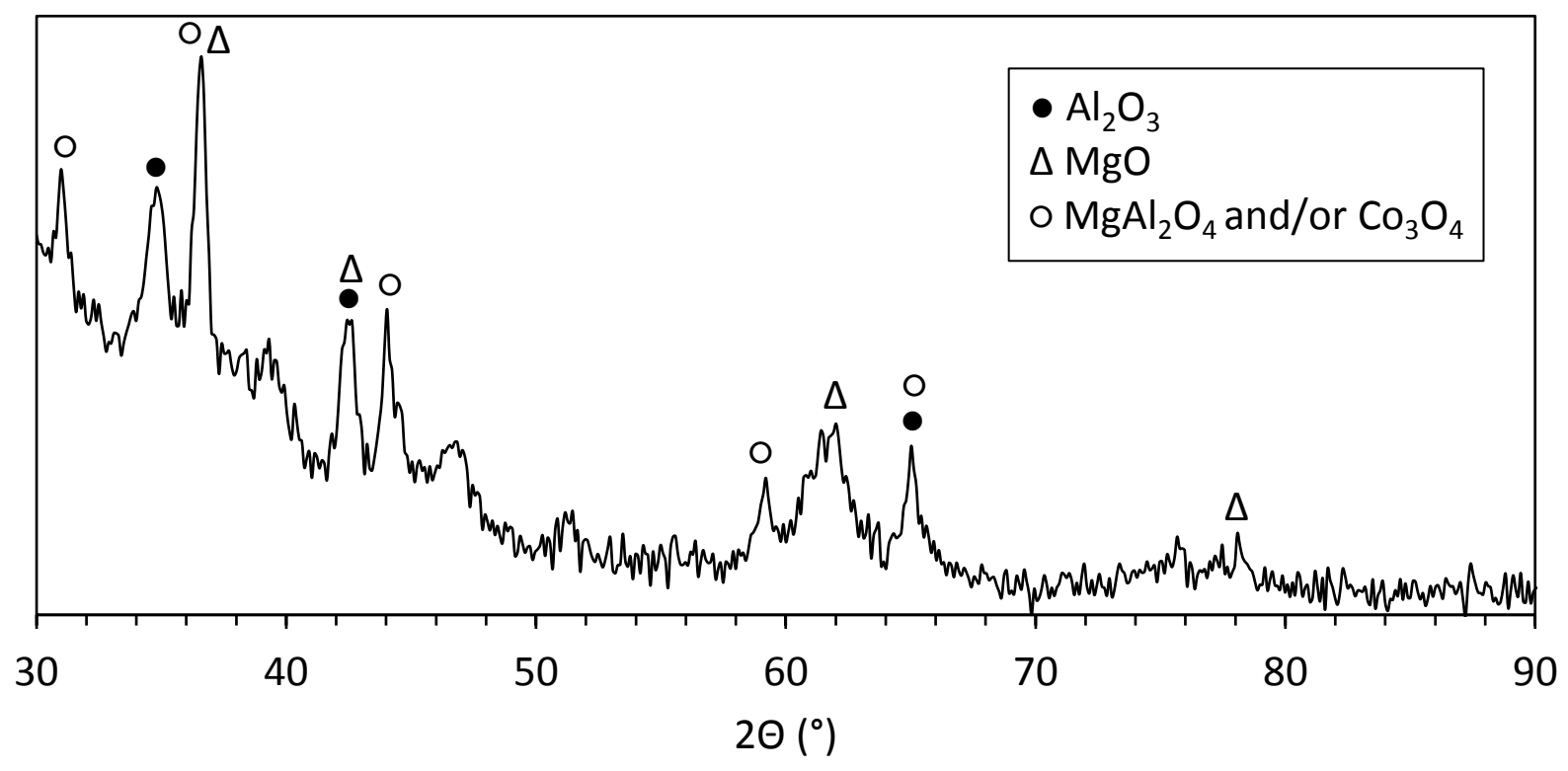

Fig. 4.21: XRD pattern of the combustion products of the mixture with $5 \mathrm{wt} \% \mathrm{Al} / \mathrm{Mg}$ (4.7:5.3 mole ratio) after removing $\mathrm{NaCl}$. 


\subsection{Discussion}

The observed formation of sparks during combustion of the mixture with $5 \mathrm{wt} \% \mathrm{~B} / \mathrm{Ti}$ is worthy of discussion. To our knowledge, this phenomenon has never been observed during combustion of sodium chlorate mixed with Fe, Sn, or other metals. During combustion of pyrotechnic compositions, the observed sparks are often tracks of single metal particles (or their agglomerates) burning in the atmosphere. In the present work, since the atmosphere was argon with only a small amount of oxygen generated by the combustion, the nature of the observed wide sparks was likely different. Apparently, fast combustion of $\mathrm{B} / \mathrm{Ti}$ composite particles led to very high local temperatures and sharp decomposition of the surrounding sodium chlorate. The molten $\mathrm{NaClO}_{3}$ virtually boiled around $\mathrm{B} /$ Ti particles, leading to the ejection of large fragments of the mixture, which continued to burn and emit light during the flight.

Note that the maximum temperature during combustion of the mixture with $5 \mathrm{wt} \% \mathrm{~B} / \mathrm{Ti}$ was significantly higher than for the mixture with $\mathrm{Fe}$, but the front velocity was almost the same (see Table 4.2). Because of this and accounting for the undesired spark phenomenon, it is concluded that the replacement of $\mathrm{Fe}$ by $\mathrm{B} / \mathrm{Ti}$ in chemical oxygen generators cannot not be recommended.

The failed attempts to ignite the mixtures with $5 \mathrm{wt} \% \mathrm{Al} / \mathrm{NaNO}_{3}$ and $5 \mathrm{wt} \% \mathrm{Al} / \mathrm{MoO}_{3}$ imply that the high exothermicity of the additive, if taken alone, does not guarantee that it will also work well in the mixture with sodium chlorate. The ignition of the additive should occur at a rate that is compatible with the ignition of sodium chlorate. It should be noted that to verify that the additive did not lose reactivity during storage, pellets that contained only $\mathrm{Al} / \mathrm{NaNO}_{3}$ were prepared and tested. The observed vigorous combustion confirmed that the additive itself was not deteriorated.

Analysis of the obtained results (see Table 4.2) indicates that for successful operation in the sodium chlorate-based mixture, the energetic additive should include a metal that ignites in oxygen at relatively low temperatures (e.g., $\mathrm{Mg}$ or $\mathrm{Ti}$ ). For example, the results for $\mathrm{Al} / \mathrm{Mg}$ additives with different mixture ratios clearly show that a significant amount of $\mathrm{Mg}$ is required for the ignition of respective mixtures with $\mathrm{NaClO}_{3}$. Note, however, that in the mixtures with $\mathrm{Mg} / \mathrm{Al}$ additives, $\mathrm{Al}$ is not an inert 
material. This is confirmed by XRD analysis, which indicated that both $\mathrm{Al}$ and $\mathrm{Mg}$ were oxidized during combustion of the mixture (see Fig. 4.19). Apparently, ignition of Mg creates local temperatures that are sufficient for the ignition of Al. This explanation is in agreement with prior results on the combustion of mechanically alloyed $\mathrm{Al} / \mathrm{Mg}$ particles where it was shown that their ignition temperatures are close to those for $\mathrm{Mg}$ (much lower than for $\mathrm{Al}$ ) and that $\mathrm{Mg}$ selectively burns first (stage I) followed by combustion of $\mathrm{Al}$ (stage II) [22, 34].

The results on combustion of $\mathrm{NaClO}_{3}$-based mixtures with $\mathrm{Al} / \mathrm{Mg}$ (4.7:5.3 mole ratio) additive are remarkable. The mixture with $5 \mathrm{wt} \% \mathrm{Al} / \mathrm{Mg}$ provides a steady propagation of the combustion front, in contrast with pulsating combustion of the mixture with $5 \mathrm{wt} \%$ Fe. The mixture with $3 \mathrm{wt} \% \mathrm{Al} / \mathrm{Mg}$ behaves like the mixture with $5 \mathrm{wt} \% \mathrm{Fe}$. These results are quite understandable from the combustion theory standpoint. It is well known that a decrease in the exothermicity of the reaction leads to the transition from a steady propagation of the front to the pulsating combustion regime [37]. The pulsating propagation of the combustion wave over a $\mathrm{NaClO}_{3}$-based oxygen generator has been demonstrated experimentally [6,7] and numerically [8]. Since $\mathrm{Al} / \mathrm{Mg}$ additive is more energetic than Fe (see Table 4.1), steady combustion requires a smaller concentration of $\mathrm{Al} / \mathrm{Mg}$ as compared with $\mathrm{Fe}$. Note also that, in contrast with $\mathrm{Mg}$, mechanically alloyed $\mathrm{Al} / \mathrm{Mg}$ powder is expected to have much better storage characteristics $[38,28]$. Thus, the use of this powder in chemical oxygen generators is worth of further consideration. 


\section{CHAPTER 5: CONCLUSION}

Thermodynamic calculations for combustion of sodium chlorate mixed with metals and various nanocomposite and mechanically alloyed reactive materials have identified the additives that can be employed at smaller amounts than the currently used iron or tin for providing the same combustion temperatures and oxygen yield.

Experiments on combustion of sodium chlorate-based mixtures with nanoscale $\mathrm{Co}_{3} \mathrm{O}_{4}$ catalyst and the most promising energetic additives were conducted in argon environment, using laser ignition. Infrared video recording was used to investigate the thermal wave propagation over the mixture pellet.

The experiments have shown that mechanically alloyed $\mathrm{Al} / \mathrm{Mg}(1: 1$ mass ratio) material is a promising alternative to iron and tin. Significantly smaller amounts of this additive are needed for a steady propagation of the combustion wave and respective steady oxygen generation. 


\section{BIBLIOGRAPHY}

[1] J. W. Mausteller, Oxygen generation systems, New York, NY: Kirk-Othmer Encyclopedia of Chemical Technology, 1996.

[2] "BASA Aviation LTD," 1999. [Online]. Available: http://www.basaaviation.com/peos_e.shtml. [Accessed 21 November 2013].

[3] T. Wydeven, "Catalytic decomposition of sodium chlorate," Journal of Catalysis, vol. XIX, no. 2, pp. 162-171, 1970.

[4] Y. Zhang, G. Kshirsagar, J. E. Ellison and J. C. Cannon, "Catalytic effects of metal oxides on the thermal decomposition of sodium chlorate," Thermochimica Acta, vol. 228, pp. 147-154, 1993.

[5] E. Shafirovich, A. Garcia, A. K. Narayana Swamy, D. J. Mast and S. D. Hornung, "On feasibility of decreasing metal fuel content in chemical oxygen generators," Combustion and Flame, vol. 159, no. 1, pp. 420-426, 2012.

[6] E. Shafirovich, A. S. Mukasyan, A. Varma, G. Kshirsagar, Y. Zhang and J. C. Cannon, "Mechanisims of combustion in low-exothermic mixtures of sodium chlorate and metal fuel," Combustion and Flame, vol. 128, no. 1-2, pp. 133-144, 2002.

[7] E. Shafirovich, C. Zhou, A. S. Mukasyan, A. Varma, G. Kshirsagar, Y. Zhang and J. C. Cannon, "Combustion fluctuations in low-exothermic condensed systems for emergency oxygen generators," Combustion and Flame, vol. 135, no. 4, pp. 557-561, 2003.

[8] V. Diakov, E. Shafirovich and A. Varma, "A numerical study of combustion stability in emergency oxygen generators," American Institude of Chemical Engineers, vol. 52, no. 4, pp. 1495-1501, 2005.

[9] W. M. Haynes, "CRS Handbook of Chemistry and Physics, 94th Ed.," Taylor \& Francis, 20132014.

[10] E. Shafirovich, C. Zhou, S. Ekambaram, A. Varma, G. Kshirsagar and J. E. Ellison, "Catalytic effects of metals on thermal decomposition of sodium chlorate for emergency oxygen generators," Industrial and Engineering Chemistry Research, vol. 46, pp. 3073-3077, 2007.

[11] E. Shafirovich, "Oxygen candle chemistry evaluation," Final Report to Jacobs Technology, El Paso, 2010.

[12] F. H. Stephens, V. Pons and R. T. Baker, "Ammonia-borane: the hydrogen source par excellence?," Dalton Transactions, pp. 2613-26, 2007.

[13] E. Dreizin, "Metal-based reactive nanomaterials," Progress in Energy and Combustion Science, vol. 35, pp. 141-167, 2009.

[14] Y. Zhang, G. Kshirsagar and J. C. Cannon, "Functions of barium peroxide in sodium chlorate chemical oxygen generators," Insdustrial and Engineering Chemistry Research, vol. 32, pp. 966969, 1993.

[15] W. H. Schechter, R. R. Miller, R. M. Bovard, C. B. Jackson and J. R. Pappenheimer, "Chlorate candles as a source for oxygen," Industrial and Chemical Engineering, vol. 40, no. 11, pp. 2348-53, 1950.

[16] M. M. Markowitz, D. A. Boryta and H. Stewart, "The differential thermal analysis of percholarates. VI. Transient perchlorate formation during the pyrolysis of the alkali metal chlorates," the Journal of Physical Chemistry, vol. 68, no. 8, pp. 2282-2289, 1964.

[17] G. Kshirsagar, "Report," B/E Aerospace, Inc., Lenexa, KS. 
[18] J. W. Mellor, Comprehensive treatise on inorganic and theoretical chemistry, Vol. 11, New York: Green and Co., 1922.

[19] Y. Zhang, G. Kshirsagar, J. E. Ellison and J. C. Cannon, "Catalytic effects of non-oxide metal compounds on the thermal decomposition of sodium chlorate," American Chemical Society, vol. 32 , no. 11, pp. 2863-65, 1993.

[20] C. W. Malich and T. Wydeven, "Catalyzed sodium chlorate candles," in Second Conference on Portable Life Support Systems. NASA SP-302, Washington, D.C., 1972.

[21] Y. L. Shoshin, R. L. Mudryy and E. Dreizin, "Preparation and characterization of Al-Mg mechanical alloy powders," Combustion and Flame, vol. 128, pp. 259-269, 2002.

[22] Y. Aly, M. Schoenitz and E. Dreizin, "Ignition and combustion of mechanically alloyed Al-Mg powders with customized particle sizes," Combustion and Flame, vol. 160, pp. 835-842, 2013.

[23] Y. L. Shoshin and E. Dreizin, "Particle combustion rates for mechanically alloyed Al-Ti and aluminum powders in burning air," Combustion and Flame, vol. 145, pp. 714-722, 2006.

[24] S. Mohan, M. A. Trunov and E. L. Dreizin, "Nano-composite energetic powders prepared by arrested reactive milling," in The 2003 Technical Meeting of the Easter States Section of the Combustion Institute, University Park, PA., 2003.

[25] Y. L. Shoshin, I. Altman, K. K. Kuo and L. T. De Luca, in Combustion of energetic materials, New York, NY., Begell House, 2002, p. 1030.

[26] T. A. Brzustowsky and I. Glassman, in Heterogeneous combustion, New York, Academic Press, 1964, pp. 75-116.

[27] R. P. Wilson and F. A. Williams, "Experimental study of the combustion of single aluminum particles in O2/Ar," Symposium (International) on Combustion, vol. 13, no. 1, pp. 833-845, 1971.

[28] H. Habu, "Application of Magnalium to solid rocket propellant," Journal of Japan Institute of Light Metals, vol. 58, no. 4, pp. 162-166, 2008.

[29] M. Trunov, V. Hoffmann, M. Schoenitz and E. Dreizin, "Combustion of boron-titanium nanocomposite powders," Journal of Propulsion and Power, vol. 24, no. 2, pp. 184-191, 2008.

[30] M. Umbrajkar, R. Broad, M. Trunov, M. Schoenitz and E. Dreizin, "Arrested reactive milling synthesis and characterization of sodium-nitrate based reactive composites," Propellants, Explosives and Pyrotechnics, vol. 32, no. 1, pp. 32-41, 2007.

[31] A. Shiryaev, International Journal of SHS, vol. 4, pp. 351-362, 1995.

[32] M. Schoenitz, S. Umbrajkar and E. Dreizin, "Kinetic analysis of thermite reactions in Al-MoO3 nanocomposites," Journal of Propulsion and Power, vol. 23, no. 4, pp. 683-687, 2007.

[33] S. Umbrajkar, S. Seshadri, M. Schoenitz, V. Hoffmann and E. Dreizin, "Aluminum-rich Al-MoO3 nanocomposite powders prepared by arrested reactive milling," Journal of Propulsion and Power, vol. 24, no. 2, pp. 192-198, 2008.

[34] Y. Aly, V. Hoffmann, M. Schoenitz and E. Dreizin, Journal of Propulsion and Power, in press.

[35] Y. Cengel and A. J. Ghajar, Heat and mass transfer: Fundamentals and applications, New York: McGraw-Hill, 2011.

[36] K. K. Kelley, "Contributions to the data on theoretical metallurgy: XIII. Highttemperature heatcontent, heat capacity, and entropy data for inorganic compounds," Bureau of Mines, Bulletin 584, Washington, D.C., 1960.

[37] K. Shkadinskii, B. Khailin and A. Merzhanov, "Propagation of a pulsating exothermic reaction front in the condensed phase," Combustion, Explosion, and Shock Waves, vol. 7, no. 1, pp. 15-22, 1971. 
[38] S. Bouaricha, J. Dodelet, D. Guay, J. Hout, S. Boily and R. Schulz, "Hydriding behavior of Mg-Al and leached $\mathrm{Mg}-\mathrm{Al}$ compounds prepared by high-energy ball-milling," Journal of Alloys and Compounds, vol. 297, no. 1-2, pp. 282-293, 2000. 


\section{APPENDIX 1}

Thermodynamic Calculations 


\section{TABle OF CONTENTS}

INTRODUCTION

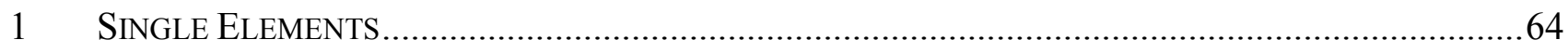

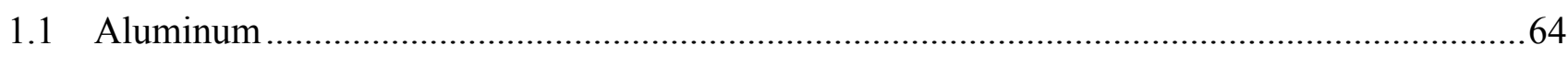

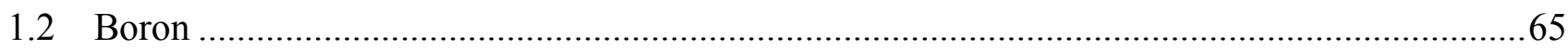

1.3 Iron

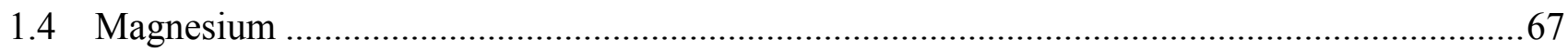

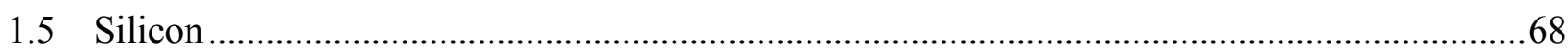

1.6 Tin

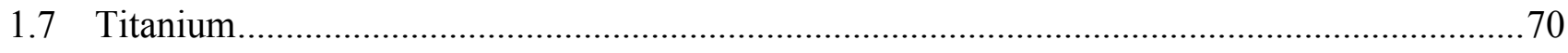

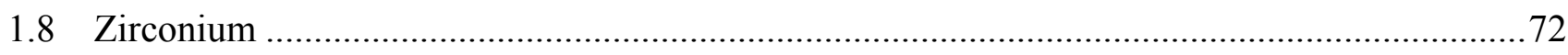

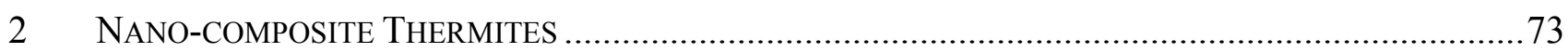

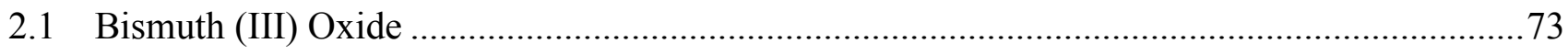

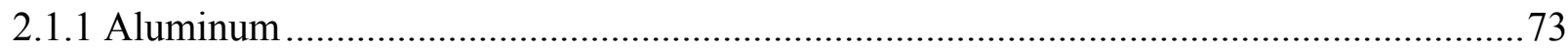

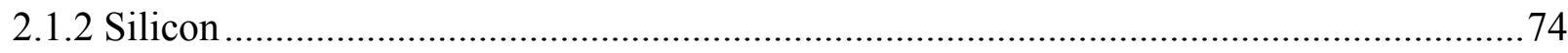

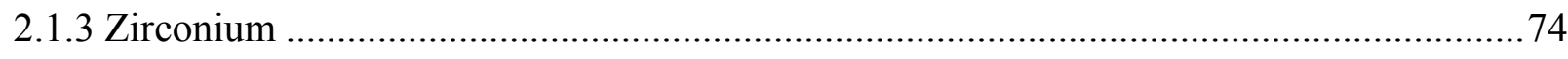

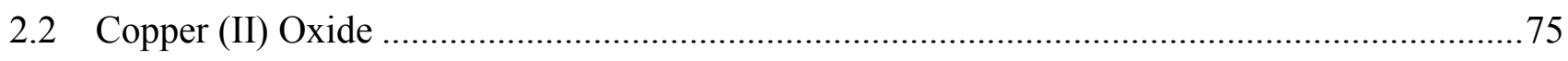

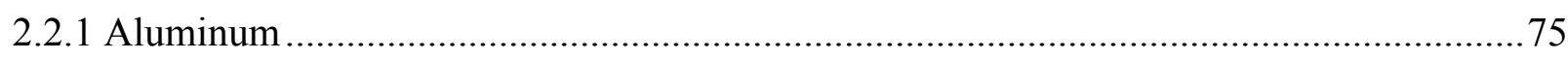

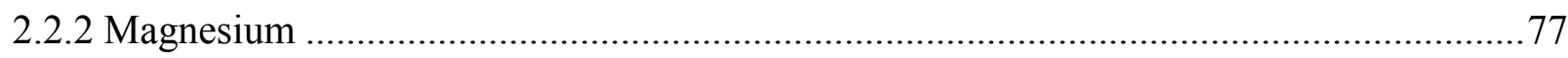

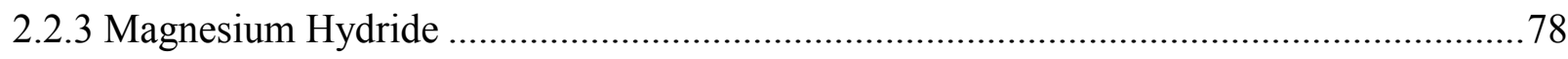

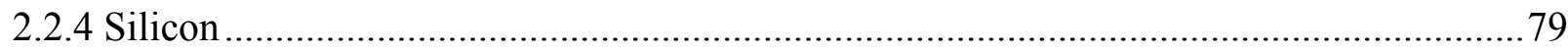

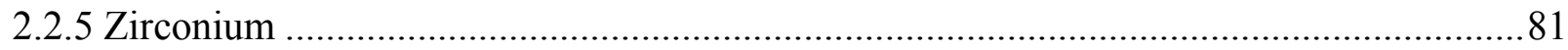

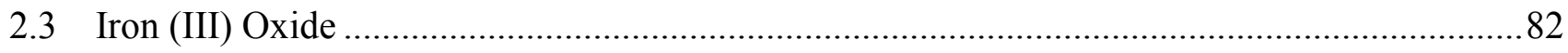

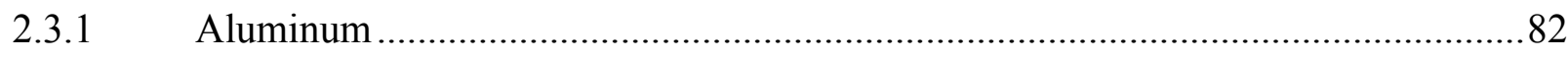

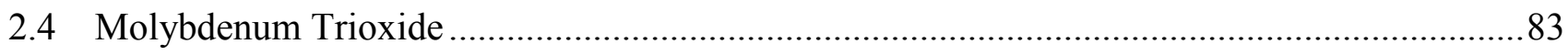

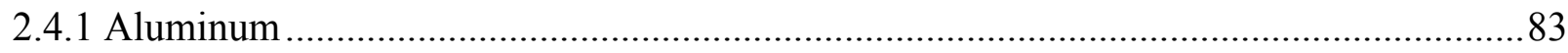

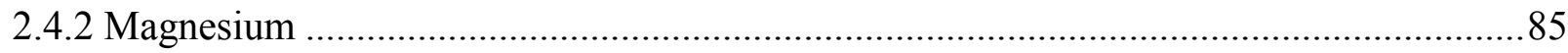

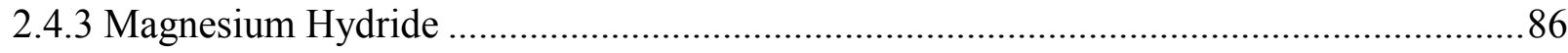




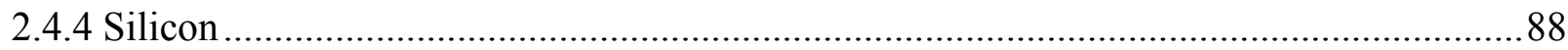

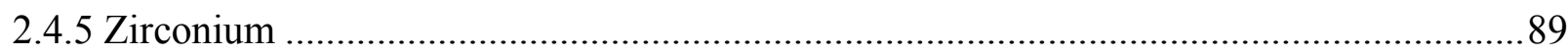

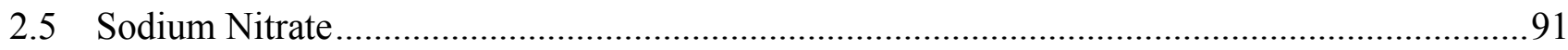

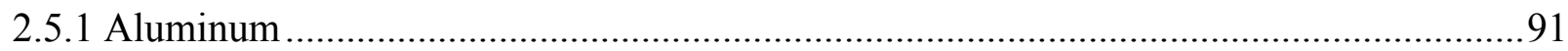

2.5.2 Aluminum and Magnesium - mole ratio 1:1 .............................................................93

2.5.3 Boron and Titanium - mole ratio 2:1 …………......................................................... 94

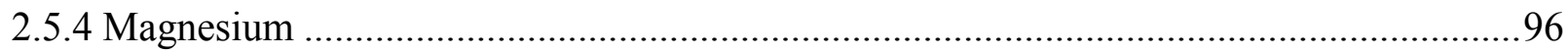

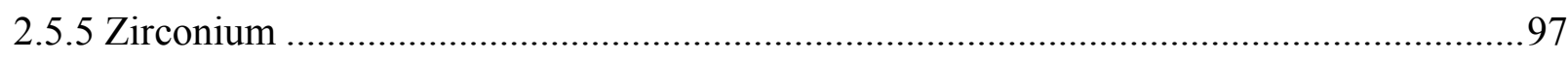

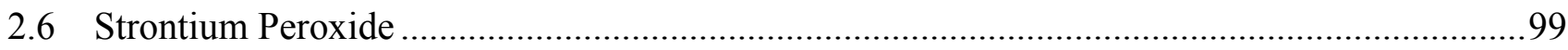

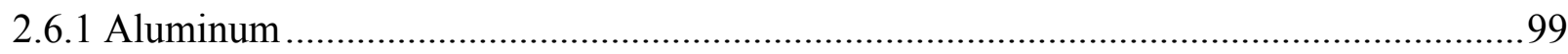

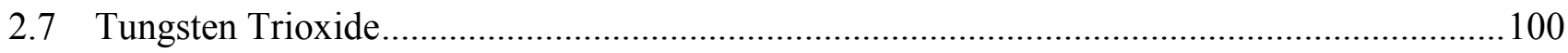

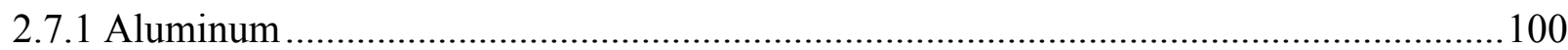

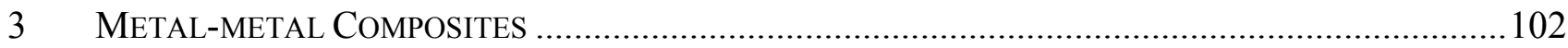

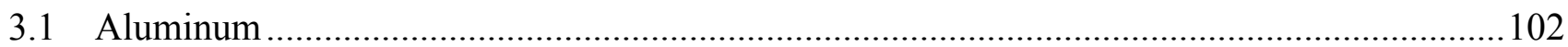

3.1.1 Iron 102

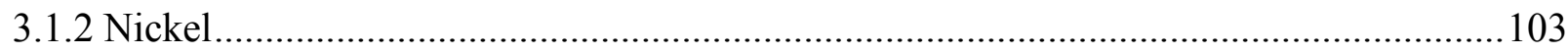

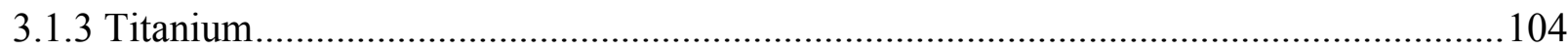

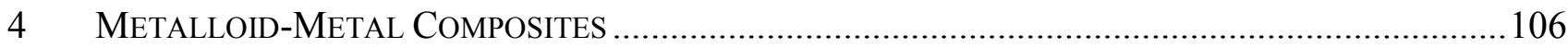

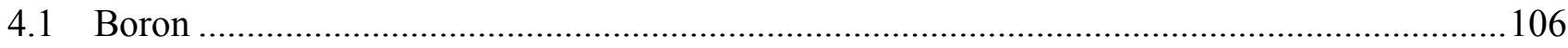

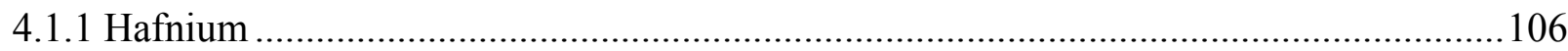

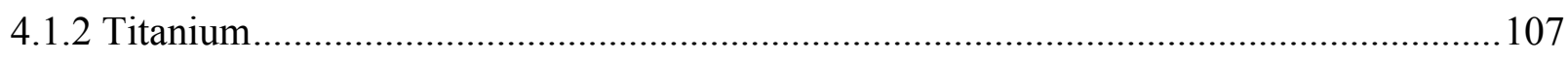

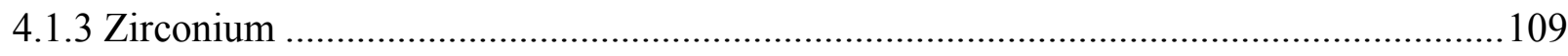

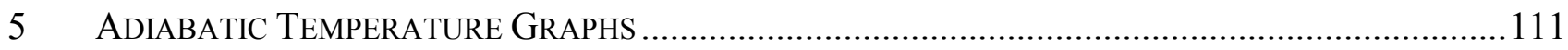

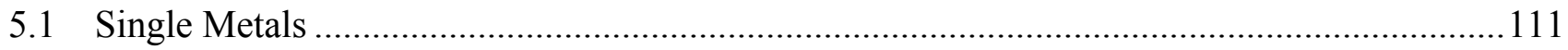

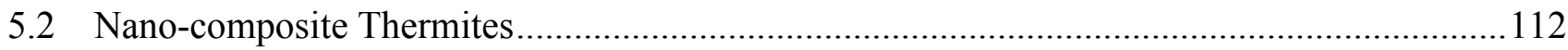

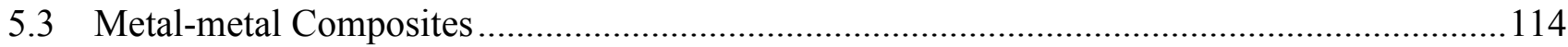

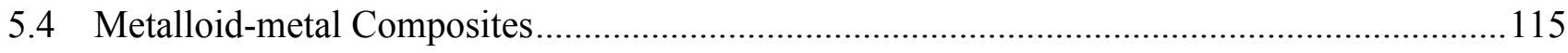




\section{INTRODUCTION}

Appendix 1 contains the results of thermodynamic calculations performed using THERMO. The compositions are presented in moles and mass fractions. The temperature refers to the adiabatic flame temperature, and calculations are performed for a pressure of $1 \mathrm{~atm}$. To reduce the size of the Appendix, only the energetic amounts corresponding to Table 4.1 are presented. As previously mentioned, sodium chlorate decomposes with heat release as shown in the following calculation. In an adiabatic scenario, sodium chlorate would decompose without an energetic additive, providing the maximum oxygen yield of $49 \mathrm{wt} \% \mathrm{O}_{2}$.

\begin{tabular}{|c|c|c|c|c|}
\hline \multicolumn{5}{|l|}{0.0 wt $\%$ Energetic Additive } \\
\hline Volume of gas products & (1itres) & 21.9955 & & \\
\hline Pressure of gas products & $(a t m)$ & 1.0000 & & \\
\hline Temperature & $(\mathrm{K})$ & 736.3141 & & \\
\hline Gas products amount & $(\operatorname{mol})$ & 0.3523 & & \\
\hline Products heat capacity & $(\mathrm{J} / \mathrm{K})$ & 25.4651 & & \\
\hline Products entropy & $(\mathrm{J} / \mathrm{K})$ & 110.4110 & & \\
\hline Products enthalpy & $(\mathrm{KJ})$ & -86.1983 & & \\
\hline \multicolumn{5}{|l|}{ Products in molar fraction } \\
\hline \multicolumn{5}{|l|}{102} \\
\hline $\mathrm{Cl} \quad 1 \mathrm{Na} \quad 1$ & (C) [] & 0.2349 & & \\
\hline Products in mass fraction & $(\mathrm{Kg})$ & 0.0250 & & \\
\hline 102 & (G) & 0.4509 & 1.0000 & (atm) \\
\hline $\mathrm{Cl} 1 \mathrm{Na} 1$ & (C) [] & 0.5491 & & \\
\hline
\end{tabular}




\begin{tabular}{|c|c|c|c|c|c|c|}
\hline \multicolumn{3}{|c|}{-02} & (G) & 0.3408 & 0.9995 & $(\mathrm{~atm})$ \\
\hline \multirow{2}{*}{$\begin{array}{l}\mathrm{Al} \\
\mathrm{Cl}\end{array}$} & 20 & 3 & (C) [] & 0.0051 & & \\
\hline & $1 \mathrm{Na}$ & 1 & (C) [] & 0.2321 & & \\
\hline Prod & ucts & in mass fraction & $(\mathrm{Kg})$ & 0.0250 & & \\
\hline $1 \mathrm{Cl}$ & $1 \mathrm{Na}$ & 1 & (G) & $2.71 E-0004$ & $3.40 \mathrm{E}-0004$ & (atm) \\
\hline $1 \mathrm{Cl}$ & $2 \mathrm{Na}$ & 2 & (G) & $2.54 \mathrm{E}-0004$ & $1.59 \mathrm{E}-0004$ & (atm) \\
\hline 10 & 2 & & (G) & 0.4362 & 0.9995 & (atm) \\
\hline Al & 20 & 3 & (C) [] & 0.0208 & & \\
\hline $\mathrm{Cl}$ & $1 \mathrm{Na}$ & 1 & (C) [ ] & 0.5425 & & \\
\hline
\end{tabular}

\subsection{Boron}

\section{3 wt\% $B$}

Volume of gas products

Pressure of gas products

Temperature

Gas products amount

Products heat capacity

Products entropy

Products enthalpy

Products in molar fraction

$1 \mathrm{Cl} 2$

102

B $\quad 6 \mathrm{Na} \quad 20 \quad 10$

B 203

Cl $1 \mathrm{Na} 1$

Products in mass fraction

$1 \mathrm{Cl} 2$

102

B $\quad 6 \mathrm{Na} \quad 20 \quad 10$

B 203

Cl $1 \mathrm{Na} 1$

\section{5 wt $\% ~ B$}

Volume of gas products

Pressure of gas products

Temperature

(litres)

(atm)

(K)

$(\mathrm{mol})$

$(\mathrm{J} / \mathrm{K})$

$(\mathrm{J} / \mathrm{K})$

$(\mathrm{KJ})$

(G)

(G)

(C)

(L) [ ]

(C) [ ]

$(\mathrm{Kg})$

(G)

(G)

(C)

(L) [ ]

(C) []

(litres)

(atm)

(K)

$(\mathrm{mol})$

$(\mathrm{J} / \mathrm{K})$

$(\mathrm{J} / \mathrm{K})$

(KJ)

Products entropy
Products enthalpy

Products in molar fraction

$1 \mathrm{Cl} 2$

$\begin{array}{llll}1 & \mathrm{Cl} & 1 \mathrm{Na} & 1\end{array}$

$\begin{array}{lll}1 & 0 & 2\end{array}$

B $\quad 6 \mathrm{Na} \quad 20 \quad 10$

B 203

Cl $1 \mathrm{Na} 1$

Products in mass fraction

$1 \mathrm{Cl} 2$

$1 \mathrm{Cl} 1 \mathrm{Na} 1$

$\begin{array}{llll}1 & \mathrm{Cl} & 2 \mathrm{Na} & 2\end{array}$

102

B $\quad 6 \mathrm{Na} \quad 20 \quad 10$

B 203

$\mathrm{Cl} 1 \mathrm{Na} 1$

(G)

(G)

(G)

(C)

(L) [ ]

(C) [ ]

$(\mathrm{Kg})$

(G)

(G)

(G)

(G)

(C)

(L) [ ]

(C) [ ]

\section{7 wt\% $\mathrm{B}$}

Volume of gas products

Pressure of gas products

Temperature

(litres)

(atm)

(K)

Gas products amount (mol)

$$
\begin{array}{r}
26.6836 \\
1.0000 \\
909.0960 \\
0.3462 \\
27.0857 \\
114.9926 \\
-85.6564
\end{array}
$$

$$
\begin{array}{r}
2.35 \mathrm{E}-0004 \\
0.3459 \\
2.35 \mathrm{E}-0004 \\
0.0028 \\
0.2337 \\
0.0250
\end{array}
$$

6. 66E-0004

0.4428

0.0025

0.0077

0.5463
$6.79 \mathrm{E}-0004$ (atm)
0.9993 (atm)

29.6648

1.0000

1023.0000

0.3420

28.1798

117.6606

$-85.1346$

1. 26E-0004

$3.73 \mathrm{E}-0005$

1. $28 \mathrm{E}-0004$

$3.58 \mathrm{E}-0004$

$8.71 \mathrm{E}-0005$

$7.39 \mathrm{E}-0005$
0.3418

0.0054

0.2334

0.0250

0.4375

0.0014

0.0150

0.5456

$$
\begin{array}{rr}
3.69 \mathrm{E}-0004 & (\mathrm{~atm}) \\
1.09 \mathrm{E}-0004 & (\mathrm{~atm}) \\
4.62 \mathrm{E}-0005 & (\mathrm{~atm}) \\
0.9995 & (\mathrm{~atm})
\end{array}
$$

$$
\begin{array}{rr}
3.69 \mathrm{E}-0004 & (\mathrm{~atm}) \\
1.09 \mathrm{E}-0004 & (\mathrm{~atm}) \\
0.9995 & \text { (atm) }
\end{array}
$$

30.7654

1.0000

1073.9633

0.3379
30.7622
1.0000
1073.5925

0.3379
30.7837

1.0000

1074.3341

0.3379 


Products heat capacity
Products entropy
Products enthalpy
Phase transition enthalpy
Products in molar fraction
1 Cl 2
1 Cl $1 \mathrm{Na} 1$
$1 \mathrm{Cl} 2 \mathrm{Na} 2$
1 O 2
$\mathrm{~B} 6 \mathrm{Na} 2010$
$\mathrm{~B} 2 \mathrm{O} 3$
$\mathrm{Cl} 1 \mathrm{Na} 1$
$\mathrm{Cl} 1 \mathrm{Na} 1$
Products $1 \mathrm{n}$ mass fraction
$1 \mathrm{Cl} 2$
$1 \mathrm{Cl} 1 \mathrm{Na} 1$
$1 \mathrm{Cl} 2 \mathrm{Na} 2$
$1 \mathrm{O} 2$
$\mathrm{~B} 6 \mathrm{Na} 2010$
$\mathrm{~B} 2 \mathrm{O} 3$
$\mathrm{Cl} 1 \mathrm{Na} 1$
$\mathrm{Cl} 1 \mathrm{Na} 1$

$\begin{array}{lrrr}(\mathrm{J} / \mathrm{K}) & 28.7383 & 28.7328 & 28.7692 \\ (\mathrm{~J} / \mathrm{K}) & 119.3838 & 118.4632 & 124.5960 \\ (\mathrm{KJ}) & -85.3084 & -86.2971 & -79.7105 \\ (\mathrm{KJ}) & 6.5866 & & \\ & & & \\ (\mathrm{G}) & 9.71 \mathrm{E}-0005 & 9.72 \mathrm{E}-0005 & 9.66 \mathrm{E}-0005 \\ (\mathrm{G}) & 1.21 \mathrm{E}-0004 & 1.21 \mathrm{E}-0004 & 1.23 \mathrm{E}-0004 \\ (\mathrm{G}) & 5.70 \mathrm{E}-0005 & 5.68 \mathrm{E}-0005 & 5.78 \mathrm{E}-0005 \\ (\mathrm{G}) & 0.3377 & 0.3377 & 0.3377 \\ (\mathrm{C}) & 1.00 \mathrm{E}-0004 & 1.00 \mathrm{E}-0004 & 9.98 \mathrm{E}-0005 \\ (\mathrm{~L})[] & 0.0078 & 0.0078 & 0.0078 \\ (\mathrm{C})[] & 0.1978 & 0.2328 & 0.0000 \\ (\mathrm{~L})[] & 0.0349 & 0.0000 & 0.2328 \\ (\mathrm{Kg}) & 0.0250 & & \\ (\mathrm{G}) & 2.75 \mathrm{E}-0004 & 2.75 \mathrm{E}-0004 & 2.74 \mathrm{E}-0004 \\ (\mathrm{G}) & 2.83 \mathrm{E}-0004 & 2.83 \mathrm{E}-0004 & 2.87 \mathrm{E}-0004 \\ (\mathrm{G}) & 2.66 \mathrm{E}-0004 & 2.66 \mathrm{E}-0004 & 2.70 \mathrm{E}-0004 \\ (\mathrm{G}) & 0.4322 & 0.4322 & 0.4322 \\ (\mathrm{C}) & 0.0011 & 0.0011 & 0.0011 \\ (\mathrm{~L})[] & 0.0217 & 0.0217 & 0.0217 \\ \text { (C) [ ] } & 0.4625 & 0.5442 & 0.0000 \\ \text { (L) [] } & 0.0817 & 0.0000 & 0.5442\end{array}$

\subsection{Iron}

\section{0 wt\% $\mathrm{Fe}$}

Volume of gas products
Pressure of gas products
Temperature
Gas products amount
Products heat capacity
Products entropy
Products enthalpy
Prodcuts by molar fraction
1 O 2
Cl $1 \mathrm{Na} 1$
Fe 203
Products by mass fraction
1 O 2
$\mathrm{Cl} 1 \mathrm{Na} 1$
$\mathrm{Fe} 203$

(litres)

(atm)

(K)

$(\mathrm{mol})$

$(\mathrm{J} / \mathrm{K})$

$(\mathrm{J} / \mathrm{K})$

(KJ)

(G)

(C) [ ]

(C) [ ]

$(\mathrm{Kg})$

(G)

(C) [ ]

(C) []

\section{0 wt\% $\mathrm{Fe}$}

Volume of gas products

Pressure of gas products

Temperature

Gas products amount

Products heat capacity

Products entropy

Products enthalpy

Products in molar fraction

$\begin{array}{llll}1 & \mathrm{Cl} & 1 \mathrm{Na} & 1\end{array}$

102

Cl $1 \mathrm{Na} 1$

$\mathrm{Fe} 203$

Products in mass fraction

$1 \mathrm{Cl} 1 \mathrm{Na} 1$

$\begin{array}{llll}1 & \mathrm{Cl} & 2 \mathrm{Na} & 2\end{array}$

102

Cl $1 \mathrm{Na} 1$

$\mathrm{Fe} 203$ (litres)

(atm)

(K)

$(\mathrm{mol})$

$(\mathrm{J} / \mathrm{K})$

$(\mathrm{J} / \mathrm{K})$

$(\mathrm{KJ})$

(G)

(G)

(C) [ ]

(C) []

( Kg)

(G)

(G)

(G)

(C) []

(C) []

$$
\begin{array}{r}
26.8573 \\
1.0000 \\
955.0000 \\
0.3317 \\
27.3366 \\
112.9519 \\
-83.1310
\end{array}
$$

0.3317

0.2278

0.0067

0.0250

0.4245

0.5326

0.0429

28.1766

1.0000

1023.0000

0.3248

27.5467

113.4099

$-82.1588$

$$
\begin{array}{r}
3.54 \mathrm{E}-0005 \\
0.3248 \\
0.2254 \\
0.0090 \\
0.0250
\end{array}
$$

$8.27 \mathrm{E}-0005$

7.02E-0005

0.4157

0.5270

0.0572

\section{$1.09 \mathrm{E}-0004$ (atm)}

0.9998 (atm)

$\begin{array}{rr}1.09 \mathrm{E}-0004 & (\mathrm{~atm}) \\ 4.62 \mathrm{E}-0005 & (\mathrm{~atm}) \\ 0.9998 & (\mathrm{~atm})\end{array}$ 


\section{0 wt\% $\mathrm{Fe}$}

\begin{tabular}{|c|c|}
\hline Volume of gas products & (litres) \\
\hline Pressure of gas products & $(\mathrm{atm})$ \\
\hline Temperature & $(\mathrm{K})$ \\
\hline Gas products amount & $(\mathrm{mol})$ \\
\hline Products heat capacity & $(\mathrm{J} / \mathrm{K})$ \\
\hline Products entropy & $(\mathrm{J} / \mathrm{K})$ \\
\hline Products enthalpy & (KJ) \\
\hline $\begin{array}{l}\text { Phase transition enthalpy } \\
\text { roducts in molar fraction }\end{array}$ & $(\mathrm{KJ})$ \\
\hline $\mathrm{Cl} 1 \mathrm{Na} 1$ & ( $G$ ) \\
\hline $\mathrm{Cl} 2 \mathrm{Na} 2$ & ( $G$ ) \\
\hline 02 & (G) \\
\hline $\mathrm{Cl} 1 \mathrm{Na} 1$ & (C) [] \\
\hline $\mathrm{Cl} 1 \mathrm{Na} 1$ & $(\mathrm{~L})[]$ \\
\hline $\mathrm{Fe} 203$ & (C) [] \\
\hline roducts in mass fraction & $(\mathrm{Kg})$ \\
\hline $\mathrm{Cl} 1 \mathrm{Na} 1$ & (G) \\
\hline $\mathrm{Cl} 2 \mathrm{Na} 2$ & (G) \\
\hline 02 & (G) \\
\hline $\mathrm{Cl} 1 \mathrm{Na} 1$ & (C) [] \\
\hline $\mathrm{Cl} 1 \mathrm{Na} 1$ & $(\mathrm{~L})$ [ ] \\
\hline $\mathrm{Fe} 20 \quad 3$ & (C) [] \\
\hline
\end{tabular}

$\begin{array}{rrr}28.3286 & 28.3232 & 28.3421 \\ 1.0000 & 1.0000 & 1.0000 \\ 1073.7774 & 1073.4235 & 1074.1313 \\ 0.3112 & 0.3112 & 0.3112 \\ 27.8009 & 27.7906 & 27.8263 \\ 113.5533 & 111.8816 & 117.6917 \\ -80.7551 & -82.5505 & -76.3105 \\ 6.2400 & & \\ & & \\ 1.11 \mathrm{E}-0004 & 1.11 \mathrm{E}-0004 & 1.13 \mathrm{E}-0004 \\ 5.23 \mathrm{E}-0005 & 5.21 \mathrm{E}-0005 & 5.30 \mathrm{E}-0005 \\ 0.3110 & 0.3110 & 0.3110 \\ 0.1571 & 0.2206 & 0.0000 \\ 0.0635 & 0.0000 & 0.2206 \\ 0.0134 & 0.0134 & 0.0134 \\ 0.0250 & & \\ 2.60 \mathrm{E}-0004 & 2.59 \mathrm{E}-0004 & 2.63 \mathrm{E}-0004 \\ 2.45 \mathrm{E}-0004 & 2.44 \mathrm{E}-0004 & 2.48 \mathrm{E}-0004 \\ 0.3981 & 0.3981 & 0.3981 \\ 0.3673 & 0.5156 & 0.0000 \\ 0.1483 & 0.0000 & 0.5156 \\ 0.0858 & 0.0858 & 0.0858\end{array}$

1.4 Magnesium

\section{6 wt $\% \mathrm{Mg}$}

Volume of gas products

Pressure of gas products

Temperature

(litres)

(atm)

$(\mathrm{K})$

$(\mathrm{mol})$

Gas products amount

$(\mathrm{J} / \mathrm{K})$

$(\mathrm{J} / \mathrm{K})$

Products entropy

Products enthalpy

(KJ)

Products in molar fraction

$1 \mathrm{Cl} 1 \mathrm{Na} 1$

$\begin{array}{llll}1 & \mathrm{Cl} & 2 \mathrm{Na} & 2\end{array}$

102

Cl $1 \mathrm{Na} 1$

Mg 101

Products in mass fraction

$\begin{array}{llll}1 & \mathrm{Cl} & 3 \mathrm{Na} & 3\end{array}$

$\begin{array}{llll}1 & \mathrm{Cl} & 1 \mathrm{Na} & 1\end{array}$

$\begin{array}{llll}1 & \mathrm{Cl} & 2 \mathrm{Na} & 2\end{array}$

102

Cl $1 \mathrm{Na} 1$

$\begin{array}{lll}M g & 10 & 1\end{array}$

(G)

(G)

(G)

(C) [ ]

(C) [ ]

(Kg)

(G)

(G)

(G)

(G)

(C) [ ]

(C) [ ]

\section{0 wt\% $\mathrm{Mg}$}

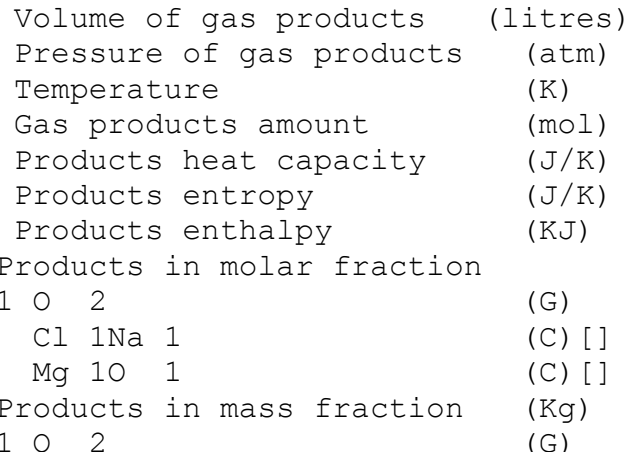

$$
\begin{array}{r}
26.0576 \\
1.0000 \\
885.3601 \\
0.3471 \\
26.7492 \\
114.2560 \\
-85.4191
\end{array}
$$

$$
\begin{array}{r}
7.15 \mathrm{E}-0007 \\
2.08 \mathrm{E}-0007 \\
0.3471 \\
0.2335 \\
0.0062 \\
0.0250
\end{array}
$$

5.74 E-0009

$1.67 \mathrm{E}-0006$

0.4443

0.5458

0.0099

$$
\begin{array}{rr}
2.06 \mathrm{E}-0006 & (\mathrm{~atm}) \\
5.99 \mathrm{E}-0007 & (\mathrm{~atm}) \\
1.0000 & (\mathrm{~atm})
\end{array}
$$

$$
\begin{array}{rr}
2.36 \mathrm{E}-0009 & (\mathrm{~atm}) \\
2.06 \mathrm{E}-0006 & (\mathrm{~atm}) \\
5.98 \mathrm{E}-0007 & (\mathrm{~atm}) \\
1.0000 & \text { (atm) }
\end{array}
$$

$9.71 \mathrm{E}-0007$

0.5156
0.0858

0.3112

.6917

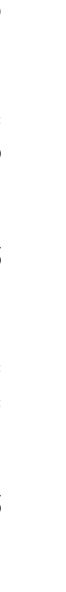



$\mathrm{Cl} 1 \mathrm{Na} 1$
(C) [ ]
0.5435
$\begin{array}{lll}M g & 10 & 1\end{array}$
(C) [ ]
0.0166

\section{6 wt\% $\mathrm{Mg}$}

\begin{tabular}{|c|c|c|c|c|}
\hline Volume of gas products & (litres) & 30.8225 & 30.8203 & 30.8381 \\
\hline Pressure of gas products & $(a t m)$ & 1.0000 & 1.0000 & 1.0000 \\
\hline Temperature & $(\mathrm{K})$ & 1073.7399 & 1073.4335 & 1074.0462 \\
\hline Gas products amount & $(\operatorname{mol})$ & 0.3386 & 0.3386 & 0.3386 \\
\hline Products heat capacity & $(\mathrm{J} / \mathrm{K})$ & 28.4166 & 28.4119 & 28.4490 \\
\hline Products entropy & $(\mathrm{J} / \mathrm{K})$ & 118.7832 & 118.0081 & 124.0869 \\
\hline Products enthalpy & $(\mathrm{KJ})$ & -84.5352 & -85.3676 & -78.8390 \\
\hline $\begin{array}{l}\text { Phase transition enthalpy } \\
\text { roducts in molar fraction }\end{array}$ & $(\mathrm{KJ})$ & 6.5286 & & \\
\hline $\mathrm{Cl} \quad 1 \mathrm{Na} 1$ & (G) & $1.21 \mathrm{E}-0004$ & $1.21 \mathrm{E}-0004$ & $1.22 \mathrm{E}-0004$ \\
\hline $\mathrm{Cl} 2 \mathrm{Na} 2$ & ( $G$ ) & $5.68 \mathrm{E}-0005$ & $5.67 E-0005$ & $5.75 E-0005$ \\
\hline $0 \quad 2$ & (G) & 0.3384 & 0.3384 & 0.3384 \\
\hline $\mathrm{Cl} 1 \mathrm{Na} 1$ & (C) [] & 0.2014 & 0.2309 & 0.0000 \\
\hline $\mathrm{Cl} 1 \mathrm{Na} 1$ & (L) [] & 0.0294 & 0.0000 & 0.2309 \\
\hline $\operatorname{Mg} 10 \quad 1$ & (C) [] & 0.0165 & 0.0165 & 0.0165 \\
\hline roducts in molar fraction & $(\mathrm{Kg})$ & 0.0250 & & \\
\hline $\mathrm{Cl} 1 \mathrm{Na} 1$ & (G) & $2.83 E-0004$ & $2.82 \mathrm{E}-0004$ & $2.86 \mathrm{E}-0004$ \\
\hline $\mathrm{Cl} 2 \mathrm{Na} 2$ & (G) & $2.66 \mathrm{E}-0004$ & $2.65 \mathrm{E}-0004$ & $2.69 \mathrm{E}-0004$ \\
\hline 02 & (G) & 0.4332 & 0.4332 & 0.4332 \\
\hline $\mathrm{Cl} 1 \mathrm{Na} 1$ & (C) [] & 0.4709 & 0.5397 & 0.0000 \\
\hline $\mathrm{Cl} 1 \mathrm{Na} 1$ & $(\mathrm{~L})[]$ & 0.0688 & 0.0000 & 0.5397 \\
\hline $\operatorname{Mg} 101$ & (C) [] & 0.0265 & 0.0265 & 0.02 \\
\hline
\end{tabular}

\subsection{Silicon}

\section{5 wt\% $\mathrm{Si}$}

\begin{tabular}{|c|c|c|c|c|}
\hline Volume of gas products & (litres) & 26.3075 & & \\
\hline Pressure of gas products & $(\mathrm{atm})$ & 1.0000 & & \\
\hline Temperature & $(\mathrm{K})$ & 896.4660 & & \\
\hline Gas products amount & $(\operatorname{mol})$ & 0.3461 & & \\
\hline Products heat capacity & $(\mathrm{J} / \mathrm{K})$ & 26.8148 & & \\
\hline Products entropy & $(\mathrm{J} / \mathrm{K})$ & 114.3882 & & \\
\hline Products enthalpy & $(\mathrm{KJ})$ & -85.5711 & & \\
\hline Products in molar fraction & & & & \\
\hline $\mathrm{Cl} 1$ & (G) & $5.23 \mathrm{E}-0009$ & $1.51 \mathrm{E}-0008$ & $(\mathrm{~atm})$ \\
\hline $\mathrm{Cl} 2 \mathrm{Na} 2$ & (G) & $3.11 \mathrm{E}-0007$ & $8.98 \mathrm{E}-0007$ & $(\mathrm{~atm})$ \\
\hline $\mathrm{Cl} 2$ & (G) & $1.66 \mathrm{E}-0008$ & $4.80 E-0008$ & $(\mathrm{~atm})$ \\
\hline O 2 & (G) & 0.3461 & 1.0000 & $(a t m)$ \\
\hline $\mathrm{Cl} 1 \mathrm{Na} 1$ & ( $G)$ & $1.03 E-0006$ & $2.97 \mathrm{E}-0006$ & $(\mathrm{~atm})$ \\
\hline $\mathrm{Cl} 1 \mathrm{Na} 1$ & (C) [] & 0.2337 & & \\
\hline $\mathrm{Na} 20 \quad 5 \mathrm{Si} 2$ & (C) [] & $1.95 \mathrm{E}-0008$ & & \\
\hline O $2 \mathrm{Si} 1$ & (C) [QUART & 0.0045 & & \\
\hline Products in mass fraction & $(\mathrm{Kg})$ & 0.0250 & & \\
\hline $\mathrm{Cl} 1$ & (G) & $8.12 \mathrm{E}-0009$ & $1.65 \mathrm{E}-0008$ & $(\mathrm{~atm})$ \\
\hline $\mathrm{Cl} 2 \mathrm{Na} 2$ & (G) & $1.61 \mathrm{E}-0006$ & $9.98 \mathrm{E}-0007$ & $(\mathrm{~atm})$ \\
\hline $\mathrm{Cl} 2$ & (G) & $5.09 \mathrm{E}-0008$ & $5.18 \mathrm{E}-0008$ & $(\mathrm{~atm})$ \\
\hline $\mathrm{Cl} 3 \mathrm{Na} 3$ & (G) & $1.08 \mathrm{E}-0008$ & $4.45 \mathrm{E}-0009$ & $(\mathrm{~atm})$ \\
\hline O 2 & (G) & 0.4430 & 1.0000 & (atm) \\
\hline $\mathrm{Cl} 1 \mathrm{Na} 1$ & (G) & $2.65 \mathrm{E}-0006$ & $3.28 \mathrm{E}-0006$ & $(\mathrm{~atm})$ \\
\hline $\mathrm{Cl} 1 \mathrm{Na} 1$ & (C) [] & 0.5463 & & \\
\hline $\mathrm{Na} 20 \quad 5 \mathrm{Si} 2$ & (C) [] & $1.53 \mathrm{E}-0007$ & & \\
\hline O 2Si 1 & (C) [] & 0.0107 & & \\
\hline .8 wt $\% \mathrm{Si}$ & & & & \\
\hline Volume of gas products & (litres) & 28.4505 & & \\
\hline Pressure of gas products & (atm) & 1.0000 & & \\
\hline Temperature & $(\mathrm{K})$ & 980.0000 & & \\
\hline Gas products amount & $(\mathrm{mol})$ & 0.3424 & & \\
\hline
\end{tabular}




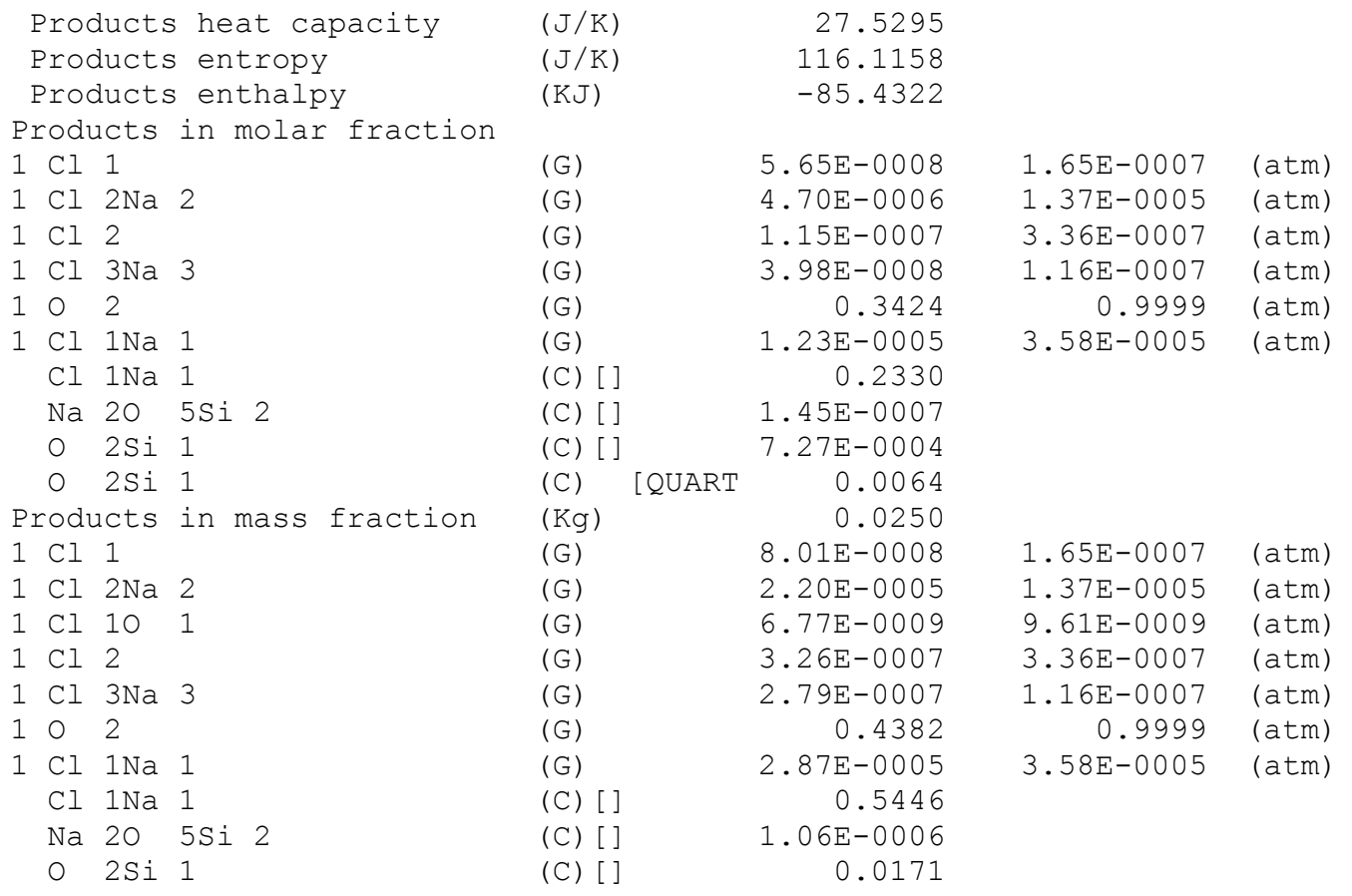

\section{2 wt\% $\mathrm{Si}$}

\begin{tabular}{|c|c|c|c|c|}
\hline Volume of gas products & litres) & 30.7393 & 30.7390 & 30.7423 \\
\hline Pressure of gas products & $(\mathrm{atm})$ & 1.0000 & 1.0000 & 1.0000 \\
\hline Temperature & $(\mathrm{K})$ & 1073.9621 & 1073.9045 & 1074.0197 \\
\hline Gas products amount & $(\operatorname{mol})$ & 0.3376 & 0.3376 & 0.3376 \\
\hline Products heat capacity & $(\mathrm{J} / \mathrm{K})$ & 28.3467 & 28.3430 & 28.3762 \\
\hline Products entropy & $(\mathrm{J} / \mathrm{K})$ & 118.4665 & 117.7797 & 123.8686 \\
\hline Products enthalpy & $(\mathrm{KJ})$ & -84.8788 & -85.6165 & -79.0771 \\
\hline Phase transition enthalpy & $(\mathrm{KJ})$ & 6.5394 & & \\
\hline Products in molar fraction & & & & \\
\hline $1 \mathrm{Cl} 2 \mathrm{Na} 2$ & (G) & $5.72 \mathrm{E}-0005$ & $5.72 \mathrm{E}-0005$ & $5.74 \mathrm{E}-0005$ \\
\hline 102 & (G) & 0.3374 & 0.3374 & 0.3374 \\
\hline $1 \mathrm{Cl} 1 \mathrm{Na} 1$ & ( $G$ ) & $1.22 \mathrm{E}-0004$ & $1.22 \mathrm{E}-0004$ & $1.22 \mathrm{E}-0004$ \\
\hline $\mathrm{Cl} 1 \mathrm{Na} 1$ & (C) [] & 0.2056 & 0.2318 & 0.0000 \\
\hline $\mathrm{Cl} \quad 1 \mathrm{Na} 1$ & (L) [] & 0.0262 & $3.81 E-0005$ & 0.2318 \\
\hline O 2 Si 1 & (C) [QUART & 0.0107 & 0.0107 & 0.0107 \\
\hline Products in mass fraction & $(\mathrm{Kg})$ & 0.0250 & & \\
\hline $1 \mathrm{Cl} 2 \mathrm{Na} 2$ & $(G)$ & $2.67 \mathrm{E}-0004$ & $2.67 \mathrm{E}-0004$ & $2.68 \mathrm{E}-0004$ \\
\hline 102 & (G) & 0.4318 & 0.4318 & 0.4318 \\
\hline $1 \mathrm{Cl} 1 \mathrm{Na} 1$ & ( $G$ ) & $2.84 \mathrm{E}-0004$ & $2.84 \mathrm{E}-0004$ & $2.85 E-0004$ \\
\hline $\mathrm{Cl} 1 \mathrm{Na} 1$ & (C) [] & 0.4807 & 0.5418 & 0.0000 \\
\hline $\mathrm{Cl} 1 \mathrm{Na} 1$ & (L) [] & 0.0612 & $8.92 \mathrm{E}-0005$ & 0.5419 \\
\hline O $2 \mathrm{Si} 1$ & (C) [QUART & 0.0257 & 0.0257 & 0.0257 \\
\hline
\end{tabular}

\section{$1.6 \quad$ Tin}

\section{7 wt $\% \mathrm{Sn}$}

Volume of gas products

Pressure of gas products

Temperature

Gas products amount

Products heat capacity

Products entropy

Products enthalpy

Products in molar fraction

$\begin{array}{llll}1 & \mathrm{Cl} & 2 \mathrm{Na} & 2\end{array}$

(litres)
$($ atm $)$
$(\mathrm{K})$
$(\mathrm{mol})$
$(\mathrm{J} / \mathrm{K})$
$(\mathrm{J} / \mathrm{K})$
$(\mathrm{KJ})$

(G)

$$
\begin{array}{r}
24.8985 \\
1.0000 \\
871.0727 \\
0.3371 \\
26.1259 \\
111.0294 \\
-83.6129
\end{array}
$$

$1.18 \mathrm{E}-0007$
3.50E-0007 (atm) 


\begin{tabular}{|c|c|c|c|c|c|}
\hline & 02 & (G) & 0.3371 & 1.0000 & (atm) \\
\hline & $\mathrm{Cl} 1 \mathrm{Na} 1$ & (G) & $4.26 \mathrm{E}-0007$ & $1.26 \mathrm{E}-0006$ & (atm) \\
\hline & $\mathrm{Cl} 1 \mathrm{Na} 1$ & (C) [] & 0.2285 & & \\
\hline & $0 \quad 2 \mathrm{Sn} 1$ & (C) [] & 0.0057 & & \\
\hline \multicolumn{2}{|r|}{ Products in mass fraction } & $(\mathrm{Kg})$ & 0.0250 & & \\
\hline \multicolumn{2}{|r|}{$1 \mathrm{Cl} 2 \mathrm{Na} 2$} & (G) & $5.52 \mathrm{E}-0007$ & $3.50 \mathrm{E}-0007$ & (atm) \\
\hline \multicolumn{2}{|r|}{102} & (G) & 0.4315 & 1.0000 & $(\mathrm{~atm})$ \\
\hline & \multirow{2}{*}{$\begin{array}{lll}\mathrm{Cl} & 1 \mathrm{Na} & 1 \\
\mathrm{Cl} & 1 \mathrm{Na} & 1\end{array}$} & ( $G)$ & $9.96 \mathrm{E}-0007$ & $1.26 \mathrm{E}-0006$ & (atm) \\
\hline & & (C) [] & 0.5342 & & \\
\hline & $0 \quad 2 \mathrm{Sn} 1$ & (C) [] & 0.0343 & & \\
\hline \multicolumn{6}{|c|}{4.9 wt $\% \mathrm{Sn}$} \\
\hline \multirow{3}{*}{\multicolumn{2}{|c|}{$\begin{array}{l}\text { Volume of gas products } \\
\text { Pressure of gas products } \\
\text { Temperature }\end{array}$}} & (litres) & 26.7663 & & \\
\hline & & $(\mathrm{atm})$ & 1.0000 & & \\
\hline & & $(\mathrm{K})$ & 972.0893 & & \\
\hline \multicolumn{2}{|r|}{ Gas products amount } & $(\mathrm{mol})$ & 0.3247 & & \\
\hline \multicolumn{2}{|r|}{ Products heat capacity } & $(\mathrm{J} / \mathrm{K})$ & 26.5713 & & \\
\hline \multicolumn{2}{|r|}{ Products entropy } & $(\mathrm{J} / \mathrm{K})$ & 110.8439 & & \\
\hline \multirow{2}{*}{\multicolumn{2}{|c|}{$\begin{array}{l}\text { Products enthalpy } \\
\text { Products in molar fraction }\end{array}$}} & $(\mathrm{KJ})$ & -81.7186 & & \\
\hline & & & & & \\
\hline \multicolumn{2}{|r|}{$1 \mathrm{Cl} 2 \mathrm{Na} 2$} & (G) & $3.52 \mathrm{E}-0006$ & $1.08 \mathrm{E}-0005$ & (atm) \\
\hline \multicolumn{2}{|r|}{$1 \mathrm{Cl} 3 \mathrm{Na} 3$} & (G) & $2.81 \mathrm{E}-0008$ & $8.66 \mathrm{E}-0008$ & $(\mathrm{~atm})$ \\
\hline \multicolumn{2}{|r|}{102} & ( $G$ ) & 0.3247 & 1.0000 & (atm) \\
\hline & $\mathrm{Cl} 1 \mathrm{Na} 1$ & (G) & $9.37 \mathrm{E}-0006$ & $2.88 \mathrm{E}-0005$ & (atm) \\
\hline & $\mathrm{Cl} 1 \mathrm{Na} 1$ & (C) [] & 0.2233 & & \\
\hline & $0 \quad 2 \mathrm{Sn} 1$ & (C) [] & 0.0103 & & \\
\hline & roducts in mass fraction & $(\mathrm{Kg})$ & 0.0250 & & \\
\hline & $\mathrm{Cl} 2 \mathrm{Na} 2$ & $(G)$ & $1.67 \mathrm{E}-0005$ & $1.10 \mathrm{E}-0005$ & (atm) \\
\hline & $\mathrm{Cl} 3 \mathrm{Na} 3$ & (G) & $2.01 \mathrm{E}-0007$ & $8.82 E-0008$ & (atm) \\
\hline & 02 & (G) & 0.4156 & 1.0000 & $(\mathrm{~atm})$ \\
\hline & $\mathrm{Cl} 1 \mathrm{Na} 1$ & (G) & $2.22 \mathrm{E}-0005$ & $2.92 \mathrm{E}-0005$ & (atm) \\
\hline & $\mathrm{Cl} 1 \mathrm{Na} 1$ & (C) [] & 0.5221 & & \\
\hline & $0 \quad 2 \operatorname{Sn} 1$ & (C) [] & 0.0622 & & \\
\hline & .5 wt $\% \mathrm{Sn}$ & & & & \\
\hline & Volume of gas products & (litres) & 28.2486 & & \\
\hline & Pressure of gas products & $(\mathrm{atm})$ & 1.0000 & & \\
\hline & Temperature & $(\mathrm{K})$ & 1073.8173 & & \\
\hline & Gas products amount & $(\mathrm{mol})$ & 0.3103 & & \\
\hline & Products heat capacity & $(\mathrm{J} / \mathrm{K})$ & 26.9297 & & \\
\hline & Products entropy & $(\mathrm{J} / \mathrm{K})$ & 109.8513 & & \\
\hline & Products enthalpy & $(\mathrm{KJ})$ & -79.9205 & & \\
\hline & roducts in molar fraction & & & & \\
\hline & $\mathrm{Cl} 2 \mathrm{Na} 2$ & (G) & $5.24 \mathrm{E}-0005$ & $1.69 \mathrm{E}-0004$ & (atm) \\
\hline & 02 & (G) & 0.3101 & 0.9995 & (atm) \\
\hline & $\mathrm{Cl} \quad 1 \mathrm{Na} 1$ & (G) & $1.12 \mathrm{E}-0004$ & $3.59 \mathrm{E}-0004$ & $(\mathrm{~atm})$ \\
\hline & $\mathrm{Cl} 1 \mathrm{Na} 1$ & (C) [] & 0.2170 & & \\
\hline & $0 \quad 2 \mathrm{Sn} 1$ & (C) [] & 0.0158 & & \\
\hline & roducts in mass fraction & $(\mathrm{Kg})$ & 0.0250 & & \\
\hline & $\mathrm{Cl} 2 \mathrm{Na} 2$ & (G) & $2.45 \mathrm{E}-0004$ & $1.69 \mathrm{E}-0004$ & (atm) \\
\hline & 02 & (G) & 0.3969 & 0.9995 & (atm) \\
\hline & $\mathrm{Cl} 1 \mathrm{Na} 1$ & (G) & $2.61 \mathrm{E}-0004$ & $3.59 \mathrm{E}-0004$ & (atm) \\
\hline & $\mathrm{Cl} 1 \mathrm{Na} 1$ & (C) [] & 0.5074 & & \\
\hline & O $\quad 2 \mathrm{Sn} 1$ & (C) [ ] & 0.0952 & & \\
\hline
\end{tabular}

\subsection{Titanium}

\section{7 wt $\% \mathrm{Ti}$}

$\begin{array}{lcr}\text { Volume of gas products } & \text { (litres) } & 25.7618 \\ \text { Pressure of gas products } & \text { (atm) } & 1.0000 \\ \text { Temperature } & (\mathrm{K}) & 877.6445 \\ \text { Gas products amount } & (\mathrm{mol}) & 0.3462\end{array}$




\begin{tabular}{|c|c|c|c|c|}
\hline Products heat capacity & $(\mathrm{J} / \mathrm{K})$ & 26.5935 & & \\
\hline Products entropy & $(\mathrm{J} / \mathrm{K})$ & 113.7447 & & \\
\hline Products enthalpy & $(\mathrm{KJ})$ & -85.3171 & & \\
\hline \multicolumn{5}{|l|}{ Products in molar fraction } \\
\hline $1 \mathrm{Cl} 1$ & (G) & $6.12 \mathrm{E}-0009$ & $1.77 \mathrm{E}-0008$ & $(\mathrm{~atm})$ \\
\hline $1 \mathrm{Cl} 2 \mathrm{Na} 2$ & (G) & $1.56 \mathrm{E}-0007$ & $4.49 \mathrm{E}-0007$ & $(\mathrm{~atm})$ \\
\hline $1 \mathrm{Cl} 2$ & (G) & $4.65 E-0008$ & $1.34 \mathrm{E}-0007$ & $(\mathrm{~atm})$ \\
\hline 102 & (G) & 0.3462 & 1.0000 & $(\mathrm{~atm})$ \\
\hline $1 \mathrm{Cl} 1 \mathrm{Na} 1$ & (G) & $5.49 \mathrm{E}-0007$ & $1.59 \mathrm{E}-0006$ & $(\mathrm{~atm})$ \\
\hline $\mathrm{Cl} 1 \mathrm{Na} 1$ & (C) [] & 0.2332 & & \\
\hline $\mathrm{Na} 20 \quad 7 \mathrm{Ti} 3$ & (C) [] & $4.98 \mathrm{E}-0008$ & & \\
\hline $\mathrm{O} \quad 2 \mathrm{Ti} 1$ & (C) [] & 0.0037 & & \\
\hline Products in mass fraction & $(\mathrm{Kg})$ & 0.0250 & & \\
\hline $1 \mathrm{Cl} 1$ & (G) & $8.67 \mathrm{E}-0009$ & $1.77 \mathrm{E}-0008$ & $(\mathrm{~atm})$ \\
\hline $1 \mathrm{Cl} 2 \mathrm{Na} 2$ & (G) & $7.27 \mathrm{E}-0007$ & $4.49 \mathrm{E}-0007$ & (atm) \\
\hline $1 \mathrm{Cl} 2$ & (G) & $1.32 \mathrm{E}-0007$ & $1.34 \mathrm{E}-0007$ & $(\mathrm{~atm})$ \\
\hline 102 & (G) & 0.4431 & 1.0000 & $(\mathrm{~atm})$ \\
\hline $1 \mathrm{Cl} 1 \mathrm{Na} 1$ & (G) & $1.28 \mathrm{E}-0006$ & $1.58 \mathrm{E}-0006$ & $(\mathrm{~atm})$ \\
\hline $\mathrm{Cl} \quad 1 \mathrm{Na} 1$ & (C) [] & 0.5452 & & \\
\hline $\mathrm{Na} 20 \quad 7 \mathrm{Ti} 3$ & (C) [] & $6.01 \mathrm{E}-0007$ & & \\
\hline $\mathrm{O} \quad 2 \mathrm{Ti} 1$ & (C) [] & 0.0117 & & \\
\hline \multicolumn{5}{|l|}{$1.3 \mathrm{wt} \% \mathrm{Ti}$} \\
\hline Volume of gas products & (litres) & 28.4807 & & \\
\hline Pressure of gas products & $(a t m)$ & 1.0000 & & \\
\hline Temperature & $(\mathrm{K})$ & 985.1498 & & \\
\hline Gas products amount & $(\operatorname{mol})$ & 0.3410 & & \\
\hline Products heat capacity & $(\mathrm{J} / \mathrm{K})$ & 27.4581 & & \\
\hline Products entropy & $(\mathrm{J} / \mathrm{K})$ & 115.8076 & & \\
\hline Products enthalpy & $(\mathrm{KJ})$ & -84.8106 & & \\
\hline \multicolumn{5}{|l|}{ Products in molar fraction } \\
\hline 102 & ( G) & 0.3409 & 0.9999 & $(\mathrm{~atm})$ \\
\hline $\mathrm{Cl} 1 \mathrm{Na} 1$ & (C) [] & 0.2318 & & \\
\hline $\mathrm{O} \quad 2 \mathrm{Ti} 1$ & (C) [] & 0.0068 & & \\
\hline Products in molar fraction & $(\mathrm{Kg})$ & 0.0250 & & \\
\hline 102 & (G) & 0.4364 & 0.9999 & $(\mathrm{~atm})$ \\
\hline $\mathrm{Cl} 1 \mathrm{Na} 1$ & (C) [] & 0.5419 & & \\
\hline $\mathrm{O} \quad 2 \mathrm{Ti} 1$ & (C) [] & 0.0217 & & \\
\hline \multicolumn{5}{|l|}{2.0 wt $\% \mathrm{Ti}$} \\
\hline Volume of gas products & (litres) & 30.4923 & 30.4900 & 30.5060 \\
\hline Pressure of gas products & $(a t m)$ & 1.0000 & 1.0000 & 1.0000 \\
\hline Temperature & $(\mathrm{K})$ & 1073.7032 & 1073.4267 & 1073.9797 \\
\hline Gas products amount & $(\operatorname{mol})$ & 0.3350 & 0.3350 & 0.3350 \\
\hline Products heat capacity & $(\mathrm{J} / \mathrm{K})$ & 28.1650 & 28.1596 & 28.1966 \\
\hline Products entropy & $(\mathrm{J} / \mathrm{K})$ & 117.8546 & 116.9817 & 123.0335 \\
\hline Products enthalpy & $(\mathrm{KJ})$ & -84.1915 & -85.1290 & -78.6294 \\
\hline Phase transition enthalpy & $(\mathrm{KJ})$ & 6.4996 & & \\
\hline \multicolumn{5}{|l|}{ Products in molar fraction } \\
\hline $1 \mathrm{Cl} 2 \mathrm{Na} 2$ & (G) & $5.62 \mathrm{E}-0005$ & $5.61 \mathrm{E}-0005$ & $5.68 \mathrm{E}-0005$ \\
\hline 102 & (G) & 0.3348 & 0.3348 & 0.3348 \\
\hline $1 \mathrm{Cl} 1 \mathrm{Na} 1$ & (G) & $1.20 \mathrm{E}-0004$ & $1.19 \mathrm{E}-0004$ & $1.21 \mathrm{E}-0004$ \\
\hline $\mathrm{Cl} 1 \mathrm{Na} 1$ & (C) [] & 0.1968 & 0.2299 & $2.18 \mathrm{E}-0005$ \\
\hline $\mathrm{Cl} 1 \mathrm{Na} 1$ & $(\mathrm{~L})[]$ & 0.0332 & 0.0000 & 0.2299 \\
\hline $\mathrm{O} \quad 2 \mathrm{Ti} 1$ & (C) [] & 0.0104 & 0.0104 & 0.0104 \\
\hline Products in mass fraction & $(\mathrm{Kg})$ & 0.0250 & & \\
\hline $1 \mathrm{Cl} 2 \mathrm{Na} 2$ & (G) & $2.63 \mathrm{E}-0004$ & $2.62 \mathrm{E}-0004$ & $2.66 \mathrm{E}-0004$ \\
\hline 102 & (G) & 0.4285 & 0.4285 & 0.4285 \\
\hline $1 \mathrm{Cl} 1 \mathrm{Na} 1$ & ( $G$ ) & $2.80 \mathrm{E}-0004$ & $2.79 \mathrm{E}-0004$ & $2.83 \mathrm{E}-0004$ \\
\hline $\mathrm{Cl} 1 \mathrm{Na} 1$ & (C) [] & 0.4600 & 0.5375 & $5.09 \mathrm{E}-0005$ \\
\hline $\mathrm{Cl} \quad 1 \mathrm{Na} 1$ & (L) [ ] & 0.0775 & 0.0000 & 0.5375 \\
\hline O $2 \mathrm{Ti} 1$ & (C) [] & 0.0334 & 0.0334 & 0.0334 \\
\hline
\end{tabular}




\subsection{Zirconium}

\section{2 wt\% $\mathrm{Zr}$}

Pressure of gas products

Temperature

Gas products amount

Products heat capacity

Products entropy

Products enthalpy

Products in molar fraction

$1 \mathrm{Cl} 2 \mathrm{Na} 2$

102

$\begin{array}{llll}1 & \mathrm{Cl} & 1 \mathrm{Na} & 1\end{array}$ Cl $1 \mathrm{Na} 1$ O 2Zr 1

Products in mass fraction

$\begin{array}{llll}1 & \mathrm{Cl} & 2 \mathrm{Na} & 2\end{array}$

102

$1 \mathrm{Cl} \quad 1 \mathrm{Na} 1$

Cl $1 \mathrm{Na} 1$

O $2 \operatorname{Zr} 1$

\section{0 wt: $\mathrm{Zr}$}

Volume of gas products

Pressure of gas products

Temperature

Products heat capacity

Products entropy

Products enthalpy

Products in molar fraction

102

Cl $1 \mathrm{Na} 1$

O $2 \mathrm{Zr} 1$

Products in mass fraction

102

Cl $1 \mathrm{Na} 1$

- $2 \mathrm{Zr} 1$
Gas products amount

(1itres)
$($ atm)
$(\mathrm{K})$
$(\mathrm{mol})$
$(\mathrm{J} / \mathrm{K})$
$(\mathrm{J} / \mathrm{K})$
$(\mathrm{KJ})$
$(\mathrm{G})$
$(\mathrm{G})$
$(\mathrm{G})$
$(\mathrm{C})[]$
$(\mathrm{C})[]$
$(\mathrm{Kg})$
$(\mathrm{G})$
$(\mathrm{G})$
$(\mathrm{G})$
$(\mathrm{C})[]$
$(\mathrm{C})[]$

(litres)

(atm)

(K)

$(\mathrm{mol})$

$(\mathrm{J} / \mathrm{K})$

$(\mathrm{J} / \mathrm{K})$

(KJ)

(G)

(C) [ ]

(C) []

$(\mathrm{Kg})$

(G)

(C) [ ]

(C) []

\section{1 wt\% $\mathrm{Zr}$}

Volume of gas products

Pressure of gas products

Temperature

(litres)

(atm)

(K)

$(\mathrm{mol})$

$(\mathrm{J} / \mathrm{K})$

Products heat capacity

Products entropy

Products enthalpy

Products in molar fraction

$1 \mathrm{Cl} 2 \mathrm{Na} 2$

102

$\begin{array}{llll}1 & \mathrm{Cl} & 1 \mathrm{Na} & 1\end{array}$

Cl $1 \mathrm{Na} 1$

O 2Zr 1

Products in mass fraction

$\begin{array}{llll}1 & \mathrm{Cl} & 2 \mathrm{Na} & 2\end{array}$

102

$1 \mathrm{Cl} 1 \mathrm{Na} 1$

Cl $1 \mathrm{Na} 1$

o 2Zr 1

(KJ)

(G)

(G)

(G)

(C) [ ]

(C) []

( $\mathrm{Kg})$

(G)

(G)

(G)

(C) [ ]

$$
\begin{array}{r}
25.8471 \\
1.0000 \\
884.1102 \\
0.3448 \\
26.5078 \\
113.4149 \\
-84.9034
\end{array}
$$

$$
\begin{array}{r}
1.97 E-0007 \\
0.3448 \\
6.80 E-0007 \\
0.2321 \\
0.0033 \\
0.0250 \\
9.21 E-0007 \\
0.4413 \\
1.59 E-0006 \\
0.5425 \\
0.0162
\end{array}
$$

\author{
5.72E-0007 (atm) \\ 1.0000 (atm) \\ 1.97E-0006 (atm) \\ 5.72E-0007 (atm) \\ 1.0000 (atm) \\ 1.97E-0006 (atm)
}

28.0532

1.0000

973.6849

0.3398

27.1295

114.8239

$-84.2103$

0.3398

0.2302

0.0055

0.0250

0.4349

0.5380

0.0270

\section{$1.0000 \quad$ (atm)}

$1.0000 \quad(\mathrm{~atm})$

30.3242

1.0000

1073.7662

0.3331

27.7899

115.9023

$-83.7971$

$5.62 \mathrm{E}-0005$

0.3329

$1.20 \mathrm{E}-0004$

0.2274

0.0085

0.0250

$\begin{array}{rr}1.69 \mathrm{E}-0004 & (\mathrm{~atm}) \\ 0.9995 & (\mathrm{~atm}) \\ 3.59 \mathrm{E}-0004 & (\mathrm{~atm})\end{array}$

2. $61 \mathrm{E}-0004$

0.4261

2. $77 \mathrm{E}-0004$

0.5315

0.0419 $\begin{array}{rr}1.67 \mathrm{E}-0004 & (\mathrm{~atm}) \\ 0.9995 & (\mathrm{~atm}) \\ 3.56 \mathrm{E}-0004 & (\mathrm{~atm})\end{array}$ 


\section{NANO-COMPOSITE THERMITES \\ 2.1 Bismuth (III) Oxide}

\subsubsection{Aluminum}

\section{2 wt $\% \mathrm{Bi}_{2} \mathrm{O}_{3} / \mathrm{Al}(1: 2)$}

Volume of gas products

Pressure of gas products

(litres)

(atm)

Temperature

(K)

$(\mathrm{mol})$

$\begin{array}{ll}\text { Products heat capacity } & (\mathrm{J} / \mathrm{K}) \\ \text { Products entropy } & (\mathrm{J} / \mathrm{K})\end{array}$

$(\mathrm{KJ})$

Products enthalpy

Products in molar fraction

$\begin{array}{llll}1 & \mathrm{Cl} & 1 \mathrm{Na} & 1\end{array}$

$\begin{array}{llll}1 & \mathrm{Cl} & 2 \mathrm{Na} & 2\end{array}$

102

Al $20 \quad 3$

Bi 203

$\mathrm{Cl} 1 \mathrm{Na} 1$

Products in mass fraction

$1 \mathrm{Cl} 1 \mathrm{Na} 1$

$\begin{array}{llll}1 & \mathrm{Cl} & 2 \mathrm{Na} & 2\end{array}$

102

Al 203

Bi 203

Cl $1 \mathrm{Na} 1$

(G)
$(G)$
$(G)$
$(C)[]$
$(C)[A, B]$
$(C)[]$
$(\mathrm{Kg})$
$(G)$
$(G)$
$(G)$
(C) []
(C) $[A, B]$
(C) []

$\begin{array}{rrr}24.7773 & & \\ 1.0000 & & \\ 873.6414 & & \\ 0.3345 & & \\ 25.9108 & & \\ 110.2128 & & \\ -83.4884 & & \\ & & \\ 4.62 \mathrm{E}-0007 & 1.38 \mathrm{E}-0006 & \text { (atm) } \\ 1.29 \mathrm{E}-0007 & 3.86 \mathrm{E}-0007 & \text { (atm) } \\ 0.3345 & 1.0000 & \text { (atm) } \\ 0.0020 & & \\ 0.0020 & & \\ 0.2250 & & \\ 0.0250 & & \\ 1.08 \mathrm{E}-0006 & 1.38 \mathrm{E}-0006 & \text { (atm) } \\ 6.04 \mathrm{E}-0007 & 3.86 \mathrm{E}-0007 & \text { (atm) } \\ 0.4281 & 1.0000 & \text { (atm) } \\ 0.0082 & & \\ 0.0376 & & \\ 0.5260 & & \end{array}$

7.4 wt $\% \mathrm{Bi}_{2} \mathrm{O}_{3} / \mathrm{Al} \quad(1: 2)$

$\begin{array}{llr}\text { Volume of gas products } & \text { (litres) } & 26.4429 \\ \text { Pressure of gas products } & (\mathrm{atm}) & 1.0000 \\ \text { Temperature } & (\mathrm{K}) & 971.7961 \\ \text { Gas products amount } & (\mathrm{mol}) & 0.3209 \\ \text { Products heat capacity } & (\mathrm{J} / \mathrm{K}) & 26.1688 \\ \text { Products entropy } & (\mathrm{J} / \mathrm{K}) & 109.4178 \\ \text { Products enthalpy } & (\mathrm{KJ}) & -81.6153\end{array}$

Products in molar fraction

1 Cl 1

(G) $\quad 4.55 \mathrm{E}-0009$

1.42E-0008 (atm)

(G) $\quad 5.68 \mathrm{E}-0009$

$1.77 \mathrm{E}-0008$ (atm)

1 Bi 406

(G) $\quad 2.75 \mathrm{E}-0008$

$\begin{array}{llll}1 & \mathrm{Cl} & 3 \mathrm{Na} & 3 \\ 1 & \mathrm{Cl} & 1 \mathrm{Na} & 1\end{array}$

$1 \mathrm{Cl} 2 \mathrm{Na} 2$

102

Al $1 \mathrm{Na} 10 \quad 2$

Al 203

Bi 203

Cl $1 \mathrm{Na} 1$

$9.18 \mathrm{E}-0006$

$8.57 \mathrm{E}-0008$

$2.86 \mathrm{E}-0005$

(atm)

(G)

(G)

(C) []

$3.44 \mathrm{E}-0006$

0.3209

$1.07 \mathrm{E}-0005$

(atm)

(atm)

$6.87 \mathrm{E}-0009$

0.0036

(C) $[A, B] \quad 0.0036$

(C) []$\quad 0.2175$

(Kg) $\quad 0.0250$

Products in mass fraction

$6.45 \mathrm{E}-0009$

(G) 2.12E-0007

1. $42 \mathrm{E}-0008$ (atm)

(G) $\quad 1.93 \mathrm{E}-0007$

$\begin{array}{llll}1 & \mathrm{Cl} & 3 \mathrm{Na} & 3\end{array}$

$\begin{array}{llll}1 & \mathrm{Cl} & 1 \mathrm{Na} & 1\end{array}$

$\begin{array}{llll}1 & \mathrm{Cl} & 2 \mathrm{Na} & 2\end{array}$

102

$2.15 \mathrm{E}-0005$

$1.77 \mathrm{E}-0008$ (atm)

$8.57 \mathrm{E}-0008$ (atm)

$2.86 \mathrm{E}-0005$ (atm)

(G) $\quad 1.61 \mathrm{E}-0005$

(G)

$1.07 \mathrm{E}-0005$ (atm)

Al $1 \mathrm{Na} 1 \mathrm{O} \quad 2$

(C) []

$2.25 \mathrm{E}-0008$

1.0000 (atm)
Al 203
Bi 203
(C) []
(C) $[\mathrm{A}, \mathrm{B}]$
0.0145
0.0663
Cl $1 \mathrm{Na} 1$
(C) []
0.5084

A greater amount than 10wt\% 


\subsubsection{Silicon}

\section{0 wt\% $\mathrm{Bi}_{2} \mathrm{O}_{3} / \mathrm{Si}(2: 3)$}

\begin{tabular}{|c|c|c|c|c|}
\hline Volume of gas products & (litres) & 24.5036 & & \\
\hline Pressure of gas products & $(a t m)$ & 1.0000 & & \\
\hline Temperature & $(\mathrm{K})$ & 873.0723 & & \\
\hline Gas products amount & $(\operatorname{mol})$ & 0.3310 & & \\
\hline Products heat capacity & $(\mathrm{J} / \mathrm{K})$ & 25.7346 & & \\
\hline Products entropy & $(\mathrm{J} / \mathrm{K})$ & 109.3070 & & \\
\hline $\begin{array}{l}\text { Products enthalpy } \\
\text { roducts in molar fraction }\end{array}$ & $(\mathrm{KJ})$ & -83.0445 & & \\
\hline 02 & (G) & 0.3310 & 1.0000 & $(a t m)$ \\
\hline $\mathrm{Bi} 203$ & (C) $[\mathrm{A}, \mathrm{B}]$ & 0.0025 & & \\
\hline $\mathrm{Cl} 1 \mathrm{Na} 1$ & (C) [] & 0.2231 & & \\
\hline $0 \quad 2 \mathrm{Si} 1$ & (C) [] & $2.81 \mathrm{E}-0004$ & & \\
\hline $\mathrm{O} \quad 2 \mathrm{Si} 1$ & (C) [QUART & 0.0034 & & \\
\hline roducts in mass fraction & $(\mathrm{Kg})$ & 0.0250 & & \\
\hline 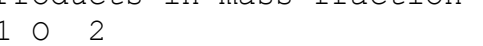 & (G) & 0.4237 & 1.0000 & $(\mathrm{~atm})$ \\
\hline $\mathrm{Bi} 2 \mathrm{O} 3$ & (C) $[\mathrm{A}, \mathrm{B}]$ & 0.0459 & & \\
\hline $\mathrm{Cl} 1 \mathrm{Na} 1$ & (C) [] & 0.5216 & & \\
\hline $0 \quad 2 \mathrm{Si} 1$ & (C) [QUART & 0.0089 & & \\
\hline
\end{tabular}

\section{8 wt $\% \mathrm{Bi}_{2} \mathrm{O}_{3} / \mathrm{Si}(2: 3)$}

\begin{tabular}{|c|c|c|c|c|c|}
\hline Volume o & of gas products & (litres) & 25.3855 & & \\
\hline Pressure & e of gas products & $(\mathrm{atm})$ & 1.0000 & & \\
\hline Temperat & ture & $(\mathrm{K})$ & 951.0000 & & \\
\hline Gas prod & ducts amount & $(\mathrm{mol})$ & 0.3148 & & \\
\hline Products & s heat capacity & $(\mathrm{J} / \mathrm{K})$ & 25.6924 & & \\
\hline Products & s entropy & $(\mathrm{J} / \mathrm{K})$ & 107.2706 & & \\
\hline Products & s enthalpy & $(\mathrm{KJ})$ & -81.3739 & & \\
\hline $\mathrm{Cl} 1$ & & (G) & $2.37 \mathrm{E}-0008$ & $7.53 \mathrm{E}-0008$ & (atm) \\
\hline $\mathrm{Cl} 2$ & & (G) & $5.58 \mathrm{E}-0008$ & $1.77 \mathrm{E}-0007$ & (atm) \\
\hline $\mathrm{Cl} 3 \mathrm{Na}$ & 3 & (G) & $1.21 \mathrm{E}-0008$ & $3.85 E-0008$ & $(\mathrm{~atm})$ \\
\hline $\mathrm{Cl} 1 \mathrm{Na}$ & 1 & (G) & $5.01 \mathrm{E}-0006$ & $1.59 \mathrm{E}-0005$ & $(\mathrm{~atm})$ \\
\hline $\mathrm{Cl} 2 \mathrm{Na}$ & 2 & (G) & $1.78 \mathrm{E}-0006$ & $5.64 \mathrm{E}-0006$ & (atm) \\
\hline 02 & & (G) & 0.3148 & 1.0000 & (atm) \\
\hline Bi 20 & 3 & (C) $[\mathrm{A}, \mathrm{B}]$ & 0.0043 & & \\
\hline $\mathrm{Cl} 1 \mathrm{Na}$ & 1 & (C) [] & 0.2142 & & \\
\hline $\mathrm{Na} 2 \mathrm{O}$ & $5 \mathrm{Si} 2$ & (C) [] & $6.84 \mathrm{E}-0008$ & & \\
\hline O $2 \mathrm{Si}$ & 1 & (C) [] & $5.50 \mathrm{E}-0004$ & & \\
\hline O $2 \mathrm{Si}$ & 1 & (C) [QUART & 0.0059 & & \\
\hline roducts & in mass fraction & $(\mathrm{Kg})$ & 0.0250 & & \\
\hline $\mathrm{Cl} 1$ & & (G) & $3.36 \mathrm{E}-0008$ & $7.53 \mathrm{E}-0008$ & $(\mathrm{~atm})$ \\
\hline $\mathrm{Cl} 2$ & & (G) & $1.58 \mathrm{E}-0007$ & $1.77 \mathrm{E}-0007$ & (atm) \\
\hline $\mathrm{Cl} 3 \mathrm{Na}$ & 3 & (G) & $8.51 E-0008$ & $3.85 E-0008$ & (atm) \\
\hline $\mathrm{Cl} 1 \mathrm{Na}$ & 1 & (G) & $1.17 \mathrm{E}-0005$ & $1.59 \mathrm{E}-0005$ & $(\mathrm{~atm})$ \\
\hline $\mathrm{Cl} 2 \mathrm{Na}$ & 2 & (G) & $8.31 E-0006$ & $5.65 E-0006$ & (atm) \\
\hline 02 & & (G) & 0.4029 & 1.0000 & (atm) \\
\hline $\mathrm{Bi} 40$ & 6 & $(G)$ & $8.94 \mathrm{E}-0008$ & 7. $62 \mathrm{E}-0009$ & (atm) \\
\hline $\mathrm{Bi} 20$ & 3 & (C) $[A, B]$ & 0.0807 & & \\
\hline $\mathrm{Cl} 1 \mathrm{Na}$ & 1 & (C) [] & 0.5007 & & \\
\hline $\mathrm{Na} 20$ & $5 \mathrm{Si} 2$ & (C) [] & $4.98 \mathrm{E}-0007$ & & \\
\hline O 2Si & 1 & (C) [QUART & 0.0156 & & \\
\hline
\end{tabular}

A greater amount than $10 \mathrm{wt} \%$ of $\mathrm{Bi}_{2} \mathrm{O}_{3} / \mathrm{Si}(2: 3)$ is required for $\mathrm{T}=1073 \mathrm{~K}$

\subsubsection{Zirconium}

\section{9 wt\% $\mathrm{Bi}_{2} \mathrm{O}_{3} / \mathrm{Zr}(2: 3)$}

Volume of gas products (litres) 24.5916 


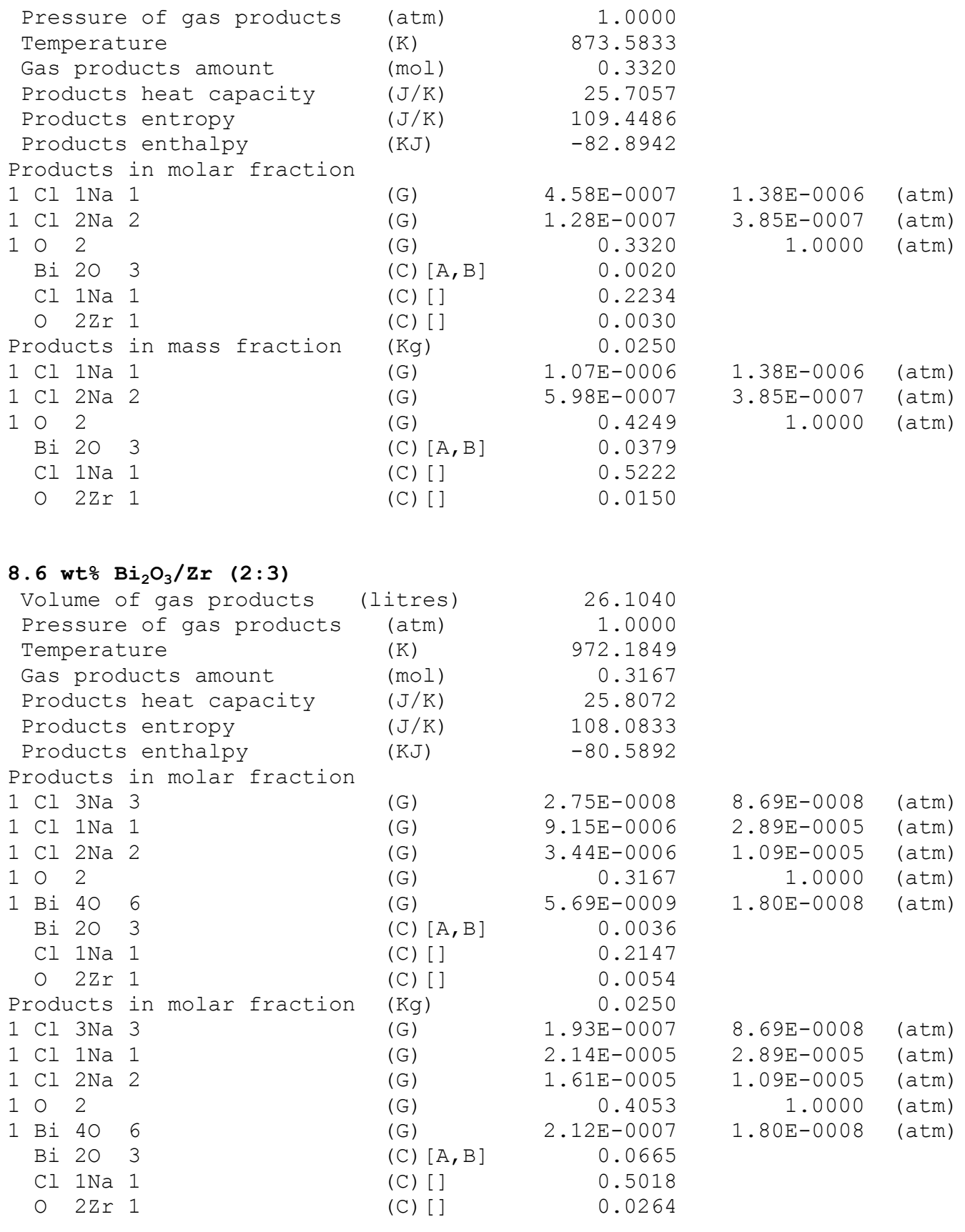

A greater amount than $10 \mathrm{wt} \%$ of $\mathrm{Bi}_{2} \mathrm{O}_{3} / \mathrm{Zr}(2: 3)$ is required for $\mathrm{T}=1073 \mathrm{~K}$

\subsection{Copper (II) Oxide}

\subsubsection{Aluminum}

2.5 wt\% CuO/Al $(3: 2)$

$\begin{array}{llr}\text { Volume of gas products } & \text { (litres) } & 25.3087 \\ \text { Pressure of gas products } & (\mathrm{atm}) & 1.0000 \\ \text { Temperature } & (\mathrm{K}) & 877.1292 \\ \text { Gas products amount } & (\mathrm{mol}) & 0.3403\end{array}$ 


Products heat capacity
Products entropy
Products enthalpy
Products in molar fraction
$1 \mathrm{Cl} 1 \mathrm{Na} 1$
$1 \mathrm{Cl} 2 \mathrm{Na} 2$
$1 \mathrm{O} 2$
$\mathrm{Al} 2 \mathrm{O} 3$
$\mathrm{Cl} 1 \mathrm{Na} 1$
$\mathrm{Cu} 10$
Products in mass fraction
$1 \mathrm{Cl} 1 \mathrm{Na} 1$
$1 \mathrm{Cl} 2 \mathrm{Na} 2$
$1 \mathrm{O} 2$
$\mathrm{Al} 20$
$\mathrm{Cl} 1 \mathrm{Na} 1$
$\mathrm{Cu} 10$

\section{3 wto $\mathrm{CuO} / \mathrm{Al}(3: 2)$}

Volume of gas products Pressure of gas products Temperature

Gas products amount

Products heat capacity

Products entropy

Products enthalpy

Products in molar fraction

$1 \mathrm{Cl} 3 \mathrm{Na} 3$

$1 \mathrm{Cl} 1 \mathrm{Na} 1$

$\begin{array}{llll}1 & \mathrm{Cl} & 2 \mathrm{Na} & 2\end{array}$

102

Al $1 \mathrm{Na} \quad 1 \mathrm{O} \quad 2$

Al 203

Cl $1 \mathrm{Na} 1$

$\mathrm{Cu} 10 \quad 1$

Products in mass fraction

$\begin{array}{llll}1 & \mathrm{Cl} & 3 \mathrm{Na} & 3\end{array}$

$\begin{array}{llll}1 & \mathrm{Cl} & 1 \mathrm{Na} & 1\end{array}$

$\begin{array}{llll}1 & \mathrm{Cl} & 2 \mathrm{Na} & 2\end{array}$

102

Al $1 \mathrm{Na} \quad 10 \quad 2$

Al $20 \quad 3$

$\mathrm{Cl} 1 \mathrm{Na} 1$

$\mathrm{Cu} 10 \quad 1$

\section{7 wt\% $\mathrm{CuO} / \mathrm{Al}(3: 2)$}

Pressure of gas products

Temperature

Gas products amount

Products heat capacity

Products entropy

Products enthalpy

Products in molar fraction

$\begin{array}{llll}1 & \mathrm{Cl} & 1 \mathrm{Na} & 1\end{array}$

$\begin{array}{llll}1 & \mathrm{Cl} & 2 \mathrm{Na} & 2\end{array}$

102

Al $20 \quad 3$

Cl $1 \mathrm{Na} 1$

$\mathrm{Cu} 10 \quad 1$

Products in mass fraction

$\begin{array}{llll}1 & \mathrm{Cl} & 1 \mathrm{Na} & 1\end{array}$

$1 \mathrm{Cl} 2 \mathrm{Na} 2$

102

Al 203

$\begin{array}{lr}(\mathrm{J} / \mathrm{K}) & 26.4678 \\ (\mathrm{~J} / \mathrm{K}) & 112.2904 \\ (\mathrm{KJ}) & -84.8236\end{array}$

(G) $\quad 5.30 \mathrm{E}-0007$

(G)

(C) [ ]

(C) [ ]

(C) []

$(\mathrm{Kg})$

(G)

(G)

(G)

(C) [ ]

(C) [ ]

(C) []

$$
\begin{array}{r}
1.50 \mathrm{E}-0007 \\
0.3403 \\
0.0021 \\
0.2290 \\
0.0064 \\
0.0250 \\
1.24 \mathrm{E}-0006 \\
7.01 \mathrm{E}-0007 \\
0.4356 \\
0.0087 \\
0.5353 \\
0.0204
\end{array}
$$

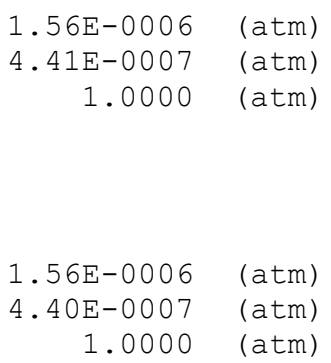

(C) [ ]

(C) [ ]

(C) []

(C) [ ]

$(\mathrm{Kg})$

(G)

(C) []

(C) [ ]

(C) []

(C) [ ]

$$
\begin{array}{r}
26.7296 \\
1.0000 \\
950.5141 \\
0.3317 \\
26.9497 \\
112.5057 \\
-84.5181
\end{array}
$$

$1.25 \mathrm{E}-0008$

5.20E-0006

$1.84 \mathrm{E}-0006$

0.3317

4.39E-0009

0.0037

0.2248

0.0110

0.0250

$8.79 \mathrm{E}-0008$

1.22E-0005

8. $62 \mathrm{E}-0006$

0.4245

1. $46 \mathrm{E}-0008$

0.0150

0.5254

0.0351

$$
\begin{array}{rr}
3.78 \mathrm{E}-0008 & (\mathrm{~atm}) \\
1.57 \mathrm{E}-0005 & (\mathrm{~atm}) \\
5.56 \mathrm{E}-0006 & (\mathrm{~atm}) \\
1.0000 & (\mathrm{~atm})
\end{array}
$$

$$
\begin{array}{rr}
3.78 \mathrm{E}-0008 & (\mathrm{~atm}) \\
1.57 \mathrm{E}-0005 & (\mathrm{~atm}) \\
5.56 \mathrm{E}-0006 & (\mathrm{~atm}) \\
1.0000 & (\mathrm{~atm})
\end{array}
$$

(litres)

(atm)

(K)

$(\mathrm{mol})$

$(\mathrm{J} / \mathrm{K})$

( $\mathrm{J} / \mathrm{K})$

(KJ)

(G)

(G)

(G)

(C) [ ]

(C) [ ]

(C) [ ]

$(\mathrm{Kg})$

(G)

(G)

(G)

(C) [ ]
29.1373

1.0000

1072.9197

0.3203

27.7827

113.2605

$-83.3577$

1.13E-0004

5. 30E-0005

0.3201

0.0057

0.2189

0.0172

0.0250

2. 64E-0004

2. $48 \mathrm{E}-0004$

0.4097

0.0233 $\begin{array}{rr}3.52 E-0004 & (\mathrm{~atm}) \\ 1.65 \mathrm{E}-0004 & (\mathrm{~atm}) \\ 0.9995 & (\mathrm{~atm})\end{array}$

$$
\begin{array}{rr}
3.53 \mathrm{E}-0004 & (\mathrm{~atm}) \\
1.66 \mathrm{E}-0004 & (\mathrm{~atm}) \\
0.9995 & (\mathrm{~atm})
\end{array}
$$



Cl $1 \mathrm{Na} 1$
(C) [ ]
0.5118

\subsubsection{Magnesium}

\section{4 wto $\mathrm{CuO} / \mathrm{Mg}(1: 1)$}

$\begin{array}{llr}\text { Volume of gas products } & \text { (litres) } & 25.2332 \\ \text { Pressure of gas products } & (\mathrm{atm}) & 1.0000 \\ \text { Temperature } & (\mathrm{K}) & 872.8009 \\ \text { Gas products amount } & (\mathrm{mol}) & 0.3410 \\ \text { Products heat capacity } & (\mathrm{J} / \mathrm{K}) & 26.4636 \\ \text { Products entropy } & (\mathrm{J} / \mathrm{K}) & 112.3756 \\ \text { Products enthalpy } & (\mathrm{KJ}) & -84.8069\end{array}$

Products in molar fraction

$1 \mathrm{Cl} 1 \mathrm{Na} 1$

$\begin{array}{llll}1 & \mathrm{Cl} & 2 \mathrm{Na} & 2\end{array}$

102

Cl $1 \mathrm{Na} 1$

$\mathrm{Cu} 10 \quad 1$

Mg 101

(C) []

(C) []

(C) []

Products in mass fraction

$1 \mathrm{Cl} 1 \mathrm{Na} 1$

$\begin{array}{llll}1 & \mathrm{Cl} & 2 \mathrm{Na} & 2\end{array}$

102

Cl $1 \mathrm{Na} 1$

$\mathrm{Cu} 10 \quad 1$

(C) []

$\begin{array}{lll}M g & 10 & 1\end{array}$

$$
\begin{array}{r}
4.57 \mathrm{E}-0007 \\
1.27 \mathrm{E}-0007 \\
0.3410 \\
0.2292 \\
0.0058 \\
0.0058 \\
0.0250 \\
1.07 \mathrm{E}-0006 \\
5.96 \mathrm{E}-0007 \\
0.4364 \\
0.5359 \\
0.0184 \\
0.0093
\end{array}
$$

\section{3 wt\% $\mathrm{CuO} / \mathrm{Mg}(1: 1)$}

Pressure of gas products

Temperature

(litres)

(atm)

(K)

$(\mathrm{mol})$

$(\mathrm{J} / \mathrm{K})$

$(\mathrm{J} / \mathrm{K})$

$(\mathrm{KJ})$

Products entropy

Products in molar fraction

$\begin{array}{llll}1 & \mathrm{Cl} & 3 \mathrm{Na} & 3\end{array}$

$\begin{array}{llll}1 & \mathrm{Cl} & 1 \mathrm{Na} & 1\end{array}$

$\begin{array}{llll}1 & \mathrm{Cl} & 2 \mathrm{Na} & 2\end{array}$

102

Cl $1 \mathrm{Na} 1$

$\mathrm{Cu} 10 \quad 1$

Mg 101

Products in mass fraction

(C) [ ]

(C) []

(C) [ ]

(Kg)

(G)

(G)

(C) [ ]

(C) []

(C) [ ]
$\begin{array}{lll}\mathrm{Cl} & 1 \mathrm{Na} & 1 \\ \mathrm{Cu} & 1 \mathrm{O} & 1\end{array}$

$\begin{array}{lll}M g & 10 & 1\end{array}$
26.7566

1.0000

950.5141

0.3320

26.9938

112.7049

$-84.4438$

1. $26 \mathrm{E}-0008$

$5.20 \mathrm{E}-0006$

$1.85 \mathrm{E}-0006$

0.3320

0.2248

0.0104

0.0104

0.0250

8. $80 \mathrm{E}-0008$

1.22E-0005

8. $63 \mathrm{E}-0006$

0.4249

0.5254

0.0329

0.0167
$3.78 \mathrm{E}-0008$

1. $57 \mathrm{E}-0005$

$5.56 \mathrm{E}-0006$

1.0000

(atm)

(atm)

(atm)

(atm)

$\begin{array}{rr}3.78 \mathrm{E}-0008 & (\mathrm{~atm}) \\ 1.57 \mathrm{E}-0005 & (\mathrm{~atm}) \\ 5.56 \mathrm{E}-0006 & (\mathrm{~atm}) \\ 1.0000 & \text { (atm) }\end{array}$

( 1.0000

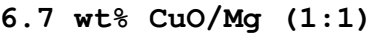

Volume of gas products

Pressure of gas products

Temperature

Gas products amount

Products heat capacity

Products entropy

Products enthalpy

Products in molar fraction

$\begin{array}{llll}\mathrm{Cl} & 1 \mathrm{Na} & 1\end{array}$ (litres)

(atm)

(K)

$(\mathrm{mol})$

$(\mathrm{J} / \mathrm{K})$

$(\mathrm{J} / \mathrm{K})$

$(\mathrm{KJ})$

(G)
29.2054

1.0000

1073.6669

0.3208

27.8568

113.5991

$-83.2121$

1.15E-0004 (atm)

$(\mathrm{atm})$

(atm)

(atm)

(atm)

(atm) 


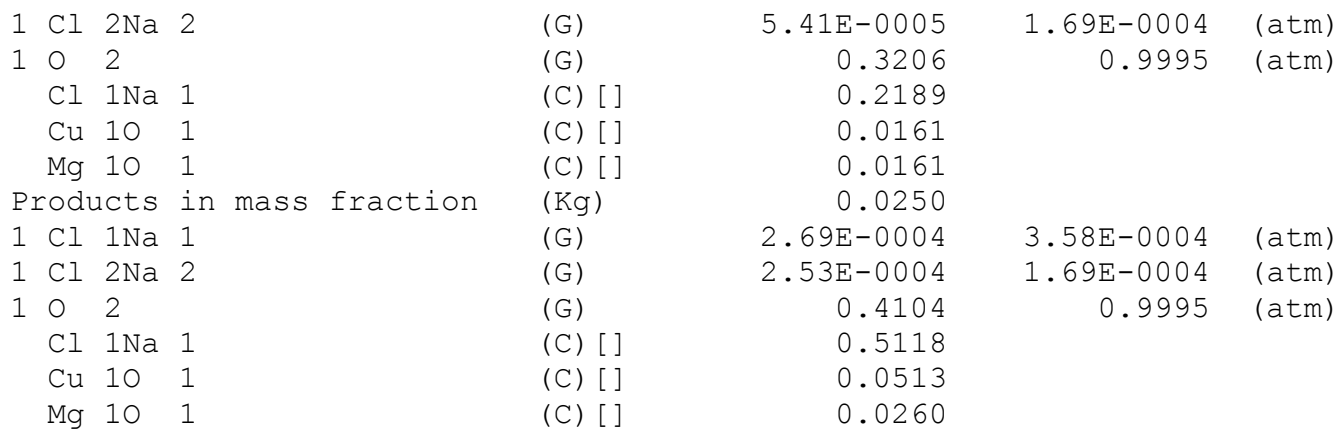

\subsubsection{Magnesium Hydride}

\section{8 wt\% $\mathrm{CuO} / \mathrm{MgH}_{2}(1: 1)$}

Volume of gas products

Pressure of gas products

Temperature

Gas products amount

Products heat capacity

Products entropy

Products enthalpy

Products in molar fraction

$1 \mathrm{Cl} 1 \mathrm{Na} 1$

$\begin{array}{llll}1 & \mathrm{Cl} & 2 \mathrm{Na} & 2\end{array}$

$1 \mathrm{H} \quad 2 \mathrm{O} \quad 1$

102

Cl $1 \mathrm{Na} 1$

$\mathrm{Cu} 10 \quad 1$

Mg 101

Products in mass fraction

$\begin{array}{llll}1 & \mathrm{Cl} & 1 \mathrm{Na} & 1\end{array}$

$\begin{array}{llll}1 & \mathrm{Cl} & 2 \mathrm{Na} & 2\end{array}$

$1 \mathrm{H} \quad 2 \mathrm{O} \quad 1$

102

Cl $1 \mathrm{Na} 1$

$\mathrm{Cu} 10 \quad 1$

$\begin{array}{lll}\text { Mg } & 10 & 1\end{array}$

3.5 wt\% $\mathrm{CuO} / \mathrm{MgH}_{2} \quad(1: 1)$

Volume of gas products

Pressure of gas products

Temperature

Gas products amount

Products heat capacity

Products entropy

Products enthalpy

Products in molar fraction

$\begin{array}{llll}1 & \mathrm{Cl} & 1 \mathrm{H} & 1\end{array}$

$\begin{array}{llll}1 & \mathrm{Cl} & 3 \mathrm{Na} & 3\end{array}$

$\begin{array}{llll}1 & \mathrm{Cl} & 1 \mathrm{Na} & 1\end{array}$

$\begin{array}{llll}1 & \mathrm{Cl} & 2 \mathrm{Na} & 2\end{array}$

$\begin{array}{lllll}1 & \mathrm{H} & 1 \mathrm{Na} & 10 & 1\end{array}$

$\begin{array}{llll}1 & \mathrm{H} & 2 \mathrm{O} & 1\end{array}$

$\begin{array}{llll}1 & \mathrm{H} & 10 & 1\end{array}$

102

Cl $1 \mathrm{Na} 1$

$\mathrm{Cu} 10 \quad 1$

Mg 101

Products in mass fraction

$1 \mathrm{Cl} 1 \mathrm{H} \quad 1$

$\begin{array}{llll}1 & \mathrm{Cl} & 3 \mathrm{Na} & 3\end{array}$

$\begin{array}{lr}\text { (litres) } & 25.3708 \\ (\mathrm{~atm}) & 1.0000 \\ (\mathrm{~K}) & 864.8707 \\ (\mathrm{~mol}) & 0.3460 \\ (\mathrm{~J} / \mathrm{K}) & 26.5214 \\ (\mathrm{~J} / \mathrm{K}) & 113.3926 \\ (\mathrm{KJ}) & -85.3959\end{array}$

(C) [ ]

(C) []

(C) [ ]

$(\mathrm{Kg})$

(G)

(G)

(G)

(G)

(C) [ ]

(C) []

(C) []

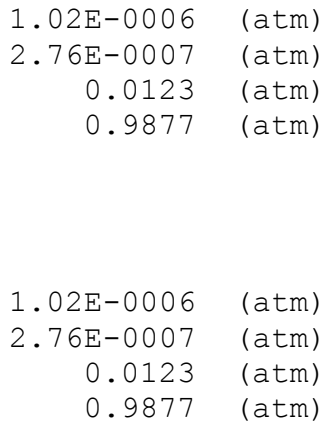

28.0525 1.0000 973.0960 0.3400 27.4133 115.3927

$-84.8740$

(KJ)

(C) [ ]

(C) []

(C) [ ]

(Kg)

(G)

$\begin{array}{rrr}3.87 \mathrm{E}-0008 & 1.14 \mathrm{E}-0007 & (\mathrm{~atm}) \\ 3.06 \mathrm{E}-0008 & 9.00 \mathrm{E}-0008 & (\mathrm{~atm}) \\ 1.01 \mathrm{E}-0005 & 2.96 \mathrm{E}-0005 & (\mathrm{~atm}) \\ 3.79 \mathrm{E}-0006 & 1.12 \mathrm{E}-0005 & (\mathrm{~atm}) \\ 3.84 \mathrm{E}-0008 & 1.13 \mathrm{E}-0007 & (\mathrm{~atm}) \\ 0.0083 & 0.0243 & (\mathrm{~atm}) \\ 1.65 \mathrm{E}-0008 & 4.84 \mathrm{E}-0008 & (\mathrm{~atm}) \\ 0.3317 & 0.9756 & (\mathrm{~atm}) \\ 0.2266 & & \\ 0.0083 & & \\ 0.0083 & & \\ 0.0250 & & \\ 5.63 \mathrm{E}-0008 & 1.14 \mathrm{E}-0007 & (\mathrm{~atm}) \\ 2.15 \mathrm{E}-0007 & 9.00 \mathrm{E}-0008 & (\mathrm{~atm})\end{array}$




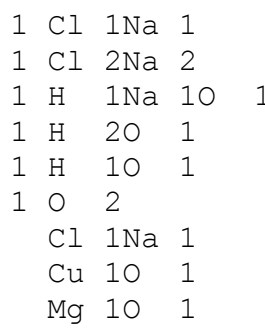

\section{4 wt\% $\mathrm{CuO} / \mathrm{MgH}_{2}(1: 1)$}

Volume of gas products Pressure of gas products Temperature

Gas products amount

Products heat capacity

Products entropy

Products enthalpy

Products in molar fraction

$\begin{array}{llll}1 & \mathrm{Cl} & 1 \mathrm{Na} & 1\end{array}$

$\begin{array}{llll}1 & \mathrm{Cl} & 2 \mathrm{Na} & 2\end{array}$

$\begin{array}{llll}1 & \mathrm{H} & 2 \mathrm{O} & 1\end{array}$

$\begin{array}{lll}1 & 0 & 2\end{array}$

Cl $1 \mathrm{Na} 1$

$\mathrm{Cu} 10 \quad 1$

Mg 101

Products in mass fraction

$1 \mathrm{Cl} \quad 1 \mathrm{Na} 1$

$\begin{array}{llll}1 & \mathrm{Cl} & 2 \mathrm{Na} & 2\end{array}$

$\begin{array}{llll}1 & \mathrm{H} & 2 \mathrm{O} & 1\end{array}$

102

Cl $1 \mathrm{Na} 1$

$\mathrm{Cu} 10 \quad 1$

$\begin{array}{lll}\text { Mg } & 10 & 1\end{array}$

$\begin{array}{lr}\text { (G) } & 2.36 \mathrm{E}-0005 \\ \text { (G) } & 1.77 \mathrm{E}-0005 \\ \text { (G) } & 6.15 \mathrm{E}-0008 \\ \text { (G) } & 0.0060 \\ \text { (G) } & 1.12 \mathrm{E}-0008 \\ \text { (G) } & 0.4246 \\ \text { (C) [ ] } & 0.5298 \\ \text { (C) [ ] } & 0.0263 \\ \text { (C) [ ] } & 0.0133\end{array}$

(litres)

(atm)

(K)

$(\mathrm{mol})$

$(\mathrm{J} / \mathrm{K})$

$(\mathrm{J} / \mathrm{K})$

(KJ)

(G)

(G)

(C) [ ]

(C) [ ]

(C) [ ]

(Kg)

(G)

(G)

(G)

(G)

(C) [ ]

(C) []

(C) [ ]

0.2220

0.0128

0.0128

0.0250

$2.79 \mathrm{E}-0004$

$2.62 \mathrm{E}-0004$

0.0092

0.4103

0.5189

0.0406

0.0206

$$
\begin{array}{rr}
2.97 \mathrm{E}-0005 & (\mathrm{~atm}) \\
1.12 \mathrm{E}-0005 & (\mathrm{~atm}) \\
1.13 \mathrm{E}-0007 & (\mathrm{~atm}) \\
0.0243 & (\text { atm }) \\
4.84 \mathrm{E}-0008 & (\text { atm }) \\
0.9756 & \text { (atm) }
\end{array}
$$

3.58E-0004 (atm)

1.68E-0004 (atm)

0.0382 (atm)

0.9612 (atm)

\subsubsection{Silicon}

\section{8 wt\% $\mathrm{CuO} / \mathrm{Si}(2: 1)$}

$\begin{array}{llr}\text { Volume of gas products } & \text { (litres) } & 25.0025 \\ \text { Pressure of gas products } & (\mathrm{atm}) & 1.0000 \\ \text { Temperature } & (\mathrm{K}) & 870.5914 \\ \text { Gas products amount } & (\mathrm{mol}) & 0.3387 \\ \text { Products heat capacity } & (\mathrm{J} / \mathrm{K}) & 26.3657 \\ \text { Products entropy } & (\mathrm{J} / \mathrm{K}) & 111.7722 \\ \text { Products enthalpy } & (\mathrm{KJ}) & -84.7237\end{array}$

Products in molar fraction

$\begin{array}{llll}1 & \mathrm{Cl} & 1 \mathrm{Na} & 1\end{array}$

$\begin{array}{llll}1 & \mathrm{Cl} & 2 \mathrm{Na} & 2\end{array}$

$1 \mathrm{Cl} 2$

102

Cl $1 \mathrm{Na} 1$

$\mathrm{Cu} 10 \quad 1$

$\mathrm{Na} 2 \mathrm{O}$ 5Si 2

O $2 \mathrm{Si} 1$

Products in mass fraction

$\begin{array}{llll}1 & \mathrm{Cl} & 1 \mathrm{Na} & 1\end{array}$

$\begin{array}{llll}1 & \mathrm{Cl} & 2 \mathrm{Na} & 2\end{array}$

$1 \mathrm{Cl} 2$

102

$\mathrm{Cl} 1 \mathrm{Na} 1$

$\mathrm{Cu} 10 \quad 1$

$\mathrm{Na} 2 \mathrm{O} 5 \mathrm{Si} 2$

- 2Si 1
(G)

(G)

(G)

(G)

(C) [ ]

(C) []

(C) [ ]

(C)

$(\mathrm{Kg})$

(G)

(G)

(G)

(G)

(C) [ ]

(C) [ ]

(C) [ ]

(C) []
4.21E-0007

1. $16 \mathrm{E}-0007$

8.29E-0009

0.3387

0.2283

0.0075

1.01E-0008

[QUART $\quad 0.0037$

0.0250

9.84E-0007

$5.44 \mathrm{E}-0007$

$2.35 \mathrm{E}-0008$

0.4335

0.5337

0.0238

7.35E-0008

0.0090
1.24E-0006 (atm)

$3.44 \mathrm{E}-0007$ (atm)

$2.45 \mathrm{E}-0008$ (atm)

1.0000 (atm) 


\section{1 wt\% $\mathrm{CuO} / \mathrm{Si}(2: 1)$}

Volume of gas product

Pressure of gas products

Temperature

Gas products amount

Products heat capacity

Products entropy

Products enthalpy

Products in molar fraction

$1 \mathrm{Cl} 1$

$1 \mathrm{Cl} 1 \mathrm{Cu} 1$

$\begin{array}{llll}1 & \mathrm{Cl} & 3 \mathrm{Na} & 3\end{array}$

$1 \mathrm{Cl} 1 \mathrm{Na} 1$

$\begin{array}{llll}1 & \mathrm{Cl} & 2 \mathrm{Na} & 2\end{array}$

$1 \mathrm{Cl} 2$

$\begin{array}{llll}1 & \mathrm{Cl} & 2 \mathrm{Cu} & 1\end{array}$

$1 \mathrm{Cl} 2 \mathrm{Cu} 2$

102

Cl $1 \mathrm{Na} 1$

$\mathrm{Cu} 10 \quad 1$

$\mathrm{Na} 2 \mathrm{O}$ 5Si 2

O $2 \mathrm{Si} 1$

Products in mass fraction

$1 \mathrm{Cl} 1$

$1 \mathrm{Cl} 1 \mathrm{Cu} 1$

$\begin{array}{llll}1 & \mathrm{Cl} & 3 \mathrm{Na} & 3\end{array}$

$\begin{array}{llll}1 & \mathrm{Cl} & 1 \mathrm{Na} & 1\end{array}$

$\begin{array}{llll}1 & \mathrm{Cl} & 2 \mathrm{Na} & 2\end{array}$

$1 \mathrm{Cl} 2$

$\begin{array}{llll}1 & \mathrm{Cl} & 2 \mathrm{Cu} & 1\end{array}$

$\begin{array}{llll}1 & \mathrm{Cl} & 2 \mathrm{Cu} & 2\end{array}$

102

Cl $1 \mathrm{Na} 1$

$\mathrm{Cu} 10 \quad 1$

$\mathrm{Na} 2 \mathrm{O} 5 \mathrm{Si} 2$

O 2Si 1

\section{0 wt\% $\mathrm{CuO} / \mathrm{Si}(2: 1)$}

Volume of gas products

Pressure of gas products

Temperature

Gas products amount

Products heat capacity

Products entropy

Products enthalpy

Products in molar fraction

$\begin{array}{llll}1 & \mathrm{Cl} & 1 \mathrm{Na} & 1\end{array}$

$\begin{array}{llll}1 & \mathrm{Cl} & 2 \mathrm{Na} & 2\end{array}$

102

Cl $1 \mathrm{Na} 1$

$\mathrm{Cu} 10 \quad 1$

O $2 \mathrm{Si} 1$

Products in molar fraction

$1 \mathrm{Cl} 1 \mathrm{Na} 1$

$\begin{array}{llll}1 & \mathrm{Cl} & 2 \mathrm{Na} & 2\end{array}$

102

Cl $1 \mathrm{Na} 1$

$\mathrm{Cu} 10 \quad 1$

- 2Si 1

\section{(litres)}

(atm)

(K)

(mol)

$(\mathrm{J} / \mathrm{K})$

$(\mathrm{J} / \mathrm{K})$

(KJ)

(G)

(G)

(G)

(G)

(G)

(G)

(G)

(G)

(C) [ ]

(C) [ ]

(C) []

(C) [ ]

(Kg)

(G)

(G)

(G)

(G)

(G)

(G)

(G)

(G)

(G)

(C) [ ]

(C) []

(C) [ ]

(C) [QUART

(litres)

(atm)

(K)

(mol)

$(\mathrm{J} / \mathrm{K})$

$(\mathrm{J} / \mathrm{K})$

(KJ)

(G)

(G)

(G)

(C) [ ]

(C) [ ]

(C) [QUART

$(\mathrm{Kg})$

(G)

(G)

(G)

(C) [ ]

(C) []

(C) [QUART
26.4111

1.0000

951.0000

0.3275

26.8446

111.6552

$-84.2493$

$2.47 \mathrm{E}-0008$

4. 44E-0009

1.26E-0008

$5.21 \mathrm{E}-0006$

$1.85 \mathrm{E}-0006$

$5.81 \mathrm{E}-0008$

1.10E-0008

4. 81E-0009

0.3275

0.2229

0.0136

8.94E-0008

0.0068

0.0250

$3.50 \mathrm{E}-0008$

$1.76 \mathrm{E}-0008$

$8.85 \mathrm{E}-0008$

1.22E-0005

$8.65 \mathrm{E}-0006$

1. $65 \mathrm{E}-0007$

5. $93 \mathrm{E}-0008$

3. $81 \mathrm{E}-0008$

0.4192

0.5210

0.0433

6.51E-0007

0.0164

7.53E-0008 (atm)

$1.36 \mathrm{E}-0008$ (atm)

3.85E-0008 (atm)

$1.59 \mathrm{E}-0005$ (atm)

5.65E-0006 (atm)

$1.77 \mathrm{E}-0007$ (atm)

$3.37 \mathrm{E}-0008$ (atm)

1.47E-0008 (atm)

1.0000 (atm)
$3.58 \mathrm{E}-0004$ (atm)

1.68E-0004 (atm)

0.9995 (atm)

0.3134

0.2159

0.0214

0.0107

0.0250

2. $62 \mathrm{E}-0004$

$2.47 \mathrm{E}-0004$

0.4012

0.5046

0.0680

0.0257 


\subsubsection{Zirconium}

\section{2 wt\% $\mathrm{CuO} / \mathrm{Zr}(2: 1)$}

$\begin{array}{llr}\text { Volume of gas products } & \text { (litres) } & 25.0921 \\ \text { Pressure of gas products } & (\mathrm{atm}) & 1.0000 \\ \text { Temperature } & (\mathrm{K}) & 875.9493 \\ \text { Gas products amount } & (\mathrm{mol}) & 0.3378 \\ \text { Products heat capacity } & (\mathrm{J} / \mathrm{K}) & 26.2483 \\ \text { Products entropy } & (\mathrm{J} / \mathrm{K}) & 11.4921 \\ \text { Products enthalpy } & (\mathrm{KJ}) & -84.2193\end{array}$

Products in molar fraction

$1 \mathrm{Cl} 1 \mathrm{Na} 1$ (G)

$\begin{array}{llll}1 & \mathrm{Cl} & 2 \mathrm{Na} & 2\end{array}$

102

Cl $1 \mathrm{Na} 1$

$\mathrm{Cu} 10 \quad 1$

O $2 \mathrm{Zr} 1$

Products in mass fraction

$\begin{array}{llll}1 & \mathrm{Cl} & 1 \mathrm{Na} & 1\end{array}$

$\begin{array}{llll}1 & \mathrm{Cl} & 2 \mathrm{Na} & 2\end{array}$

102

Cl $1 \mathrm{Na} 1$

$\mathrm{Cu} 10 \quad 1$

o $2 \operatorname{Zr} 1$

\section{6 wt\% $\mathrm{CuO} / \mathrm{Zr}(2: 1)$}

Volume of gas products

Pressure of gas products

Temperature

Gas products amount

Products heat capacity

Products entropy

Products enthalpy

Products in molar fraction

$\begin{array}{llll}1 & \mathrm{Cl} & 3 \mathrm{Na} & 3\end{array}$

$\begin{array}{llll}1 & \mathrm{Cl} & 1 \mathrm{Na} & 1\end{array}$

$1 \mathrm{Cl} 2 \mathrm{Na} 2$

102

Cl $1 \mathrm{Na} 1$

$\mathrm{Cu} 10 \quad 1$

O $2 \mathrm{Zr} 1$

Products in mass fraction

$\begin{array}{llll}1 & \mathrm{Cl} & 3 \mathrm{Na} & 3\end{array}$

$1 \mathrm{Cl} 1 \mathrm{Na} 1$

$\begin{array}{llll}1 & \mathrm{Cl} & 2 \mathrm{Na} & 2\end{array}$

102

Cl $1 \mathrm{Na} 1$

$\mathrm{Cu} 10 \quad 1$

o $2 \mathrm{Zr} 1$

\section{6 wt\% $\mathrm{CuO} / \mathrm{Zr}(2: 1)$}

Volume of gas products

Pressure of gas products

Temperature

(G)

(C) [ ]

(C) []

(C) [ ]

$(\mathrm{Kg})$

(G)

(G)

(G)

(C) [ ]

(C) [ ]

(C) [ ]

(litres)

(atm)

(K)

$(\mathrm{mol})$

$(\mathrm{J} / \mathrm{K})$

$(\mathrm{J} / \mathrm{K})$

$(\mathrm{KJ})$

(G)

(C) [ ]

(C) []

(C) []

( Kg)

(G)

(G)

(C) []

(C) []

(C) [ ]

(litres)

(atm)

(K)

$(\mathrm{mol})$

$(\mathrm{J} / \mathrm{K})$

$(\mathrm{J} / \mathrm{K})$

$(\mathrm{KJ})$

Products enthalpy

Products in molar fraction

$1 \mathrm{Cl} 1 \mathrm{Na} 1$

$\begin{array}{llll}1 & \mathrm{Cl} & 2 \mathrm{Na} & 2\end{array}$

102

$\mathrm{Cl} 1 \mathrm{Na} 1$

$\mathrm{Cu} \quad 10 \quad 1$

O $2 \mathrm{Zr} 1$

(G)

(C) [ ]

(C) [ ]

(C) []

$$
\begin{array}{r}
5.05 \mathrm{E}-0007 \\
1.42 \mathrm{E}-0007 \\
0.3378 \\
0.2274 \\
0.0064 \\
0.0032 \\
0.0250 \\
1.18 \mathrm{E}-0006 \\
6.65 \mathrm{E}-0007 \\
0.4324 \\
0.5315 \\
0.0203 \\
0.0158
\end{array}
$$

$$
\begin{array}{r}
26.9622 \\
1.0000 \\
972.4361 \\
0.3270 \\
26.7486 \\
111.6693 \\
-82.9170
\end{array}
$$

$2.87 \mathrm{E}-0008$

$9.52 \mathrm{E}-0006$

$3.58 \mathrm{E}-0006$

0.3270

0.2217

0.0112

0.0056

0.0250

2.01E-0007

2.23E-0005

1. $67 \mathrm{E}-0005$

0.4185

0.5183

0.0356

0.0276

$$
\begin{array}{rr}
8.78 \mathrm{E}-0008 & \text { (atm) } \\
2.91 \mathrm{E}-0005 & (\mathrm{~atm}) \\
1.09 \mathrm{E}-0005 & (\mathrm{~atm}) \\
1.0000 & (\mathrm{~atm})
\end{array}
$$

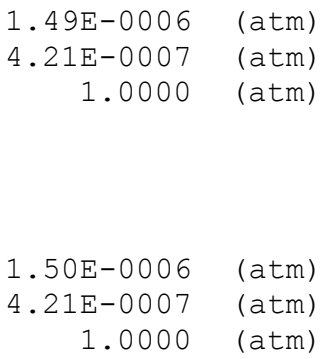

$8.78 \mathrm{E}-0008$ (atm)

$2.91 \mathrm{E}-0005$ (atm)

$1.0000 \quad(\mathrm{~atm})$
28.4923

1.0000

1071.6002

0.3136

27.1755

111.0377

$-81.8192$

$1.07 \mathrm{E}-0004$

5.02E-0005

0.3134

0.2145

0.0172

0.0086 $\begin{array}{rr}3.42 \mathrm{E}-0004 & (\mathrm{~atm}) \\ 1.60 \mathrm{E}-0004 & (\mathrm{~atm}) \\ 0.9995 & (\mathrm{~atm})\end{array}$ 


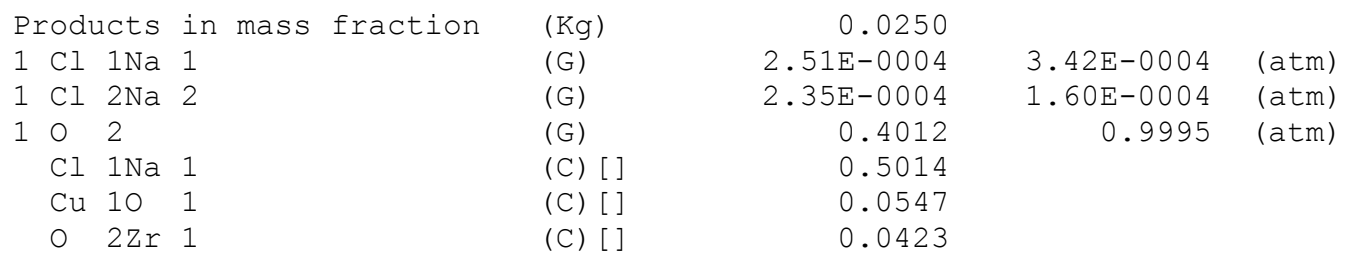

\subsection{Iron (III) Oxide}

\subsubsection{Aluminum}

\section{1 wt\% $\mathrm{Fe}_{2} \mathrm{O}_{3} / \mathrm{Al}(1: 2)$}

Volume of gas products

Pressure of gas products

(litres)

25.9432

(atm)

(K)

Gas products amount

$(\mathrm{mol})$

$(\mathrm{J} / \mathrm{K})$

Products heat capacity

$(\mathrm{J} / \mathrm{K})$

Products entropy

(KJ)

Products in molar fraction

$\begin{array}{llll}1 & \mathrm{Cl} & 1 \mathrm{Na} & 1\end{array}$

(G)

$\begin{array}{llll}1 & \mathrm{Cl} & 2 \mathrm{Na} & 2\end{array}$

(G)

102

Al 203

Cl $1 \mathrm{Na} 1$

Fe 203

Products in mass fraction

$\begin{array}{llll}1 & \mathrm{Cl} & 3 \mathrm{Na} & 3\end{array}$

$\begin{array}{llll}1 & \mathrm{Cl} & 1 \mathrm{Na} & 1\end{array}$

$\begin{array}{llll}1 & \mathrm{Cl} & 2 \mathrm{Na} & 2\end{array}$

102

Al 203

Cl $1 \mathrm{Na} 1$

$\mathrm{Fe} 203$

(C) [ ]

(C) [ ]

(C) []

$(\mathrm{Kg})$

(G)

(G)

(G)

(G)

(C) []

(C) []

(C) [ ]

1.0000

896.6846

0.3412

26.8293

113.2308

$-86.1368$

\section{2 wt\% $\mathrm{Fe}_{2} \mathrm{O}_{3} / \mathrm{Al}(1: 2)$}

Volume of gas products

Pressure of gas products

Temperature

1.02E-0006

$3.09 \mathrm{E}-0007$

0.3412

0.0025

0.2299

0.0025

0.0250

$9.44 \mathrm{E}-0009$

$2.39 \mathrm{E}-0006$

1. $44 \mathrm{E}-0006$

0.4367

0.0100

0.5375

0.0157

$3.00 \mathrm{E}-0006$

$9.04 \mathrm{E}-0007$

(atm)

1.0000

(atm)

(atm)

$$
\begin{array}{rr}
3.94 \mathrm{E}-0009 & (\mathrm{~atm}) \\
3.00 \mathrm{E}-0006 & (\mathrm{~atm}) \\
9.04 \mathrm{E}-0007 & (\mathrm{~atm}) \\
1.0000 & (\mathrm{~atm})
\end{array}
$$

Gas products amount

Products heat capacity

Products entropy

Products enthalpy

Products in molar fraction

$1 \mathrm{Cl} 3 \mathrm{Na} 3$

$\begin{array}{llll}1 & \mathrm{Cl} & 1 \mathrm{Na} & 1\end{array}$

$\begin{array}{llll}1 & \mathrm{Cl} & 2 \mathrm{Na} & 2\end{array}$

102

Al $1 \mathrm{Na} 10 \quad 2$

Al 203

Cl $1 \mathrm{Na} 1$

$\mathrm{Fe} 2 \mathrm{O} 3$

Products in mass fraction

(litres)

27.1607

(atm)

(K)

$(\mathrm{mol})$

$(\mathrm{J} / \mathrm{K})$

$(\mathrm{J} / \mathrm{K})$

(KJ)

1.0000

955.0000

0.3354

27.3654

113.7219

$-86.7178$

(G) $\quad 1.51 \mathrm{E}-0008$

(G) $\quad 5.98 \mathrm{E}-0006$

(G)

(G)

(C) []

$2.15 \mathrm{E}-0006$

0.3354

(C) [ ]

$4.28 \mathrm{E}-0009$

(C) []

0.0037

0.2273

(C) [ ]

(Kg)

0.0037

0.0250

$1 \mathrm{Cl} 3 \mathrm{Na} 3$

$1 \mathrm{Cl} 1 \mathrm{Na} 1$

$\begin{array}{llll}1 & \mathrm{Cl} & 2 \mathrm{Na} & 2\end{array}$

102

Al $1 \mathrm{Na} \quad 1 \mathrm{O} \quad 2$

(G)

(G)

(G)

(G)

(C) []

Al 203

$\mathrm{Cl} 1 \mathrm{Na} 1$

(C) [ ]

(C) []

(C) []

$$
\begin{array}{rr}
4.51 \mathrm{E}-0008 & (\mathrm{~atm}) \\
1.78 \mathrm{E}-0005 & (\mathrm{~atm}) \\
6.40 \mathrm{E}-0006 & (\mathrm{~atm}) \\
1.0000 & (\mathrm{~atm})
\end{array}
$$

$1.06 \mathrm{E}-0007$

1. $40 \mathrm{E}-0005$

1. $00 \mathrm{E}-0005$

0.4293

1.39E-0008

4.51E-0008 (atm)

$1.78 \mathrm{E}-0005$ (atm)

6.40E-0006 (atm)

1.0000 (atm)

0.5315

0.0239 


\section{0 wt\% $\mathrm{Fe}_{2} \mathrm{O}_{3} / \mathrm{Al}(1: 2)$}

Volume of gas products

Pressure of gas products

Temperature

Gas products amount

Products heat capacity

Products entropy

Products enthalpy

Products in molar fraction

$\begin{array}{llll}1 & \mathrm{Cl} & 1 \mathrm{Na} & 1\end{array}$

$\begin{array}{llll}1 & \mathrm{Cl} & 2 \mathrm{Na} & 2\end{array}$

102

Al 203

Cl $1 \mathrm{Na} 1$

$\mathrm{Fe} 203$

Products in mass fraction

$\begin{array}{llll}1 & \mathrm{Cl} & 1 \mathrm{Na} & 1\end{array}$

$1 \mathrm{Cl} 2 \mathrm{Na} 2$

102

Al $20 \quad 3$

$\mathrm{Cl} 1 \mathrm{Na} 1$

$\mathrm{Fe} 203$

$\begin{array}{lr}\text { (litres) } & 29.6659 \\ (\mathrm{~atm}) & 1.0000 \\ (\mathrm{~K}) & 1072.9664 \\ (\mathrm{~mol}) & 0.3261 \\ (\mathrm{~J} / \mathrm{K}) & 28.1411 \\ (\mathrm{~J} / \mathrm{K}) & 114.9914 \\ (\mathrm{KJ}) & -86.9514\end{array}$

1.15E-0004

$5.40 \mathrm{E}-0005$

0.3259

0.0059

0.2229

0.0059

0.0250

$2.69 \mathrm{E}-0004$

$2.52 \mathrm{E}-0004$

0.4171

0.0239

0.5211

0.0374

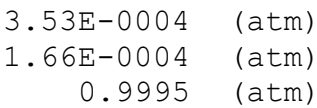

\subsection{Molybdenum Trioxide}

\subsubsection{Aluminum}

\section{9 wt\% $\mathrm{MoO}_{3} / \mathrm{Al}(1: 2)$}

$\begin{array}{llr}\text { Volume of gas products } & \text { (litres) } & 25.2016 \\ \text { Pressure of gas products } & (\mathrm{atm}) & 1.0000 \\ \text { Temperature } & (\mathrm{K}) & 866.0000 \\ \text { Gas products amount } & (\mathrm{mol}) & 0.3432 \\ \text { Products heat capacity } & (\mathrm{J} / \mathrm{K}) & 26.4583 \\ \text { Products entropy } & (\mathrm{J} / \mathrm{K}) & 112.7152 \\ \text { Products enthalpy } & (\mathrm{KJ}) & -86.5927\end{array}$

Products in molar fraction

$1 \mathrm{Cl} 1$

$1 \mathrm{Cl} 2$

$\begin{array}{lllll}1 & \mathrm{Cl} & 2 \mathrm{Mo} & 10 & 2\end{array}$

$1 \mathrm{Cl} 1 \mathrm{Na} 1$

$\begin{array}{llll}1 & \mathrm{Cl} & 2 \mathrm{Na} & 2\end{array}$

$\begin{array}{llll}1 & \mathrm{Cl} & 10 & 1\end{array}$

1 Mo $30 \quad 9$

1 Mo 4012

1 Mo 5015

102

Al 203

Cl $1 \mathrm{Na} 1$

$\mathrm{Mo} \quad 1 \mathrm{Na} 2 \mathrm{O} \quad 4$

Products in mass fraction

$1 \mathrm{Cl} 1$

$\begin{array}{lll}1 & \mathrm{Cl} & 2\end{array}$

$1 \mathrm{Cl} 2 \mathrm{Mo} 10 \quad 2$

$1 \mathrm{Cl} 1 \mathrm{Na} 1$

$\begin{array}{llll}1 & \mathrm{Cl} & 2 \mathrm{Na} & 2\end{array}$

$\begin{array}{llll}1 & \mathrm{Cl} & 10 & 1\end{array}$

1 Mo $30 \quad 9$

1 Mo 4012

1 Mo 5015

102

Al $20 \quad 3$
(G)

(G)

(C) []

(C) [ ]

(C) []

( Kg)

(G)

(G)

(G)

(G)

(C) [ ]
$3.83 \mathrm{E}-0007$

2. $90 \mathrm{E}-0004$

0.0011

3. $63 \mathrm{E}-0007$

$9.88 \mathrm{E}-0008$

3. $13 \mathrm{E}-0008$

2. 30E-0007

1.75E-0007

7.23E-0009

0.3419

0.0024

0.2277

0.0013

0.0250

5. $43 \mathrm{E}-0007$

8.22E-0004

0.0084

$8.49 \mathrm{E}-0007$

4. $62 \mathrm{E}-0007$

$6.44 \mathrm{E}-0008$

$3.96 \mathrm{E}-0006$

$4.04 \mathrm{E}-0006$

2. $08 \mathrm{E}-0007$

0.4376

0.0098
1.11E-0006

8. $44 \mathrm{E}-0004$

0.0031

$1.06 \mathrm{E}-0006$

$2.88 \mathrm{E}-0007$

$9.11 \mathrm{E}-0008$

6. 69 $\mathrm{E}-0007$

5.11E-0007

$2.11 \mathrm{E}-0008$

0.9961

(atm)

(atm)

(atm)

(atm)

(atm)

(atm)

(atm)

(atm)

(atm)

(atm)

$\begin{array}{rr}1.12 E-0006 & (\mathrm{~atm}) \\ 8.44 \mathrm{E}-0004 & (\mathrm{~atm}) \\ 0.0031 & (\mathrm{~atm}) \\ 1.06 \mathrm{E}-0006 & (\mathrm{~atm}) \\ 2.88 \mathrm{t}-0007 & (\mathrm{~atm}) \\ 9.12 \mathrm{E}-0008 & (\mathrm{~atm}) \\ 6.69 \mathrm{t}-0007 & (\mathrm{~atm}) \\ 5.11 \mathrm{t}-0007 & (\mathrm{~atm}) \\ 2.11 \mathrm{E}-0008 & (\mathrm{~atm}) \\ 0.9961 & \text { (atm) }\end{array}$



$\mathrm{Cl} 1 \mathrm{Na} 1$
(C) [ ]
0.5323
Mo $1 \mathrm{Na} 2 \mathrm{O} \quad 4$
(C) [ ]
0.0111

3.1 wto $\mathrm{MoO}_{3} / \mathrm{Al}(1: 2)$

$\begin{array}{llr}\text { Volume of gas products } & \text { (litres) } & 27.7103 \\ \text { Pressure of gas products } & (\mathrm{atm}) & 1.0000 \\ \text { Temperature } & (\mathrm{K}) & 968.3807 \\ \text { Gas products amount } & (\mathrm{mol}) & 0.3375 \\ \text { Products heat capacity } & (\mathrm{J} / \mathrm{K}) & 27.2139 \\ \text { Products entropy } & (\mathrm{J} / \mathrm{K}) & 114.5666 \\ \text { Products enthalpy } & (\mathrm{KJ}) & -86.1577\end{array}$

Products in molar fraction

$1 \mathrm{Cl} 1$

$\begin{array}{lll}1 & \mathrm{Cl} & 2\end{array}$

$1 \mathrm{Cl} 2 \mathrm{Mo} 10 \quad 2$

$\begin{array}{llll}1 & \mathrm{Cl} & 3 \mathrm{Na} & 3\end{array}$

$\begin{array}{llll}1 & \mathrm{Cl} & 1 \mathrm{Na} & 1\end{array}$

$\begin{array}{llll}1 & \mathrm{Cl} & 2 \mathrm{Na} & 2\end{array}$

$\begin{array}{llll}1 & \mathrm{Cl} & 10 & 1\end{array}$

1 Mo $30 \quad 9$

1 Mo 4012

102

Al $20 \quad 3$

Cl $1 \mathrm{Na} 1$

Mo $1 \mathrm{Na} 2 \mathrm{O} 4$

(C) [ ]

(C) []

(L) [ ]

Products in mass fraction

$1 \mathrm{Cl} 1$

$1 \mathrm{Cl} 2$

$1 \mathrm{Cl} 2 \mathrm{Mo} 10 \quad 2$

$\begin{array}{llll}1 & \mathrm{Cl} & 3 \mathrm{Na} & 3\end{array}$

$1 \mathrm{Cl} 1 \mathrm{Na} 1$

$\begin{array}{llll}1 & \mathrm{Cl} & 2 \mathrm{Na} & 2\end{array}$

$\begin{array}{llll}1 & \mathrm{Cl} & 10 & 1\end{array}$

1 Mo 206

1 Mo $30 \quad 9$

1 Mo 4012

1 Mo 5015

102

Al 203

$\mathrm{Cl} 1 \mathrm{Na} 1$

Mo $1 \mathrm{Na} 2 \mathrm{O} 4$

( $\mathrm{Kg})$

(C) [ ]

(C) [ ]

(L) [ ]

4. 30E-0004

0.0017

$2.54 \mathrm{E}-0008$

$8.78 \mathrm{E}-0006$

$3.27 \mathrm{E}-0006$

1. $71 \mathrm{E}-0007$

3. 35E-0007

$8.30 \mathrm{E}-0008$

0.3353

0.0039

0.2232

0.0022

0.0250

4.05E-0006

0.0012

0.0139

$1.78 \mathrm{E}-0007$

$2.05 \mathrm{E}-0005$

1. $53 \mathrm{E}-0005$

$3.52 \mathrm{E}-0007$

$3.67 \mathrm{E}-0008$

$5.79 \mathrm{E}-0006$

1.91E-0006

$4.26 \mathrm{E}-0008$

0.4291

0.0160

0.5218

0.0179

4.9 wt $\% \mathrm{MOO}_{3} / \mathrm{Al}(1: 2)$

Volume of gas products

Pressure of gas products

Temperature

Gas products amount

(litres)

(atm)

(K)

$(\mathrm{mol})$

$(\mathrm{J} / \mathrm{K})$

$(\mathrm{J} / \mathrm{K})$

Products entropy

(KJ)

Products enthalpy

Products in molar fraction

$1 \mathrm{Cl} 2$

(G)

(G)

(G)

(G)

(G)

(C) [ ]

(C) []

(L) [ ]

(Kg)

(G)

(G)

(G)

(G)

(G)

$1 \mathrm{Cl} 2$

$\begin{array}{lllll}1 & \mathrm{Cl} & 2 \mathrm{Mo} & 10 & 2\end{array}$

29.8495

1.0000

1069.9702

0.3290

27.9169

115.5434

$-86.8680$

$\mathrm{Cl} 1 \mathrm{Na} 1$

$\begin{array}{llll}1 & \mathrm{Cl} & 2 \mathrm{Na} & 2\end{array}$

102
$7.02 \mathrm{E}-0004$

0.0027

1.09E-0004

$5.07 \mathrm{E}-0005$

0.3254

0.0062

0.2162

0.0035

0.0250

0.0020

0.0218

$2.54 \mathrm{E}-0004$

$2.37 \mathrm{E}-0004$

0.4165

$$
\begin{array}{rr}
8.46 \mathrm{E}-0006 & (\mathrm{~atm}) \\
0.0013 & (\mathrm{~atm}) \\
0.0052 & (\mathrm{~atm}) \\
7.54 \mathrm{E}-0008 & (\mathrm{~atm}) \\
2.60 \mathrm{E}-0005 & (\mathrm{~atm}) \\
9.68 \mathrm{E}-0006 & (\mathrm{~atm}) \\
5.07 \mathrm{E}-0007 & (\mathrm{~atm}) \\
9.93 \mathrm{E}-0007 & (\mathrm{~atm}) \\
2.46 \mathrm{E}-0007 & (\mathrm{~atm}) \\
0.9935 & \text { (atm) }
\end{array}
$$

$\begin{array}{rr}8.46 \mathrm{E}-0006 & (\mathrm{~atm}) \\ 0.0013 & (\mathrm{~atm}) \\ 0.0052 & (\mathrm{~atm})\end{array}$

$7.54 \mathrm{E}-0008$ (atm)

2. $60 \mathrm{E}-0005$ (atm)

9.68E-0006 (atm)

$5.07 \mathrm{E}-0007$ (atm)

9.43E-0009 (atm)

9.93E-0007 (atm)

2.46E-0007 (atm)

4.39E-0009 (atm)

0.9935 (atm)
0.0021

0.0083

$3.30 \mathrm{E}-0004$

1. $54 \mathrm{E}-0004$

0.9890

0.0021

0.0083

$3.30 \mathrm{E}-0004$

1. $54 \mathrm{E}-0004$

0.9890 (atm)

(atm)

(atm)

(atm)

(atm)

(atm)

(atm)

(atm)

(atm) 

Al 203
(C) [ ]
0.0253
$\mathrm{Cl} 1 \mathrm{Na} 1$
(C) []
0.5055
Mo $1 \mathrm{Na} 2 \mathrm{O} \quad 4$
(L) [ ]
0.0284

\subsubsection{Magnesium}

\section{7 wt\% $\mathrm{MoO}_{3} / \mathrm{Mg}(1: 3)$}

Volume of gas product.

Pressure of gas products

Temperature

Gas products amount

Products heat capacity

Products entropy

Products enthalpy

Products in molar fraction

$1 \mathrm{Cl} 1$

$\begin{array}{llll}1 & \mathrm{Cl} & 1 \mathrm{Na} & 1\end{array}$

$1 \mathrm{Cl} 2 \mathrm{Na} 2$

$\begin{array}{lll}1 & \mathrm{Cl} & 2\end{array}$

102

$\mathrm{Cl} 1 \mathrm{Na} 1$

Mg 1Mo 104

$\begin{array}{lll}M g & 10 & 1\end{array}$

$\mathrm{Mo} 1 \mathrm{Na} 2 \mathrm{O} 4$

Products in mass fraction

$1 \mathrm{Cl} 1 \mathrm{Na} 1$

$\begin{array}{llll}1 & \mathrm{Cl} & 2 \mathrm{Na} & 2\end{array}$

$\begin{array}{lll}1 & \mathrm{Cl} & 2\end{array}$

102

Cl $1 \mathrm{Na} 1$

Mg $1 \mathrm{Mo} 10 \quad 4$

$\begin{array}{lll}M g & 10 & 1\end{array}$

Mo $1 \mathrm{Na} 2 \mathrm{O} \quad 4$

\section{9 wt\% $\mathrm{MoO}_{3} / \mathrm{Mg}(1: 3)$}

Volume of gas product

Pressure of gas products

Temperature

Gas products amount

Products heat capacity

Products entropy

Products enthalpy

Products in molar fraction

$1 \mathrm{Cl} 1$

$\begin{array}{llll}1 & \mathrm{Cl} & 3 \mathrm{Na} & 3\end{array}$

$\begin{array}{llll}1 & \mathrm{Cl} & 1 \mathrm{Na} & 1\end{array}$

$\begin{array}{llll}1 & \mathrm{Cl} & 2 \mathrm{Na} & 2\end{array}$

$\begin{array}{llll}1 & \mathrm{Cl} & 10 & 1\end{array}$

$\begin{array}{lll}1 & \mathrm{Cl} & 2\end{array}$

102

$\mathrm{Cl} 1 \mathrm{Na} 1$

Mg 1Mo 104

$\begin{array}{lll}M g & 10 & 1\end{array}$

Mo $1 \mathrm{Na} 2 \mathrm{O} 4$

Products in mass fraction

$1 \mathrm{Cl} 1$

$1 \mathrm{Cl} 2 \mathrm{Mo} \quad 10 \quad 2$

$\begin{array}{llll}1 & \mathrm{Cl} & 3 \mathrm{Na} & 3\end{array}$

$\begin{array}{llll}1 & \mathrm{Cl} & 1 \mathrm{Na} & 1\end{array}$

$\begin{array}{llll}1 & \mathrm{Cl} & 2 \mathrm{Na} & 2\end{array}$

$\begin{array}{llll}1 & \mathrm{Cl} & 10 & 1\end{array}$

$1 \mathrm{Cl} 2$

102

$\begin{array}{lr}\text { (litres) } & 25.2131 \\ (\mathrm{~atm}) & 1.0000 \\ (\mathrm{~K}) & 866.0000 \\ (\mathrm{~mol}) & 0.3434 \\ (\mathrm{~J} / \mathrm{K}) & 26.4851 \\ (\mathrm{~J} / \mathrm{K}) & 112.7834 \\ (\mathrm{KJ}) & -86.3385\end{array}$

$3.73 \mathrm{E}-0009$

3. $63 \mathrm{E}-0007$

$9.89 \mathrm{E}-0008$

$2.76 \mathrm{E}-0008$

0.3434

0.2309

0.0020

0.0039

(C) []

(C) []

(C) [ ]

(Kg)

(G)

(G)

(G)

(G)

(C) [ ]

(C) []

(C) [ ]

(C) [ ]

$2.96 \mathrm{E}-0008$

0.0250

$8.50 \mathrm{E}-0007$

4. $62 \mathrm{E}-0007$

7. $82 \mathrm{E}-0008$

0.4395

0.5397

0.0145

0.0063

$2.44 \mathrm{E}-000$

$$
\begin{array}{rr}
1.06 \mathrm{E}-0006 & (\mathrm{~atm}) \\
2.88 \mathrm{E}-0007 & (\mathrm{~atm}) \\
8.03 \mathrm{E}-0008 & (\mathrm{~atm}) \\
1.0000 & (\mathrm{~atm})
\end{array}
$$

27.8133

1.0000

973.1565

0.3371

27.3444

114.6215

$-85.9331$

(KJ)

(G)

(C) [ ]

(C) $\quad[]$

(C) [ ]

(L) [ ]

(Kg)

(G)

(G)

(G)

(G)

(G)

(G)

(G)

(G)
$9.69 \mathrm{E}-0008$

3. $04 \mathrm{E}-0008$

1. $00 \mathrm{E}-0005$

$3.77 \mathrm{E}-0006$

$5.75 \mathrm{E}-0009$

4. 26E-0007

0.3371

0.2280

0.0034

0.0067

4. 79E-0007

0.0250

$1.37 \mathrm{E}-0007$

1. $32 \mathrm{E}-0008$

$2.13 \mathrm{E}-0007$

$2.34 \mathrm{E}-0005$

$1.76 \mathrm{E}-0005$

$1.18 \mathrm{E}-0008$

$1.21 \mathrm{E}-0006$

0.4314
$2.87 \mathrm{E}-0007$ (atm)

9.02E-0008 (atm)

2.97E-0005 (atm)

$1.12 \mathrm{E}-0005$ (atm)

$1.71 \mathrm{E}-0008$ (atm)

$1.26 \mathrm{E}-0006$ (atm)

1.0000 (atm) 


$\begin{array}{lllllr}\mathrm{Cl} & 1 \mathrm{Na} & 1 & & \text { (C) [] } & 0.5330 \\ \mathrm{Mg} & 1 \mathrm{Mo} & 10 & 4 & \text { (C) [] } & 0.0247 \\ \mathrm{Mg} & 10 & 1 & & \text { (C) [] } & 0.0108 \\ \mathrm{Mo} & 1 \mathrm{Na} & 20 & 4 & \text { (L) [] } & 3.95 \mathrm{E}-0006\end{array}$

\section{5 wt\% $\mathrm{MoO}_{3} / \mathrm{Mg}(1: 3)$}

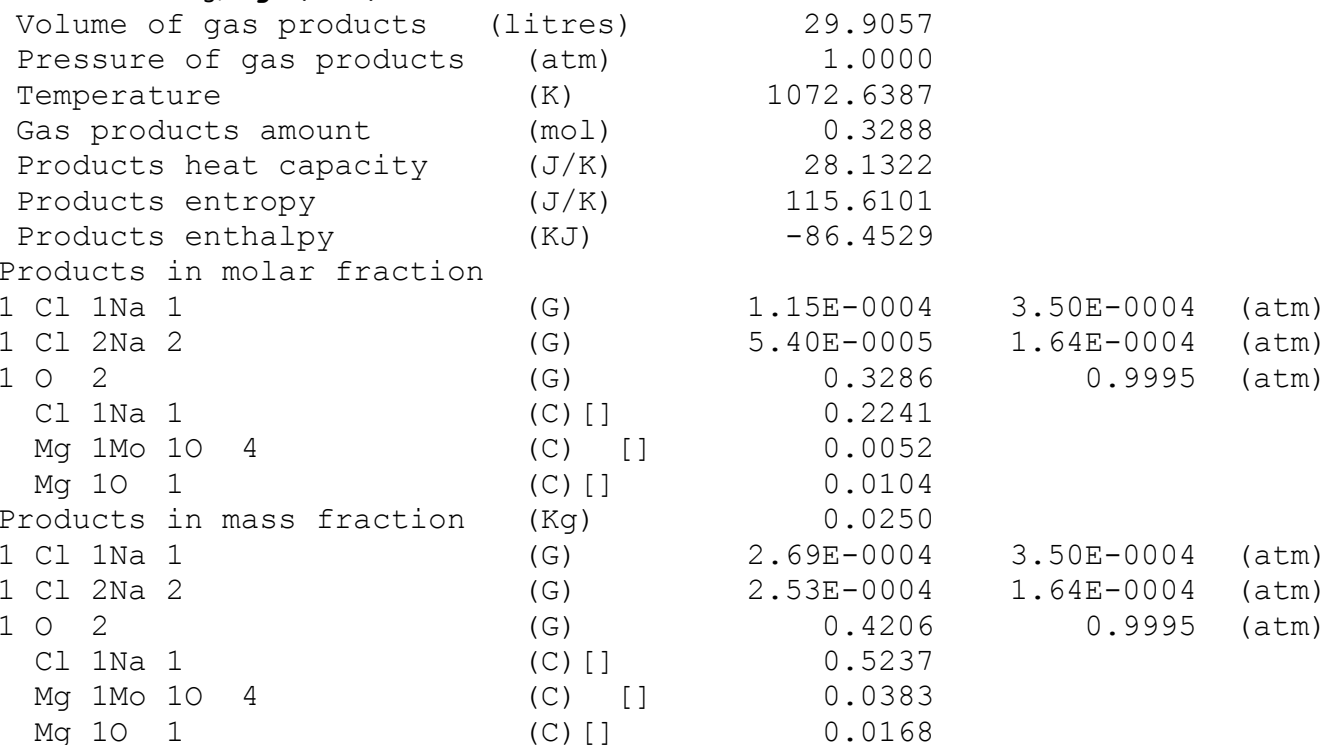

\subsubsection{Magnesium Hydride}

\section{4 wt\% $\mathrm{MoO}_{3} / \mathrm{MgH}_{2}(1: 3)$}

Volume of gas products

Pressure of gas products

Temperature

Gas products amount

Products heat capacity

Products entropy

Products enthalpy

Products in molar fraction

$1 \mathrm{Cl} 1$

$\begin{array}{llll}1 & \mathrm{Cl} & 1 \mathrm{Na} & 1\end{array}$

$\begin{array}{llll}1 & \mathrm{Cl} & 2 \mathrm{Na} & 2\end{array}$

$1 \mathrm{Cl} 2$

$\begin{array}{llll}1 & \mathrm{H} & 2 \mathrm{O} & 1\end{array}$

$\begin{array}{llll}1 & \mathrm{Cl} & 1 \mathrm{H} & 1\end{array}$

102

$\mathrm{Cl} 1 \mathrm{Na} 1$

Mg 1Mo $10 \quad 4$

$\begin{array}{lll}M g & 10 & 1\end{array}$

Mo $1 \mathrm{Na} \quad 2 \mathrm{O} \quad 4$

Products in mass fraction

$1 \mathrm{Cl} 1 \mathrm{Na} 1$

$\begin{array}{llll}1 & \mathrm{Cl} & 2 \mathrm{Na} & 2\end{array}$

$1 \mathrm{Cl} 2$

$\begin{array}{llll}1 & \mathrm{H} & 2 \mathrm{O} & 1\end{array}$

$\begin{array}{llll}1 & \mathrm{Cl} & 1 \mathrm{H} & 1\end{array}$

102

Cl $1 \mathrm{Na} 1$

Mg $1 \mathrm{Mo} 104$

$\begin{array}{lll}M g & 10 & 1\end{array}$

Mo $1 \mathrm{Na} 2 \mathrm{O}$

2.3 wt $\% \mathrm{MoO}_{3} / \mathrm{MgH}_{2} \quad(1: 3)$

$\begin{array}{lr}\text { (litres) } & 25.5078 \\ (\mathrm{~atm}) & 1.0000 \\ (\mathrm{~K}) & 866.0000 \\ (\mathrm{~mol}) & 0.3474 \\ (\mathrm{~J} / \mathrm{K}) & 26.5926 \\ (\mathrm{~J} / \mathrm{K}) & 113.8219 \\ (\mathrm{KJ}) & -86.6770\end{array}$

$3.77 \mathrm{E}-0009$

3. $68 \mathrm{E}-0007$

1. $00 \mathrm{E}-0007$

$2.77 \mathrm{E}-0008$

0.0047

$1.14 \mathrm{E}-0005$

0.3427

0.2316

0.0016

$\begin{array}{lr}\text { (C) }[] & 0.0031 \\ \text { (C) }[] & 0.718 .0006\end{array}$

(C) [ ]

$(\mathrm{Kg})$

(G)

(G)

(G)

(G)

(G)

(G)

(C) [ ]

(C) []

(C) []

(C) [ ]
$1.08 \mathrm{E}-0008$ (atm)

$1.06 \mathrm{E}-0006$ (atm)

$2.88 \mathrm{E}-0007$ (atm)

7.99E-0008 (atm)

0.0135 (atm)

$3.27 \mathrm{E}-0005$ (atm)

0.9864 (atm)
$1.06 \mathrm{E}-0006$ (atm)

$2.88 \mathrm{E}-0007$ (atm)

7.98E-0008 (atm)

$0.0135 \quad(\mathrm{~atm})$

$3.27 \mathrm{E}-0005$ (atm)

0.9864 (atm) 


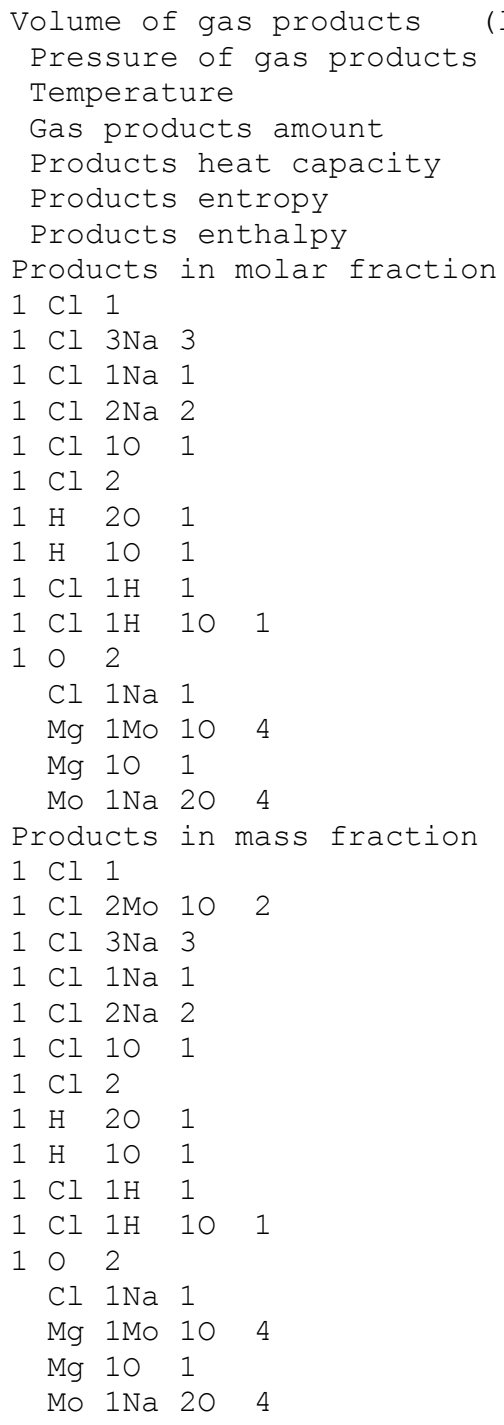

\section{7 wt $\% \mathrm{MoO}_{3} / \mathrm{MgH}_{2} \quad(1: 3)$}

Volume of gas products
Pressure of gas products
Temperature
Gas products amount
Products heat capacity
Products entropy
Products enthalpy
Products in molar fraction
$1 \mathrm{Cl} 1 \mathrm{Na} 1$
$1 \mathrm{Cl} 2 \mathrm{Na} 2$
$1 \mathrm{H} 2 \mathrm{O} 1$
$1 \mathrm{Cl} 1 \mathrm{H} 1$
$1 \mathrm{O} 2$
$\mathrm{Cl} 1 \mathrm{Na} 1$
$\mathrm{Mg} 1 \mathrm{MO} 10 \quad 4$
$\mathrm{Mg} 1 \mathrm{O} 1$
$\mathrm{Mo} 1 \mathrm{Na} 2 \mathrm{O} 4$
$\mathrm{Products}$ in mass fraction
$1 \mathrm{Cl} 1 \mathrm{Na} 1$
$1 \mathrm{Cl} 2 \mathrm{Na} 2$
$1 \mathrm{H} 2 \mathrm{O} 1$
$1 \mathrm{Cl} 1 \mathrm{H} 1$
$1 \mathrm{O} 2$

$$
\begin{array}{r}
28.1729 \\
1.0000 \\
965.1667 \\
0.3443 \\
27.4651 \\
116.2139 \\
-86.4602
\end{array}
$$

$$
\begin{array}{rrr}
7.81 \mathrm{E}-0008 & 2.27 \mathrm{E}-0007 & \text { (atm) } \\
2.30 \mathrm{E}-0008 & 6.67 \mathrm{E}-0008 & \text { (atm) } \\
8.19 \mathrm{E}-0006 & 2.38 \mathrm{E}-0005 & \text { (atm) } \\
3.02 \mathrm{E}-0006 & 8.78 \mathrm{E}-0006 & \text { (atm) } \\
4.68 \mathrm{E}-0009 & 1.36 \mathrm{E}-0008 & \text { (atm) } \\
3.49 \mathrm{E}-0007 & 1.01 \mathrm{E}-0006 & (\mathrm{~atm}) \\
0.0077 & 0.0224 & (\mathrm{~atm}) \\
1.36 \mathrm{E}-0008 & 3.94 \mathrm{E}-0008 & (\mathrm{~atm}) \\
7.86 \mathrm{E}-0005 & 2.28 \mathrm{E}-0004 & (\mathrm{~atm}) \\
1.40 \mathrm{E}-0008 & 4.07 \mathrm{E}-0008 & \text { (atm) } \\
0.3365 & 0.9774 & \text { (atm) }
\end{array}
$$$$
\begin{array}{lr}
\text { (G) } & 0.0077 \\
\text { (G) } & 1.36 \mathrm{E}-0008
\end{array}
$$$$
\begin{array}{ll}
\text { (G) } & 1.36 \mathrm{E}-0008 \\
\text { (G) } & 7.86 \mathrm{E}-0005
\end{array}
$$$$
\text { (G) } \quad 1.40 \mathrm{E}-0008
$$

(C) []

(C) [ ]

(L) [ ]

( Kg )

(G)

(C) [ ]

(C) []

(C) [ ]

(L) [ ]

0.2294

0.0025

0.0052

$3.97 \mathrm{E}-0005$

0.0250

1.11E-0007

$9.29 \mathrm{E}-0009$

1. $61 \mathrm{E}-0007$

1.91E-0005

1. $41 \mathrm{E}-0005$

$9.64 \mathrm{E}-0009$

9.91E-0007

0.0055

9.22E-0009

$1.15 \mathrm{E}-0004$

$2.94 \mathrm{E}-0008$

0.4307

0.5362

0.0187

0.0084

$3.27 E-0004$

$\begin{array}{rr}2.27 \mathrm{E}-0007 & (\mathrm{~atm}) \\ 3.39 \mathrm{E}-0009 & (\mathrm{~atm}) \\ 6.67 \mathrm{E}-0008 & (\mathrm{~atm}) \\ 2.38 \mathrm{E}-0005 & (\mathrm{~atm}) \\ 8.78 \mathrm{E}-0006 & (\mathrm{~atm}) \\ 1.36 \mathrm{t}-0008 & (\mathrm{~atm}) \\ 1.01 \mathrm{E}-0006 & (\mathrm{~atm}) \\ 0.0224 & (\mathrm{~atm}) \\ 3.94 \mathrm{E}-0008 & (\mathrm{~atm}) \\ 2.28 \mathrm{E}-0004 & (\mathrm{~atm}) \\ 4.07 \mathrm{t}-0008 & (\mathrm{~atm}) \\ 0.9774 & (\mathrm{~atm})\end{array}$

$\begin{array}{lr}(\mathrm{atm}) & 30.9235 \\ (\mathrm{~K}) & 1.0000 \\ (\mathrm{~mol}) & 1073.5692 \\ (\mathrm{~J} / \mathrm{K}) & 0.3397 \\ (\mathrm{~J} / \mathrm{K}) & 28.4489 \\ (\mathrm{KJ}) & 118.4110 \\ & -87.1790\end{array}$

(G)

(G)

(G)

(G)

(G)

(C) [ ]

(C) [ ]

(C) [ ]

(L) [ ]

(Kg)

(G)

(G)

(G)

(G)

(G)

$$
\begin{array}{rrr}
1.22 \mathrm{E}-0004 & 3.58 \mathrm{E}-0004 & (\mathrm{~atm}) \\
5.71 \mathrm{E}-0005 & 1.68 \mathrm{E}-0004 & (\mathrm{~atm}) \\
0.0122 & 0.0359 & (\mathrm{~atm}) \\
5.12 \mathrm{E}-0004 & 0.0015 & (\mathrm{~atm}) \\
0.3268 & 0.9621 & (\mathrm{~atm}) \\
0.2254 & & \\
0.0039 & & \\
0.0086 & & \\
2.61 \mathrm{E}-0004 & & \\
0.0250 & & \\
2.84 \mathrm{E}-0004 & 3.57 \mathrm{E}-0004 & (\mathrm{~atm}) \\
2.67 \mathrm{E}-0004 & 1.68 \mathrm{E}-0004 & (\mathrm{~atm}) \\
0.0088 & 0.0359 & (\mathrm{~atm}) \\
7.47 \mathrm{E}-0004 & 0.0015 & (\mathrm{~atm}) \\
0.4183 & 0.9621 & (\mathrm{~atm})
\end{array}
$$




$\begin{array}{llllll}\mathrm{Cl} & 1 \mathrm{Na} & 1 & & \text { (C) [] } & 0.5270 \\ \mathrm{Mg} & 1 \mathrm{Mo} & 10 & 4 & \text { (C) [] } & 0.0287 \\ \mathrm{Mg} & 10 & 1 & & \text { (C) [] } & 0.0138 \\ \mathrm{Mo} & 1 \mathrm{Na} & 20 & 4 & \text { (L) [] } & 0.0022\end{array}$

\subsubsection{Silicon}

\section{$2.2 \mathrm{wt} \div \mathrm{MoO}_{3} / \mathrm{Si}(2: 3)$}

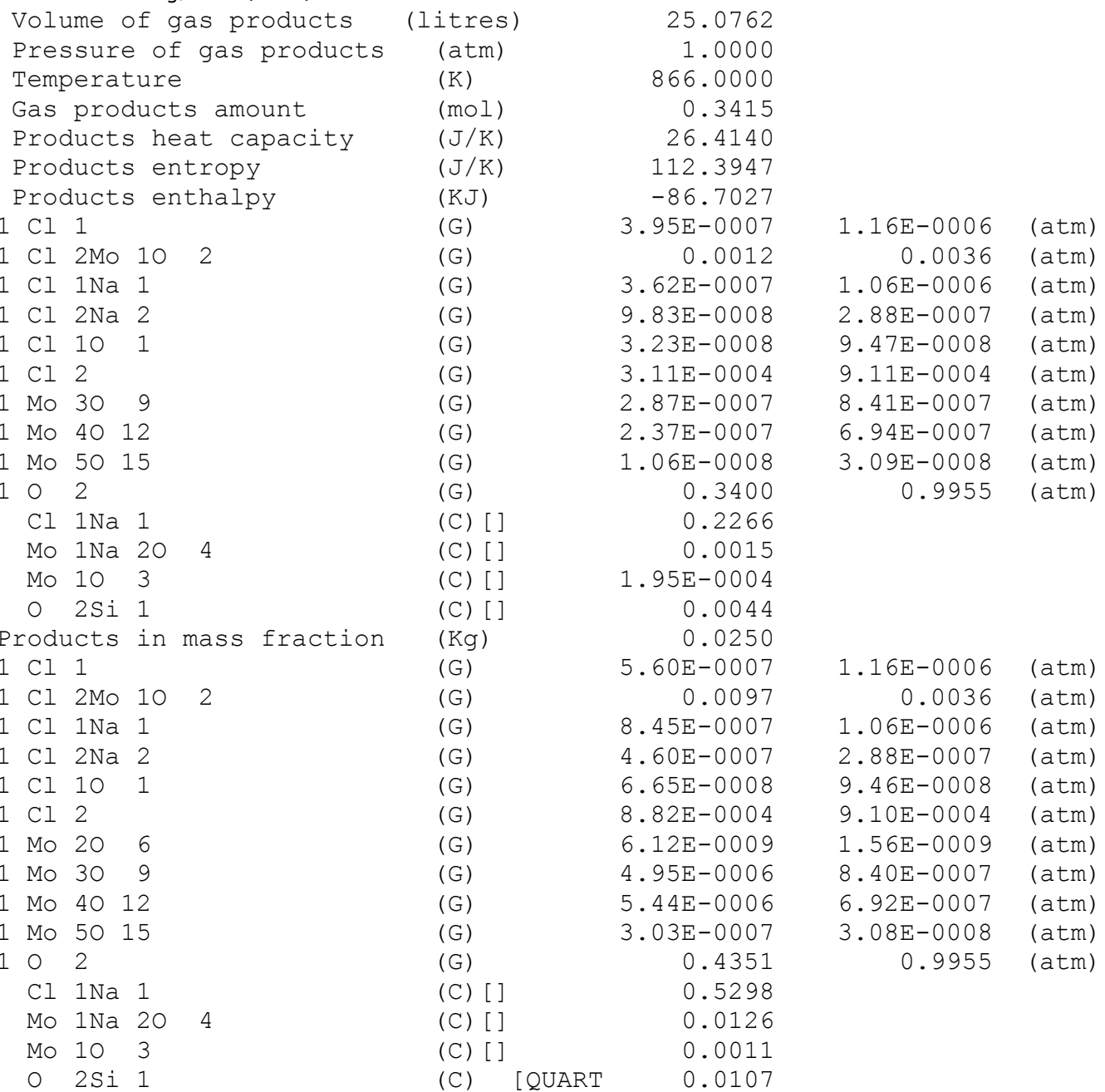

\section{8 wt\% $\mathrm{MoO}_{3} / \mathrm{Si}(2: 3)$}

$\begin{array}{llr}\text { Volume of gas products } & \text { (litres) } & 27.7398 \\ \text { Pressure of gas products } & (\mathrm{atm}) & 1.0000 \\ \text { Temperature } & (\mathrm{K}) & 980.0000 \\ \text { Gas products amount } & (\mathrm{mol}) & 0.3338 \\ \text { Products heat capacity } & (\mathrm{J} / \mathrm{K}) & 27.2063 \\ \text { Products entropy } & (\mathrm{J} / \mathrm{K}) & 114.2040 \\ \text { Products enthalpy } & (\mathrm{KJ}) & -86.3444\end{array}$

Products in molar fraction

$1 \mathrm{Cl} 1$

$\begin{array}{lllll}1 & \mathrm{Cl} & 2 \mathrm{Mo} & 10 & 2\end{array}$

$\begin{array}{llll}1 & \mathrm{Cl} & 3 \mathrm{Na} & 3\end{array}$

$\begin{array}{llll}1 & \mathrm{Cl} & 1 \mathrm{Na} & 1\end{array}$

$\begin{array}{llll}1 & \mathrm{Cl} & 2 \mathrm{Na} & 2\end{array}$

$\begin{array}{llll}1 & \mathrm{Cl} & 10 & 1\end{array}$

$1 \mathrm{Cl} 2$

1 Mo 206
(G)
$3.70 \mathrm{E}-0006$
0.0023
$3.88 \mathrm{E}-0008$
$1.20 \mathrm{E}-0005$
4. 58E-0006
$2.15 \mathrm{E}-0007$
$5.08 \mathrm{E}-0004$
4. $67 \mathrm{E}-0009$

$\begin{array}{rr}1.11 \mathrm{E}-0005 & (\mathrm{~atm}) \\ 0.0069 & (\mathrm{~atm}) \\ 1.16 \mathrm{E}-0007 & (\mathrm{~atm}) \\ 3.58 \mathrm{E}-0005 & (\mathrm{~atm}) \\ 1.37 \mathrm{E}-0005 & (\mathrm{~atm}) \\ 6.44 \mathrm{E}-0007 & (\mathrm{~atm}) \\ 0.0015 & (\mathrm{~atm}) \\ 1.40 \mathrm{E}-0008 & (\mathrm{~atm})\end{array}$




\begin{tabular}{|c|c|c|c|c|}
\hline \multicolumn{5}{|c|}{1 M० 309} \\
\hline $1 \mathrm{Mo}$ & 40 & 12 & & \\
\hline 0 & 2 & & & \\
\hline $\mathrm{Cl}$ & $1 \mathrm{Na}$ & 1 & & \\
\hline Mo & $1 \mathrm{Na}$ & 20 & 4 & \\
\hline 0 & $2 \mathrm{Si}$ & 1 & & \\
\hline Produ & acts & in & mass & fraction \\
\hline $1 \mathrm{Cl}$ & 1 & & & \\
\hline $1 \mathrm{Cl}$ & $2 \mathrm{Mo}$ & 10 & 2 & \\
\hline $1 \mathrm{Cl}$ & $3 \mathrm{Na}$ & 3 & & \\
\hline $1 \mathrm{Cl}$ & $1 \mathrm{Na}$ & 1 & & \\
\hline $1 \mathrm{Cl}$ & $2 \mathrm{Na}$ & 2 & & \\
\hline $1 \mathrm{Cl}$ & 10 & 1 & & \\
\hline $1 \mathrm{Cl}$ & 2 & & & \\
\hline 1 Mo & 20 & 6 & & \\
\hline $1 \mathrm{Mo}$ & 30 & 9 & & \\
\hline 1 Mo & 40 & 12 & & \\
\hline 1 Mo & 50 & 15 & & \\
\hline 10 & 2 & & & \\
\hline $\mathrm{Cl}$ & $1 \mathrm{Na}$ & 1 & & \\
\hline Mo & $1 \mathrm{Na}$ & 20 & 4 & \\
\hline 0 & $2 \mathrm{Si}$ & 1 & & \\
\hline 0 & $2 \mathrm{Si}$ & 1 & & \\
\hline
\end{tabular}

$\begin{array}{lrrr}\text { (G) } & 4.64 \mathrm{E}-0007 & 1.39 \mathrm{E}-0006 & (\mathrm{~atm}) \\ \text { (G) } & 1.14 \mathrm{E}-0007 & 3.40 \mathrm{E}-0007 & (\mathrm{~atm}) \\ \text { (G) } & 0.3310 & 0.9915 & (\mathrm{~atm}) \\ \text { (C) [ ] } & 0.2203 & & \\ \text { (L) [ ] } & 0.0028 & & \\ \text { (C) [ ] } & 0.0077 & & \\ (\mathrm{Kg}) & 0.0250 & & \\ \text { (G) } & 5.26 \mathrm{E}-0006 & 1.11 \mathrm{E}-0005 & (\mathrm{~atm}) \\ \text { (G) } & 0.0183 & 0.0069 & (\mathrm{~atm}) \\ \text { (G) } & 2.72 \mathrm{E}-0007 & 1.16 \mathrm{E}-0007 & (\mathrm{~atm}) \\ \text { (G) } & 2.79 \mathrm{E}-0005 & 3.58 \mathrm{E}-0005 & (\mathrm{~atm}) \\ \text { (G) } & 2.14 \mathrm{E}-0005 & 1.37 \mathrm{E}-0005 & (\mathrm{~atm}) \\ \text { (G) } & 4.42 \mathrm{E}-0007 & 6.44 \mathrm{E}-0007 & (\mathrm{~atm}) \\ \text { (G) } & 0.0014 & 0.0015 & (\mathrm{~atm}) \\ \text { (G) } & 5.37 \mathrm{E}-0008 & 1.40 \mathrm{E}-0008 & (\mathrm{~atm}) \\ \text { (G) } & 8.02 \mathrm{E}-0006 & 1.39 \mathrm{E}-0006 & (\mathrm{~atm}) \\ \text { (G) } & 2.61 \mathrm{E}-0006 & 3.40 \mathrm{E}-0007 & (\mathrm{~atm}) \\ \text { (G) } & 5.92 \mathrm{E}-0008 & 6.16 \mathrm{E}-0009 & (\mathrm{~atm}) \\ \text { (G) } & 0.4237 & 0.9915 & (\mathrm{~atm}) \\ \text { (C) [ ] } & 0.5150 & & \\ \text { (L) [ ] } & 0.0231 & & \\ \text { (C) [ ] } & 1.83 \mathrm{E}-0005 & & \\ \text { (C) [QUART } & 0.0184 & & \end{array}$

\section{8 wt\% $\mathrm{MoO}_{3} / \mathrm{Si}(2: 3)$}

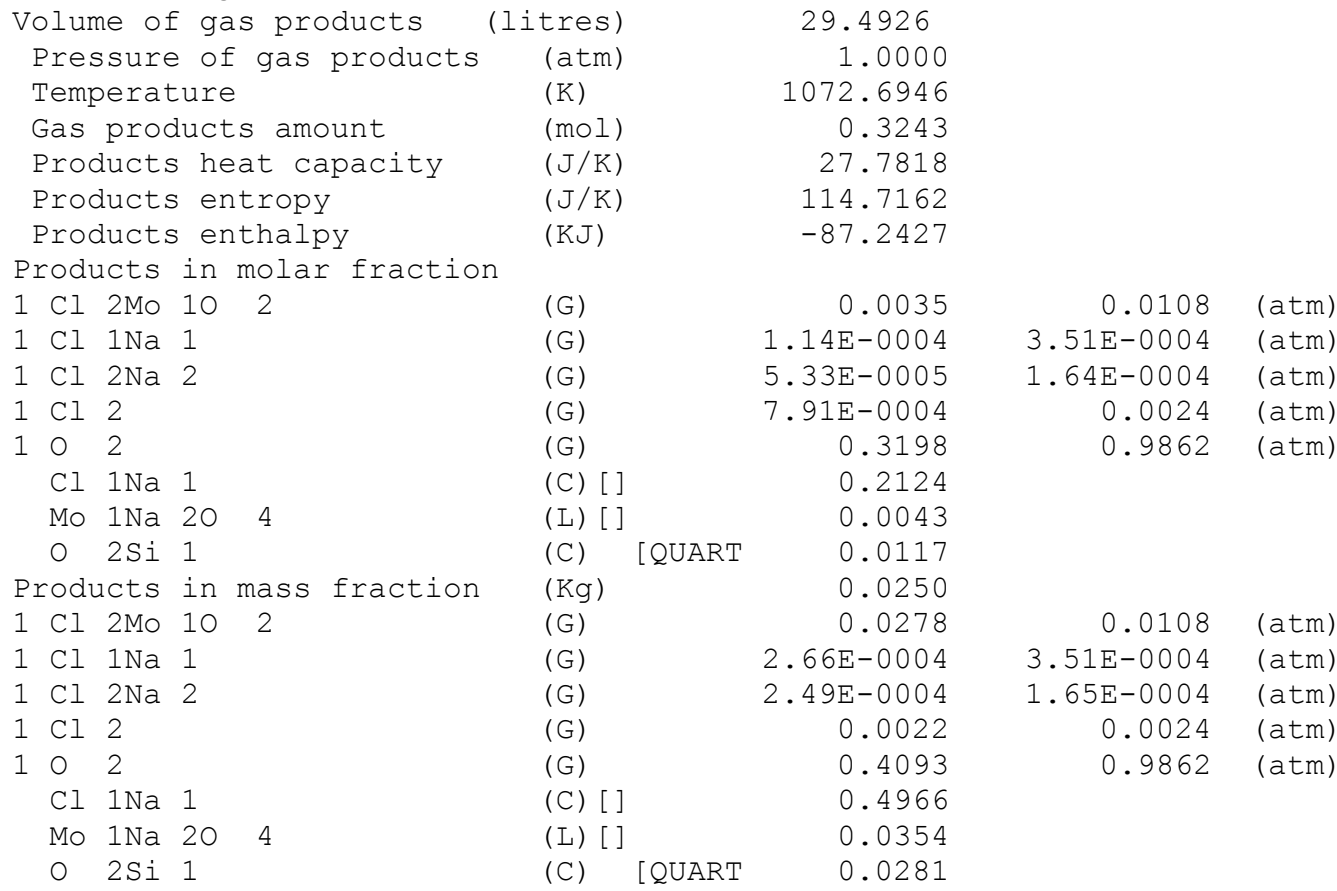

\subsubsection{Zirconium}

\section{8 wt $\% \mathrm{MoO}_{3} / \mathrm{Zr}(2: 3)$}

Volume of gas products

Pressure of gas products

Temperature

Gas products amount

Products heat capacity

Products entropy

Products enthalpy

Products in molar fraction

$1 \mathrm{Cl} 1$

( litres)
$(\mathrm{atm})$
$(\mathrm{K})$
$(\mathrm{mol})$
$(\mathrm{J} / \mathrm{K})$
$(\mathrm{J} / \mathrm{K})$
$(\mathrm{KJ})$

(G)

$$
\begin{array}{r}
25.6509 \\
1.0000 \\
889.8930 \\
0.3400 \\
26.3761 \\
112.4613 \\
-85.3635
\end{array}
$$

$6.17 \mathrm{E}-0007$
$1.82 \mathrm{E}-0006 \quad$ (atm) 


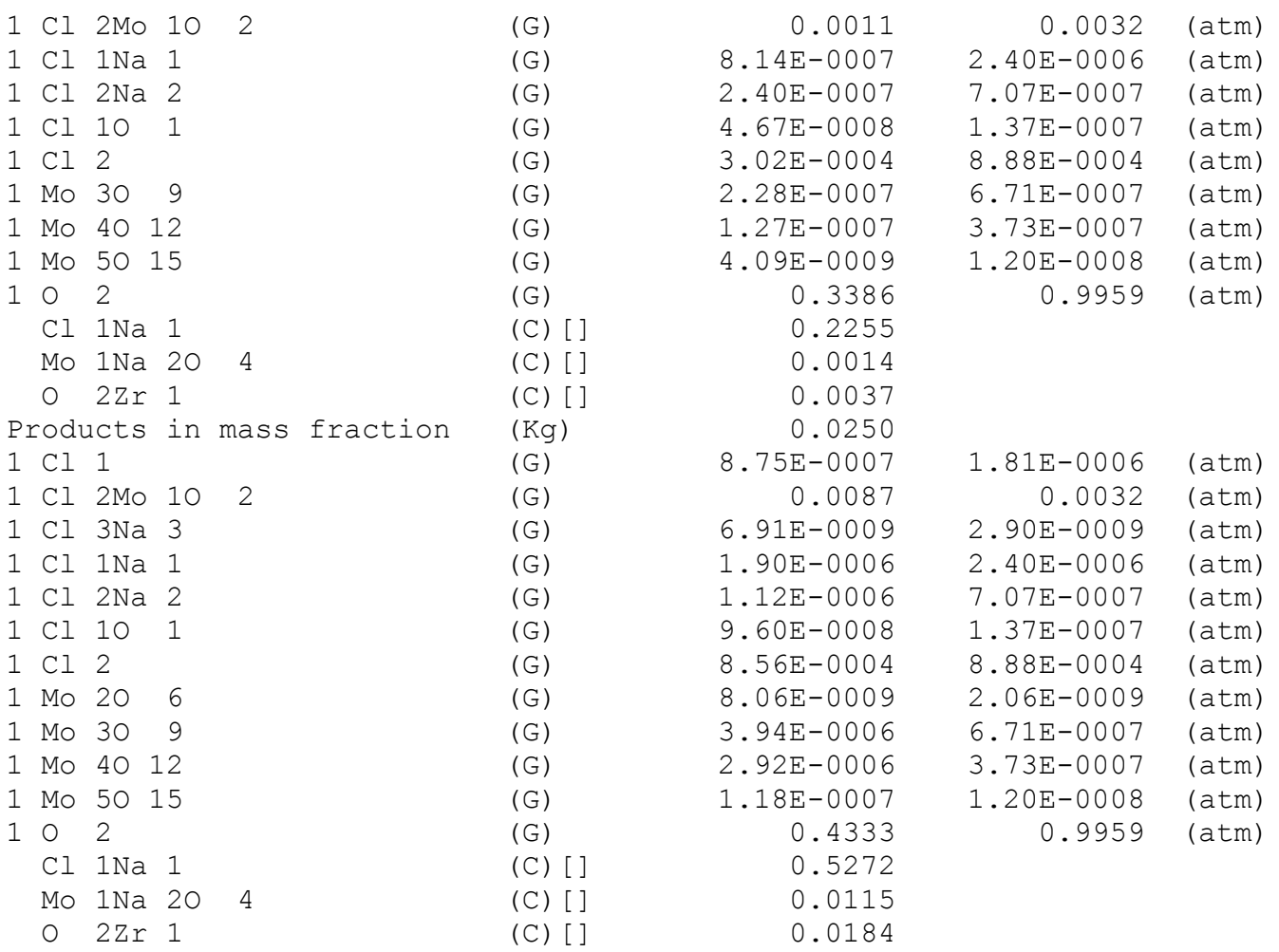

\section{6 wt\% $\mathrm{MoO}_{3} / \mathrm{Zr}(2: 3)$}

\begin{tabular}{|c|c|c|c|c|c|c|}
\hline \multirow{3}{*}{\multicolumn{3}{|c|}{$\begin{array}{l}\text { Volume of gas products } \\
\text { Pressure of gas products } \\
\text { Temperature }\end{array}$}} & (litres) & 27.5275 & & \\
\hline & & & $(a t m)$ & 1.0000 & & \\
\hline & & & $(\mathrm{K})$ & 977.8034 & & \\
\hline \multicolumn{3}{|c|}{ Gas products amount } & $(\mathrm{mol})$ & 0.3320 & & \\
\hline \multicolumn{3}{|c|}{ Products heat capacity } & $(\mathrm{J} / \mathrm{K})$ & 26.8653 & & \\
\hline \multirow{2}{*}{\multicolumn{3}{|c|}{$\begin{array}{l}\text { Products entropy } \\
\text { Products enthalpy }\end{array}$}} & $(\mathrm{J} / \mathrm{K})$ & 113.1642 & & \\
\hline \multicolumn{6}{|c|}{$\begin{array}{l}\text { Products enthalpy } \\
\text { roducts in molar fraction }\end{array}$} & \\
\hline Cl 1 & .11 & & (G) & $3.36 \mathrm{E}-0006$ & $1.01 \mathrm{E}-0005$ & $(\mathrm{~atm})$ \\
\hline $\mathrm{Cl} 2 \mathrm{Mo}$ & 10 & 2 & (G) & 0.0018 & 0.0055 & (atm) \\
\hline $\mathrm{Cl} 3 \mathrm{Na}$ & 3 & & (G) & $3.56 \mathrm{E}-0008$ & $1.07 \mathrm{E}-0007$ & $(\mathrm{~atm})$ \\
\hline $\mathrm{Cl} 1 \mathrm{Na}$ & 1 & & (G) & $1.12 \mathrm{E}-0005$ & $3.37 E-0005$ & $(\mathrm{~atm})$ \\
\hline $\mathrm{Cl} 2 \mathrm{Na}$ & 2 & & (G) & $4.27 E-0006$ & $1.29 \mathrm{E}-0005$ & (atm) \\
\hline $\mathrm{Cl} 10$ & 1 & & (G) & $1.96 \mathrm{E}-0007$ & $5.90 \mathrm{E}-0007$ & $(\mathrm{~atm})$ \\
\hline $\mathrm{Cl} 2$ & & & (G) & $4.48 E-0004$ & 0.0013 & $(\mathrm{~atm})$ \\
\hline Mo 20 & 6 & & (G) & $3.63 E-0009$ & $1.09 \mathrm{E}-0008$ & (atm) \\
\hline Mo 30 & 9 & & (G) & $3.35 E-0007$ & $1.01 \mathrm{E}-0006$ & (atm) \\
\hline Mo 40 & 12 & & (G) & 7. $53 \mathrm{E}-0008$ & $2.27 \mathrm{E}-0007$ & $(\mathrm{~atm})$ \\
\hline 02 & & & (G) & 0.3297 & 0.9931 & (atm) \\
\hline $\mathrm{Cl} 1 \mathrm{Na}$ & 1 & & (C) [ ] & 0.2195 & & \\
\hline $\mathrm{Mo} \quad 1 \mathrm{Na}$ & 20 & 4 & $(\mathrm{~L})$ [ ] & 0.0023 & & \\
\hline $0 \quad 2 \mathrm{Zr}$ & $=1$ & & (C) [] & 0.0061 & & \\
\hline roducts & in & mass fraction & $(\mathrm{Kg})$ & 0.0250 & & \\
\hline $\mathrm{Cl} 1$ & & & (G) & $4.76 \mathrm{E}-0006$ & $1.01 E-0005$ & (atm) \\
\hline $\mathrm{Cl} 2 \mathrm{Mo}$ & 10 & 2 & (G) & 0.0145 & 0.0055 & $(\mathrm{~atm})$ \\
\hline $\mathrm{Cl} 3 \mathrm{Na}$ & 3 & & (G) & $2.50 \mathrm{E}-0007$ & $1.07 \mathrm{E}-0007$ & (atm) \\
\hline $\mathrm{Cl} 1 \mathrm{Na}$ & 1 & & (G) & $2.62 \mathrm{E}-0005$ & $3.37 E-0005$ & $(\mathrm{~atm})$ \\
\hline $\mathrm{Cl} 2 \mathrm{Na}$ & 2 & & (G) & $1.99 \mathrm{E}-0005$ & $1.28 \mathrm{E}-0005$ & (atm) \\
\hline Cl 10 & 1 & & (G) & $4.03 E-0007$ & $5.90 \mathrm{E}-0007$ & (atm) \\
\hline $\mathrm{Cl} 2$ & & & (G) & 0.0013 & 0.0014 & (atm) \\
\hline Mo 20 & 6 & & (G) & $4.18 \mathrm{E}-0008$ & $1.09 \mathrm{E}-0008$ & $(\mathrm{~atm})$ \\
\hline Mo 30 & 9 & & (G) & $5.78 \mathrm{E}-0006$ & $1.01 E-0006$ & (atm) \\
\hline Mo 40 & 12 & & (G) & $1.73 E-0006$ & $2.27 E-0007$ & (atm) \\
\hline Mo 50 & 15 & & (G) & $3.59 \mathrm{E}-0008$ & $3.75 E-0009$ & $(\mathrm{~atm})$ \\
\hline 02 & & & (G) & 0.4220 & 0.9931 & (atm) \\
\hline
\end{tabular}



Cl $1 \mathrm{Na} 1$
(C) []
0.5131
Mo $1 \mathrm{Na} 2 \mathrm{O} \quad 4$
(L) [ ]
0.0187
O $2 \mathrm{Zr} 1$
(C) []
0.0303

7.0 wt\% $\mathrm{MoO}_{3} / \mathrm{Zr}(2: 3)$

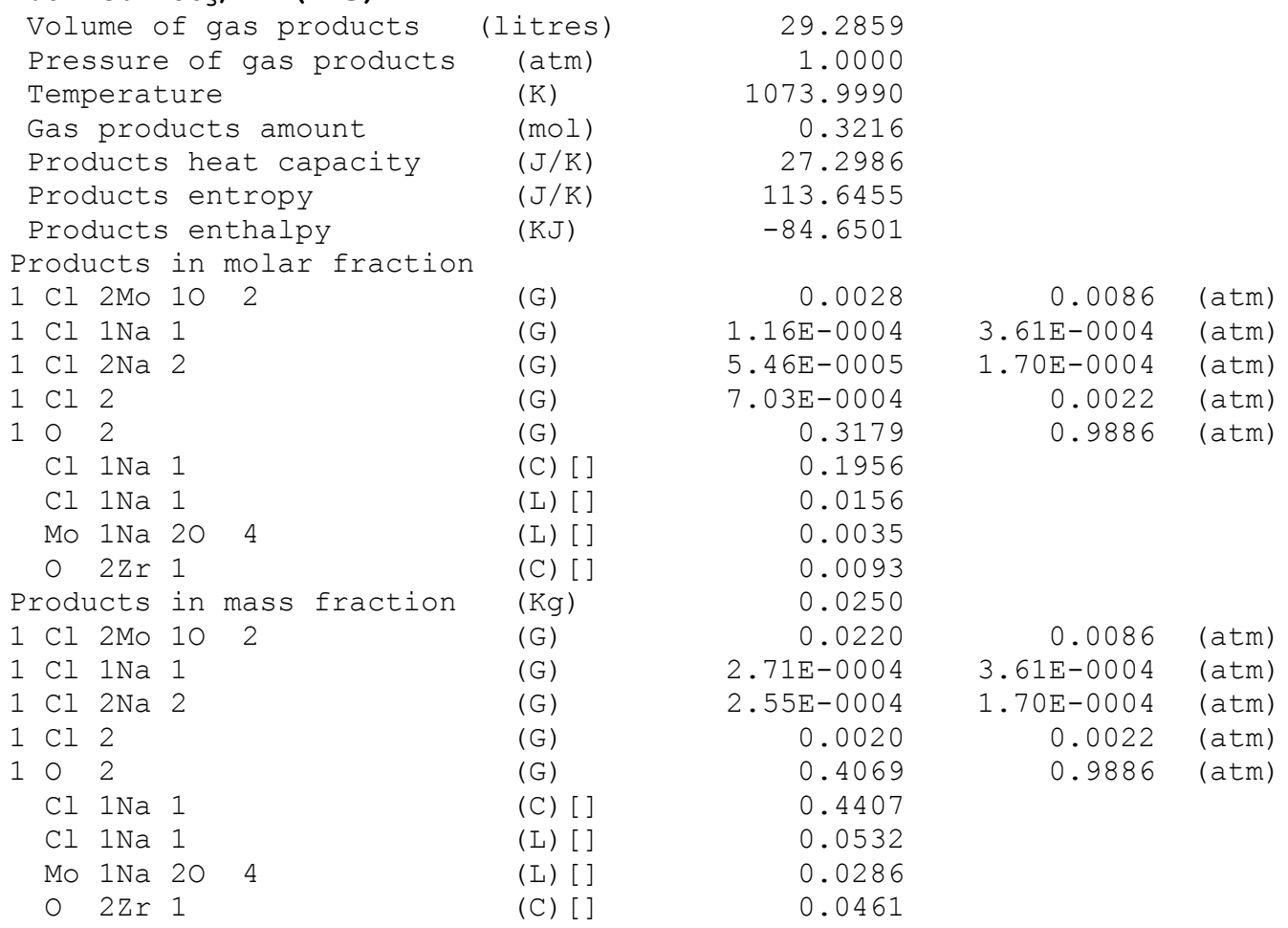

\subsection{Sodium Nitrate}

\subsubsection{Aluminum}

1.2 wt\% $\mathrm{NaNO}_{3} / \mathrm{Al}(1: 2)$

Volume of gas products

Pressure of gas products

Temperature

Gas products amount

Products heat capacity

Products entropy

Products enthalpy

Products in molar fraction

$1 \mathrm{Cl} 1 \mathrm{Na} 1$

$1 \mathrm{Cl} 2 \mathrm{Na} 2$

$1 \mathrm{~N} 2$

$\begin{array}{lllll}1 & \mathrm{~N} & 1 \mathrm{Na} & 10 & 3\end{array}$

$1 \mathrm{~N} \quad 10 \quad 1$

$\begin{array}{llll}1 & \mathrm{~N} & 10 & 2\end{array}$

102

Al $1 \mathrm{Na} \quad 10 \quad 2$

Al 203

Cl $1 \mathrm{Na} 1$

Products in mass fraction

$\begin{array}{llll}1 & \mathrm{Cl} & 1 \mathrm{Na} & 1\end{array}$

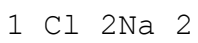

$1 \mathrm{~N} 2$

$1 \mathrm{~N} \quad 1 \mathrm{Na} 10 \quad 3$

$1 \mathrm{~N} \quad 10 \quad 1$

$\begin{array}{llll}1 & \mathrm{~N} & 10 & 2\end{array}$

102

$\begin{array}{lr}\text { (litres) } & 25.5709 \\ (\mathrm{~atm}) & 1.0000 \\ (\mathrm{~K}) & 865.0576 \\ (\mathrm{~mol}) & 0.3486 \\ (\mathrm{~J} / \mathrm{K}) & 26.5803 \\ (\mathrm{~J} / \mathrm{K}) & 113.9617 \\ (\mathrm{KJ}) & -85.9108\end{array}$

$$
\begin{array}{r}
3.57 \mathrm{E}-0007 \\
9.67 \mathrm{E}-0008 \\
0.0011 \\
1.05 \mathrm{E}-0008 \\
2.68 \mathrm{E}-0007 \\
9.45 \mathrm{E}-0008 \\
0.3475 \\
0.0022 \\
0.0011 \\
0.2321 \\
0.0250
\end{array}
$$

$$
\begin{array}{rr}
1.02 \mathrm{E}-0006 & (\mathrm{~atm}) \\
2.77 \mathrm{E}-0007 & (\mathrm{~atm}) \\
0.0031 & (\mathrm{~atm}) \\
3.01 \mathrm{E}-0008 & (\mathrm{~atm}) \\
7.69 \mathrm{E}-0007 & (\mathrm{~atm}) \\
2.71 \mathrm{E}-0007 & (\mathrm{~atm}) \\
0.9969 & (\mathrm{~atm})
\end{array}
$$

8.34E-0007

4. 52E-0007

0.0012

$3.57 \mathrm{E}-0008$

3.22E-0007

$1.74 \mathrm{E}-0007$

0.4448 $\begin{array}{rr}1.02 \mathrm{E}-0006 & (\mathrm{~atm}) \\ 2.78 \mathrm{E}-0007 & (\mathrm{~atm}) \\ 0.0031 & (\mathrm{~atm}) \\ 3.01 \mathrm{E}-0008 & (\mathrm{~atm}) \\ 7.69 \mathrm{E}-0007 & (\mathrm{~atm}) \\ 2.71 \mathrm{E}-0007 & (\mathrm{~atm}) \\ 0.9969 & (\mathrm{~atm})\end{array}$ 

Al $1 \mathrm{Na} \quad 10 \quad 2$
(C) []
0.0071
Al 203
(C) [ ]
0.0044
Cl $1 \mathrm{Na} 1$
(C) []
0.5425

\section{3 wt\% $\mathrm{NaNO}_{3} / \mathrm{Al}(1: 2)$}

$\begin{array}{llr}\text { Volume of gas products } & \text { (litres) } & 27.8250 \\ \text { Pressure of gas products } & (\mathrm{atm}) & 1.0000 \\ \text { Temperature } & (\mathrm{K}) & 950.5141 \\ \text { Gas products amount } & (\mathrm{mol}) & 0.3452 \\ \text { Products heat capacity } & (\mathrm{J} / \mathrm{K}) & 27.3362 \\ \text { Products entropy } & (\mathrm{J} / \mathrm{K}) & 115.9095 \\ \text { Products enthalpy } & (\mathrm{KJ}) & -86.4087\end{array}$

Products in molar fraction

$\begin{array}{llll}1 & \mathrm{Cl} & 3 \mathrm{Na} & 3\end{array}$

(G) $\quad 1.30 \mathrm{E}-0008$

(G) $\quad 5.41 \mathrm{E}-0006$

$\begin{array}{llll}1 & \mathrm{Cl} & 1 \mathrm{Na} & 1\end{array}$

5. $41 \mathrm{E}-0006$
$1.92 \mathrm{E}-0006$

$3.78 \mathrm{E}-0008$

$1.57 \mathrm{E}-0005$

(atm)

$1 \mathrm{~N} 2$

$\begin{array}{lllll}1 & \mathrm{~N} & 1 \mathrm{Na} & 10 & 3\end{array}$

$\begin{array}{llll}1 & \mathrm{~N} & 10 & 1\end{array}$

$\begin{array}{llll}1 & \mathrm{~N} & 10 & 2\end{array}$

102

Al $1 \mathrm{Na} 1 \mathrm{O} \quad 2$

Al $20 \quad 3$

$\mathrm{Cl} 1 \mathrm{Na} 1$

(C) []

(C) [ ]

(C) [ ]

Products in mass fraction

$(\mathrm{Kg})$

Cl $3 \mathrm{Na} 3$

$1 \mathrm{~N} 2$

$1 \mathrm{~N} \quad 1 \mathrm{Na} 10 \quad 3$

$\begin{array}{llll}1 & \mathrm{~N} & 10 & 2\end{array}$

102

Al $1 \mathrm{Na} \quad 10 \quad 2$

Al $20 \quad 3$

(C) [ ]

(C) []

0.0021

$5.56 \mathrm{E}-0006$

(atm)

$1.44 \mathrm{E}-0008$

$1.16 \mathrm{E}-0006$

0.0060

(atm)

$4.16 \mathrm{E}-0008$

$3.35 \mathrm{E}-0006$

(atm)

$1.97 \mathrm{E}-0007$

0.3432

0.0041

5.70E-0007

(atm)

0.9940

(atm)

0.0021

0.2295

0.0250

$9.15 \mathrm{E}-0008$

1.27E-0005

3.78E-0008 (atm)

$1.57 \mathrm{E}-0005$ (atm)

$8.98 \mathrm{E}-0006$

0.0023

4. 88 E-0008

$5.56 \mathrm{E}-0006$

(atm)

0.0060 (atm)

$4.16 \mathrm{E}-0008$ (atm)

$1.39 \mathrm{E}-0006$

3. $62 \mathrm{E}-0007$

0.4392

$3.35 \mathrm{E}-0006$

(atm)

$5.70 \mathrm{E}-0007$

(atm)

0.9940 (atm)

Cl $1 \mathrm{Na} 1$

(C) [ ]

\section{6 wt\% $\mathrm{NaNO}_{3} / \mathrm{Al}(1: 2)$}

Volume of gas products

Pressure of gas products

(litres)

0.0136

0.0084

0.5364

Temperature

(atm)

(K)

$(\mathrm{mol})$

$(\mathrm{J} / \mathrm{K})$

$(\mathrm{J} / \mathrm{K})$

$(\mathrm{KJ})$

Products heat capa
Products entropy

Products enthalpy

Products in molar fraction

$1 \mathrm{Cl} 1 \mathrm{Na} 1$

(G)

(G)

$\begin{array}{llll}1 & \mathrm{Cl} & 2 \mathrm{Na} & 2\end{array}$

$\begin{array}{lll}1 & \mathrm{~N} & 2\end{array}$

102

Al $1 \mathrm{Na} \quad 10 \quad 2$

Al 203

$\mathrm{Cl} 1 \mathrm{Na} 1$

Products in mass fraction

(G)

(C) [ ]

(C) []

(C) [ ]

(Kg)

(G)

(G)

$1 \mathrm{Cl} 2 \mathrm{Na} 2$

$1 \mathrm{~N} 2$

102

Al $1 \mathrm{Na} \quad 102$

(G)

(C) []

(C) []

30.9633

1.0000

1069.6101

0.3414

28.3868

118.5298

$-86.3637$

Al 203

(C) [ ]

1. $12 \mathrm{E}-0004$

$3.27 \mathrm{E}-0004$

(atm)

5.21E-0005

0.0032

1.53E-0004

0.0095 (atm)

0.3380

0.0065

0.0032

0.2262

0.0250

2. 61E-0004

3.27E-0004 (atm)

$2.44 \mathrm{E}-0004$

0.0036

0.4326

0.0212

0.0132

0.5288 


\subsubsection{Aluminum and Magnesium - mole ratio 1:1}

\section{6 wto $\mathrm{NaNO}_{3} / \mathrm{Al} / \mathrm{Mg}(1: 1: 1)$}

Volume of gas products

Pressure of gas products

Temperature

Gas products amount

Products heat capacity

Products entropy

Products enthalpy

Products in molar fraction

$1 \mathrm{Cl} 1 \mathrm{Na} 1$

$\begin{array}{llll}1 & \mathrm{Cl} & 2 \mathrm{Na} & 2\end{array}$

$1 \mathrm{~N} 2$

$1 \mathrm{~N} \quad 1 \mathrm{Na} 10 \quad 3$

$1 \mathrm{~N} \quad 10 \quad 1$

$\begin{array}{llll}1 & \mathrm{~N} & 10 & 2\end{array}$

102

Al $2 \mathrm{Mg} 10 \quad 4$

Al $1 \mathrm{Na} 10 \quad 2$

Cl $1 \mathrm{Na} 1$

$\begin{array}{lll}M g & 10 & 1\end{array}$

Products in mass fraction

$1 \mathrm{Cl} 1 \mathrm{Na} 1$

$\begin{array}{llll}1 & \mathrm{Cl} & 2 \mathrm{Na} & 2\end{array}$

$1 \mathrm{~N} 2$

$1 \mathrm{~N} \quad 1 \mathrm{Na} \quad 10 \quad 3$

$\begin{array}{llll}1 & \mathrm{~N} & 10 & 1\end{array}$

$\begin{array}{llll}1 & \mathrm{~N} & 10 & 2\end{array}$

102

Al $2 \mathrm{Mg} 10 \quad 4$

Al $1 \mathrm{Na} 1 \mathrm{O} 2$

Cl $1 \mathrm{Na} 1$

$\operatorname{Mg} 101$

$$
\begin{array}{r}
25.9910 \\
1.0000 \\
880.4857 \\
0.3481 \\
26.7262 \\
114.3930 \\
-85.9321
\end{array}
$$

$\begin{array}{rrrr}\text { (G) } & 6.08 \mathrm{E}-0007 & 1.75 \mathrm{E}-0006 & (\mathrm{~atm}) \\ \text { (G) } & 1.74 \mathrm{E}-0007 & 4.99 \mathrm{E}-0007 & (\mathrm{~atm}) \\ \text { (G) } & 0.0015 & 0.0042 & (\mathrm{~atm}) \\ \text { (G) } & 1.81 \mathrm{E}-0007 & 5.19 \mathrm{E}-0007 & (\mathrm{~atm}) \\ \text { (G) } & 3.90 \mathrm{E}-0007 & 1.12 \mathrm{E}-0006 & (\mathrm{~atm}) \\ \text { (G) } & 1.19 \mathrm{E}-0007 & 3.42 \mathrm{E}-0007 & (\mathrm{~atm}) \\ \text { (G) } & 0.3467 & 0.9958 & (\mathrm{~atm})\end{array}$

(C) [ ] $9.09 \mathrm{E}-0008$

(C) [] 0.0029

(C) [ ] 0.2311

(C) []$\quad 0.0029$

(Kg) $\quad 0.0250$

(G) $\quad 1.42 \mathrm{E}-0006$

(G) $\quad 8.13 \mathrm{E}-0007$

(G) $\quad 0.0016$

(G) $\quad 6.14 \mathrm{E}-0007$

(G) $\quad 4.68 \mathrm{E}-0007$

(G) $\quad 2.19 \mathrm{E}-0007$

(G) $\quad 0.4437$

(C) [ ] 5.17E-0007

(C) [] 0.0096

(C) [ ] $\quad 0.5403$

(C) [ ] 0.0047

$\begin{array}{rr}1.75 \mathrm{E}-0006 & (\mathrm{~atm}) \\ 5.00 \mathrm{E}-0007 & (\mathrm{~atm}) \\ 0.0042 & (\mathrm{~atm}) \\ 5.19 \mathrm{E}-0007 & (\mathrm{~atm}) \\ 1.12 \mathrm{E}-0006 & (\mathrm{~atm}) \\ 3.42 \mathrm{E}-0007 & (\mathrm{~atm}) \\ 0.9958 & (\mathrm{~atm})\end{array}$

\section{8 wt\% $\mathrm{NaNO}_{3} / \mathrm{Al} / \mathrm{Mg}(1: 1: 1)$}

Volume of gas products

Pressure of gas products

Temperature

Gas products amount

Products heat capacity

Products entropy

Products enthalpy

Products in molar fraction

$1 \mathrm{Cl} 3 \mathrm{Na} 3$

$\begin{array}{llll}1 & \mathrm{Cl} & 1 \mathrm{Na} & 1\end{array}$

$\begin{array}{llll}1 & \mathrm{Cl} & 2 \mathrm{Na} & 2\end{array}$

$1 \mathrm{~N} 2$

$1 \mathrm{~N} \quad 1 \mathrm{Na} \quad 10 \quad 2$

$1 \mathrm{~N} \quad 1 \mathrm{Na} \quad 10 \quad 3$

$\begin{array}{llll}1 & \mathrm{~N} & 10 & 1\end{array}$

$\begin{array}{llll}1 & \mathrm{~N} & 10 & 2\end{array}$

102

Al $2 \mathrm{Mg} \quad 10 \quad 4$

Al $1 \mathrm{Na} 1 \mathrm{O} \quad 2$

$\mathrm{Cl} 1 \mathrm{Na} 1$

$\begin{array}{lll}\text { Mg } & 10 & 1\end{array}$

Products in mass fraction

$\begin{array}{llll}1 & \mathrm{Cl} & 3 \mathrm{Na} & 3\end{array}$

$\begin{array}{llll}1 & \mathrm{Cl} & 1 \mathrm{Na} & 1\end{array}$

$\begin{array}{llll}1 & \mathrm{Cl} & 2 \mathrm{Na} & 2\end{array}$

$1 \mathrm{~N} 2$

$1 \mathrm{~N} \quad 1 \mathrm{Na} 10 \quad 2$

$1 \mathrm{~N} \quad 1 \mathrm{Na} \quad 10 \quad 3$

$1 \mathrm{~N} \quad 101$

\section{(litres)}

(atm)

(K)

$(\mathrm{mol})$

$(\mathrm{J} / \mathrm{K})$

$(\mathrm{J} / \mathrm{K})$

(KJ)

(G)

(G)

(G)

(G)

(G)

(G)

(G)

(G)

(G)

(C) []

(C) []

(C) [ ]

(C) []

$(\mathrm{Kg})$

(G)

(G)

(G)

(G)

(G)

(G)

(G)

$$
\begin{array}{r}
28.5937 \\
1.0000 \\
977.3928 \\
0.3450 \\
27.5833 \\
116.7146 \\
-85.9137
\end{array}
$$

3. $64 \mathrm{E}-0008$

1.15E-0005

4.38E-0006

0.0026

$5.78 \mathrm{E}-0009$

$1.83 \mathrm{E}-0007$

$1.77 \mathrm{E}-0006$

$2.46 \mathrm{E}-0007$

0.3424

$9.42 \mathrm{E}-0008$

0.0051

0.2283

0.0051

0.0250

$2.55 \mathrm{E}-0007$

2. $69 \mathrm{E}-0005$

$2.05 \mathrm{E}-0005$

0.0029

1.59E-0008

$6.23 \mathrm{E}-0007$

2.12E-0006 $\begin{array}{rr}1.06 \mathrm{E}-0007 & (\mathrm{~atm}) \\ 3.34 \mathrm{E}-0005 & (\mathrm{~atm}) \\ 1.27 \mathrm{E}-0005 & (\mathrm{~atm}) \\ 0.0074 & (\mathrm{~atm}) \\ 1.67 \mathrm{E}-0008 & (\mathrm{~atm}) \\ 5.31 \mathrm{E}-0007 & (\mathrm{~atm}) \\ 5.13 \mathrm{E}-0006 & (\mathrm{~atm}) \\ 7.12 \mathrm{E}-0007 & (\mathrm{~atm}) \\ 0.9925 & (\mathrm{~atm})\end{array}$

1.06E-0007 (atm)

3.33E-0005 (atm)

$1.27 \mathrm{E}-0005$ (atm)

0.0074 (atm)

1.67E-0008 (atm)

5.31E-0007 (atm)

5.13E-0006 (atm) 


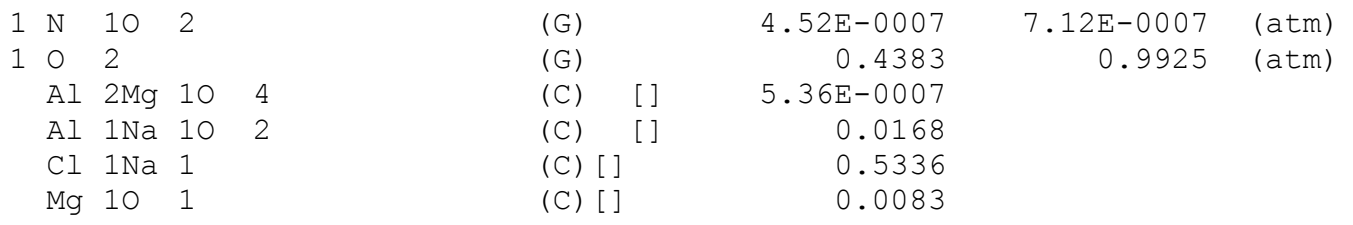

4.4 wt\% $\mathrm{NaNO}_{3} / \mathrm{Al} / \mathrm{Mg}(1: 1: 1)$

Volume of gas products

Pressure of gas products

(litres)

Temperature

Gas products amount

Products heat capacity

Products entropy

Products enthalpy

Phase transition enthalpy

Products in molar fraction

$1 \mathrm{Cl} 1 \mathrm{Na} 1$

$1 \mathrm{Cl} 2 \mathrm{Na} 2$

$1 \mathrm{~N} 2$

102

Al $1 \mathrm{Na} 10 \quad 2$

$\mathrm{Cl} 1 \mathrm{Na} 1$

$\mathrm{Cl} 1 \mathrm{Na} 1$

$\operatorname{Mg} 101$

Products in mass fraction

$1 \mathrm{Cl} 1 \mathrm{Na} 1$

$\begin{array}{llll}1 & \mathrm{Cl} & 2 \mathrm{Na} & 2\end{array}$

$1 \mathrm{~N} 2$

102

Al $1 \mathrm{Na} 102$

Cl $1 \mathrm{Na} 1$

$\mathrm{Cl} 1 \mathrm{Na} 1$

Mg 101 (atm)

$(\mathrm{K})$

(mol)

$(\mathrm{J} / \mathrm{K})$

$(\mathrm{J} / \mathrm{K})$

$(\mathrm{KJ})$

(KJ)

(G)

(G)

(G)

(G)

(C) [ ]

(C) []

(L) []

(C) [ ]

(Kg)

(G)

(G)

(G)

(G)

(C) []

(C) []

(L) [ ]

(C) []

$$
\begin{array}{r}
31.0450 \\
1.0000 \\
1073.9296 \\
0.3410 \\
28.4535 \\
119.3978 \\
-85.9048 \\
6.3469
\end{array}
$$

$1.22 \mathrm{E}-0004$

5. $74 \mathrm{E}-0005$

0.0040

0.3368

0.0081

0.1974

0.0269

0.0081

0.0250

2. $86 \mathrm{E}-0004$

2. $68 \mathrm{E}-0004$

0.0045

0.4311

0.0265

0.4615

0.0629

0.0130

$$
\begin{array}{r}
31.0424 \\
1.0000 \\
1073.5585 \\
0.3410 \\
28.4492 \\
118.6889 \\
-86.6661
\end{array}
$$

1.22E-0004

5.73E-0005

0.0040

0.3368

0.0081

0.2243

0.0000

0.0081

$2.85 \mathrm{E}-0004$

$2.68 \mathrm{E}-0004$

0.0045

0.4311

0.0265

0.5244

0.0000

0.0130

$$
\begin{array}{r}
31.0642 \\
1.0000 \\
1074.3007 \\
0.3410 \\
28.4847 \\
124.5985 \\
-80.3192
\end{array}
$$

1. $24 \mathrm{E}-0004$

5. $82 \mathrm{E}-0005$

0.0040

0.3368

0.0081

0.0000

0.2243

0.0081

2. $90 \mathrm{E}-0004$

2. 72E-0004

0.0045

0.4311

0.0265

0.0000

0.5243

0.0130

\subsubsection{Boron and Titanium - mole ratio 2:1}

\section{0 wt\% $\mathrm{NaNO}_{3} / \mathrm{B} / \mathrm{Ti}(1: 2: 1)$}

Volume of gas products

Pressure of gas products

Temperature

Gas products amount

Products heat capacity

Products entropy

Products enthalpy

Products in molar fraction

$1 \mathrm{~N} 2$

$\begin{array}{lll}1 & 0 & 2\end{array}$

B $\quad 6 \mathrm{Na} \quad 2010$

B $1 \mathrm{Na} 10 \quad 2$

Cl $1 \mathrm{Na} 1$

O $2 \mathrm{Ti} 1$

Products in mass fraction

$1 \mathrm{~N} 2$

102

B $\quad 6 \mathrm{Na} \quad 20 \quad 10$

B $1 \mathrm{Na} 10 \quad 2$

Cl $1 \mathrm{Na} 1$

- $2 \mathrm{Ti} 1$

1.9 wt\% $\mathrm{NaNO}_{3} / \mathrm{B} / \mathrm{Ti}(1: 2: 1)$

Volume of gas products

Pressure of gas products

Temperature (litres)

(atm)

(K)

$(\mathrm{mol})$

$(\mathrm{J} / \mathrm{K})$

$(\mathrm{J} / \mathrm{K})$

$(\mathrm{KJ})$

(G)

(G)

(C)

(C) []

(C) []

(C) [ ]

( Kg)

(G)

(G)

(C)

(C) [ ]

(C) []

(C) [ ]

(litres)

(atm)

(K)
25.7362

1.0000

873.2764

0.3476

26.6666

114.0096

$-85.8176$

$8.09 E-0004$
0.3468

4. $05 \mathrm{E}-0004$

8.09E-0004

0.2325

0.0016

0.0250

9.07E-0004

0.4438

0.0044

0.0021

0.5436

0.0052

28.5765

1.0000

981.6442
0.0023 (atm)

0.9977 (atm)

$\begin{array}{ll}0.0023 & \text { (atm) } \\ 0.9977 & \text { (atm) }\end{array}$ 


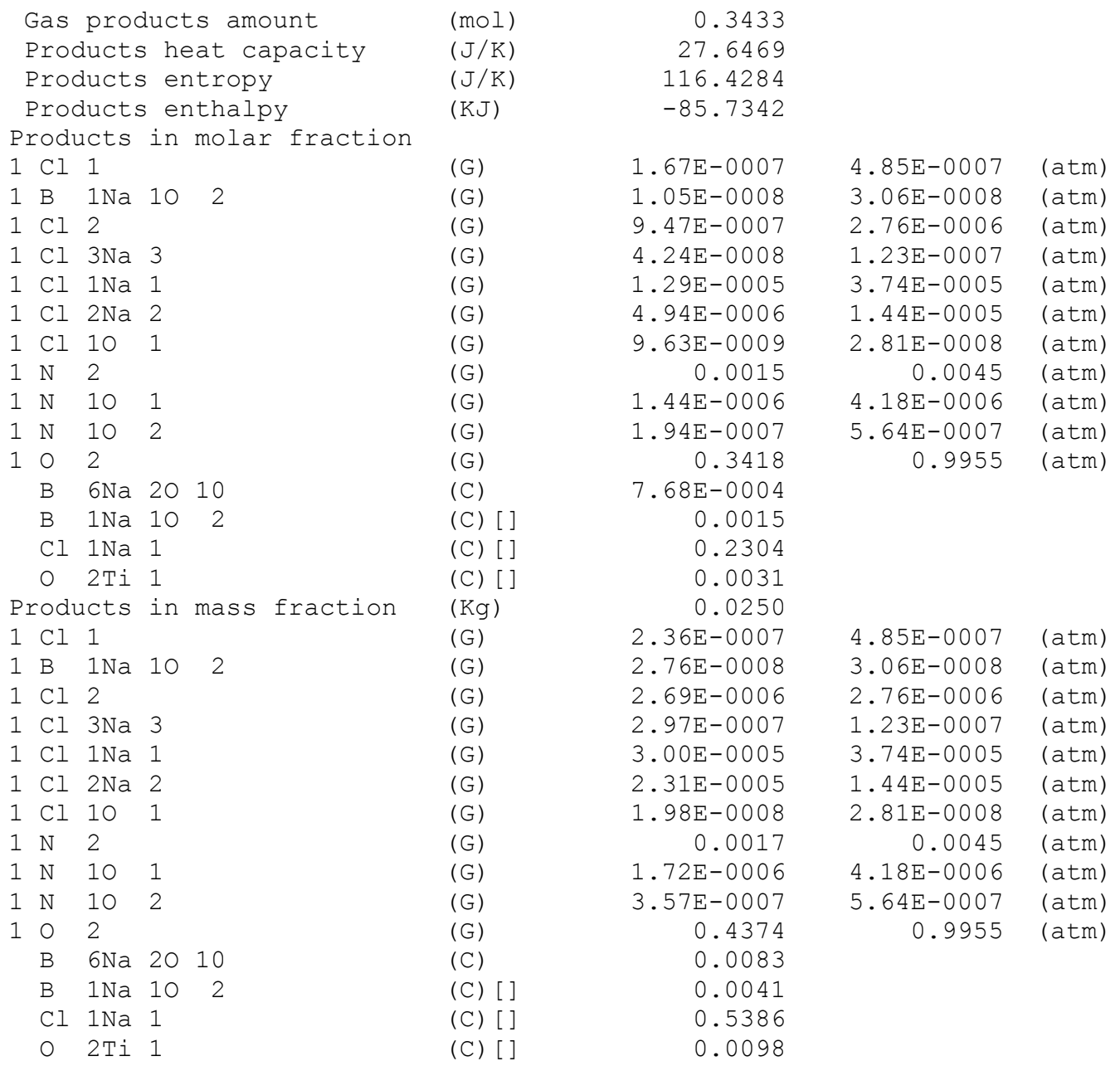

\section{9 wt\% $\mathrm{NaNO}_{3} / \mathrm{B} / \mathrm{Ti} \quad(1: 2: 1)$}

Volume of gas products Pressure of gas products

(litres)

(atm)

Temperature

Gas products amount

Products heat capacity

Products entropy

Products enthalpy

Phase transition enthalpy

Products in molar fraction

$\begin{array}{llll}1 & \mathrm{Cl} & 1 \mathrm{Na} & 1\end{array}$

$1 \mathrm{Cl} 2 \mathrm{Na} 2$

$1 \mathrm{~N} 2$

102

B $\quad 6 \mathrm{Na} 20 \quad 10$

B $1 \mathrm{Na} 10 \quad 2$

Cl $1 \mathrm{Na} 1$

$\mathrm{Cl} 1 \mathrm{Na} 1$

O $2 \mathrm{Ti} 1$

Products in mass fraction

$\begin{array}{llll}1 & \mathrm{Cl} & 1 \mathrm{Na} & 1\end{array}$

$\begin{array}{llll}1 & \mathrm{Cl} & 2 \mathrm{Na} & 2\end{array}$

$1 \mathrm{~N} 2$

102

B $\quad 6 \mathrm{Na} \quad 20 \quad 10$

B $1 \mathrm{Na} 10 \quad 2$

$\mathrm{Cl} 1 \mathrm{Na} 1$

$\mathrm{Cl} 1 \mathrm{Na} 1$
(K)

(mol)

( J / K)

$(\mathrm{J} / \mathrm{K})$

(KJ)

(KJ)

(G)

(G)

(G)

(G)

(C)

(C) []

(C) [ ]

(L) []

(C) [ ]

(Kg)

(G)

(G)

(G)

(G)

(C)

(C) []

(C) []

(L) [ ]
30.8339

1.0000

1073.7746

0.3388

28.5078

118.7654

$-85.6133$

6.4458

1.21E-0004

$5.68 \mathrm{E}-0005$

0.0023

0.3362

0.0012

0.0024

0.2037

0.0241

0.0047

0.0250

$2.83 E-0004$

$2.65 \mathrm{E}-0004$

0.0026

0.4303

0.0127

0.0062

0.4762

0.0564

$$
\begin{array}{r}
30.8316 \\
1.0000 \\
1073.4073 \\
0.3388 \\
28.5039 \\
118.1298 \\
-86.2960
\end{array}
$$

1.21E-0004

5. 67E-0005

0.0023

0.3362

0.0012

0.0024

0.2278

0.0000

0.0047

$2.82 \mathrm{E}-0004$

2. $65 \mathrm{E}-0004$

0.0026

0.4303

0.0127

0.0062

0.5326

0.0000

$$
\begin{array}{r}
30.8530 \\
1.0000 \\
1074.1419 \\
0.3388 \\
28.5410 \\
124.1315 \\
-79.8502
\end{array}
$$

1.23E-0004

5. $77 \mathrm{E}-0005$

0.0023

0.3362

0.0012

0.0024

0.0000

0.2278

0.0047

$2.87 \mathrm{E}-0004$

$2.70 \mathrm{E}-0004$

0.0026

0.4303

0.0127

0.0062

0.0000

0.5325 


\subsubsection{Magnesium}

\section{2 wt $\% \mathrm{NaNO}_{3} / \mathrm{Mg}(1: 3)$}

Volume of gas products

Pressure of gas products

Temperature

Gas products amount

Products heat capacity

Products entropy

Products enthalpy

Products in molar fraction

$\begin{array}{llll}1 & \mathrm{Cl} & 1 \mathrm{Na} & 1\end{array}$

$1 \mathrm{Cl} 2 \mathrm{Na} 2$

$1 \mathrm{~N} 2$

$\begin{array}{lllll}1 & \mathrm{~N} & 1 \mathrm{Na} & 10 & 2\end{array}$

$1 \mathrm{~N} \quad 1 \mathrm{Na} 1 \mathrm{O} \quad 3$

$1 \mathrm{~N} \quad 10 \quad 1$

$\begin{array}{llll}1 & \mathrm{~N} & 10 & 2\end{array}$

$\begin{array}{lll}1 & 0 & 2\end{array}$

Cl $1 \mathrm{Na} 1$

$\operatorname{Mg} 101$

N $1 \mathrm{Na} 10 \quad 3$

$\mathrm{Na} 2 \mathrm{O} 2$

Products in mass fraction

$\begin{array}{llll}1 & \mathrm{Cl} & 1 \mathrm{Na} & 1\end{array}$

$\begin{array}{llll}1 & \mathrm{Cl} & 2 \mathrm{Na} & 2\end{array}$

$1 \mathrm{~N} 2$

$1 \mathrm{~N} \quad 1 \mathrm{Na} \quad 10 \quad 2$

$1 \mathrm{~N} \quad 1 \mathrm{Na} \quad 10 \quad 3$

$\begin{array}{llll}1 & \mathrm{~N} & 10 & 1\end{array}$

$\begin{array}{llll}1 & \mathrm{~N} & 10 & 2\end{array}$

102

Cl $1 \mathrm{Na} 1$

$\begin{array}{lll}\mathrm{Mg} & 10 & 1\end{array}$

N $1 \mathrm{Na} 10 \quad 3$

$\mathrm{Na} 2 \mathrm{O} 2$

\section{5 wt\% $\mathrm{NaNO}_{3} / \mathrm{Mg}(1: 3)$}

\section{Volume of gas products}

Pressure of gas products

Temperature

Gas products amount

Products heat capacity

Products entropy

Products enthalpy

Products in molar fraction

$1 \mathrm{Cl} 3 \mathrm{Na} 3$

$\begin{array}{llll}1 & \mathrm{Cl} & 1 \mathrm{Na} & 1\end{array}$

$\begin{array}{llll}1 & \mathrm{Cl} & 2 \mathrm{Na} & 2\end{array}$

$1 \mathrm{~N} 2$

$1 \mathrm{~N} \quad 1 \mathrm{Na} 1 \mathrm{O} \quad 2$

$1 \mathrm{~N} 1 \mathrm{Na} 1 \mathrm{O} 3$

$1 \mathrm{~N} \quad 10 \quad 1$

$\begin{array}{llll}1 & \mathrm{~N} & 10 & 2\end{array}$

102

Cl $1 \mathrm{Na} 1$

Mg 101

$\mathrm{Na} 2 \mathrm{O} 2$

Products in mass fraction

$1 \mathrm{Cl} 3 \mathrm{Na} 3$

$\begin{array}{llll}1 & \mathrm{Cl} & 1 \mathrm{Na} & 1\end{array}$

$\begin{array}{lr}\text { (litres) } & 25.4137 \\ (\mathrm{~atm}) & 1.0000 \\ (\mathrm{~K}) & 865.9245 \\ (\mathrm{~mol}) & 0.3461 \\ (\mathrm{~J} / \mathrm{K}) & 26.6482 \\ (\mathrm{~J} / \mathrm{K}) & 113.6753 \\ (\mathrm{KJ}) & -85.7604\end{array}$

(G)

(G)

(G)

(G)

(G)

(G)

(G)

(G)

(C) []

(C) []

(L) []

(C) [ ]

$(\mathrm{Kg})$

(G)

(G)

(G)

(G)

(G)

(C) [ ]

(C) []

(L) []

(C) []

3. $65 E-0007$

$1.24 \mathrm{E}-0004$

2. $50 \mathrm{E}-0006$

$5.24 \mathrm{E}-0004$

$9.18 \mathrm{E}-0008$

3. $21 \mathrm{E}-0008$

0.3455

0.2321

0.0057

0.0011

$1.24 \mathrm{E}-0004$

0.0250

$8.54 \mathrm{E}-0007$

4. $65 \mathrm{E}-0007$

1. 39E-0004

$6.89 \mathrm{E}-0006$

0.0018

$1.10 \mathrm{E}-0007$

$5.90 \mathrm{E}-0008$

0.4422

0.5425

0.0092

0.0038

$3.87 \mathrm{E}-0004$

$1.06 \mathrm{E}-0006$

$2.87 \mathrm{E}-0007$

$3.58 \mathrm{E}-0004$

7. $21 \mathrm{E}-0006$

0.0015

$2.65 \mathrm{E}-0007$

9.26E-0008

0.9981

(atm)

(atm)

(atm)

(atm)

(atm)

(atm)

(atm)

(atm)

(litres)

(atm)

(K)

(mol)

$(\mathrm{J} / \mathrm{K})$

$(\mathrm{J} / \mathrm{K})$

(KJ)

28.2563

1.0000

971.4611

0.3430

27.5933

116.2617

$-85.6186$

(G)

(G)

(G)

(G)

(G)

(G)

(G)

(G)

(G)

(C) [ ]

(C) [ ]

(L) [ ]

(Kg)

(G)

$2.90 \mathrm{E}-0008$

9.72E-0006

3. $65 \mathrm{E}-0006$

0.0015

$2.74 \mathrm{E}-0005$

9.51E-0004

1.25E-0006

1. $82 \mathrm{E}-0007$

0.3406

0.2290

0.0119

0.0015

0.0250

$2.04 \mathrm{E}-0007$

2.27E-0005 $\begin{array}{rr}8.46 \mathrm{E}-0008 & (\mathrm{~atm}) \\ 2.83 \mathrm{E}-0005 & (\mathrm{~atm}) \\ 1.06 \mathrm{E}-0005 & (\mathrm{~atm}) \\ 0.0043 & (\mathrm{~atm}) \\ 8.00 \mathrm{E}-0005 & (\mathrm{~atm}) \\ 0.0028 & (\mathrm{~atm}) \\ 3.66 \mathrm{E}-0006 & (\mathrm{~atm}) \\ 5.31 \mathrm{E}-0007 & (\mathrm{~atm}) \\ 0.9928 & (\mathrm{~atm}) \\ & \\ & \\ 8.46 \mathrm{E}-0008 & (\mathrm{~atm}) \\ 2.83 \mathrm{E}-0005 & (\mathrm{~atm})\end{array}$ 


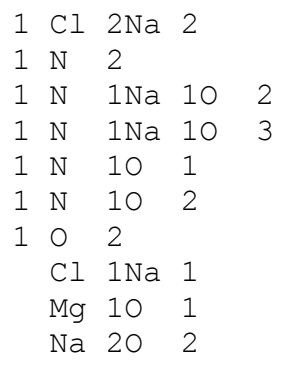

\section{9 wto $\mathrm{NaNO}_{3} / \mathrm{Mg}(1: 3)$}

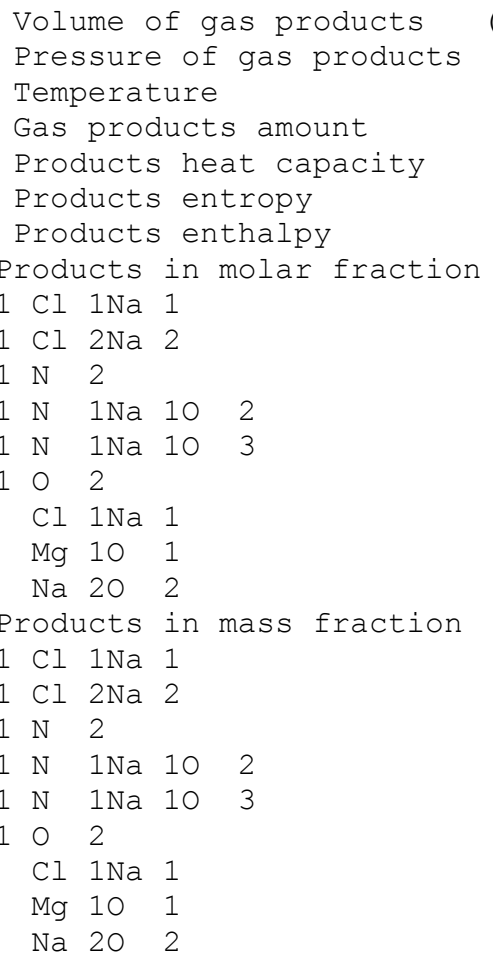

$\begin{array}{lr}\text { (G) } & 1.70 \mathrm{E}-0005 \\ (\mathrm{G}) & 0.0017 \\ (\mathrm{G}) & 7.57 \mathrm{E}-0005 \\ (\mathrm{G}) & 0.0032 \\ (\mathrm{G}) & 1.51 \mathrm{E}-0006 \\ (\mathrm{G}) & 3.35 \mathrm{E}-0007 \\ (\mathrm{G}) & 0.4359 \\ \text { (C) [ ] } & 0.5353 \\ \text { (C) [] } & 0.0191 \\ \text { (L) [] } & 0.0046\end{array}$

$\begin{array}{lr}\text { (litres) } & 30.6133 \\ (\mathrm{~atm}) & 1.0000 \\ (\mathrm{~K}) & 1067.0462 \\ (\mathrm{~mol}) & 0.3384 \\ (\mathrm{~J} / \mathrm{K}) & 28.4951 \\ (\mathrm{~J} / \mathrm{K}) & 118.1310 \\ (\mathrm{KJ}) & -86.0211\end{array}$

(C) [ ]

(C) [ ]

(L) [ ]

$(\mathrm{Kg})$

$(\mathrm{G})$

(C) [ ]

(C) []

(L) [ ]$$
-86.0211
$$

0.5272

0.0299

0.0084

$$
\begin{array}{rr}
1.06 \mathrm{E}-0005 & \text { (atm) } \\
0.0043 & (\mathrm{~atm}) \\
8.00 \mathrm{E}-0005 & (\mathrm{~atm}) \\
0.0028 & (\mathrm{~atm}) \\
3.66 \mathrm{E}-0006 & (\mathrm{~atm}) \\
5.31 \mathrm{E}-0007 & (\mathrm{~atm}) \\
0.9928 & (\mathrm{~atm})
\end{array}
$$

$$
\begin{array}{rrr}
1.04 \mathrm{E}-0004 & 3.09 \mathrm{E}-0004 & \text { (atm) } \\
4.85 \mathrm{E}-0005 & 1.43 \mathrm{E}-0004 & \text { (atm) } \\
0.0027 & 0.0079 & (\mathrm{~atm}) \\
7.79 \mathrm{E}-0005 & 2.30 \mathrm{E}-0004 & \text { (atm) } \\
7.22 \mathrm{E}-0004 & 0.0021 & (\mathrm{~atm}) \\
0.3347 & 0.9892 & (\mathrm{~atm}) \\
0.2255 & & \\
0.0185 & & \\
0.0027 & & \\
0.0250 & & \\
2.44 \mathrm{E}-0004 & 3.09 \mathrm{E}-0004 & (\mathrm{~atm}) \\
2.27 \mathrm{E}-0004 & 1.43 \mathrm{E}-0004 & (\mathrm{~atm}) \\
0.0030 & 0.0079 & (\mathrm{~atm}) \\
2.15 \mathrm{E}-0004 & 2.30 \mathrm{E}-0004 & (\mathrm{~atm}) \\
0.0025 & 0.0021 & (\mathrm{~atm}) \\
0.4284 & 0.9892 & (\mathrm{~atm})
\end{array}
$$

\subsubsection{Zirconium}

\section{9 wt\% $\mathrm{NaNO}_{3} / \mathrm{Zr}(2: 3)$}

Volume of gas products

Pressure of gas products

Temperature

Gas products amount

Products heat capacity

Products entropy

Products enthalpy

Products in molar fraction

$1 \mathrm{Cl} 1 \mathrm{Na} 1$

$\begin{array}{llll}1 & \mathrm{Cl} & 2 \mathrm{Na} & 2\end{array}$

$1 \mathrm{~N} 2$

$\begin{array}{lllll}1 & \mathrm{~N} & 1 \mathrm{Na} & 10 & 2\end{array}$

$1 \mathrm{~N} \quad 1 \mathrm{Na} \quad 10 \quad 3$

$\begin{array}{llll}1 & \mathrm{~N} & 10 & 1\end{array}$

$\begin{array}{llll}1 & \mathrm{~N} & 10 & 2\end{array}$

102

Cl $1 \mathrm{Na} 1$

$\mathrm{N} \quad 1 \mathrm{Na} 1 \mathrm{O} \quad 3$

$\mathrm{Na} 2 \mathrm{O} 2$

O 2Zr 1 (litres)

(atm)

(K)

(mol)

$(\mathrm{J} / \mathrm{K})$

$(\mathrm{J} / \mathrm{K})$

(KJ)

(G)

(G)

(G)

(G)

(G)

(G)

(G)

(G)

(C) [ ]

(L) []

(C) [ ]

(C) [ ]
25.3519

1.0000

870.5284

0.3435

26.4714

112.9820

$-85.2660$

4.26E-0007

$1.18 \mathrm{E}-0007$

1. $60 \mathrm{E}-0004$

$2.99 \mathrm{E}-0006$

5.75E-0004

$1.11 \mathrm{E}-0007$

3. 72E-0008

0.3427

0.2304

0.0012

1. $60 \mathrm{E}-0004$

0.0032 


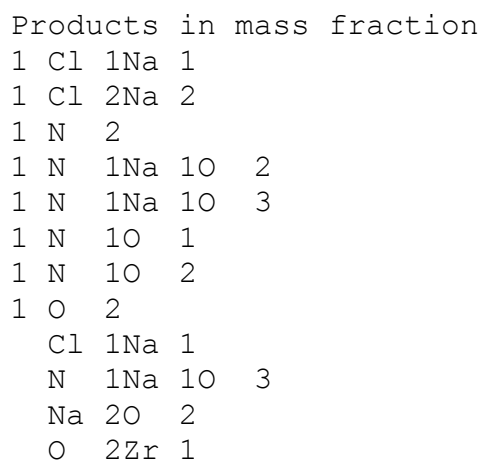

$\begin{array}{lrrr}(\mathrm{Kg}) & 0.0250 & & \\ (\mathrm{G}) & 9.96 \mathrm{E}-0007 & 1.24 \mathrm{E}-0006 & (\mathrm{~atm}) \\ (\mathrm{G}) & 5.50 \mathrm{E}-0007 & 3.43 \mathrm{E}-0007 & (\mathrm{~atm}) \\ (\mathrm{G}) & 1.79 \mathrm{E}-0004 & 4.66 \mathrm{E}-0004 & (\mathrm{~atm}) \\ (\mathrm{G}) & 8.27 \mathrm{E}-0006 & 8.72 \mathrm{E}-0006 & (\mathrm{~atm}) \\ (\mathrm{G}) & 0.0020 & 0.0017 & (\mathrm{~atm}) \\ (\mathrm{G}) & 1.33 \mathrm{E}-0007 & 3.23 \mathrm{E}-0007 & (\mathrm{~atm}) \\ (\mathrm{G}) & 6.85 \mathrm{E}-0008 & 1.08 \mathrm{E}-0007 & (\mathrm{~atm}) \\ \text { (G) } & 0.4387 & 0.9978 & (\mathrm{~atm}) \\ \text { (C) [] } & 0.5386 & & \\ (\mathrm{~L})[] & 0.0042 & & \\ \text { (C) [] } & 4.99 \mathrm{E}-0004 & & \\ \text { (C) [] } & 0.0158 & & \end{array}$

\section{8 wt $\% \mathrm{NaNO}_{3} / \mathrm{Zr} \quad(2: 3)$}

$\begin{array}{llr}\text { Volume of gas products } & \text { (litres) } & 27.8716 \\ \text { Pressure of gas products } & (\mathrm{atm}) & 1.0000 \\ \text { Temperature } & (\mathrm{K}) & 971.2591 \\ \text { Gas products amount } & (\mathrm{mol}) & 0.3384 \\ \text { Products heat capacity } & (\mathrm{J} / \mathrm{K}) & 27.1401 \\ \text { Products entropy } & (\mathrm{J} / \mathrm{K}) & 114.6460 \\ \text { Products enthalpy } & (\mathrm{KJ}) & -84.6535\end{array}$

Products in molar fraction

$1 \mathrm{Cl} 1 \mathrm{Na} 1$

(G) $\quad 9.54 \mathrm{E}-0006$

$\begin{array}{llll}1 & \mathrm{Cl} & 2 \mathrm{Na} & 2\end{array}$

$1 \mathrm{~N} 2$

$\begin{array}{lllll}1 & \mathrm{~N} & 1 \mathrm{Na} & 10 & 2\end{array}$

$\begin{array}{lllll}1 & \mathrm{~N} & 1 \mathrm{Na} & 10 & 3\end{array}$

$\begin{array}{llll}1 & \mathrm{~N} & 10 & 1\end{array}$

$\begin{array}{llll}1 & \mathrm{~N} & 10 & 2\end{array}$

$\begin{array}{lll}1 & 0 & 2\end{array}$

$1 \mathrm{Cl} 3 \mathrm{Na} 3$

Cl $1 \mathrm{Na} 1$

$\mathrm{Na} 2 \mathrm{O} 2$

O $2 \mathrm{Zr} 1$

Products in mass fraction

(C) []

(L) [ ]

(C) [ ]

$1 \quad \mathrm{Cl} 1 \mathrm{Na} 1$

$\begin{array}{llll}1 & \mathrm{Cl} & 2 \mathrm{Na} & 2\end{array}$

$1 \mathrm{~N} 2$

$\begin{array}{lllll}1 & \mathrm{~N} & 1 \mathrm{Na} & 10 & 2\end{array}$

$1 \mathrm{~N} \quad 1 \mathrm{Na} 10 \quad 3$

$\begin{array}{llll}1 & \mathrm{~N} & 10 & 1\end{array}$

$\begin{array}{llll}1 & \mathrm{~N} & 10 & 2\end{array}$

102

$\begin{array}{llll}1 & \mathrm{Cl} & 3 \mathrm{Na} & 3\end{array}$

Cl $1 \mathrm{Na} 1$

$\mathrm{Na} 2 \mathrm{O} 2$

- $2 \mathrm{Zr} 1$

$2.82 \mathrm{E}-0005$

(atm)

$1.06 \mathrm{E}-0005$ (atm)

0.0048 (atm)

$2.85 \mathrm{E}-0005$

$9.90 \mathrm{E}-0004$

1.30E-0006

1.89E-0007

0.3358

$2.84 \mathrm{E}-0008$

0.2259

0.0016

0.0064

0.0250

$2.23 \mathrm{E}-0005$

1. $67 \mathrm{E}-0005$

0.0018

7.86E-0005 0.0034

$1.56 \mathrm{E}-0006$

$3.48 \mathrm{E}-0007$

0.4298

$8.41 \mathrm{E}-0005$

(atm)

0.0029 (atm)

3.84E-0006 (atm)

5.59E-0007 (atm)

0.9921 (atm)

8.40E-0008 (atm)

$$
\begin{array}{rr}
2.82 E-0005 & (\mathrm{~atm}) \\
1.06 \mathrm{E}-0005 & (\mathrm{~atm}) \\
0.0048 & (\mathrm{~atm}) \\
8.41 \mathrm{E}-0005 & (\mathrm{~atm}) \\
0.0029 & (\mathrm{~atm}) \\
3.84 \mathrm{E}-0006 & (\mathrm{~atm}) \\
5.59 \mathrm{E}-0007 & (\mathrm{~atm}) \\
0.9921 & (\mathrm{~atm})
\end{array}
$$

1.99E-0007 8.40E-0008 (atm)

\section{0 wt $\% \mathrm{NaNO}_{3} / \mathrm{Zr} \quad(2: 3)$}

$\begin{array}{llr}\text { Volume of gas products } & \text { (litres) } & 30.1243 \\ \text { Pressure of gas products } & (\mathrm{atm}) & 1.0000 \\ \text { Temperature } & (\mathrm{K}) & 1073.4109 \\ \text { Gas products amount } & (\mathrm{mol}) & 0.3310 \\ \text { Products heat capacity } & (\mathrm{J} / \mathrm{K}) & 27.8225 \\ \text { Products entropy } & (\mathrm{J} / \mathrm{K}) & 115.6654 \\ \text { Products enthalpy } & (\mathrm{KJ}) & -84.4782\end{array}$

Products in molar fraction

$1 \mathrm{Cl} 1 \mathrm{Na} 1$

(G) $\quad 1.18 \mathrm{E}-0004$

$\begin{array}{llll}1 & \mathrm{Cl} & 2 \mathrm{Na} & 2\end{array}$

$1 \mathrm{~N} 2$

$\begin{array}{lllll}1 & \mathrm{~N} & 1 \mathrm{Na} & 10 & 2\end{array}$

$\begin{array}{lllll}1 & \mathrm{~N} & 1 \mathrm{Na} & 10 & 3\end{array}$

102

(G)

Cl $1 \mathrm{Na} 1$

(C) [ ]

$$
\begin{array}{rr}
3.56 \mathrm{E}-0004 & (\mathrm{~atm}) \\
1.67 \mathrm{E}-0004 & (\mathrm{~atm}) \\
0.0090 & (\mathrm{~atm}) \\
2.56 \mathrm{E}-0004 & (\mathrm{~atm}) \\
0.0022 & (\text { atm }) \\
0.9880 & (\mathrm{~atm})
\end{array}
$$




\begin{tabular}{|c|c|c|c|c|c|c|c|c|}
\hline $\mathrm{Na}$ & 20 & 2 & & & (L) [ ] & 0.0030 & & \\
\hline 0 & $2 Z r$ & 1 & & & (C) [] & 0.0101 & & \\
\hline Produ & acts & in & mass & fraction & $(\mathrm{Kg})$ & 0.0250 & & \\
\hline $1 \mathrm{Cl}$ & $1 \mathrm{Na}$ & 1 & & & (G) & $2.76 \mathrm{E}-0004$ & $3.56 \mathrm{E}-0004$ & (atm) \\
\hline $1 \mathrm{Cl}$ & $2 \mathrm{Na}$ & 2 & & & (G) & $2.59 \mathrm{E}-0004$ & $1.67 \mathrm{E}-0004$ & $(\mathrm{~atm})$ \\
\hline $1 \mathrm{~N}$ & 2 & & & & (G) & 0.0033 & 0.0090 & (atm) \\
\hline $1 \mathrm{~N}$ & $1 \mathrm{Na}$ & 10 & 2 & & (G) & $2.34 \mathrm{E}-0004$ & $2.56 \mathrm{E}-0004$ & $(\mathrm{~atm})$ \\
\hline $1 \mathrm{~N}$ & $1 \mathrm{Na}$ & 10 & 3 & & (G) & 0.0025 & 0.0022 & $(\mathrm{~atm})$ \\
\hline 0 & 2 & & & & (G) & 0.4186 & 0.9880 & $(\mathrm{~atm})$ \\
\hline $\mathrm{Cl}$ & $1 \mathrm{Na}$ & 1 & & & (C) [] & 0.5156 & & \\
\hline $\mathrm{Na}$ & 20 & 2 & & & $(\mathrm{~L})[]$ & 0.0093 & & \\
\hline O & $2 Z r$ & 1 & & & (C) [ ] & 0.0500 & & \\
\hline
\end{tabular}

\subsection{Strontium Peroxide}

\subsubsection{Aluminum}

\section{6 wt\% $\mathrm{SrO}_{2} / \mathrm{Al}(3: 4)$}

Pressure of gas products

(litres)

(atm)

(K)

$(\mathrm{mol})$

$(\mathrm{J} / \mathrm{K})$

$(\mathrm{J} / \mathrm{K})$

$(\mathrm{KJ})$

Products entropy

Products enthalpy

Products in molar fraction

$\begin{array}{llll}1 & \mathrm{Cl} & 1 \mathrm{Na} & 1\end{array}$

$\begin{array}{llll}1 & \mathrm{Cl} & 2 \mathrm{Na} & 2\end{array}$

102

Al $20 \quad 4 \mathrm{Sr} 1$

$\mathrm{Cl} 1 \mathrm{Na} 1$

O $1 \mathrm{Sr} 1$

Products in mass fraction

$\begin{array}{llll}1 & \mathrm{Cl} & 1 \mathrm{Na} & 1\end{array}$

$1 \mathrm{Cl} 2 \mathrm{Na} 2$

102

Al $20 \quad 4 \mathrm{Sr} 1$

$\mathrm{Cl} 1 \mathrm{Na} 1$

$0 \quad \operatorname{Sr} 1$

\section{3 wt\% $\mathrm{SrO}_{2} / \mathrm{Al}(3: 4)$}

Volume of gas products

Pressure of gas products

Temperature

Gas products amount

Products heat capacity

Products entropy

Products enthalpy

Products in molar fraction

$\begin{array}{llll}1 & \mathrm{Cl} & 3 \mathrm{Na} & 3\end{array}$

$1 \mathrm{Cl} 1 \mathrm{Na} 1$

$\begin{array}{llll}1 & \mathrm{Cl} & 2 \mathrm{Na} & 2\end{array}$

102

Al $20 \quad 4 \mathrm{Sr} 1$

Cl $1 \mathrm{Na} 1$

0 1Sr 1

Products in mass fraction

$\begin{array}{llll}1 & \mathrm{Cl} & 3 \mathrm{Na} & 3\end{array}$

$1 \mathrm{Cl} 1 \mathrm{Na} 1$

$1 \mathrm{Cl} 2 \mathrm{Na} 2$

102

Al $20 \quad 4 \mathrm{Sr} 1$
(G)

(G)

(G)

(C) $\quad[]$

(C) []

(C) [ ]

$(\mathrm{Kg})$

(G)

(G)

(G)

(C) [ ]

(C) [ ]

(C) [ ] (1itres)

atm)

(K)

(mol)

( J / K)

$(\mathrm{J} / \mathrm{K})$

(KJ)

(G)

(G)

(G)

(G)

(C) []

(C) [ ]

(C) [ ]

(Kg)

(G)

(G)

(G)

(G)

(C) [ ]
25.0220

1.0000

854.4149

0.3454

26.3249

112.6949

$-86.1657$

$2.42 \mathrm{E}-0007$

$6.31 \mathrm{E}-0008$

0.3454

0.0017

0.2311

$8.57 \mathrm{E}-0004$

0.0250

5. 65E-0007

$2.95 \mathrm{E}-0007$

0.4421

0.0141

0.5403

0.0036

$$
\begin{array}{rr}
7.00 \mathrm{E}-0007 & (\mathrm{~atm}) \\
1.83 \mathrm{E}-0007 & (\mathrm{~atm}) \\
1.0000 & (\mathrm{~atm})
\end{array}
$$

27.6545

1.0000

964.8249

0.3380

27.0979

114.2681

$-86.4369$

$2.22 \mathrm{E}-0008$

$7.97 \mathrm{E}-0006$

2.93E-0006

0.3380

0.0035

0.2271

0.0018

0.0250

$1.56 \mathrm{E}-0007$

$1.86 \mathrm{E}-0005$

$1.37 \mathrm{E}-0005$

0.4327

0.0291
$6.58 \mathrm{E}-0008$ (atm)

$2.36 \mathrm{E}-0005$ (atm)

8.68E-0006 (atm)

1.0000 (atm) 

$\mathrm{Cl} 1 \mathrm{Na} 1$
(C) [ ]
0.5309
$0 \operatorname{SSr} 1$
(C) []
0.0073

\section{3 wto $\mathrm{SrO}_{2} / \mathrm{Al}(3: 4)$}

$\begin{array}{llr}\text { Volume of gas products } & \text { (litres) } & 29.9778 \\ \text { Pressure of gas products } & (\mathrm{atm}) & 1.0000 \\ \text { Temperature } & (\mathrm{K}) & 1072.8315 \\ \text { Gas products amount } & (\mathrm{mol}) & 0.3296 \\ \text { Products heat capacity } & (\mathrm{J} / \mathrm{K}) & 27.8244 \\ \text { Products entropy } & (\mathrm{J} / \mathrm{K}) & 115.2218 \\ \text { Products enthalpy } & (\mathrm{KJ}) & -87.2493\end{array}$

Products in molar fraction

$1 \mathrm{Cl} 1 \mathrm{Na} 1$

$\begin{array}{llll}1 & \mathrm{Cl} & 2 \mathrm{Na} & 2\end{array}$

102

Al $20 \quad 4 \mathrm{Sr} 1$

Cl $1 \mathrm{Na} 1$

O $1 \mathrm{Sr} 1$

Products in mass fraction

0.3294

0.0057

(C) []$\quad 0.2222$

(C) [ ] $\quad 0.0028$

0.0250

$\begin{array}{llll}1 & \mathrm{Cl} & 1 \mathrm{Na} & 1\end{array}$

$\begin{array}{llll}1 & \mathrm{Cl} & 2 \mathrm{Na} & 2\end{array}$

102

Al $20 \quad 4 \mathrm{Sr} 1$

$\mathrm{Cl} 1 \mathrm{Na} 1$

$(\mathrm{Kg})$

1. $65 \mathrm{E}-0004$

$(\mathrm{atm})$

0.9995 (atm)

$0 \operatorname{SSr} 1$

(G)

(G)

(G)

(C) $\quad[]$

(C) []

$2.71 \mathrm{E}-0004$

$2.54 \mathrm{E}-0004$

0.4216

$3.52 \mathrm{E}-0004$ (atm)

$1.65 \mathrm{E}-0004$ (atm)

0.9995 (atm)

\subsection{Tungsten Trioxide}

\subsubsection{Aluminum}

\section{3 wt\% $\mathrm{WO}_{3} / \mathrm{Al}(1: 2)$}

Volume of gas product

Pressure of gas products

Temperature

(1itres)

(atm)

(K)

$(\mathrm{mol})$

$(\mathrm{J} / \mathrm{K})$

$(\mathrm{J} / \mathrm{K})$

$(\mathrm{KJ})$

Products enthalpy

Products in molar fraction

$\begin{array}{llll}1 & \mathrm{Cl} & 1 \mathrm{Na} & 1\end{array}$

$\begin{array}{llll}1 & \mathrm{Cl} & 2 \mathrm{Na} & 2\end{array}$

102

Al 203

Cl $1 \mathrm{Na} 1$

O $3 \mathrm{~W} \quad 1$

Products in mass fraction

$\begin{array}{llll}1 & \mathrm{Cl} & 1 \mathrm{Na} & 1\end{array}$

$\begin{array}{llll}1 & \mathrm{Cl} & 2 \mathrm{Na} & 2\end{array}$

102

Al 203

Cl $1 \mathrm{Na} 1$

O 3W 1

(G)

(G)

(G)

(C) [ ]

(C) []

(C) [ ]

$(\mathrm{Kg})$

(G)

(G)

(G)

(C) [ ]

(C) [ ]

(C) []

\section{1 wt\% $\mathrm{WO}_{3} / \mathrm{Al}(1: 2)$}

Volume of gas products

Pressure of gas products

Temperature

Gas products amount

Products heat capacity

Products entropy

Products enthalpy

Products in molar fraction (litres)

(atm)

(K)

$(\mathrm{mol})$

$(\mathrm{J} / \mathrm{K})$

$(\mathrm{J} / \mathrm{K})$

$(\mathrm{KJ})$

$$
\begin{array}{r}
25.2317 \\
1.0000 \\
872.1786 \\
0.3412 \\
26.3308 \\
112.1389 \\
-85.6498
\end{array}
$$

$$
\begin{array}{r}
4.48 \mathrm{E}-0007 \\
1.25 \mathrm{E}-0007 \\
0.3412 \\
0.0020 \\
0.2295 \\
0.0020 \\
0.0250 \\
1.05 \mathrm{E}-0006 \\
5.83 \mathrm{E}-0007 \\
0.4367 \\
0.0082 \\
0.5364 \\
0.0187
\end{array}
$$

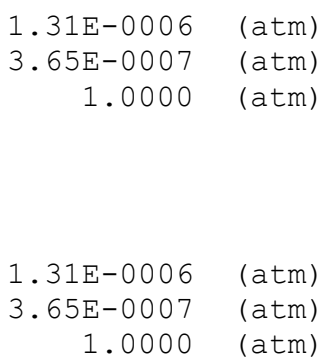

27.3159

1.0000

968.9041

0.3325

26.9249

112.8352

$-85.4202$ 


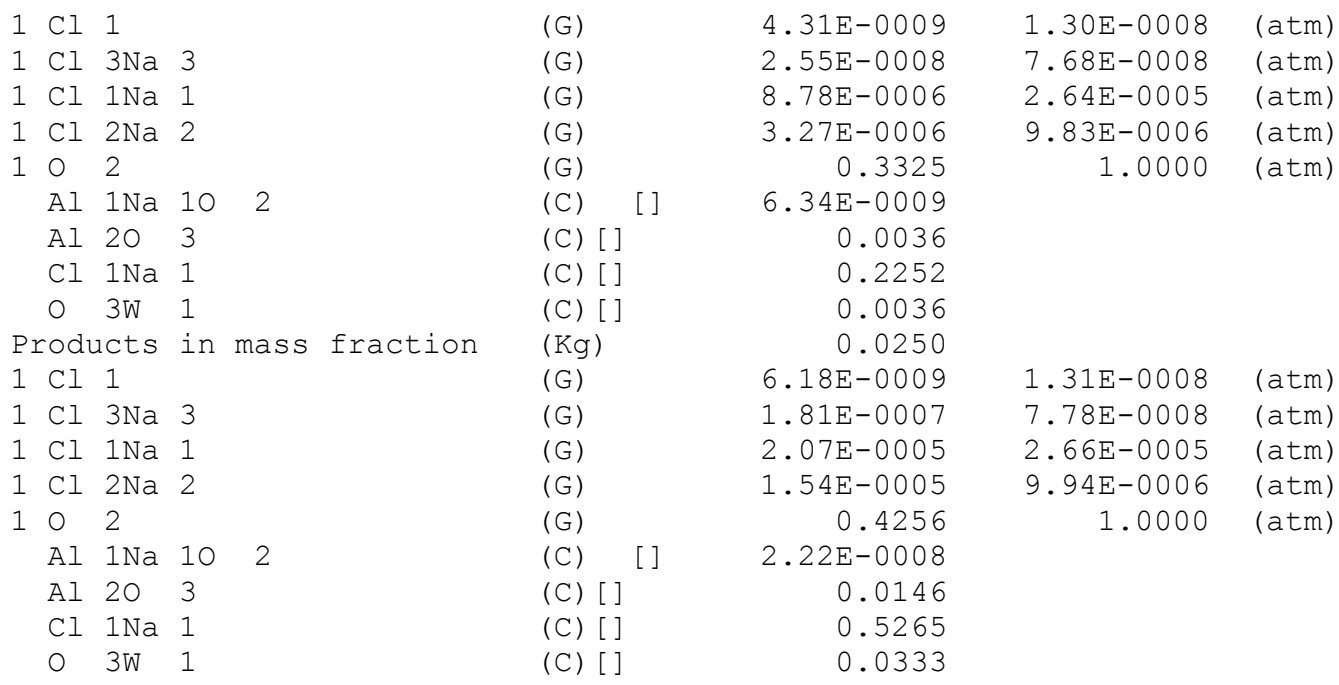

\section{4 wto $\mathrm{wO}_{3} / \mathrm{Al}(1: 2)$}

\begin{tabular}{|c|c|c|c|c|c|}
\hline Volume o & of gas products & (litres) & 29.1693 & & \\
\hline Pressure & e of gas products & (atm) & 1.0000 & & \\
\hline Temperat & ture & $(\mathrm{K})$ & 1069.9689 & & \\
\hline Gas prod & ducts amount & $(\mathrm{mol})$ & 0.3215 & & \\
\hline Products & s heat capacity & $(\mathrm{J} / \mathrm{K})$ & 27.4294 & & \\
\hline Products & s entropy & $(\mathrm{J} / \mathrm{K})$ & 112.8481 & & \\
\hline Products & s enthalpy & $(\mathrm{KJ})$ & -85.6642 & & \\
\hline roducts & in molar fraction & & & & \\
\hline $\mathrm{Cl} 1 \mathrm{Na}$ & 1 & (G) & $1.06 \mathrm{E}-0004$ & $3.30 \mathrm{E}-0004$ & $(\mathrm{~atm})$ \\
\hline $\mathrm{Cl} 2 \mathrm{Na}$ & 2 & (G) & $4.95 \mathrm{E}-0005$ & $1.54 \mathrm{E}-0004$ & $(\mathrm{~atm})$ \\
\hline 02 & & (G) & 0.3214 & 0.9995 & $(\mathrm{~atm})$ \\
\hline Al 20 & 3 & (C) [] & 0.0056 & & \\
\hline $\mathrm{Cl} 1 \mathrm{Na}$ & 1 & (C) [] & 0.2196 & & \\
\hline $0 \quad 3 W$ & 1 & (C) [] & 0.0056 & & \\
\hline roducts & in mass fraction & $(\mathrm{Kg})$ & 0.0250 & & \\
\hline $\mathrm{Cl} 1 \mathrm{Na}$ & 1 & $(G)$ & $2.48 \mathrm{E}-0004$ & $3.30 \mathrm{E}-0004$ & $(\mathrm{~atm})$ \\
\hline $\mathrm{Cl} 2 \mathrm{Na}$ & 2 & (G) & $2.31 E-0004$ & $1.54 \mathrm{E}-0004$ & (atm) \\
\hline 02 & & (G) & 0.4113 & 0.9995 & $(a t m)$ \\
\hline Al 20 & 3 & (C) [] & 0.0228 & & \\
\hline $\mathrm{Cl} 1 \mathrm{Na}$ & 1 & (C) [] & 0.5134 & & \\
\hline $0 \quad 3 W$ & 1 & (C) [] & 0.0519 & & \\
\hline
\end{tabular}




\section{Metal-metal Composites}

\subsection{Aluminum}

\subsubsection{Iron}

\section{1 wt $\% \mathrm{Al} / \mathrm{Fe}(1: 1)$}

Pressure of gas products

(litres)

(atm)

Temperature

(K)

Gas products amount

$(\mathrm{mol})$

$(\mathrm{J} / \mathrm{K})$

Products entropy (J/K)

Products enthalpy

$(\mathrm{KJ})$

Products in molar fraction

$\begin{array}{llll}1 & \mathrm{Cl} & 1 \mathrm{Na} & 1\end{array}$

$\begin{array}{llll}1 & \mathrm{Cl} & 2 \mathrm{Na} & 2\end{array}$

102

Al $20 \quad 3$

Cl $1 \mathrm{Na} 1$

$\mathrm{Fe} 203$

Products in mass fraction

$\begin{array}{llll} & \mathrm{Cl} & 3 \mathrm{Na} & 3\end{array}$

$\begin{array}{llll}1 & \mathrm{Cl} & 1 \mathrm{Na} & 1\end{array}$

$\begin{array}{llll}1 & \mathrm{Cl} & 2 \mathrm{Na} & 2\end{array}$

102

Al $20 \quad 3$

$\mathrm{Cl} 1 \mathrm{Na} 1$

$\mathrm{Fe} 203$

(G)

(C) [ ]

(C) []

(C) [ ]

$(\mathrm{Kg})$

(G)

(G)

(G)

(C) [ ]

(C) []

(C) []

\section{7 wt $\% \mathrm{Al} / \mathrm{Fe}(1: 1)$}

Volume of gas products

Pressure of gas products

Temperature

Gas products amount

Products heat capacity

Products entropy

Products enthalpy

Products in molar fraction

$1 \mathrm{Cl} 1$

$\begin{array}{llll}1 & \mathrm{Cl} & 3 \mathrm{Na} & 3\end{array}$

$1 \mathrm{Cl} 1 \mathrm{Na} 1$

$\begin{array}{llll}1 & \mathrm{Cl} & 2 \mathrm{Na} & 2\end{array}$

102

Al $1 \mathrm{Na} 1 \mathrm{O} \quad 2$

Al $20 \quad 3$

$\mathrm{Cl} 1 \mathrm{Na} 1$

$\mathrm{Fe} 203$

Products in mass fraction

$1 \mathrm{Cl} 1$

$\begin{array}{llll}1 & \mathrm{Cl} & 3 \mathrm{Na} & 3\end{array}$

$\begin{array}{llll}1 & \mathrm{Cl} & 1 \mathrm{Na} & 1\end{array}$

$\begin{array}{llll}1 & \mathrm{Cl} & 2 \mathrm{Na} & 2\end{array}$

102

Al $1 \mathrm{Na} \quad 10 \quad 2$

Al 203

Cl $1 \mathrm{Na} 1$

$\mathrm{Fe} 203$ (litres)

(atm)

(K)

$(\mathrm{mol})$

$(\mathrm{J} / \mathrm{K})$

$(\mathrm{J} / \mathrm{K})$

(KJ)

(G)

(G)

(G)

(G)

(G)

(C) [ ]

(C) [ ]

(C) [ ]

(C) [ ]

( $\mathrm{Kg})$

(G)

(G)

(G)

(G)

(C) $\quad[]$

(C) [ ]

(C) []

(C) [ ]
26.2543

1.0000

901.5401

0.3435

26.8616

113.9015

$-84.9724$

1.20E-0006

$3.70 \mathrm{E}-0007$

0.3435

0.0017

0.2323

0.0017

0.0250

$1.18 \mathrm{E}-0008$

$2.82 \mathrm{E}-0006$

$1.73 \mathrm{E}-0006$

0.4396

0.0068

0.5430

0.0106

4.89E-0009 (atm)

$3.51 \mathrm{E}-0006$ (atm)

$1.08 \mathrm{E}-0006$ (atm)

$1.0000 \quad(\mathrm{~atm})$

$$
\begin{array}{r}
28.2082 \\
1.0000 \\
982.4010 \\
0.3386 \\
27.4701 \\
115.2619 \\
-84.4558
\end{array}
$$

$6.62 \mathrm{E}-0009$

4. $30 \mathrm{E}-0008$

$1.29 \mathrm{E}-0005$

$4.99 \mathrm{E}-0006$

0.3386

$1.04 \mathrm{E}-0008$

0.0026

0.2309

0.0026

0.0250

$9.39 \mathrm{E}-0009$

3. $02 \mathrm{E}-0007$

3. $02 \mathrm{E}-0005$

2. $33 \mathrm{E}-0005$

0.4334

$3.29 \mathrm{E}-0008$

0.0105

0.5397

0.0164

$$
\begin{array}{rr}
1.95 \mathrm{E}-0008 & \text { (atm) } \\
1.27 \mathrm{E}-0007 & (\mathrm{~atm}) \\
3.82 \mathrm{E}-0005 & (\mathrm{~atm}) \\
1.47 \mathrm{E}-0005 & (\mathrm{~atm}) \\
0.9999 & (\mathrm{~atm})
\end{array}
$$

\section{6 wto $\mathrm{Al} / \mathrm{Fe}(1: 1)$}

Volume of gas products (litres)

Pressure of gas products

(atm)

30.1872
1.0000

30.1846

1.0000

30.2074

1.0000 


Temperature
Gas products amount
Products heat capacity
Products entropy
Products enthalpy
Phase transition enthalpy
Products in molar fraction
$1 \mathrm{Cl} 1 \mathrm{Na} 1$
$1 \mathrm{Cl} 2 \mathrm{Na} 2$
$1 \mathrm{O} 2$
$\mathrm{Al} 2 \mathrm{O} 3$
$\mathrm{Cl} 1 \mathrm{Na} 1$
$\mathrm{Cl} 1 \mathrm{Na} 1$
$\mathrm{Fe} 2 \mathrm{O} 3$
Products $\mathrm{in}$ mass fraction
$1 \mathrm{Cl} 1 \mathrm{Na} 1$
$1 \mathrm{Cl} 2 \mathrm{Na} 2$
$1 \mathrm{O} 2$
$\mathrm{Al} 2 \mathrm{O} 3$
$\mathrm{Cl} 1 \mathrm{Na} 1$
$\mathrm{Cl} 1 \mathrm{Na} 1$
$\mathrm{Fe} 2 \mathrm{O} 3$

$\begin{array}{lrrr}(\mathrm{K}) & 1074.1062 & 1073.7055 & 1074.5069 \\ (\mathrm{~mol}) & 0.3316 & 0.3316 & 0.3316 \\ (\mathrm{~J} / \mathrm{K}) & 28.2111 & 28.2071 & 28.2422 \\ (\mathrm{~J} / \mathrm{K}) & 116.9817 & 116.2970 & 122.3192 \\ (\mathrm{KJ}) & -83.6761 & -84.4114 & -77.9436 \\ (\mathrm{KJ}) & 6.4678 & & \\ & & & \\ (\mathrm{G}) & 1.19 \mathrm{E}-0004 & 1.19 \mathrm{E}-0004 & 1.21 \mathrm{E}-0004 \\ (\mathrm{G}) & 5.60 \mathrm{E}-0005 & 5.59 \mathrm{E}-0005 & 5.68 \mathrm{E}-0005 \\ (\mathrm{G}) & 0.3314 & 0.3314 & 0.3314 \\ (\mathrm{C})[] & 0.0039 & 0.0039 & 0.0039 \\ (\mathrm{C})[] & 0.2026 & 0.2285 & 0.0000 \\ (\mathrm{~L})[] & 0.0260 & 0.0000 & 0.2285 \\ (\mathrm{C})[] & 0.0039 & 0.0039 & 0.0039 \\ (\mathrm{Kg}) & 0.0250 & & \\ (\mathrm{G}) & 2.79 \mathrm{E}-0004 & 2.78 \mathrm{E}-0004 & 2.83 \mathrm{E}-0004 \\ (\mathrm{G}) & 2.62 \mathrm{E}-0004 & 2.61 \mathrm{E}-0004 & 2.66 \mathrm{E}-0004 \\ (\mathrm{G}) & 0.4241 & 0.4241 & 0.4241 \\ (\mathrm{C})[] & 0.0160 & 0.0160 & 0.0160 \\ (\mathrm{C})[] & 0.4735 & 0.5342 & 0.0000 \\ (\mathrm{~L})[] & 0.0607 & 0.0000 & 0.5342 \\ \text { (C) [] } & 0.0251 & 0.0251 & 0.0251\end{array}$

\subsubsection{Nickel}

\section{1 wto $\mathrm{Al} / \mathrm{Ni}(1: 1)$}

Pressure of gas products

Temperature

Gas products amount

Products heat capacity

Products entropy

Products enthalpy

Products in molar fraction

$\begin{array}{llll}1 & \mathrm{Cl} & 1 \mathrm{Na} & 1\end{array}$

$\begin{array}{llll}1 & \mathrm{Cl} & 2 \mathrm{Na} & 2\end{array}$

102

Al $2 \mathrm{Ni} \quad 10 \quad 4$

$\mathrm{Cl} 1 \mathrm{Na} 1$

$\mathrm{Ni} 10 \quad 1$

Products in mass fraction

$\begin{array}{llll}1 & \mathrm{Cl} & 1 \mathrm{Na} & 1\end{array}$

$\begin{array}{llll}1 & \mathrm{Cl} & 2 \mathrm{Na} & 2\end{array}$

102

Al $2 \mathrm{Ni} 10 \quad 4$

Cl $1 \mathrm{Na} 1$

Ni 101

molar fraction
4
mass fraction
4

\section{0 wt\% $\mathrm{Al} / \mathrm{Ni}(1: 1)$}

Volume of gas products

Pressure of gas products

Temperature

Gas products amount

Products heat capacity

Products entropy

Products enthalpy

Products in molar fraction

102

Al $2 \mathrm{Ni} 10$

Cl $1 \mathrm{Na} 1$

$\mathrm{Ni} 101$

Products in mass fraction

102

( $G$ )

(G)

(G)

(C) []

(C) []

(C) []

( Kg)

(G)

(G)

(G)

(C) []

(C) []

(C) [ ]

$$
\begin{array}{r}
25.5885 \\
1.0000 \\
876.2088 \\
0.3444 \\
26.5686 \\
113.2996 \\
-84.9885
\end{array}
$$

$5.20 E-0007$

$1.46 \mathrm{E}-0007$

0.3444

0.0016

0.2323

0.0016

0.0250

1.22E-0006

$6.85 \mathrm{E}-0007$

0.4408

0.0113

0.5430

0.0048
1. 51E-0006

$4.25 \mathrm{E}-0007$

1.0000

(atm)

(atm)

(atm)

$$
\begin{array}{rr}
1.51 \mathrm{E}-0006 & (\mathrm{~atm}) \\
4.25 \mathrm{E}-0007 & (\mathrm{~atm}) \\
1.0000 & (\mathrm{~atm})
\end{array}
$$

$$
\begin{array}{r}
28.0488 \\
1.0000 \\
978.7479 \\
0.3380 \\
27.3773 \\
114.9434 \\
-84.2134
\end{array}
$$

0.3380

0.0029

0.2302

0.0029

0.0250

0.4326

\subsection{0 (atm)}

1.0000 (atm) 

Al $2 \mathrm{Ni} \quad 10 \quad 4$
(C) []
0.0206
$\mathrm{Cl} 1 \mathrm{Na} 1$
(C) []
0.5380
Ni 101
(C) [ ]
0.0087

3.1 wto $\mathrm{Al} / \mathrm{Ni}(1: 1)$

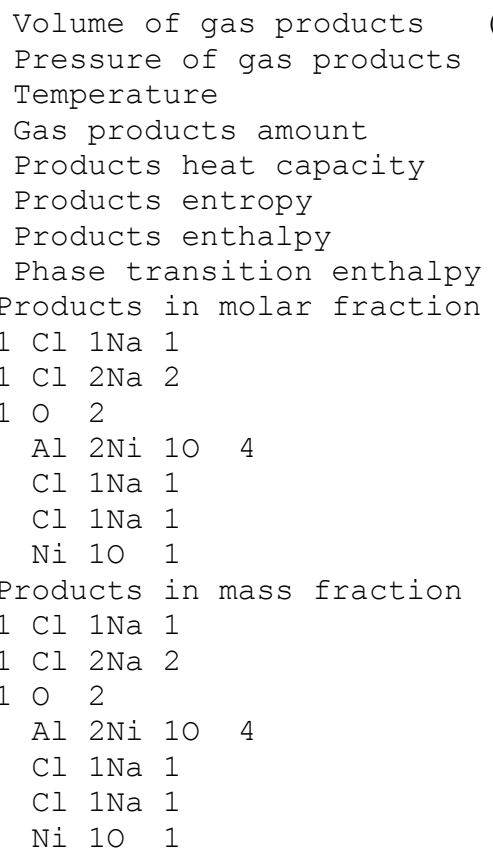

(litres)

(atm)

(K)

$(\mathrm{mol})$

$(\mathrm{J} / \mathrm{K})$

$(\mathrm{J} / \mathrm{K})$

$(\mathrm{KJ})$

(KJ)

(G)

(C) [ ]

(C) []

(L) [ ]

(C) [ ]

$(\mathrm{Kg})$

(G)

(G)

(G)

(C) [ ]

(C) []

(L) []

(C) [ ]

$$
\begin{array}{r}
30.0642 \\
1.0000 \\
1073.9067 \\
0.3303 \\
28.1157 \\
116.5861 \\
-83.2465 \\
6.4324
\end{array}
$$

1. $18 \mathrm{E}-0004$

5. 56E-0005

0.3301

0.0045

0.2010

0.0263

0.0045

0.0250

$2.77 \mathrm{E}-0004$

2. 60E-0004

0.4225

0.0320

0.4699

0.0616

0.0135

$$
\begin{array}{r}
30.0618 \\
1.0000 \\
1073.5452 \\
0.3303 \\
28.1116 \\
115.8920 \\
-83.9920
\end{array}
$$

1. 18E-0004

5. 55E-0005

0.3301

0.0045

0.2274

0.0000

0.0045

$2.76 \mathrm{E}-0004$

$2.59 \mathrm{E}-0004$

0.4225

0.0320

0.5315

0.0000

0.0135
30.0823

1.0000

1074.2681

0.3303

28.1475

121.8813

$-77.5595$

1.20E-0004

$5.64 \mathrm{E}-0005$

0.3301

0.0045

0.0000

0.2274

0.0045

2. $80 \mathrm{E}-0004$

2. $63 \mathrm{E}-0004$

0.4225

0.0320

0.0000

0.5315

0.0135

\subsubsection{Titanium}

\section{6 wt $\%$ Al/Ti $(1: 1)$}

$\begin{array}{llr}\text { Volume of gas products } & \text { (litres) } & 26.4563 \\ \text { Pressure of gas products } & (\mathrm{atm}) & 1.0000 \\ \text { Temperature } & (\mathrm{K}) & 900.0000 \\ \text { Gas products amount } & (\mathrm{mol}) & 0.3467 \\ \text { Products heat capacity } & (\mathrm{J} / \mathrm{K}) & 26.8174 \\ \text { Products entropy } & (\mathrm{J} / \mathrm{K}) & 114.5444 \\ \text { Products enthalpy } & (\mathrm{KJ}) & -84.9752\end{array}$

Products in molar fraction

$1 \mathrm{Cl} 1$

(G) $\quad 1.23 \mathrm{E}-0008$

(G) $\quad 8.07 \mathrm{E}-0008$

(G) $\quad 1.16 \mathrm{E}-0006$

$\begin{array}{llll}1 & \mathrm{Cl} & 1 \mathrm{Na} & 1\end{array}$

$1 \mathrm{Cl} 2 \mathrm{Na} 2$

102

Al $20 \quad 5 \mathrm{Ti} 1$

$\mathrm{Cl} 1 \mathrm{Na} 1$

$\mathrm{Na} 2 \mathrm{O} \quad 7 \mathrm{Ti} 3$

(G)

(C) []

(C) [ ]

$3.53 \mathrm{E}-0007$

0.3467

0.0010

(C) []

0.2335

O $2 \mathrm{Ti} 1$

(C) [ ]

Products in mass fraction

$(\mathrm{Kg})$

$\begin{array}{lll}1 & \mathrm{Cl} & 1\end{array}$

$1 \mathrm{Cl} 2$

(G)

(G)

(G)

$1 \mathrm{Cl} 3 \mathrm{Na} 3$

$\begin{array}{llll}1 & \mathrm{Cl} & 1 \mathrm{Na} & 1\end{array}$

$\begin{array}{llll}1 & \mathrm{Cl} & 2 \mathrm{Na} & 2\end{array}$

102

Al $20 \quad 5 \mathrm{Ti} 1$

Cl $1 \mathrm{Na} 1$

$\mathrm{Na} 2 \mathrm{O} \quad 7 \mathrm{Ti} 3$

- 2Ti 1

(G)

(G)

(G)

(C) []

(C) []

3. 55E-0008

(atm)

$2.33 \mathrm{E}-0007$ (atm)

3. $34 \mathrm{E}-0006$

(atm)

$1.02 \mathrm{E}-0006$

(atm)

1.0000 (atm)

8. $74 \mathrm{E}-0008$

0.0010

0.0250

1. $74 \mathrm{E}-0008$

$2.29 \mathrm{E}-0007$

1. $11 \mathrm{E}-0008$

$2.70 E-0006$

1. $65 \mathrm{E}-0006$

0.4437

0.0073

(C) []

0.5458

(C) [ ]

1.05E-0006

0.0032

3. 55E-0008 (atm)

2.33E-0007 (atm)

4.57E-0009 (atm)

3.34E-0006 (atm)

$1.02 \mathrm{E}-0006$ (atm)

$1.0000 \quad(\mathrm{~atm})$

1.1 wt\% $\mathrm{Al} / \mathrm{Ti}(1: 1)$

Volume of gas products (litres)

28.8057 


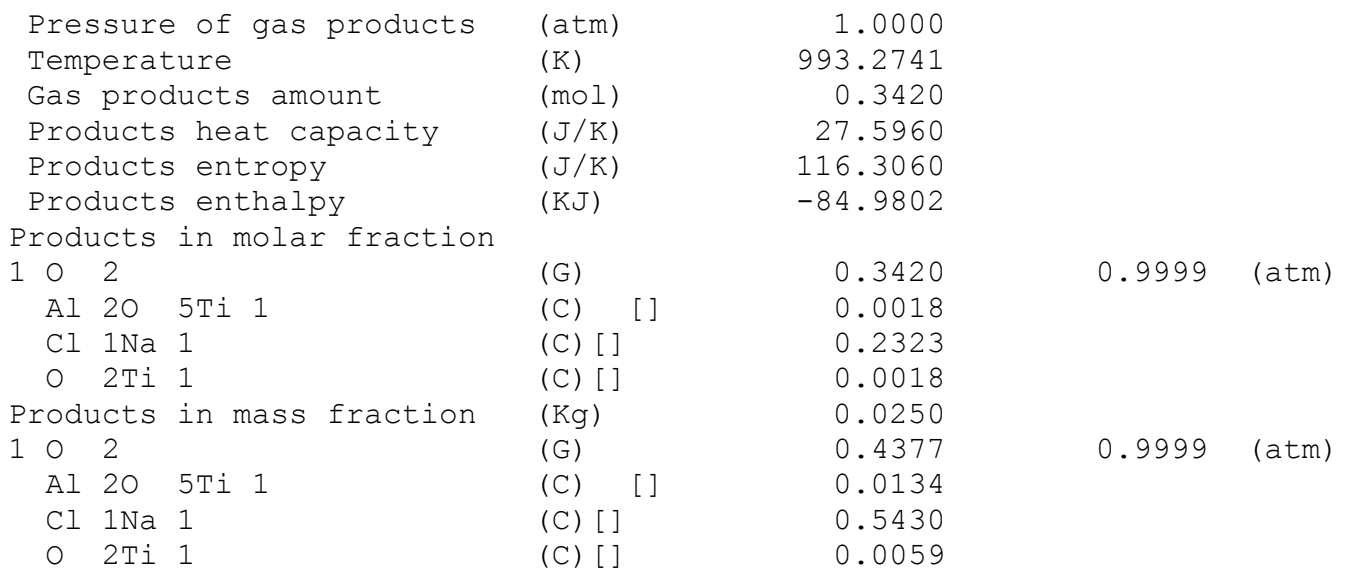

\section{6 wt\% Al/Ti $(1: 1)$}

\begin{tabular}{|c|c|c|c|c|}
\hline Volume of gas products & Litres) & 30.7254 & 30.7231 & 30.7441 \\
\hline Pressure of gas products & $(a t m)$ & 1.0000 & 1.0000 & 1.0000 \\
\hline Temperature & $(\mathrm{K})$ & 1073.9677 & 1073.6053 & 1074.3301 \\
\hline Gas products amount & $(\mathrm{mol})$ & 0.3375 & 0.3375 & 0.3375 \\
\hline Products heat capacity & $(\mathrm{J} / \mathrm{K})$ & 28.2743 & 28.2704 & 28.3064 \\
\hline Products entropy & $(\mathrm{J} / \mathrm{K})$ & 118.2501 & 117.5840 & 123.6655 \\
\hline Products enthalpy & $(\mathrm{KJ})$ & -84.5352 & -85.2506 & -78.7190 \\
\hline $\begin{array}{l}\text { Phase transition enthalpy } \\
\text { Products in molar fraction }\end{array}$ & $(\mathrm{KJ})$ & 6.5316 & & \\
\hline $\mathrm{Cl} 1 \mathrm{Na} 1$ & (G) & $1.21 E-0004$ & $1.21 E-0004$ & $1.23 E-0004$ \\
\hline $\mathrm{Cl} 2 \mathrm{Na} 2$ & (G) & $5.69 E-0005$ & $5.68 \mathrm{E}-0005$ & $5.77 E-0005$ \\
\hline 02 & (G) & 0.3373 & 0.3373 & 0.3373 \\
\hline Al $20 \quad 5 \mathrm{Ti} 1$ & (C) $\quad[]$ & 0.0027 & 0.0027 & 0.0027 \\
\hline $\mathrm{Cl} 1 \mathrm{Na} 1$ & (C) [] & 0.2056 & 0.2309 & 0.0000 \\
\hline $\mathrm{Cl} 1 \mathrm{Na} 1$ & $(\mathrm{~L})[]$ & 0.0253 & 0.0000 & 0.2309 \\
\hline $\mathrm{O} \quad 2 \mathrm{Ti} 1$ & (C) [] & 0.0027 & 0.0027 & 0.0027 \\
\hline Products in mass fraction & $(\mathrm{Kg})$ & 0.0250 & & \\
\hline $\mathrm{Cl} 1 \mathrm{Na} 1$ & $(G)$ & $2.83 E-0004$ & $2.82 \mathrm{E}-0004$ & $2.87 \mathrm{E}-0004$ \\
\hline $\mathrm{Cl} 2 \mathrm{Na} 2$ & (G) & $2.66 \mathrm{E}-0004$ & $2.65 \mathrm{E}-0004$ & $2.70 E-0004$ \\
\hline 02 & (G) & 0.4317 & 0.4317 & 0.4317 \\
\hline Al $20 \quad 5 \mathrm{Ti} 1$ & (C) [ ] & 0.0194 & 0.0194 & 0.0194 \\
\hline $\mathrm{Cl} 1 \mathrm{Na} 1$ & (C) [] & 0.4806 & 0.5397 & 0.0000 \\
\hline $\mathrm{Cl} 1 \mathrm{Na} 1$ & (L) [] & 0.0591 & 0.0000 & 0.5397 \\
\hline $0 \quad 2 \mathrm{Ti} 1$ & (C) [] & 0.0085 & 0.0085 & 0.0085 \\
\hline
\end{tabular}




\section{Metalloid-Metal Composites}

\subsection{Boron}

\subsubsection{Hafnium}

\section{2 wto $\mathrm{B} / \mathrm{Hf}(1: 2)$}

Volume of gas products

Pressure of gas products

Temperature

Gas products amount

Products heat capacity

Products entropy

Products enthalpy

Products in molar fraction

$1 \mathrm{Cl} 1$

$\begin{array}{lll}1 & \mathrm{Cl} & 2\end{array}$

$\begin{array}{llll}1 & \mathrm{Cl} & 1 \mathrm{Na} & 1\end{array}$

$\begin{array}{llll}1 & \mathrm{Cl} & 2 \mathrm{Na} & 2\end{array}$

$\begin{array}{llll}1 & \mathrm{Cl} & 10 & 1\end{array}$

102

B $\quad 6 \mathrm{Na} \quad 20 \quad 10$

B 203

$\mathrm{Cl} 1 \mathrm{Na} 1$

Hf 102

Products in mass fraction

$1 \mathrm{Cl} 1$

$1 \mathrm{Cl} 2$

$\begin{array}{llll}1 & \mathrm{Cl} & 1 \mathrm{Na} & 1\end{array}$

$\begin{array}{llll}1 & \mathrm{Cl} & 2 \mathrm{Na} & 2\end{array}$

$\begin{array}{llll}1 & \mathrm{Cl} & 10 & 1\end{array}$

102

B $\quad 6 \mathrm{Na} \quad 20 \quad 10$

B 203

Cl $1 \mathrm{Na} 1$

Hf 102

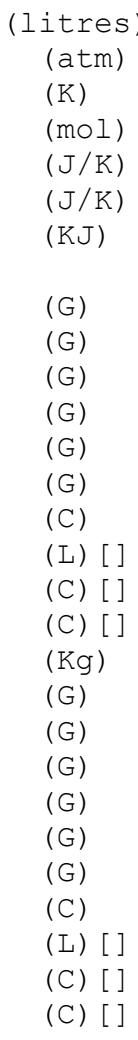

itres

K)

$\mathrm{mol})$

$\mathrm{J} / \mathrm{K})$

(G)

(L) [ ]

C) [ ]

(C) []

(G)

(G)

(G)

(G)

(G)

C)

C) []

(C) []

$$
\begin{array}{r}
25.7418 \\
1.0000 \\
881.3309 \\
0.3445 \\
26.5192 \\
113.2959 \\
-84.9028
\end{array}
$$

$5.02 \mathrm{E}-0007$

2.73E-0004

$6.19 \mathrm{E}-0007$

1. $78 \mathrm{E}-0007$

3. $91 \mathrm{E}-0008$

0.3442

$2.73 E-0004$

$6.79 \mathrm{E}-0004$

0.2315

0.0015

0.0250

7.12E-0007

$7.75 \mathrm{E}-0004$

1. $45 \mathrm{E}-0006$

8.30E-0007

8.04E-0008

0.4405

0.0030

0.0019

0.5412

0.0126

$$
\begin{array}{rr}
1.46 \mathrm{E}-0006 & \text { (atm) } \\
7.93 \mathrm{E}-0004 & \text { (atm) } \\
1.80 \mathrm{E}-0006 & \text { (atm) } \\
5.16 \mathrm{E}-0007 & \text { (atm) } \\
1.13 \mathrm{E}-0007 & \text { (atm) } \\
0.9992 & \text { (atm) }
\end{array}
$$

\section{1 wto $\mathrm{B} / \mathrm{Hf}(1: 2)$}

$\begin{array}{llr}\text { Volume of gas products } & \text { (litres) } & 28.1029 \\ \text { Pressure of gas products } & (\mathrm{atm}) & 1.0000 \\ \text { Temperature } & (\mathrm{K}) & 979.2917 \\ \text { Gas products amount } & (\mathrm{mol}) & 0.3384 \\ \text { Products heat capacity } & (\mathrm{J} / \mathrm{K}) & 27.2385 \\ \text { Products entropy } & (\mathrm{J} / \mathrm{K}) & 114.7895 \\ \text { Products enthalpy } & (\mathrm{KJ}) & -84.1227\end{array}$

Products in molar fraction

$2.05 \mathrm{E}-0006$

$6.06 \mathrm{E}-0006$

(atm)

$1.57 \mathrm{E}-0004$

$3.83 \mathrm{E}-0008$

$1 \mathrm{Cl} 3 \mathrm{Na} 3$

$1.19 \mathrm{E}-0005$

$4.54 \mathrm{E}-0006$

1.20E-0007

0.3383

$1 \mathrm{Cl} 10 \quad 1$

102

B $\quad 6 \mathrm{Na} \quad 20 \quad 10$

(C)

B 203

Cl $1 \mathrm{Na} 1$

Hf 102

(L) [ ]

(C) []

(C) [ ]

Products in mass fraction

$(\mathrm{Kg})$

$1 \mathrm{Cl} 1$

$1 \mathrm{Cl} 2$

(G)

(G)

$\begin{array}{llll}1 & \mathrm{Cl} & 3 \mathrm{Na} & 3\end{array}$

$\begin{array}{llll}1 & \mathrm{Cl} & 1 \mathrm{Na} & 1\end{array}$

$\begin{array}{llll}1 & \mathrm{Cl} & 2 \mathrm{Na} & 2\end{array}$

1. 58E-0004

0.0021

0.2296

0.0026

0.0250

2.92E-0006

4. $44 \mathrm{E}-0004$

2. $73 \mathrm{E}-0007$

2. $81 \mathrm{E}-0005$

4. 63E-0004

(atm)

$1.13 \mathrm{E}-0007$ (atm)

3.51E-0005 (atm)

1. 34E-0005

3. $54 \mathrm{E}-0007$

(atm)

0.9995

(atm)

6.09E-0006 (atm)

4.62E-0004 (atm)

1.15E-0007 (atm)

3.55E-0005 (atm)

$2.15 \mathrm{E}-0005$ 1.36E-0005 (atm) 
$\begin{array}{llll}1 & \mathrm{Cl} & 10 & 1\end{array}$

102

B $\quad 6 \mathrm{Na} \quad 20 \quad 10$

B 203

Cl $1 \mathrm{Na} 1$

Hf 102
(G)

(G)

(C)

(L) [ ]

(C) []

(C) []
$2.47 E-0007$
0.4330
0.0017
0.0060
0.5368
0.0221

\subsection{E-0007 (atm) \\ 0.9995 (atm)}

\section{2 wto $B / H f(1: 2)$}

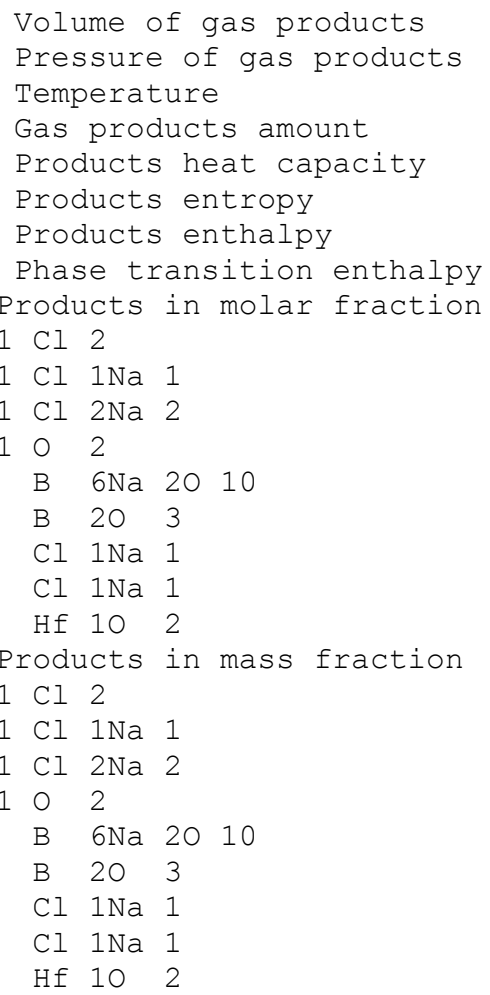

\begin{tabular}{|c|c|c|c|}
\hline itres) & 30.1522 & 30.1506 & 30.1674 \\
\hline (atm) & 1.0000 & 1.0000 & 1.0000 \\
\hline$(\mathrm{K})$ & 1073.7167 & 1073.4218 & 1074.0116 \\
\hline$(\operatorname{mol})$ & 0.3313 & 0.3313 & 0.3313 \\
\hline$(\mathrm{J} / \mathrm{K})$ & 27.8939 & 27.8904 & 27.9269 \\
\hline$(\mathrm{J} / \mathrm{K})$ & 116.2698 & 115.6954 & 121.6697 \\
\hline$(\mathrm{KJ})$ & -83.1606 & -83.7775 & -77.3612 \\
\hline (KJ) & 6.4163 & & \\
\hline (G) & $9.53 \mathrm{E}-0005$ & $9.54 \mathrm{E}-0005$ & $9.50 \mathrm{E}-0005$ \\
\hline (G) & $1.18 \mathrm{E}-0004$ & $1.18 \mathrm{E}-0004$ & $1.20 \mathrm{E}-0004$ \\
\hline (G) & $5.56 \mathrm{E}-0005$ & $5.55 \mathrm{E}-0005$ & $5.63 \mathrm{E}-0005$ \\
\hline (G) & 0.3310 & 0.3310 & 0.3310 \\
\hline (C) & $9.84 \mathrm{E}-0005$ & $9.85 \mathrm{E}-0005$ & $9.81 E-0005$ \\
\hline (L) [ ] & 0.0037 & 0.0037 & 0.0037 \\
\hline (C) [ ] & 0.2051 & 0.2269 & 0.0000 \\
\hline (L) [ ] & 0.0218 & 0.0000 & 0.2269 \\
\hline (C) [ ] & 0.0040 & 0.0040 & 0.0040 \\
\hline$(\mathrm{Kg})$ & 0.0250 & & \\
\hline (G) & $2.70 \mathrm{E}-0004$ & $2.70 E-0004$ & $2.70 \mathrm{E}-0004$ \\
\hline (G) & $2.76 \mathrm{E}-0004$ & $2.76 \mathrm{E}-0004$ & $2.80 \mathrm{E}-0004$ \\
\hline (G) & $2.60 \mathrm{E}-0004$ & $2.59 \mathrm{E}-0004$ & $2.63 \mathrm{E}-0004$ \\
\hline (G) & 0.4236 & 0.4236 & 0.4236 \\
\hline (C) & 0.0011 & 0.0011 & 0.0011 \\
\hline (L) [ ] & 0.0103 & 0.0103 & 0.0103 \\
\hline (C) [ ] & 0.4795 & 0.5305 & 0.0000 \\
\hline (L) [ ] & 0.0510 & 0.0000 & 0.530 \\
\hline (C) [ ] & 0.0337 & 0.0337 & 0.033 \\
\hline
\end{tabular}

\subsubsection{Titanium}

\section{5 wto $\mathrm{B} / \mathrm{Ti}(1: 1)$}

$\begin{array}{llr}\text { Volume of gas products } & \text { (litres) } & 25.6979 \\ \text { Pressure of gas products } & (\mathrm{atm}) & 1.0000 \\ \text { Temperature } & (\mathrm{K}) & 873.5065 \\ \text { Gas products amount } & (\mathrm{mol}) & 0.3470 \\ \text { Products heat capacity } & (\mathrm{J} / \mathrm{K}) & 26.6199 \\ \text { Products entropy } & (\mathrm{J} / \mathrm{K}) & 113.8397 \\ \text { Products enthalpy } & (\mathrm{KJ}) & -85.4909\end{array}$

Products in molar fraction

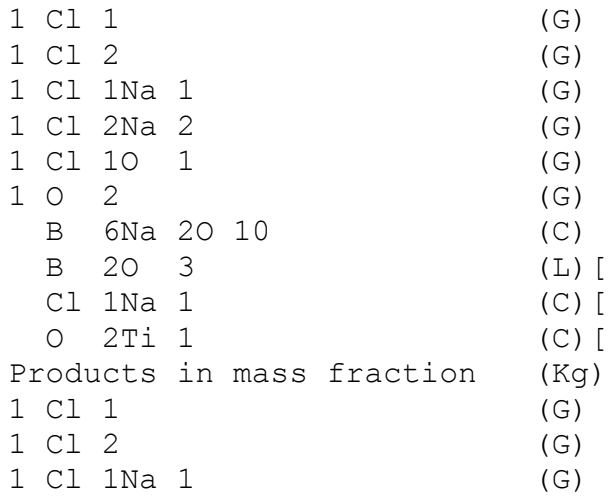

$\begin{array}{rrr}4.44 \mathrm{E}-0007 & 1.28 \mathrm{E}-0006 & (\mathrm{~atm}) \\ 2.88 \mathrm{E}-0004 & 8.29 \mathrm{E}-0004 & (\mathrm{~atm}) \\ 4.77 \mathrm{E}-0007 & 1.37 \mathrm{E}-0006 & (\mathrm{~atm}) \\ 1.33 \mathrm{E}-0007 & 3.84 \mathrm{E}-0007 & (\mathrm{~atm}) \\ 3.55 \mathrm{E}-0008 & 1.02 \mathrm{E}-0007 & (\mathrm{~atm}) \\ 0.3467 & 0.9992 & (\mathrm{~atm}) \\ 2.88 \mathrm{E}-0004 & & \\ 2.02 \mathrm{E}-0004 & & \\ 0.2331 & & \\ 0.0021 & & \\ 0.0250 & & \\ 6.30 \mathrm{E}-0007 & 1.28 \mathrm{E}-0006 & (\mathrm{~atm}) \\ 8.16 \mathrm{E}-0004 & 8.29 \mathrm{E}-0004 & (\mathrm{~atm}) \\ 1.12 \mathrm{E}-0006 & 1.38 \mathrm{E}-0006 & (\mathrm{~atm})\end{array}$




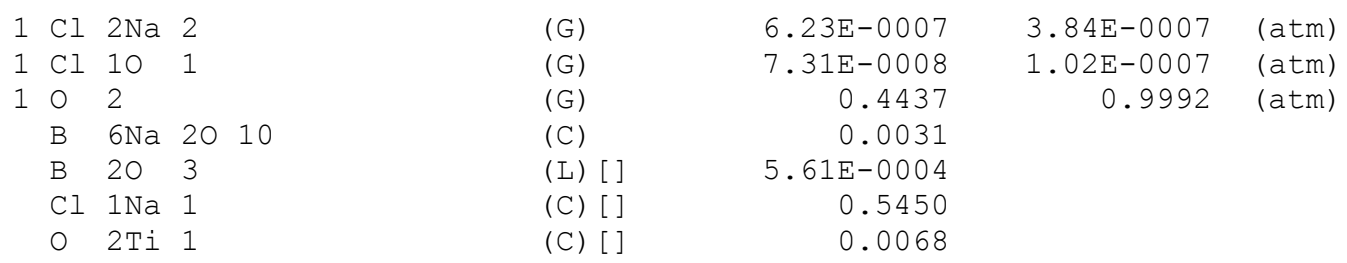

\section{0 wt\% $\mathrm{B} / \mathrm{Ti}(1: 1)$}

$\begin{array}{llr}\text { Volume of gas products } & \text { (litres) } & 28.7711 \\ \text { Pressure of gas products } & (\mathrm{atm}) & 1.0000 \\ \text { Temperature } & (\mathrm{K}) & 993.8224 \\ \text { Gas products amount } & (\mathrm{mol}) & 0.3414 \\ \text { Products heat capacity } & (\mathrm{J} / \mathrm{K}) & 27.6751 \\ \text { Products entropy } & (\mathrm{J} / \mathrm{K}) & 116.3477 \\ \text { Products enthalpy } & (\mathrm{KJ}) & -85.0657\end{array}$

Products in molar fraction

$1 \mathrm{Cl} 2$

102

B $6 \mathrm{Na} 2 \mathrm{O} \quad 10$

(C)

B 203

Cl $1 \mathrm{Na} 1$

O $2 \mathrm{Ti} 1$

(L) [ ]

(C) []

(C) [ ]

Products in mass fraction

$1 \mathrm{Cl} 2$

102

B $\quad 6 \mathrm{Na} 20 \quad 10$

B 203

Cl $1 \mathrm{Na} 1$

(C)

(L) [ ]

(C) [ ]

O $2 \mathrm{Ti} 1$

(C) []

$$
\begin{array}{rrr}
1.47 \mathrm{E}-0004 & 4.29 \mathrm{E}-0004 & \text { (atm) } \\
0.3413 & 0.9995 & \text { (atm) } \\
1.48 \mathrm{E}-0004 & & \\
0.0017 & & \\
0.2322 & & \\
0.0043 & & \\
0.0250 & & \\
4.16 \mathrm{E}-0004 & 4.29 \mathrm{E}-0004 & \text { (atm) } \\
0.4368 & 0.9995 & \text { (atm) } \\
0.0016 & & \\
0.0047 & & \\
0.5428 & & \\
0.0136 & &
\end{array}
$$

\begin{tabular}{|c|c|c|c|c|}
\hline Volume of gas products & (litres) & 30.5906 & 30.5879 & 30.6038 \\
\hline Pressure of gas products & $(a t m)$ & 1.0000 & 1.0000 & 1.0000 \\
\hline Temperature & $(\mathrm{K})$ & 1073.7027 & 1073.4256 & 1073.9797 \\
\hline Gas products amount & $(\mathrm{mol})$ & 0.3361 & 0.3361 & 0.3361 \\
\hline Products heat capacity & $(\mathrm{J} / \mathrm{K})$ & 28.3880 & 28.3821 & 28.4170 \\
\hline Products entropy & $(\mathrm{J} / \mathrm{K})$ & 118.4950 & 117.5393 & 123.1964 \\
\hline Products enthalpy & $(\mathrm{KJ})$ & -84.6211 & -85.6476 & -79.5719 \\
\hline $\begin{array}{l}\text { Phase transition enthalpy } \\
\text { roducts in molar fraction }\end{array}$ & $(\mathrm{KJ})$ & 6.0757 & & \\
\hline $\mathrm{Cl} 2$ & (G) & $9.67 \mathrm{E}-0005$ & $9.67 \mathrm{E}-0005$ & $9.65 \mathrm{E}-0005$ \\
\hline $\mathrm{Cl} 1 \mathrm{Na} 1$ & (G) & $1.20 \mathrm{E}-0004$ & 1.20E-0004 & $1.21 E-0004$ \\
\hline $\mathrm{Cl} 2 \mathrm{Na} 2$ & ( $G$ ) & $5.64 \mathrm{E}-0005$ & $5.63 E-0005$ & $5.71 E-0005$ \\
\hline 02 & (G) & 0.3358 & 0.3358 & 0.3358 \\
\hline B $\quad 6 \mathrm{Na} \quad 20 \quad 10$ & (C) & $9.98 \mathrm{E}-0005$ & $9.99 \mathrm{E}-0005$ & $9.97 E-0005$ \\
\hline B $20 \quad 3$ & (L) [] & 0.0029 & 0.0029 & 0.0029 \\
\hline $\mathrm{Cl} 1 \mathrm{Na} 1$ & (C) [] & 0.1946 & 0.2309 & 0.0160 \\
\hline $\mathrm{Cl} 1 \mathrm{Na} 1$ & (L) [] & 0.0363 & 0.0000 & 0.2149 \\
\hline $\mathrm{O} \quad 2 \mathrm{Ti} 1$ & (C) [] & 0.0064 & 0.0064 & 0.0064 \\
\hline roducts in mass fraction & $(\mathrm{Kg})$ & 0.0250 & & \\
\hline $\mathrm{Cl} 2$ & (G) & $2.74 \mathrm{E}-0004$ & $2.74 \mathrm{E}-0004$ & $2.74 \mathrm{E}-0004$ \\
\hline $\mathrm{Cl} 1 \mathrm{Na} 1$ & ( $G$ ) & $2.81 \mathrm{E}-0004$ & $2.80 \mathrm{E}-0004$ & $2.83 E-0004$ \\
\hline $\mathrm{Cl} 2 \mathrm{Na} 2$ & (G) & $2.64 \mathrm{E}-0004$ & $2.63 \mathrm{E}-0004$ & $2.67 E-0004$ \\
\hline 02 & (G) & 0.4298 & 0.4298 & 0.4298 \\
\hline B $\quad 6 \mathrm{Na} \quad 20 \quad 10$ & (C) & 0.0011 & 0.0011 & 0.0011 \\
\hline B $20 \quad 3$ & $(\mathrm{~L})[]$ & 0.0081 & 0.0081 & 0.0081 \\
\hline $\mathrm{Cl} 1 \mathrm{Na} 1$ & (C) [] & 0.4549 & 0.5398 & 0.0000 \\
\hline $\mathrm{Cl} 1 \mathrm{Na} 1$ & $(\mathrm{~L})[]$ & 0.0849 & 0.0000 & 0.5398 \\
\hline $0 \quad 2 \mathrm{Ti} 1$ & (C) [] & 0.0204 & 0.0204 & 0.0204 \\
\hline
\end{tabular}

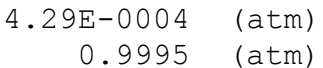

\section{5 wto $\mathrm{B} / \mathrm{Ti}(1: 1)$}




\subsubsection{Zirconium}

\section{7 wt $\%$ B/Zr (1:2)}

$\begin{array}{llr}\text { Volume of gas products } & \text { (litres) } & 25.9523 \\ \text { Pressure of gas products } & (\mathrm{atm}) & 1.0000 \\ \text { Temperature } & (\mathrm{K}) & 884.3511 \\ \text { Gas products amount } & (\mathrm{mol}) & 0.3461 \\ \text { Products heat capacity } & (\mathrm{J} / \mathrm{K}) & 26.6791 \\ \text { Products entropy } & (\mathrm{J} / \mathrm{K}) & 113.9291 \\ \text { Products enthalpy } & (\mathrm{KJ}) & -85.3327\end{array}$

Products in molar fraction

$1 \mathrm{Cl} 1$

(G) $\quad 5.30 \mathrm{E}-0007$

$1 \mathrm{Cl} 2$

$\begin{array}{llll}1 & \mathrm{Cl} & 1 \mathrm{Na} & 1\end{array}$

$\begin{array}{llll}1 & \mathrm{Cl} & 2 \mathrm{Na} & 2\end{array}$

$\begin{array}{llll}1 & \mathrm{Cl} & 10 & 1\end{array}$

102

B $6 \mathrm{Na} 20 \quad 10$

B 203

$\mathrm{Cl} 1 \mathrm{Na} 1$

O $2 \mathrm{Zr} 1$

$2.70 \mathrm{E}-0004$

$6.89 \mathrm{E}-0007$

Products in mass fraction

$(\mathrm{Kg})$

$1 \mathrm{Cl} 1$

(G) $\quad 7.52 \mathrm{E}-0007$

$1 \mathrm{Cl} 2$

$\begin{array}{llll}1 & \mathrm{Cl} & 3 \mathrm{Na} & 3\end{array}$

$\begin{array}{llll}1 & \mathrm{Cl} & 2 \mathrm{Na} & 2\end{array}$

$\begin{array}{llll}1 & \mathrm{Cl} & 10 & 1\end{array}$

102

B $\quad 6 \mathrm{Na} \quad 20 \quad 10$

B 203

(L) [ ]

$\mathrm{Cl} 1 \mathrm{Na} 1$

(C) []

2. $.00 \mathrm{E}-0007$

$4.09 \mathrm{E}-0008$

0.3458

$2.70 \mathrm{E}-0004$

$7.41 \mathrm{E}-0004$

0.2327

0.0016

0.0250

$\begin{array}{rr}1.53 E-0006 & (\mathrm{~atm}) \\ 7.79 \mathrm{E}-0004 & (\mathrm{~atm}) \\ 1.99 \mathrm{E}-0006 & (\mathrm{~atm}) \\ 5.77 \mathrm{E}-0007 & (\mathrm{~atm}) \\ 1.18 \mathrm{E}-0007 & (\mathrm{~atm}) \\ 0.9992 & (\mathrm{~atm})\end{array}$

$7.66 \mathrm{E}-0004$

$5.46 \mathrm{E}-0009$

$1.61 \mathrm{E}-0006$

$9.33 \mathrm{E}-0007$

$8.41 \mathrm{E}-0008$

0.4426

0.0029

0.0021

0.5440

(C) [ ] 0.0076

$\begin{array}{rr}1.53 \mathrm{E}-0006 & \text { (atm) } \\ 7.80 \mathrm{E}-0004 & (\mathrm{~atm}) \\ 2.25 \mathrm{E}-0009 & (\mathrm{~atm}) \\ 1.99 \mathrm{E}-0006 & (\mathrm{~atm}) \\ 5.77 \mathrm{E}-0007 & (\mathrm{~atm}) \\ 1.18 \mathrm{E}-0007 & (\mathrm{~atm}) \\ 0.9992 & (\mathrm{~atm})\end{array}$

O $2 \mathrm{Zr} 1$

(1itres)

Volume of gas products

(atm)

$(\mathrm{K})$

Temperature

Gas products amount

$(\mathrm{mol})$

Products heat capacity

$(\mathrm{J} / \mathrm{K})$

$(\mathrm{J} / \mathrm{K})$

Products entropy

$(\mathrm{KJ})$

Products in molar fraction

$1 \mathrm{Cl} 2$

102

(C)

(L) [ ]

(C) []

(C) [ ]

B 203

Cl $1 \mathrm{Na} 1$

O $2 \mathrm{Zr} 1$

( $\mathrm{Kg})$

Products in mass fraction

(G)

(C)

(L) [ ]

(C) []

(C) [ ]

$$
\begin{array}{r}
28.3592 \\
1.0000 \\
979.3001 \\
0.3415 \\
27.4807 \\
115.8076 \\
-84.8861
\end{array}
$$

102

B $\quad 6 \mathrm{Na} \quad 20 \quad 10$

$1.58 \mathrm{E}-0004$

0.3414

$1.59 \mathrm{E}-0004$

4.63E-0004 (atm)

0.0022

0.2317

0.0027

0.0250

$4.49 \mathrm{E}-0004$

0.4369

0.0017

0.0061

0.5417

$\mathrm{Cl} 1 \mathrm{Na} 1$

0.0131

$\begin{array}{rr}4.63 \mathrm{E}-0004 & (\mathrm{~atm}) \\ 0.9995 & (\mathrm{~atm})\end{array}$

\section{9 wt\% $\mathrm{B} / \mathrm{Zr}(1: 2)$}

Volume of gas products

Pressure of gas products

(litres)

(atm)

Temperature

(K)

$(\mathrm{mol})$

Gas products amount

$(\mathrm{J} / \mathrm{K})$

Products entropy

$(\mathrm{J} / \mathrm{K})$

$$
\begin{array}{r}
30.5219 \\
1.0000 \\
1073.7119 \\
0.3353 \\
28.2735 \\
118.0223
\end{array}
$$

$$
\begin{array}{r}
30.5194 \\
1.0000 \\
1073.4170 \\
0.3353 \\
28.2682 \\
117.1536
\end{array}
$$




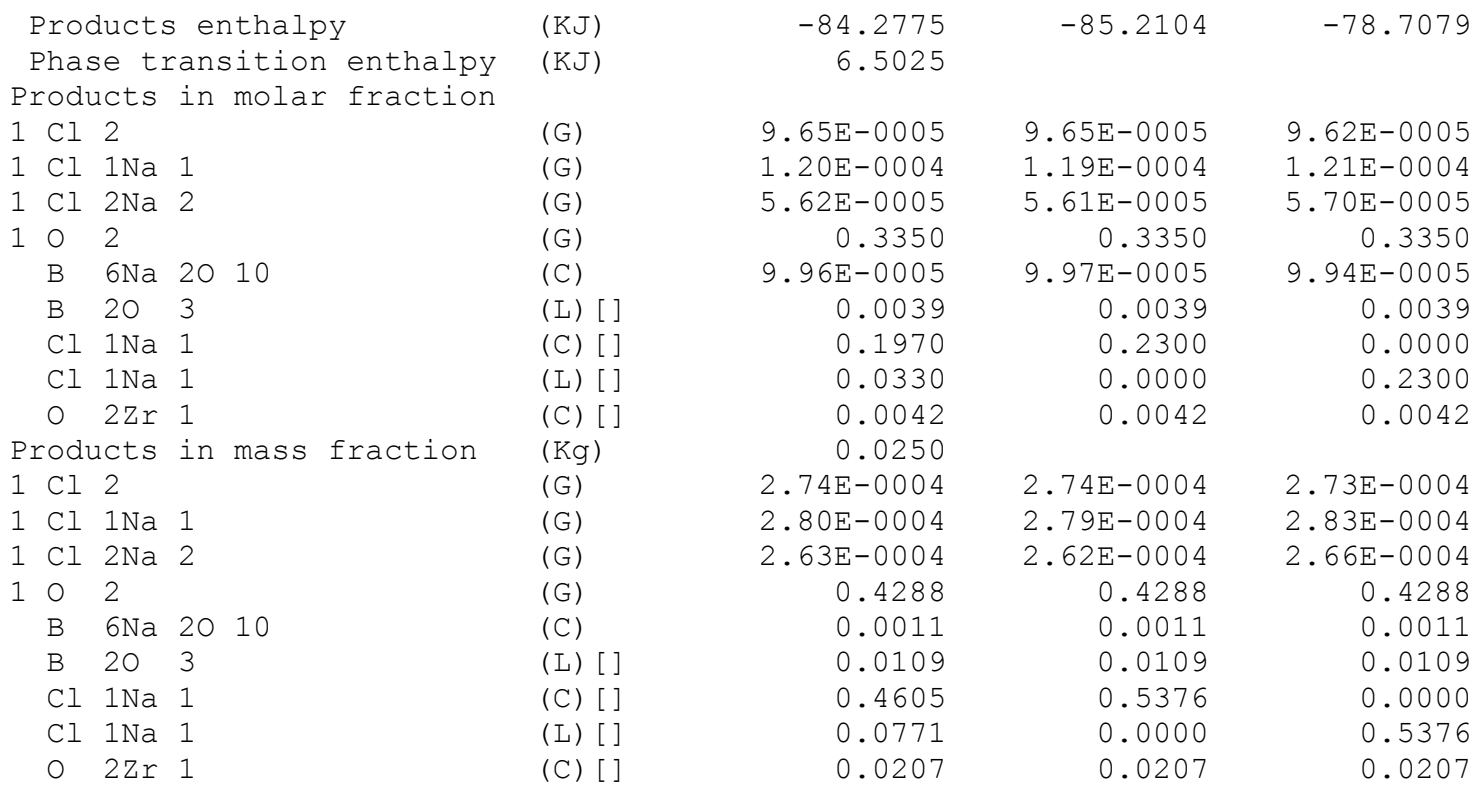




\section{ADIABATIC TEMPERATURE GRAPHS}

\subsection{Single Metals}

Al

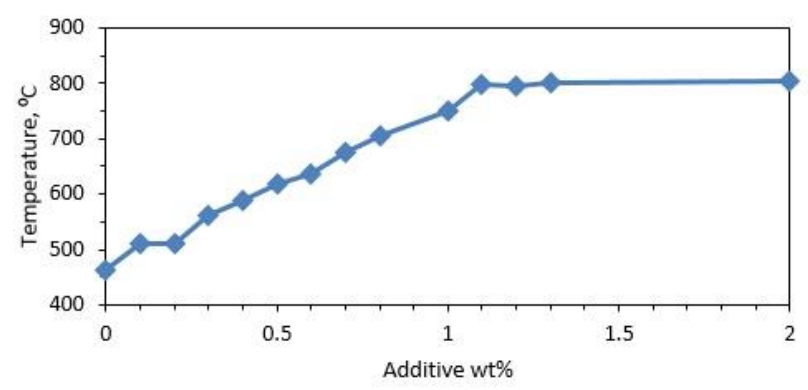

$\mathrm{Fe}$

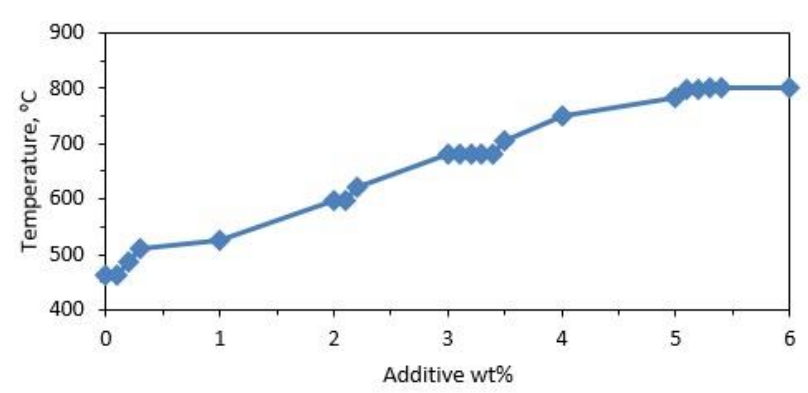

Si

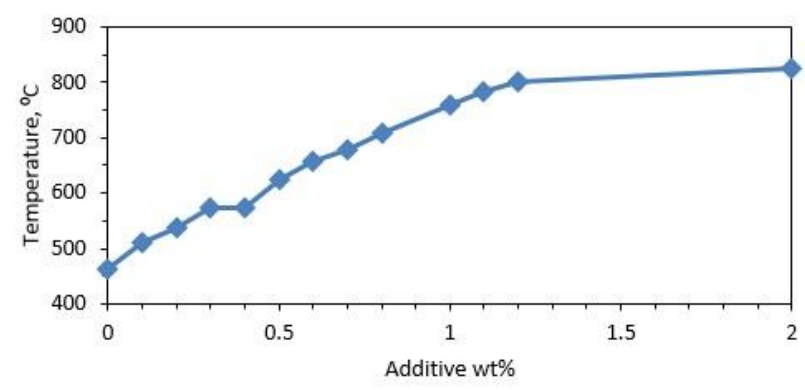

Ti

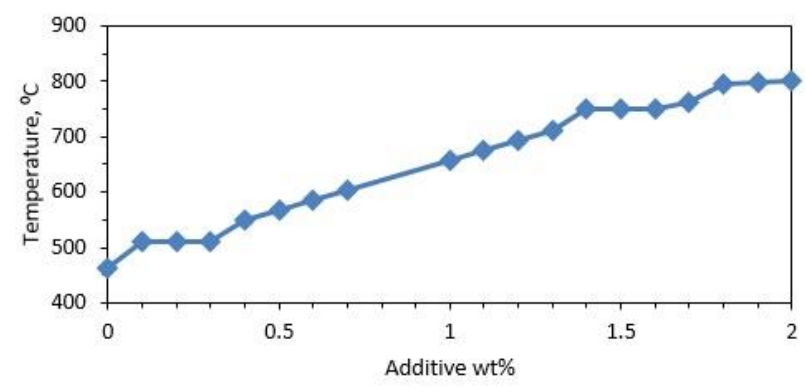

B

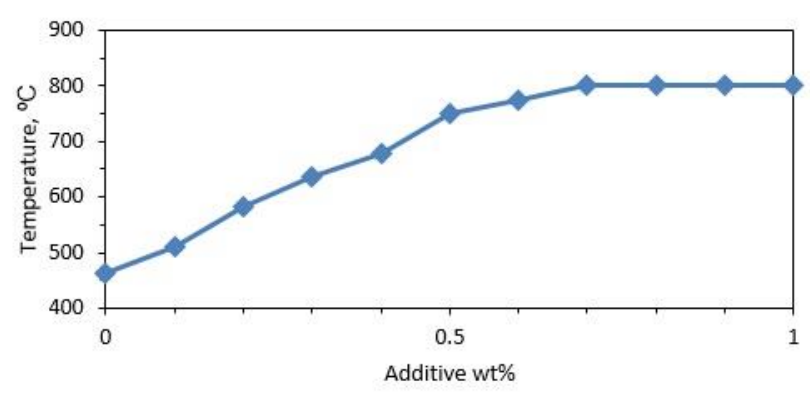

Mg

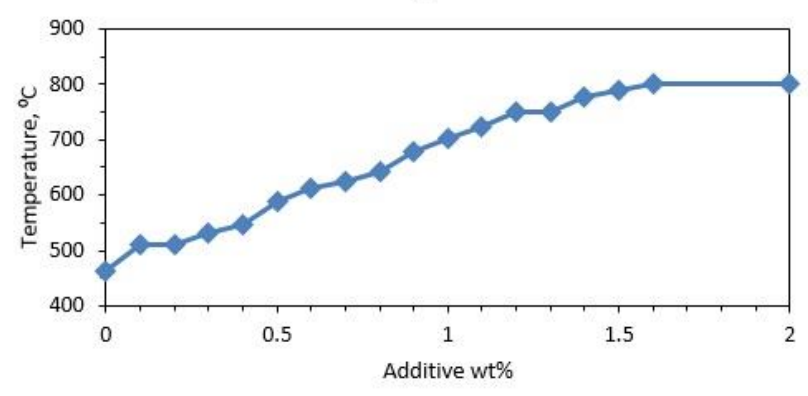

Sn

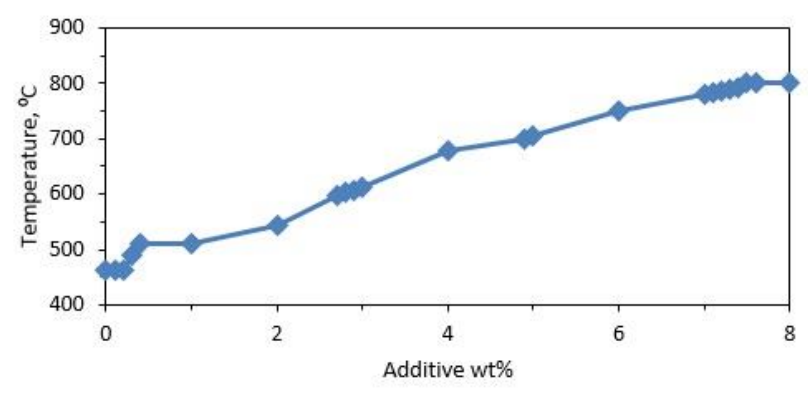

$\mathrm{Zr}$

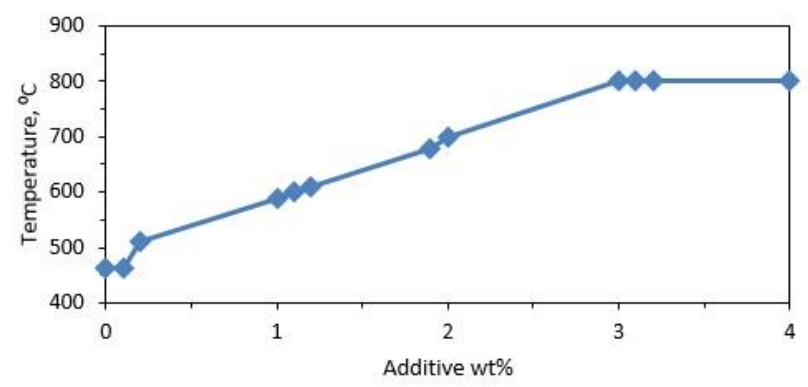




\subsection{NANO-COMPOSITE ThERMITES}

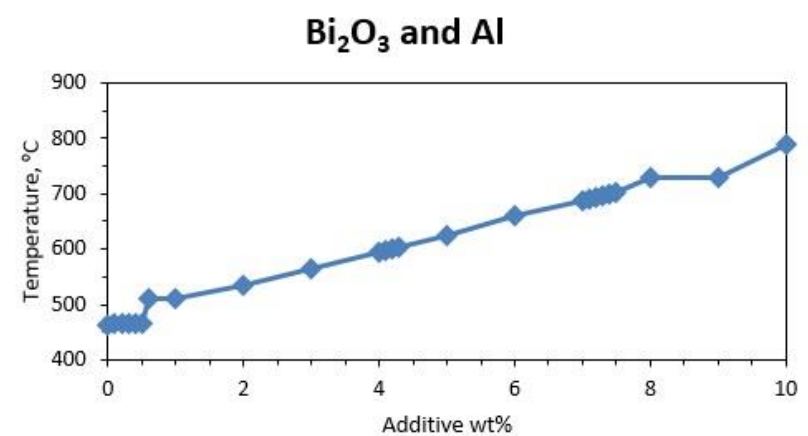

$\mathrm{Bi}_{2} \mathrm{O}_{3}$ and $\mathrm{Zr}$

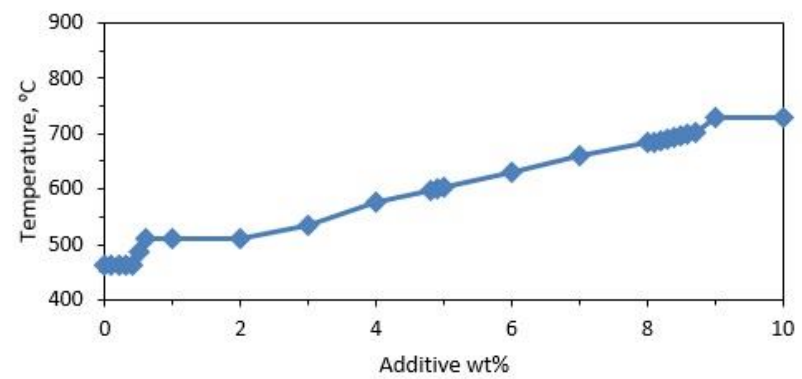

\section{$\mathrm{CuO}$ and $\mathrm{Mg}$}

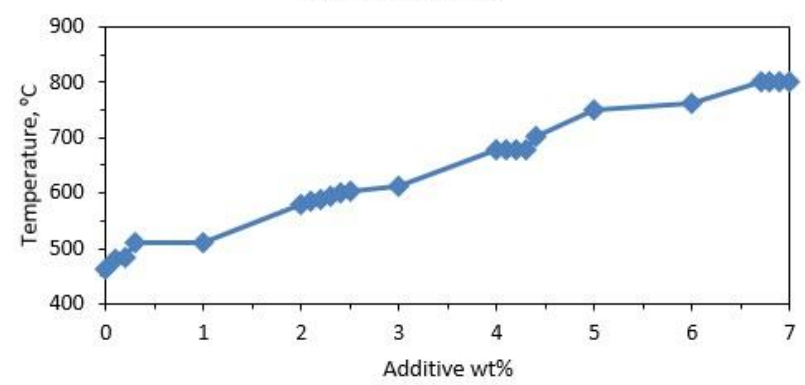

$\mathrm{CuO}$ and $\mathrm{Si}$

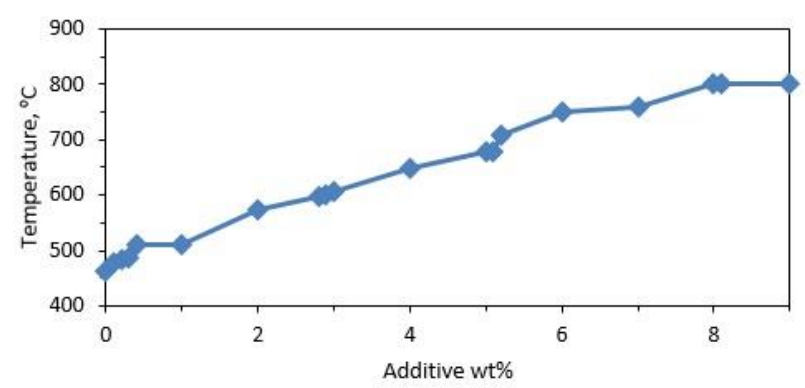

$\mathrm{Bi}_{2} \mathrm{O}_{3}$ and $\mathrm{Si}$

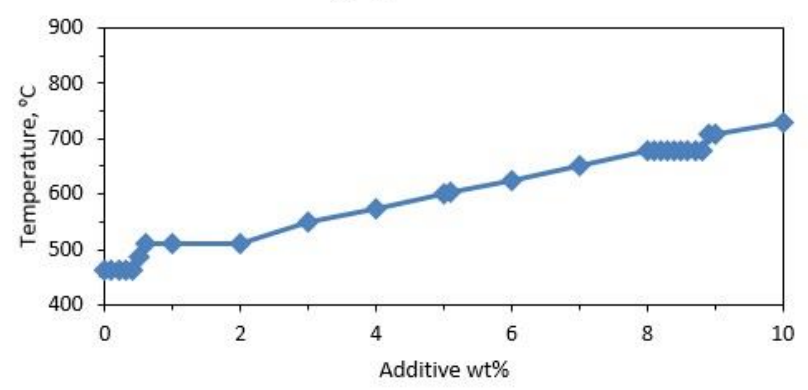

$\mathrm{CuO}$ and $\mathrm{Al}$

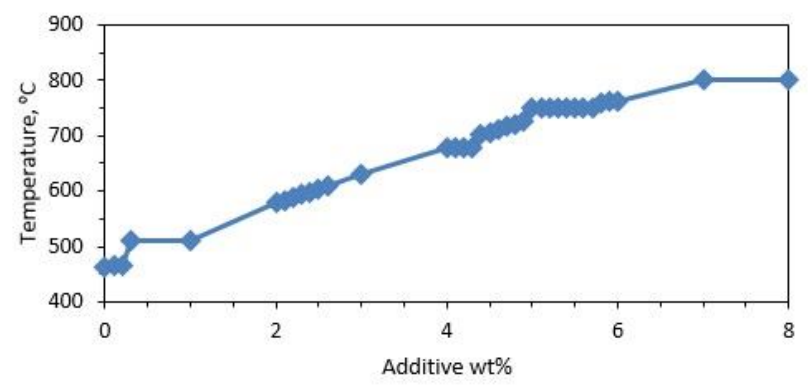

$\mathrm{CuO}$ and $\mathrm{MgH}_{2}$

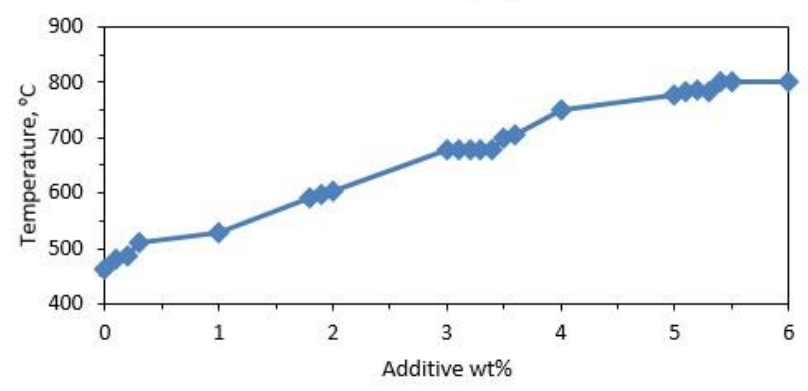

$\mathrm{CuO}$ and $\mathrm{Zr}$

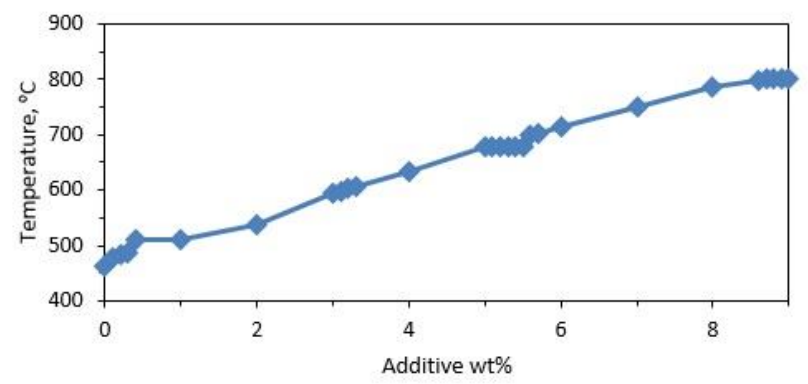




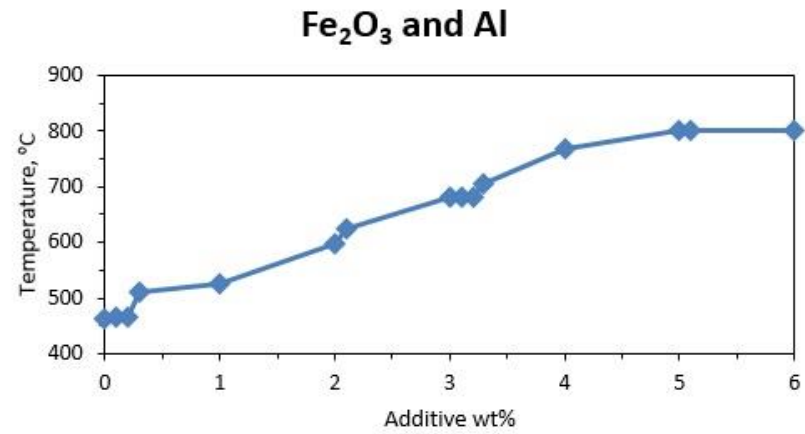

$\mathrm{MoO}_{3}$ and $\mathrm{Mg}$

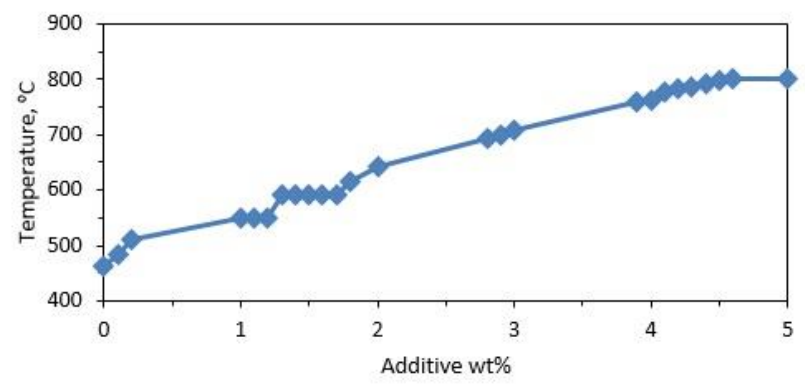

$\mathrm{MoO}_{3}$ and $\mathrm{Si}$

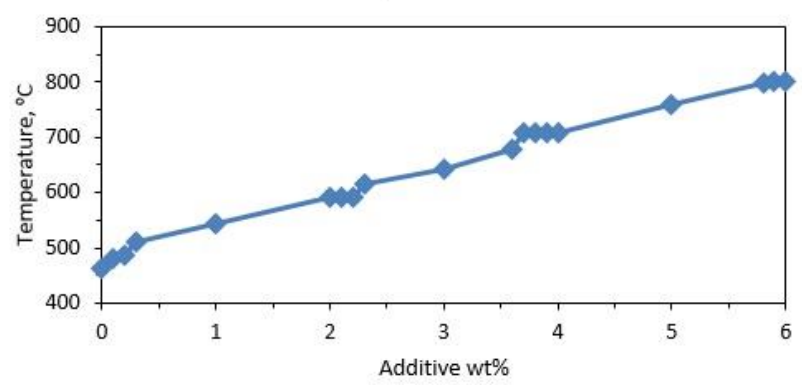

$\mathrm{NaNO}_{3}$ and $\mathrm{Al}$

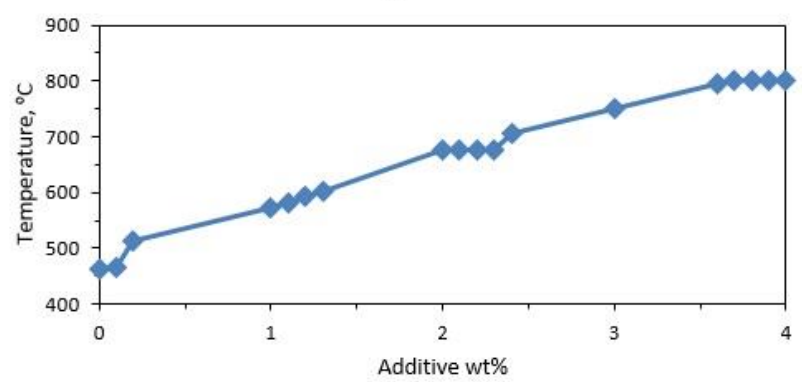

$\mathrm{MoO}_{3}$ and $\mathrm{Al}$

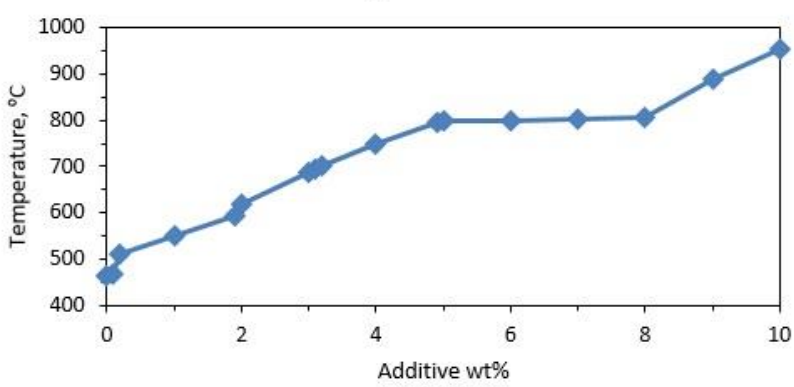

$\mathrm{MoO}_{3}$ and $\mathrm{MgH}_{2}$

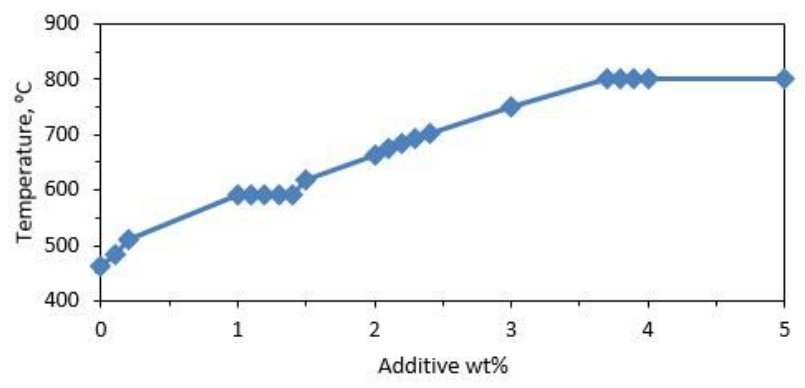

$\mathrm{MoO}_{3}$ and $\mathrm{Zr}$

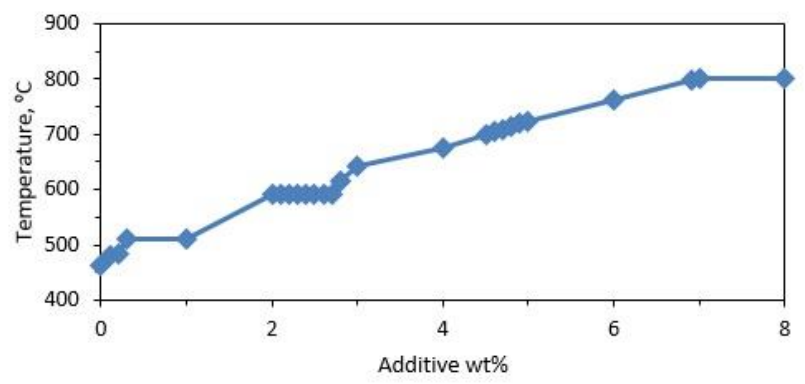

NaNO3, Al, and Mg (1:1:1)

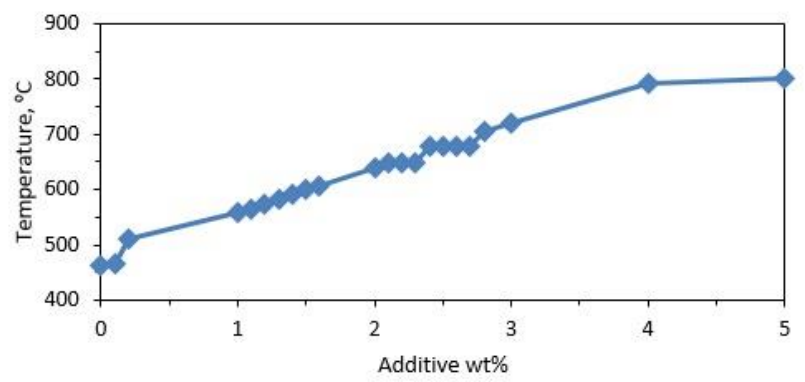




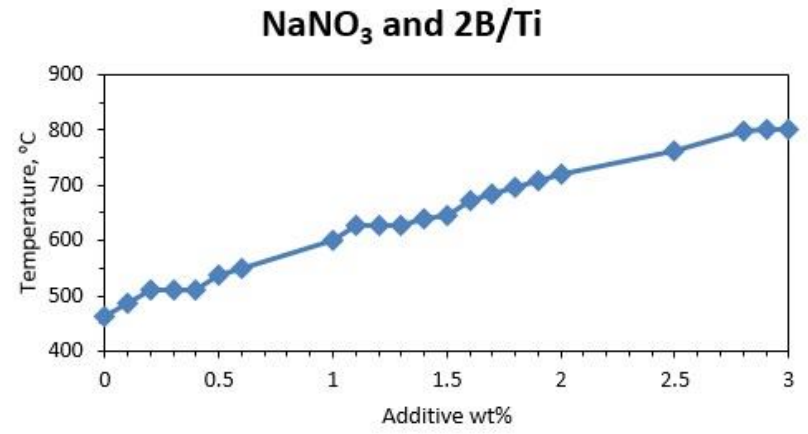

$\mathrm{NaNO}_{3}$ and $\mathrm{Zr}$

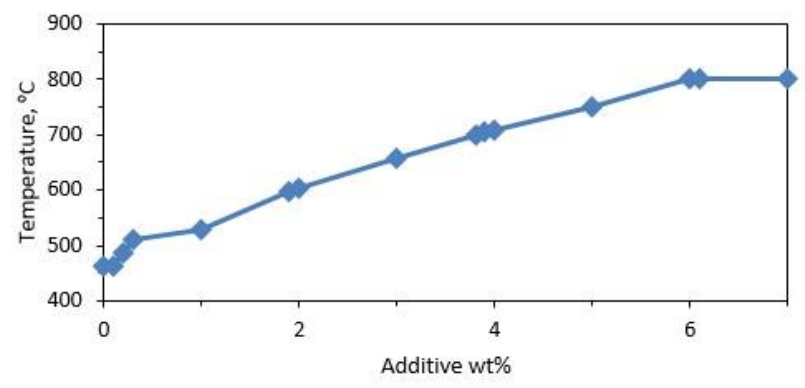

$\mathrm{WO}_{3}$ and $\mathrm{Al}$

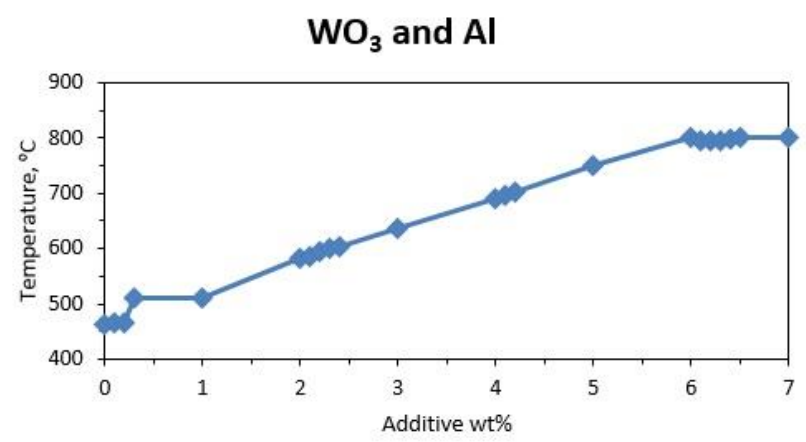

\subsection{Metal-Metal CoMposites}

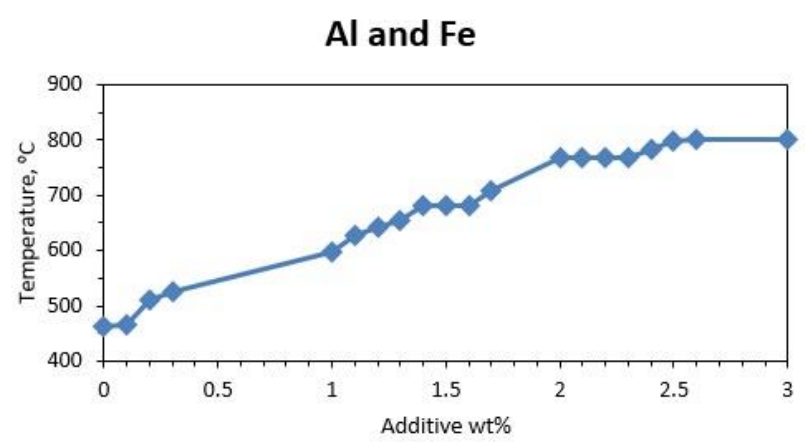

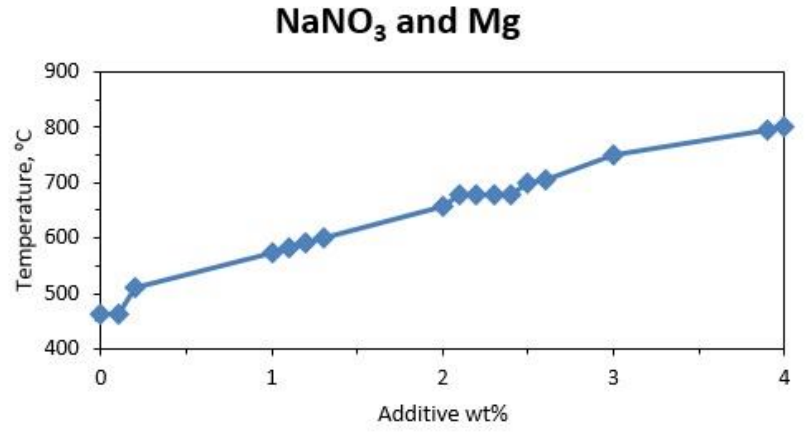

$\mathrm{SrO}_{2}$ and $\mathrm{Al}$

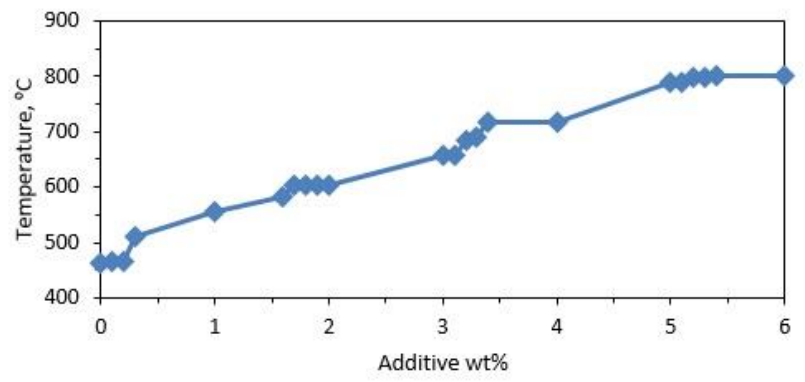




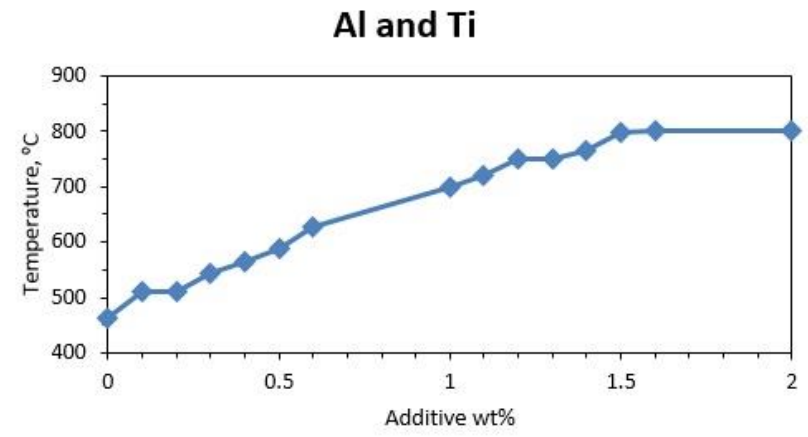

\subsection{Metalloid-Metal Composites}
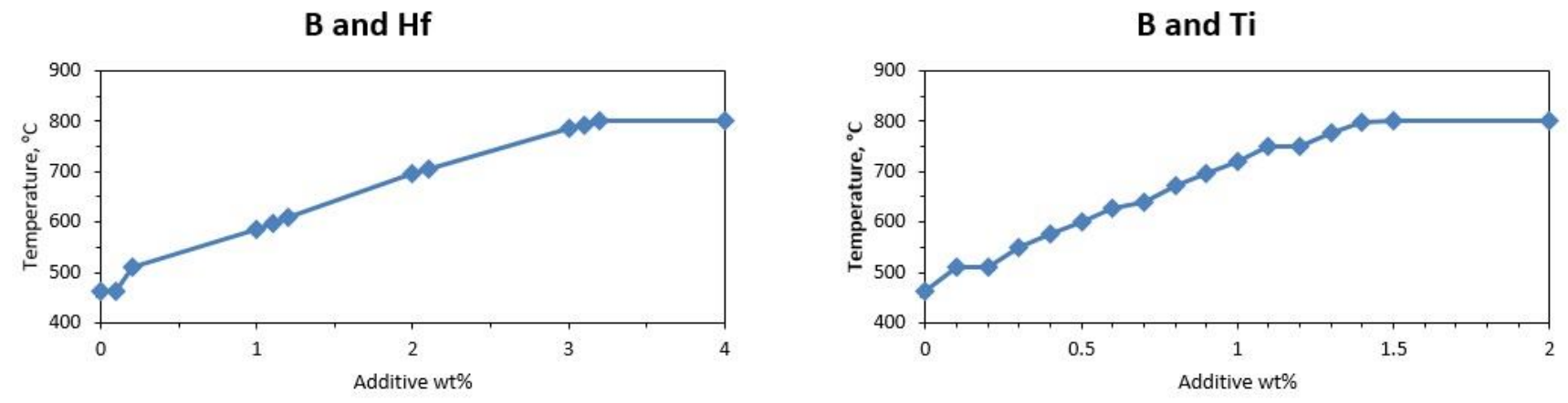

$B$ and $\mathrm{Zr}$

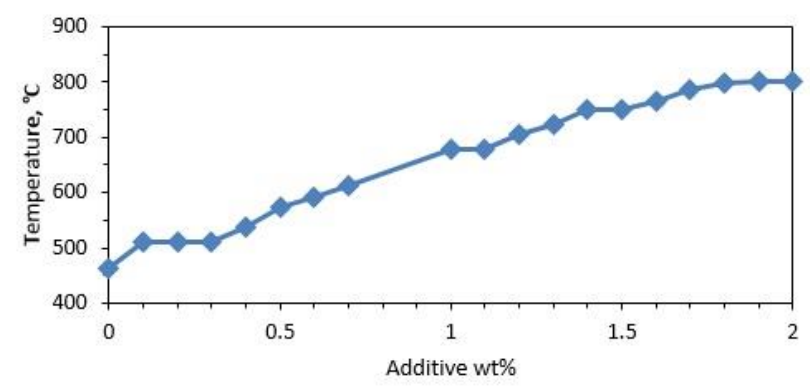


APPENDIX 2

Additional Graphs 


\section{TABLE OF CONTENTS}

INTRODUCTION

1 IRON 120

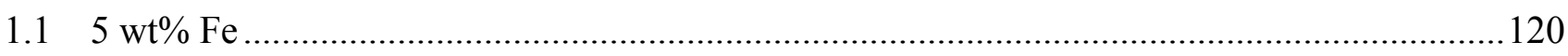

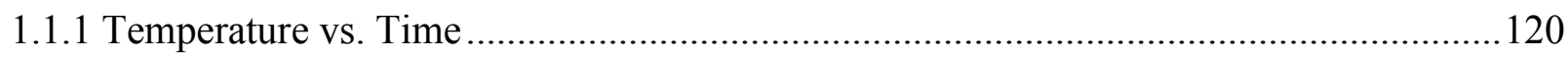

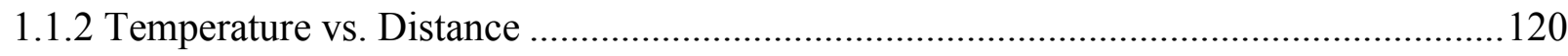

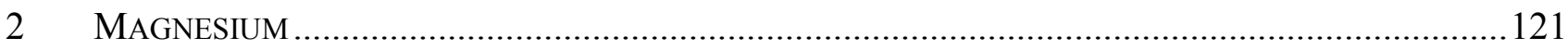

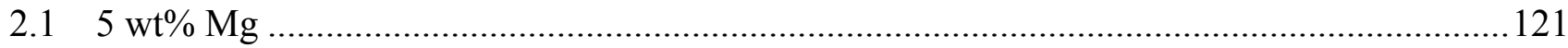

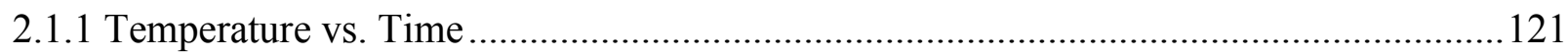

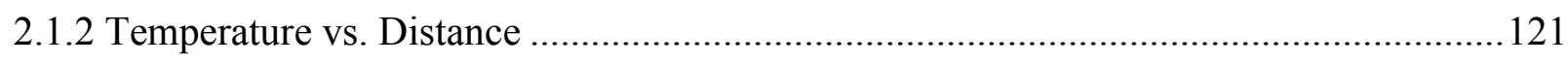

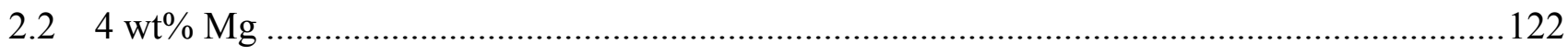

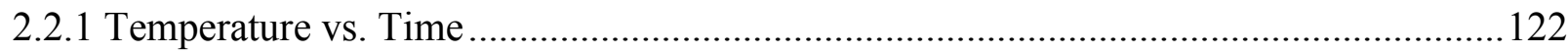

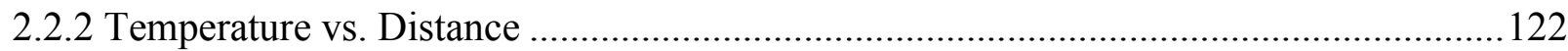

2.2.3 Maximum Temperature and Combustion Front vs. Time ........................................ 123

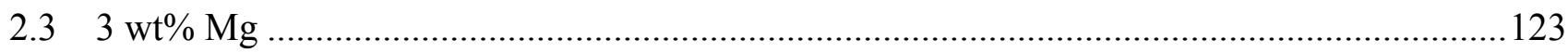

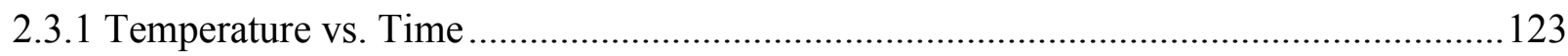

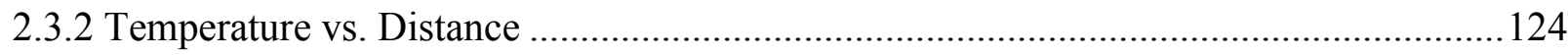

2.3.3 Maximum Temperature and Combustion Front vs. Time ........................................ 124

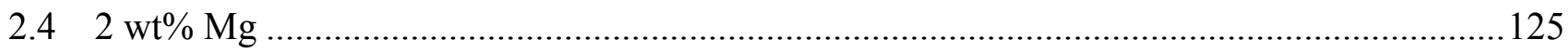

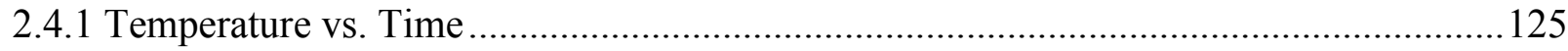

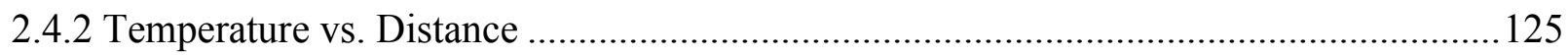

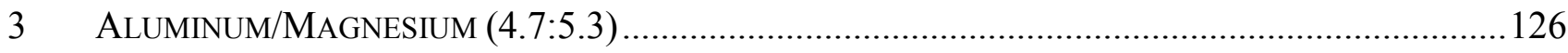

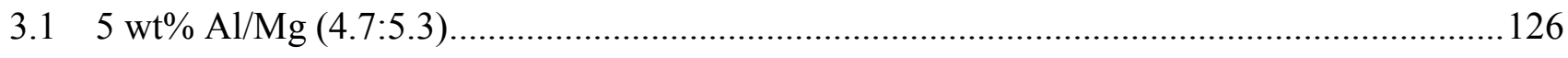

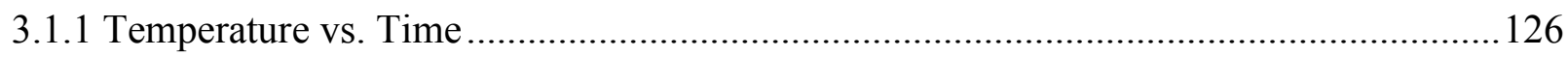

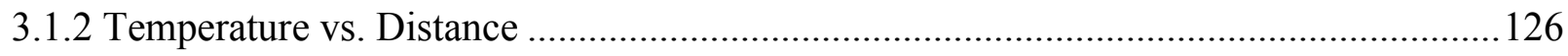

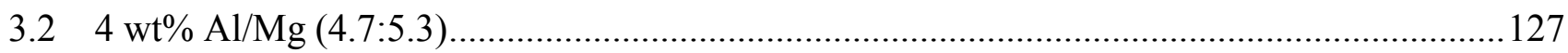

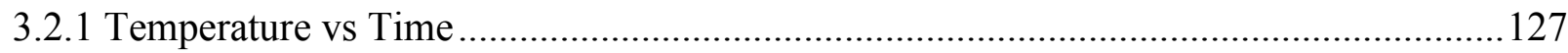

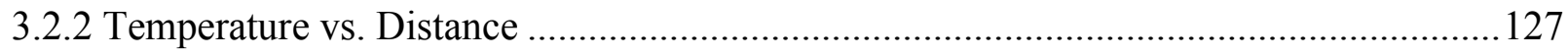

3.2.3 Maximum Temperature and Combustion Front vs. Time .......................................... 128 


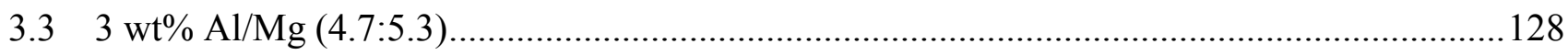

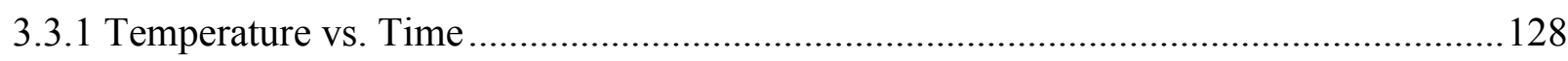

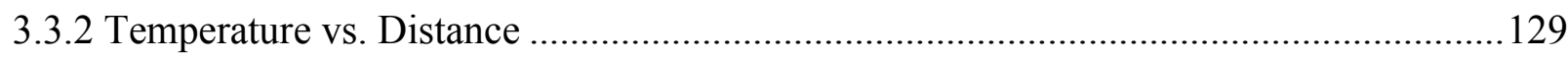

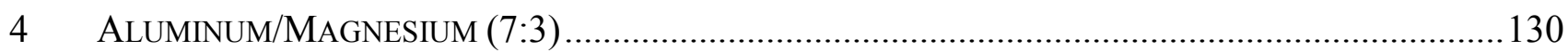

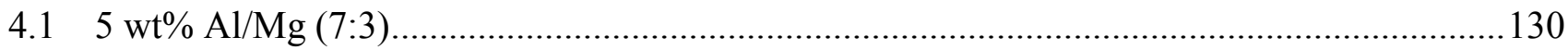

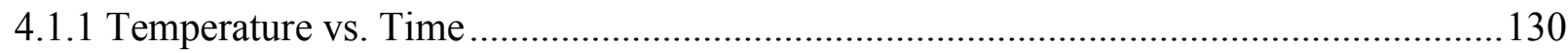

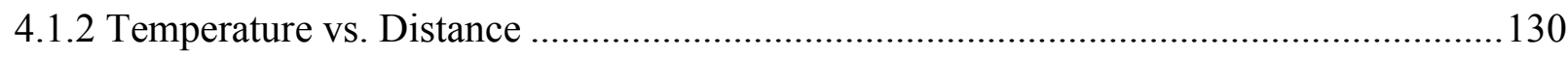

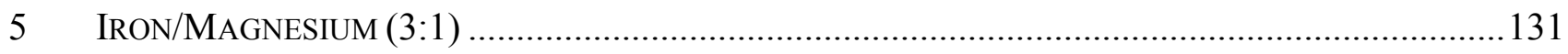

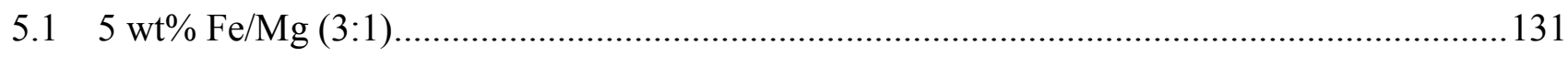

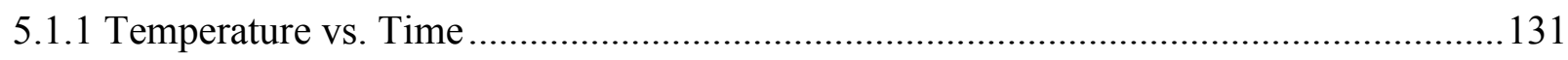

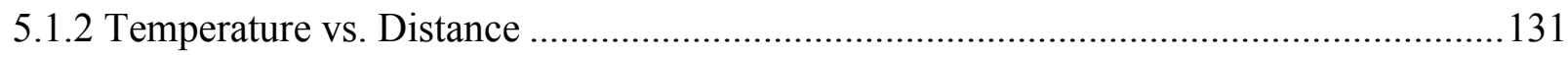

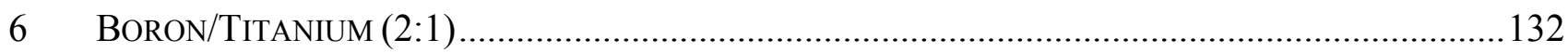

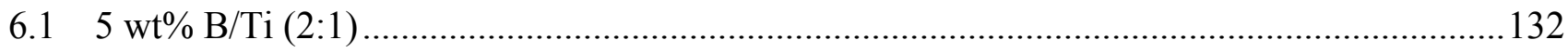

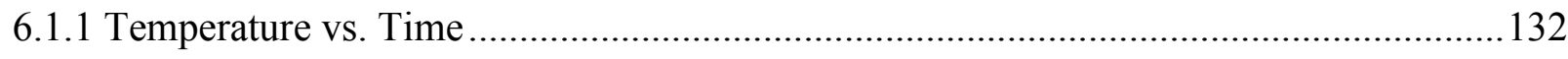

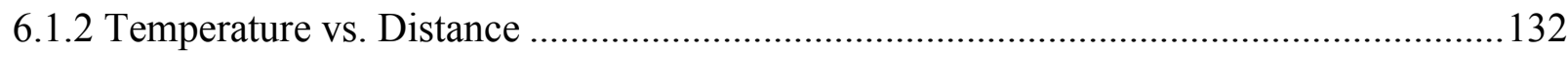




\section{INTRODUCTION}

Appendix 2 consists of mainly two graphs per tested energetic additive that provided selfsustained combustion. Temperature vs. Time graphs might be difficult to follow; however, unstable combustion phenomena can be observed such as combustion pulsations in the form of temperature peaks. The combustion front can then be better understood if the temperature of the entire pellet is obtained per time unit such as the Temperature vs. Distance graphs. Finally, the Maximum Temperature and Combustion Front vs. Time that are not reported in the main body of the thesis, are shown in Appendix 2. 


\section{IRON}

\subsection{5 wt\% Fe}

\subsubsection{Temperature vs. Time}

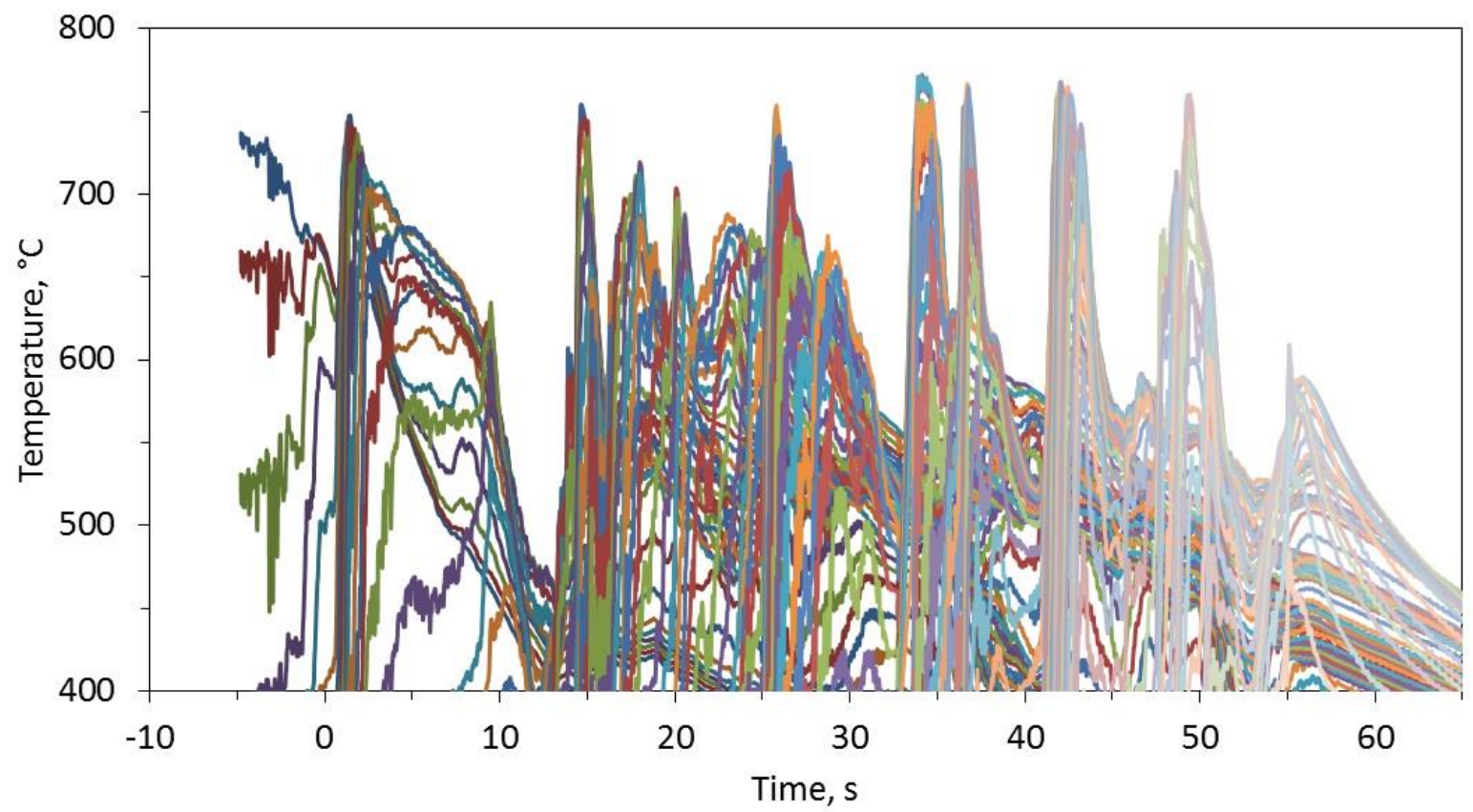

\subsubsection{Temperature vs. Distance}

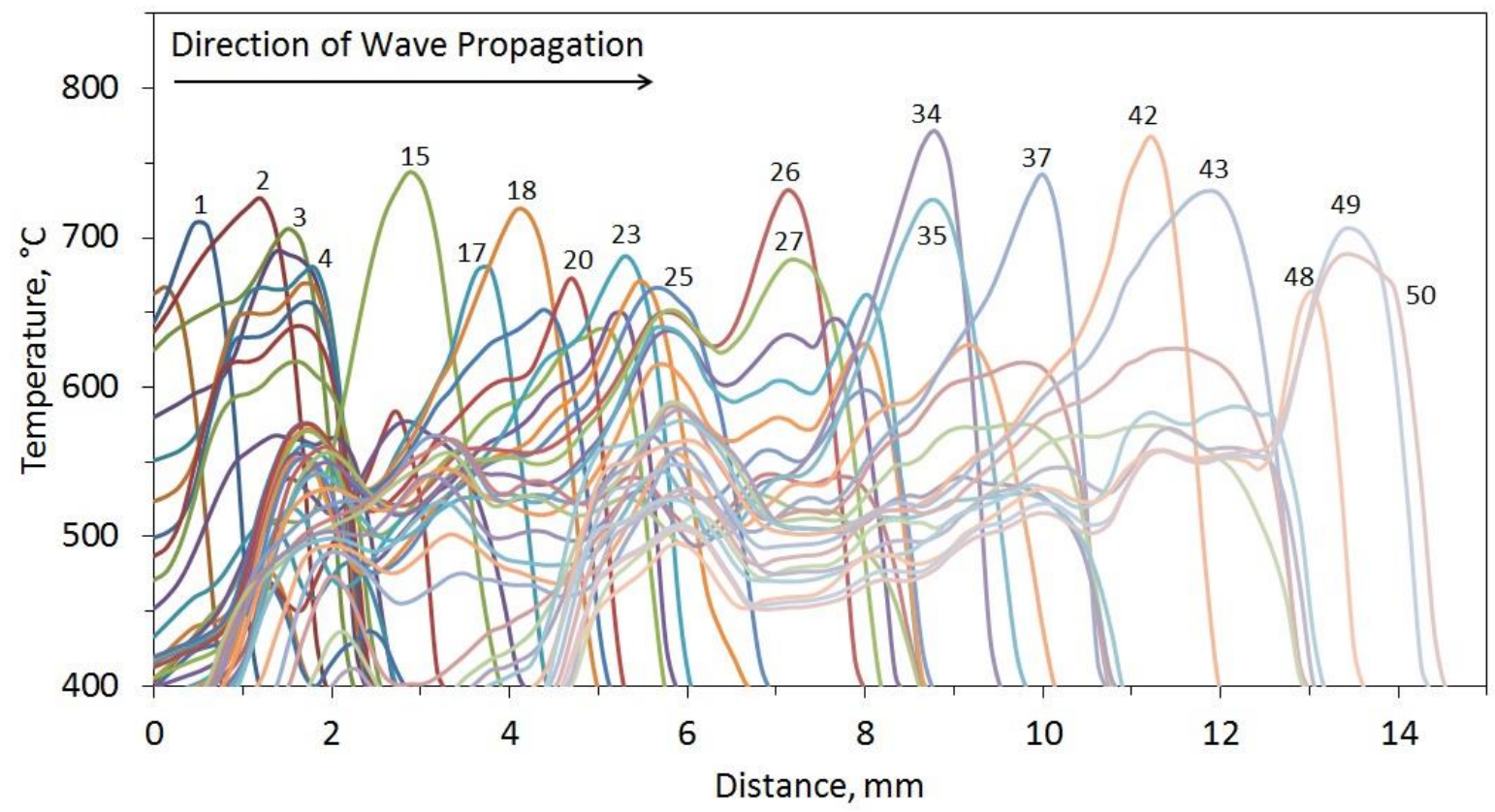




\section{MAgnesium}

\subsection{5 wt $\%$ Mg}

\subsubsection{Temperature vs. Time}

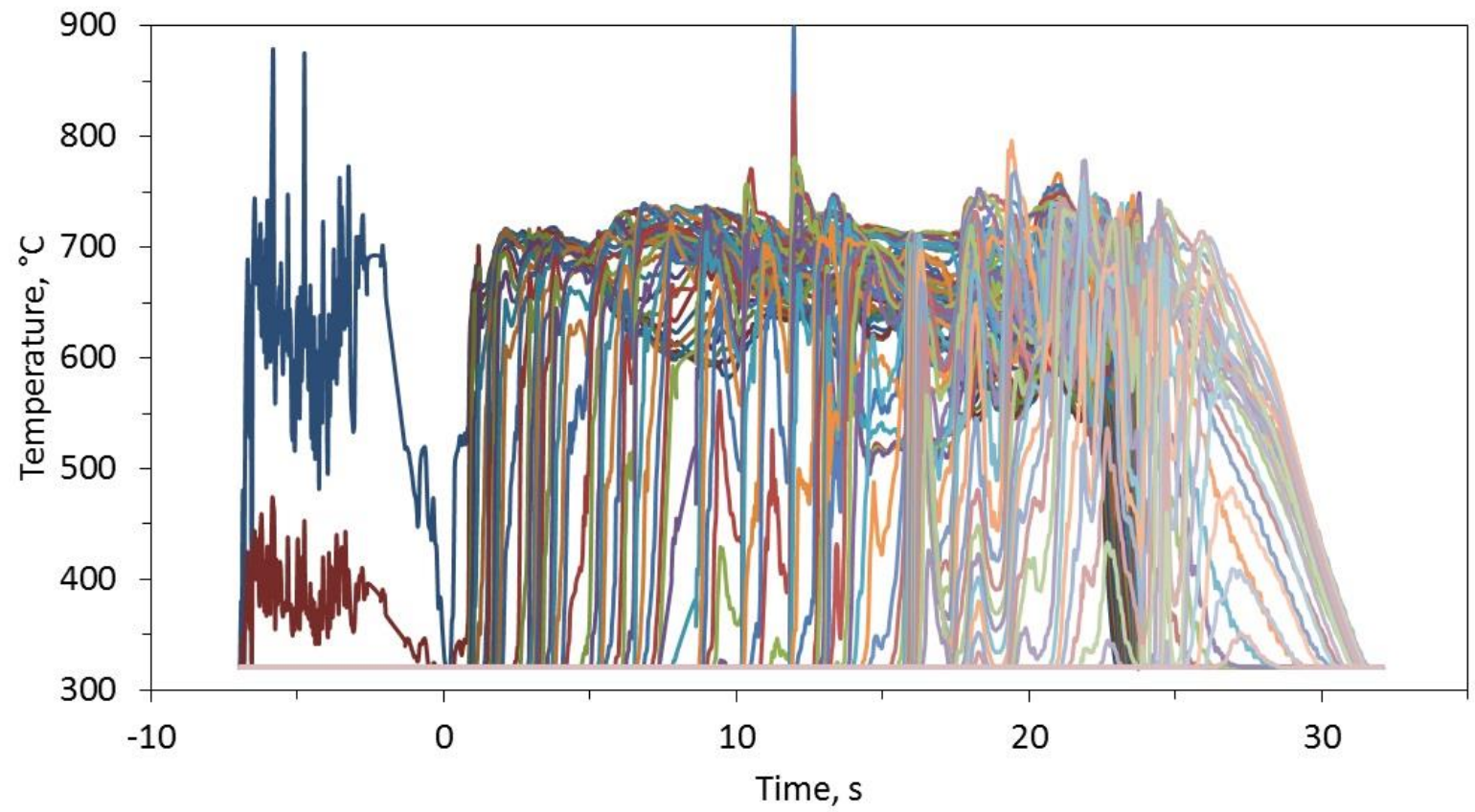

\subsubsection{Temperature vs. Distance}

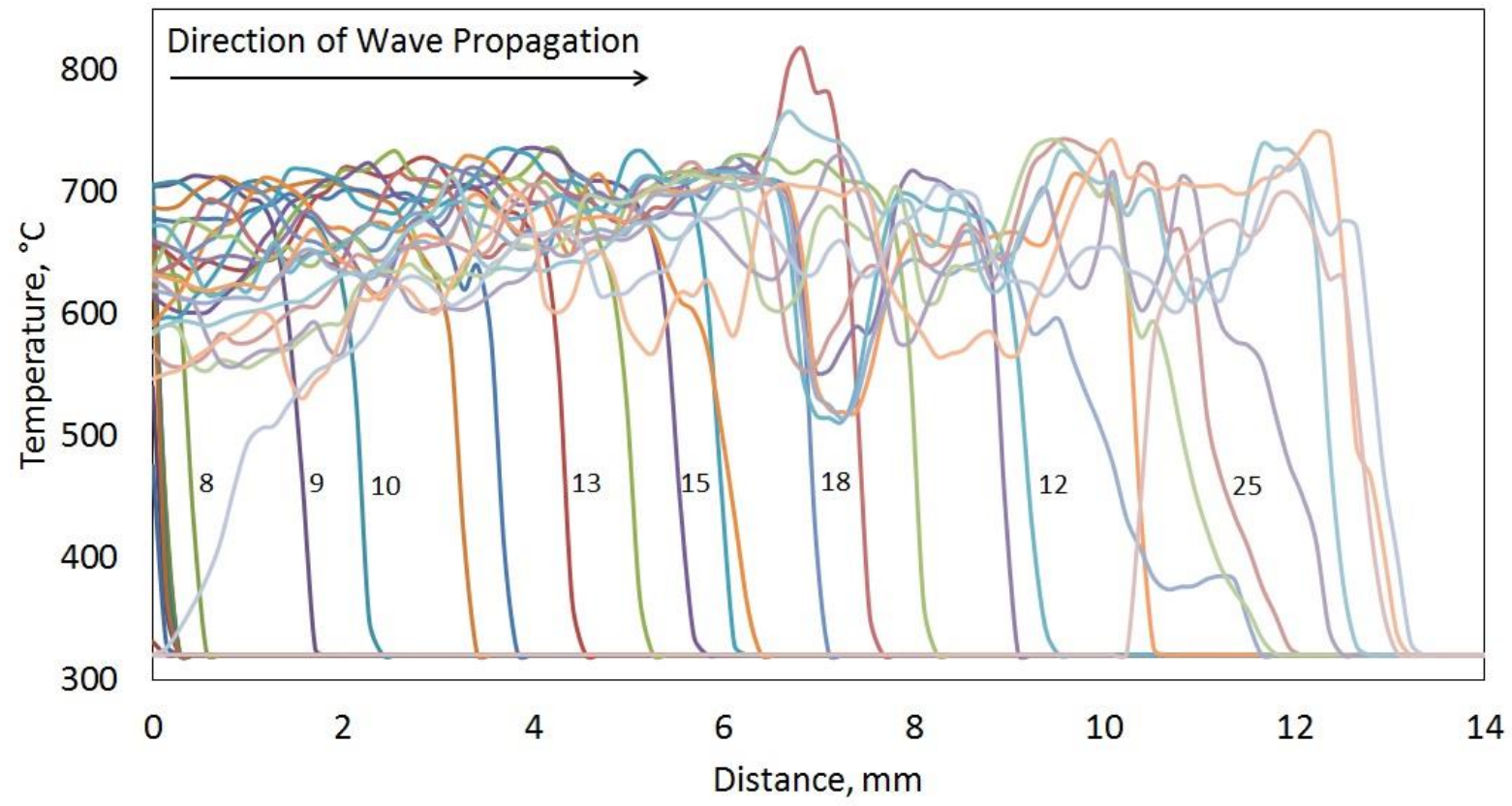




\section{$2.24 \mathrm{wt} \% \mathrm{Mg}$}

\subsubsection{Temperature vs. Time}

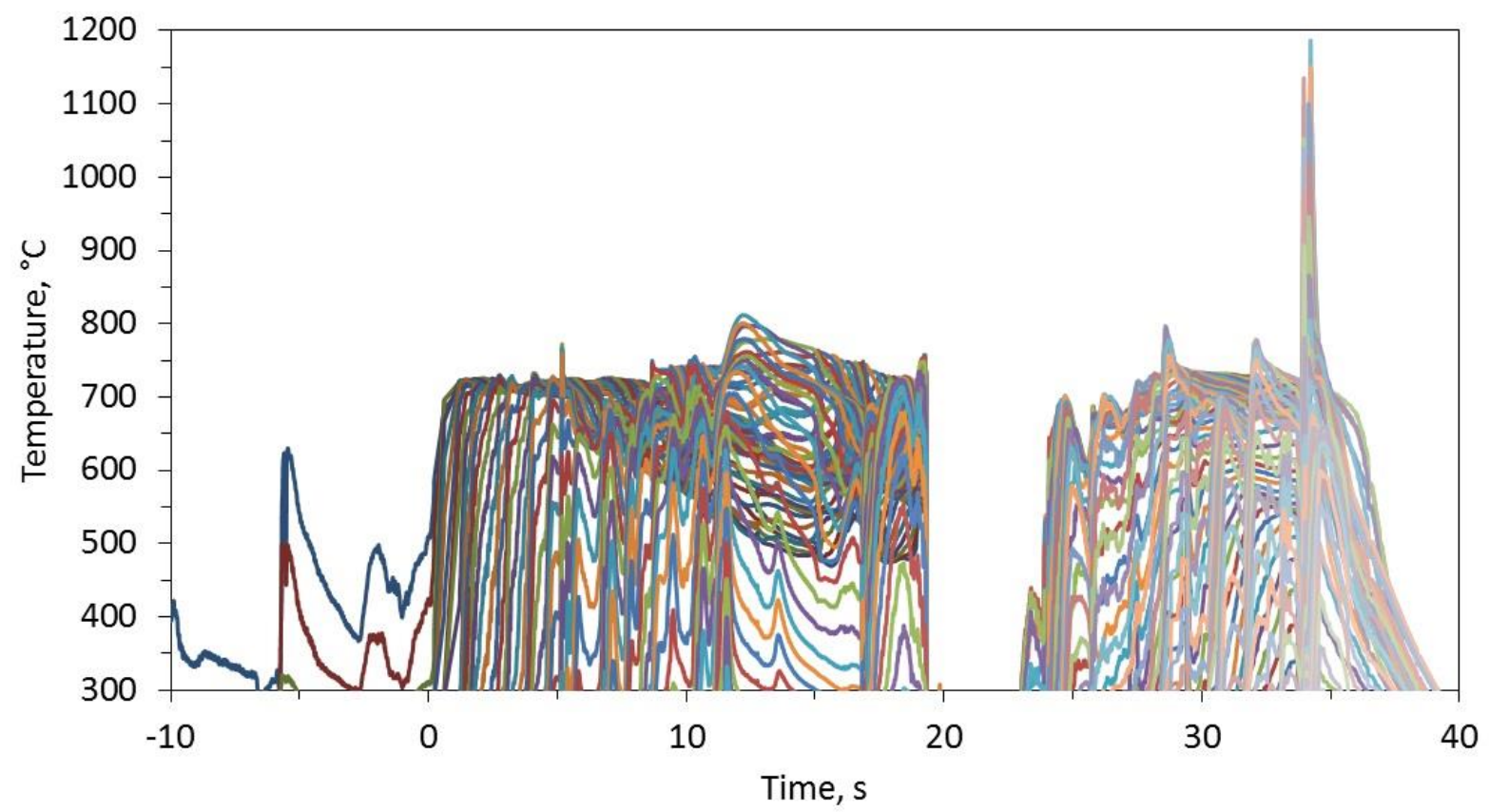

\subsubsection{Temperature vs. Distance}

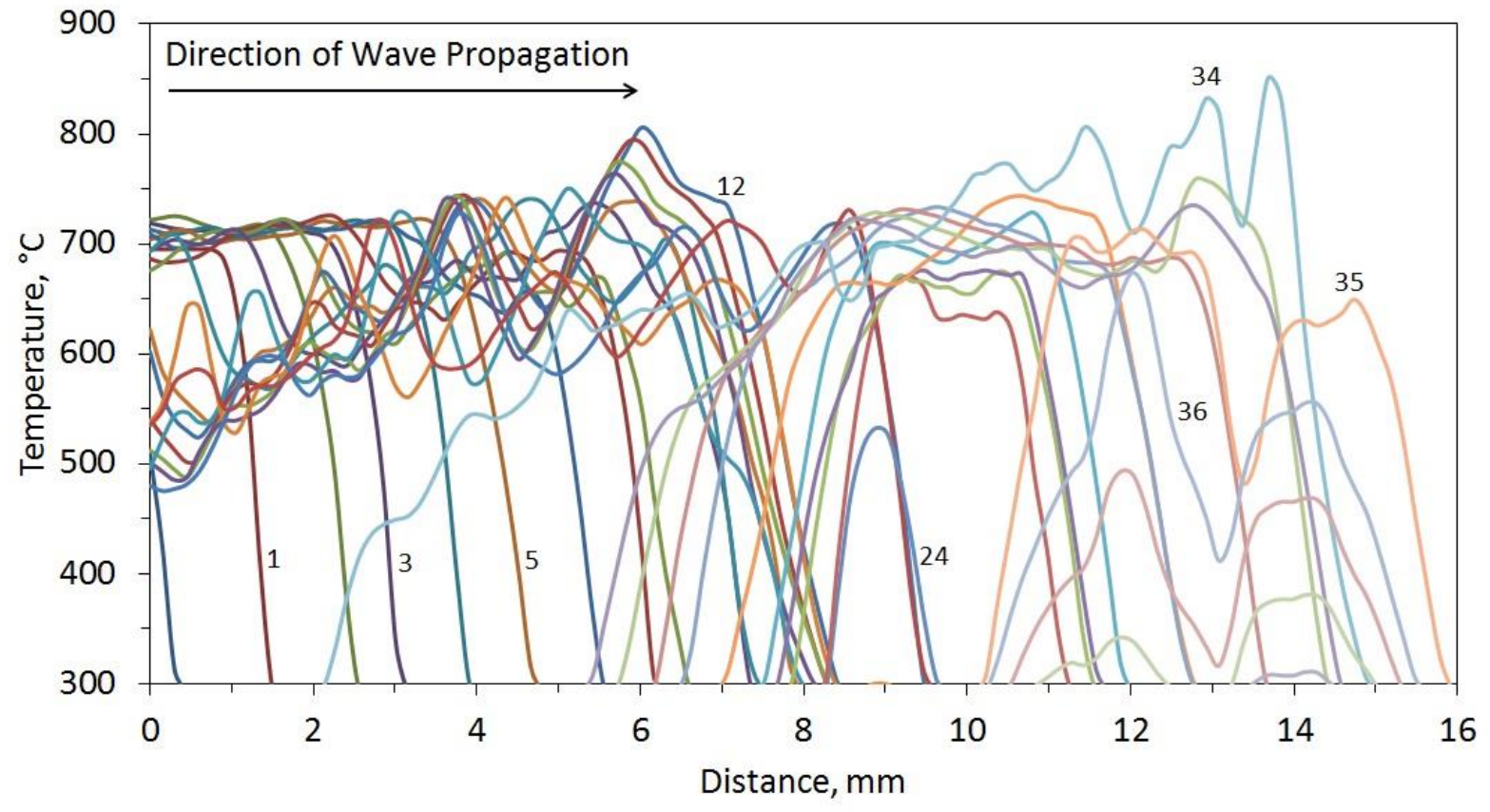




\subsubsection{Maximum Temperature and Combustion Front vs. Time}

Temperature Distance

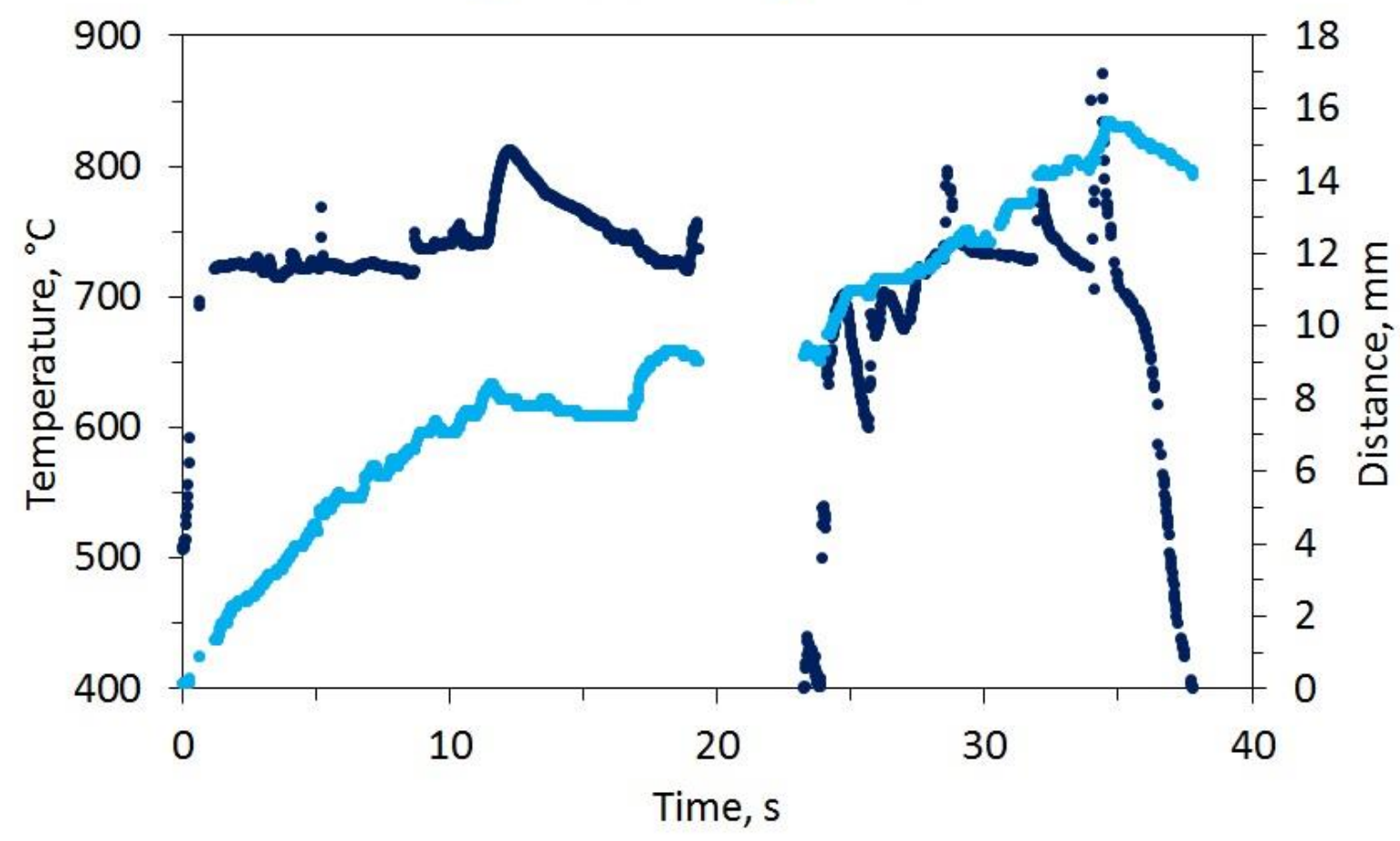

\section{$2.3 \quad 3$ wt $\%$ Mg}

\subsubsection{Temperature vs. Time}

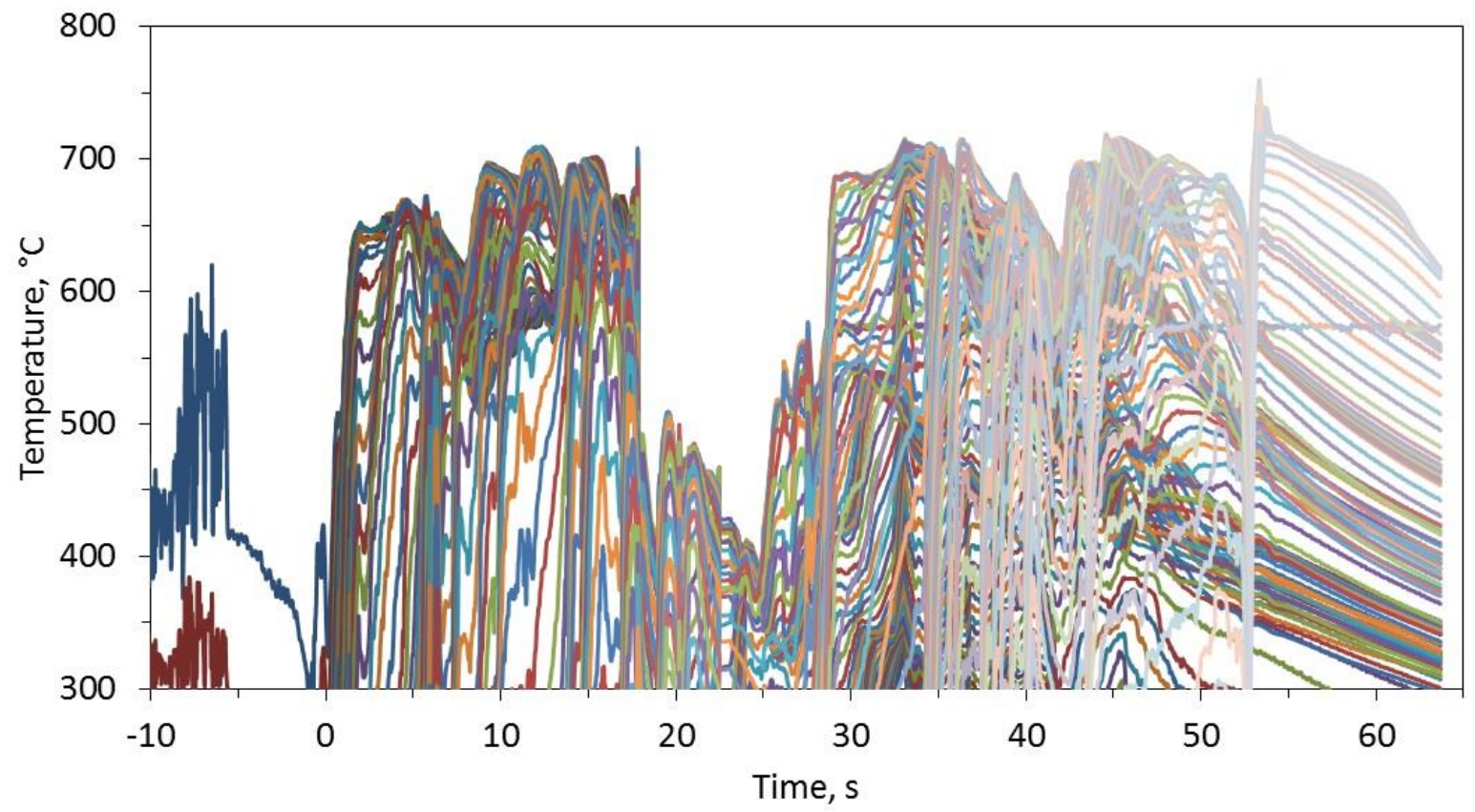




\subsubsection{Temperature vs. Distance}

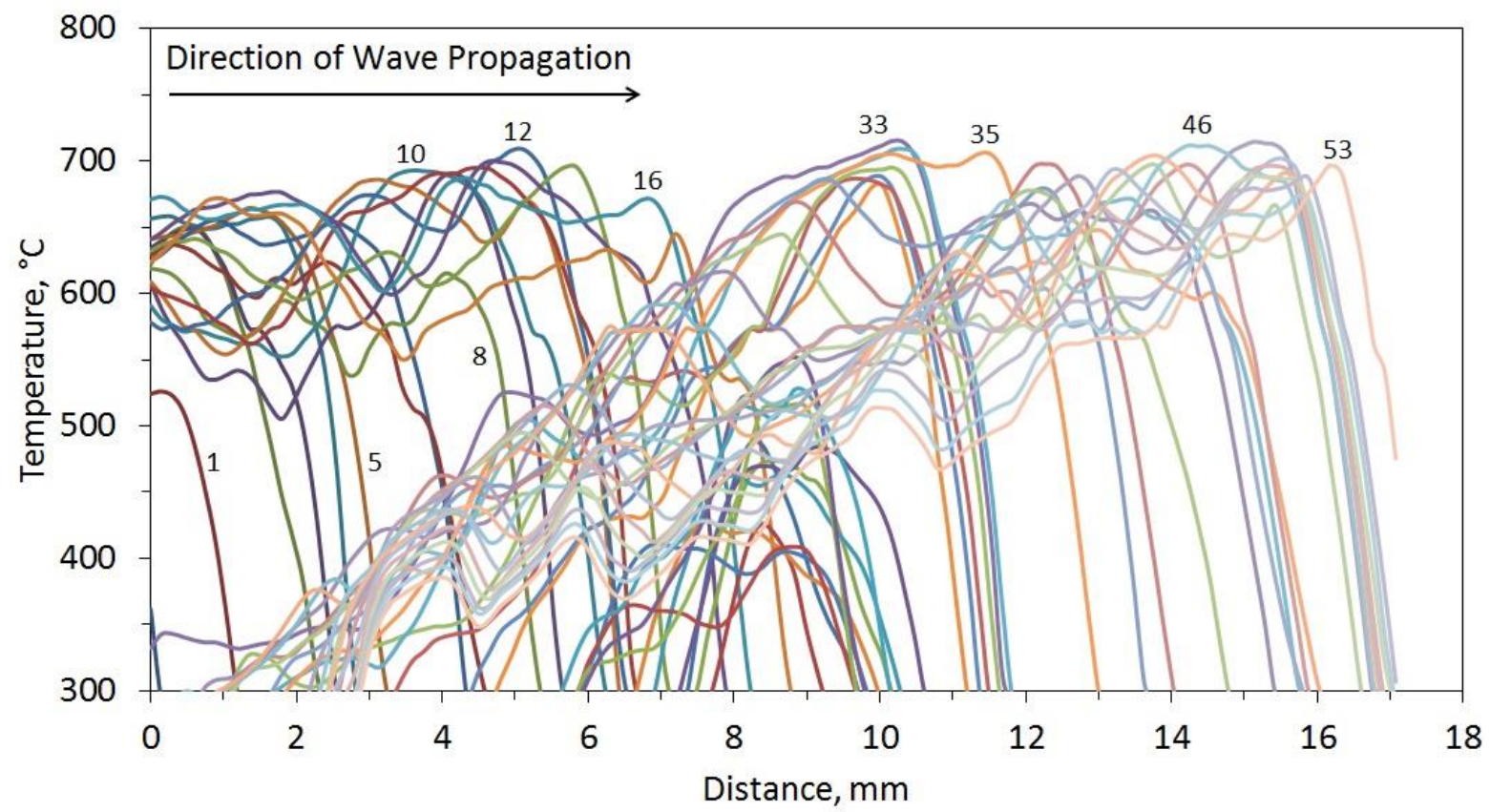

\subsubsection{Maximum Temperature and Combustion Front vs. Time}

Temperature Distance

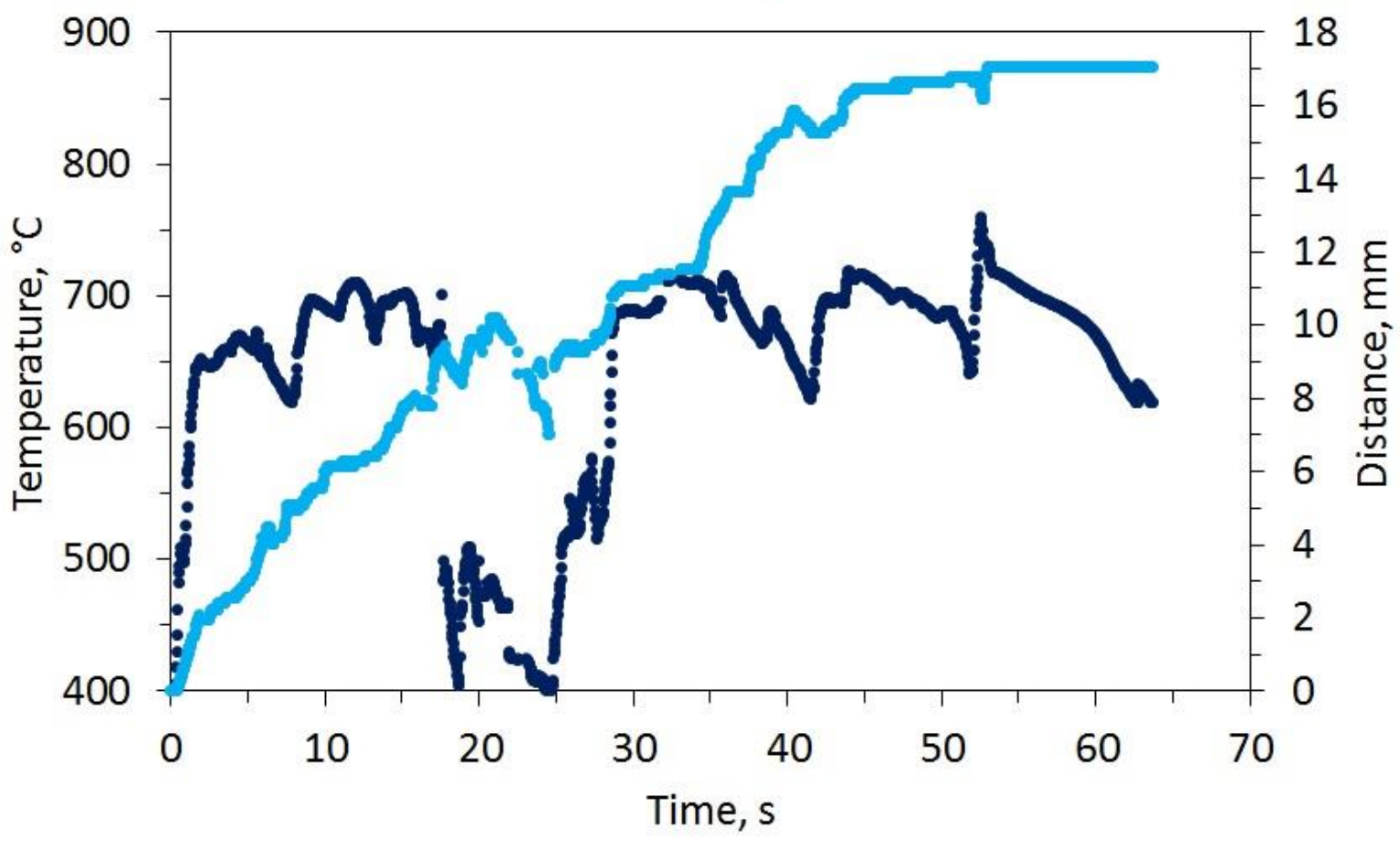




\section{$2.4 \quad 2$ wt $\% ~ M g$}

\subsubsection{Temperature vs. Time}

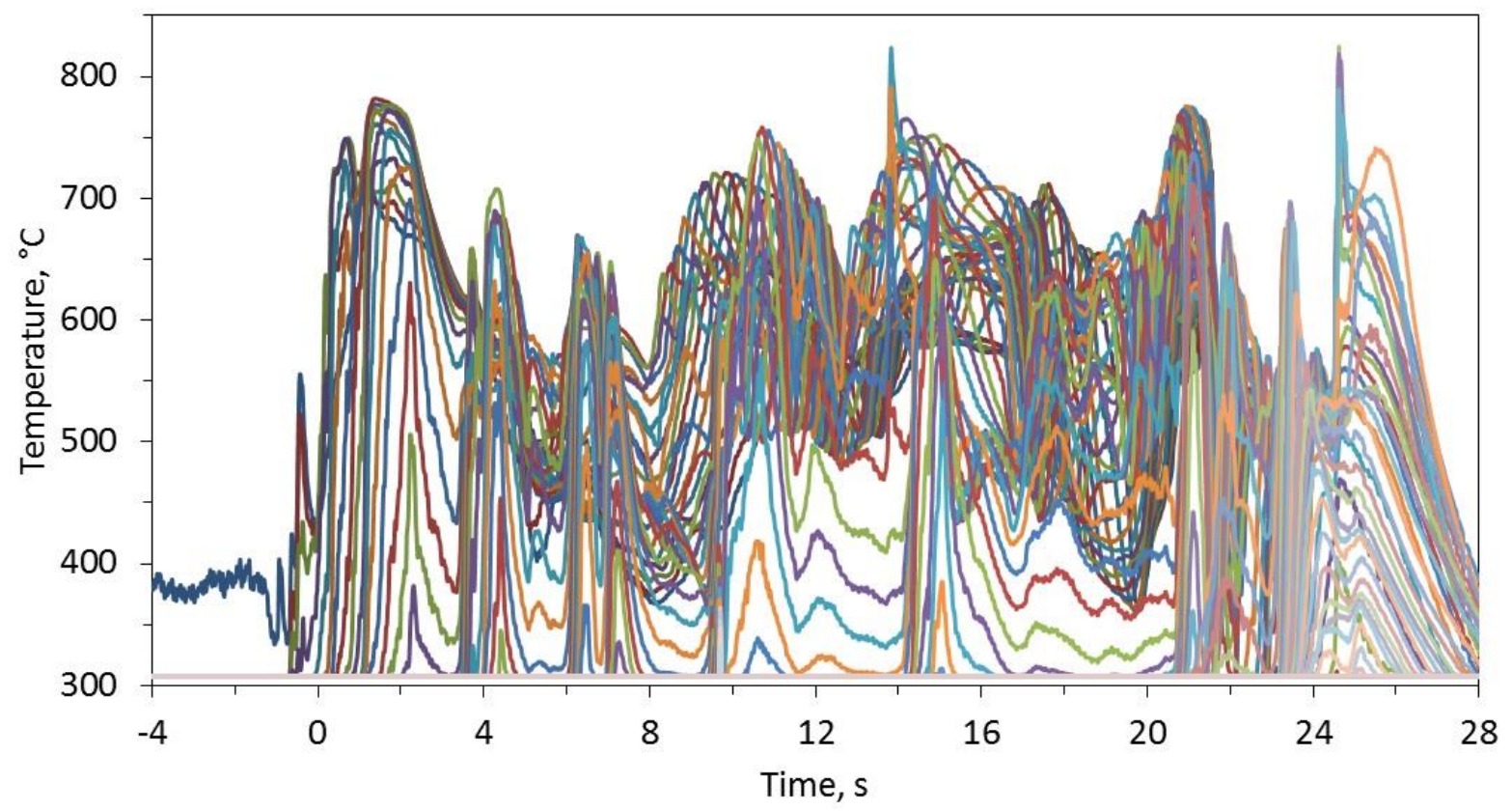

\subsubsection{Temperature vs. Distance}

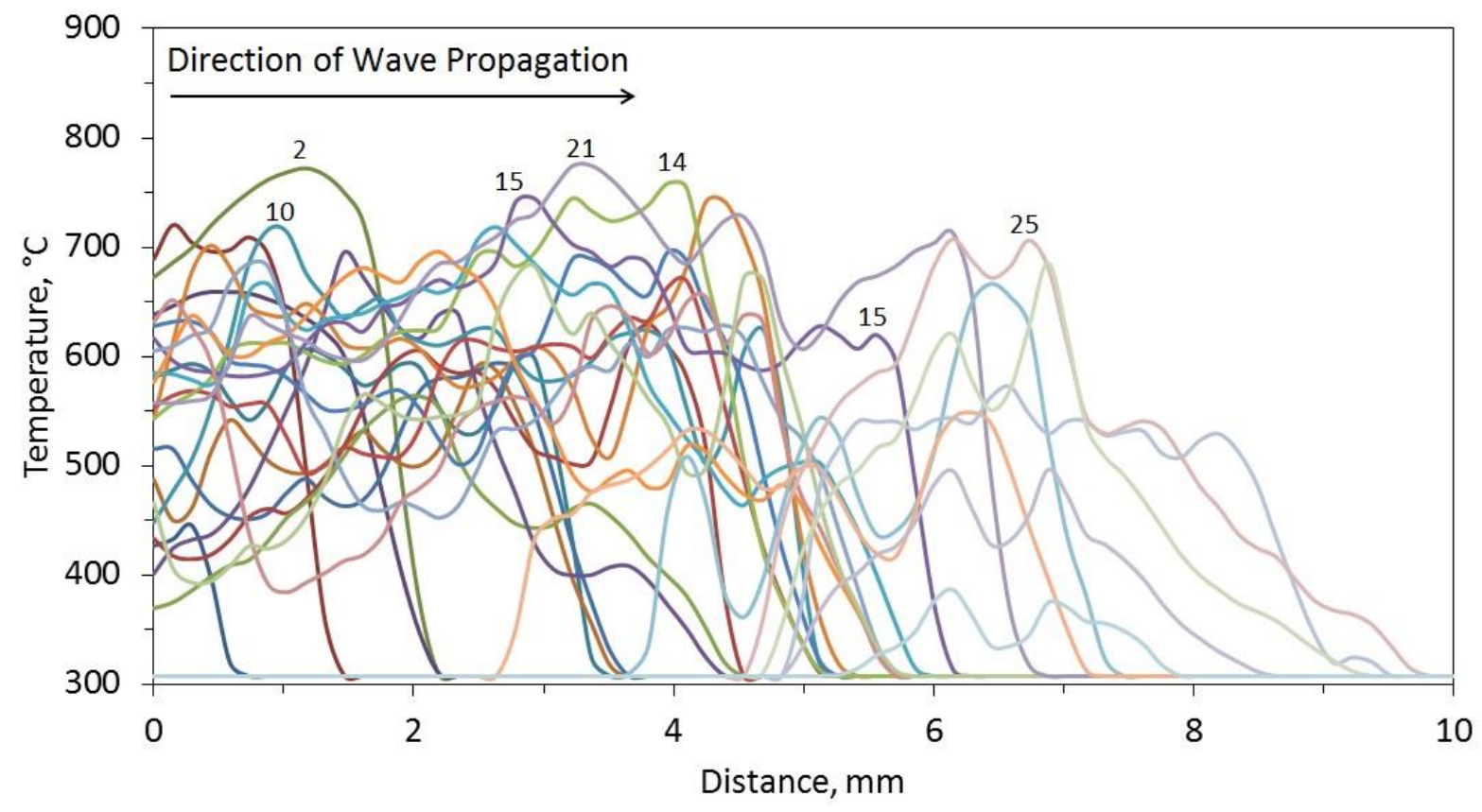




\section{Aluminum/Magnesium (4.7:5.3)}

\section{$3.15 \mathrm{wt} \% \mathrm{Al} / \mathrm{Mg}(4.7: 5.3)$}

\subsubsection{Temperature vs. Time}

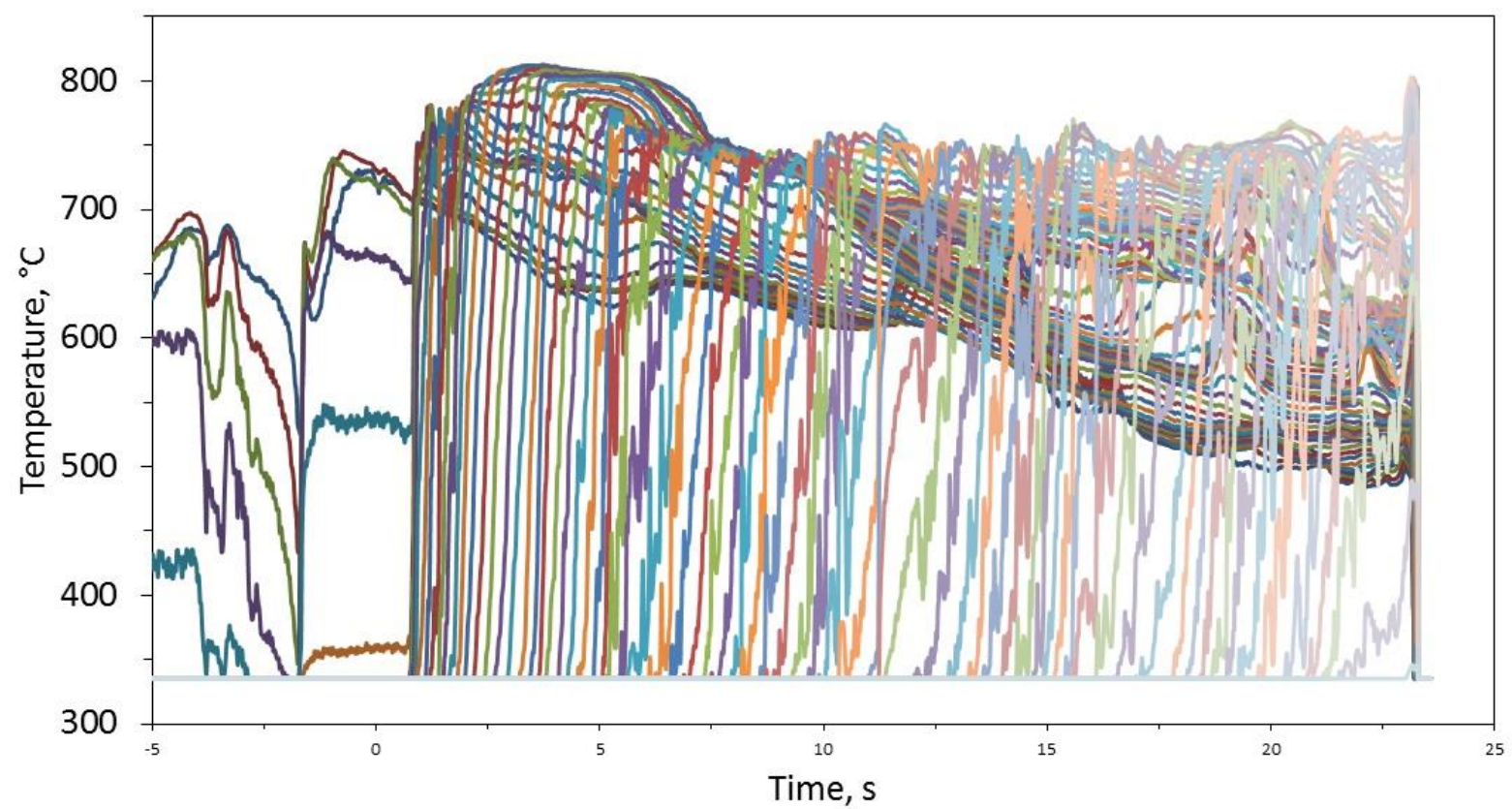

\subsubsection{Temperature vs. Distance}

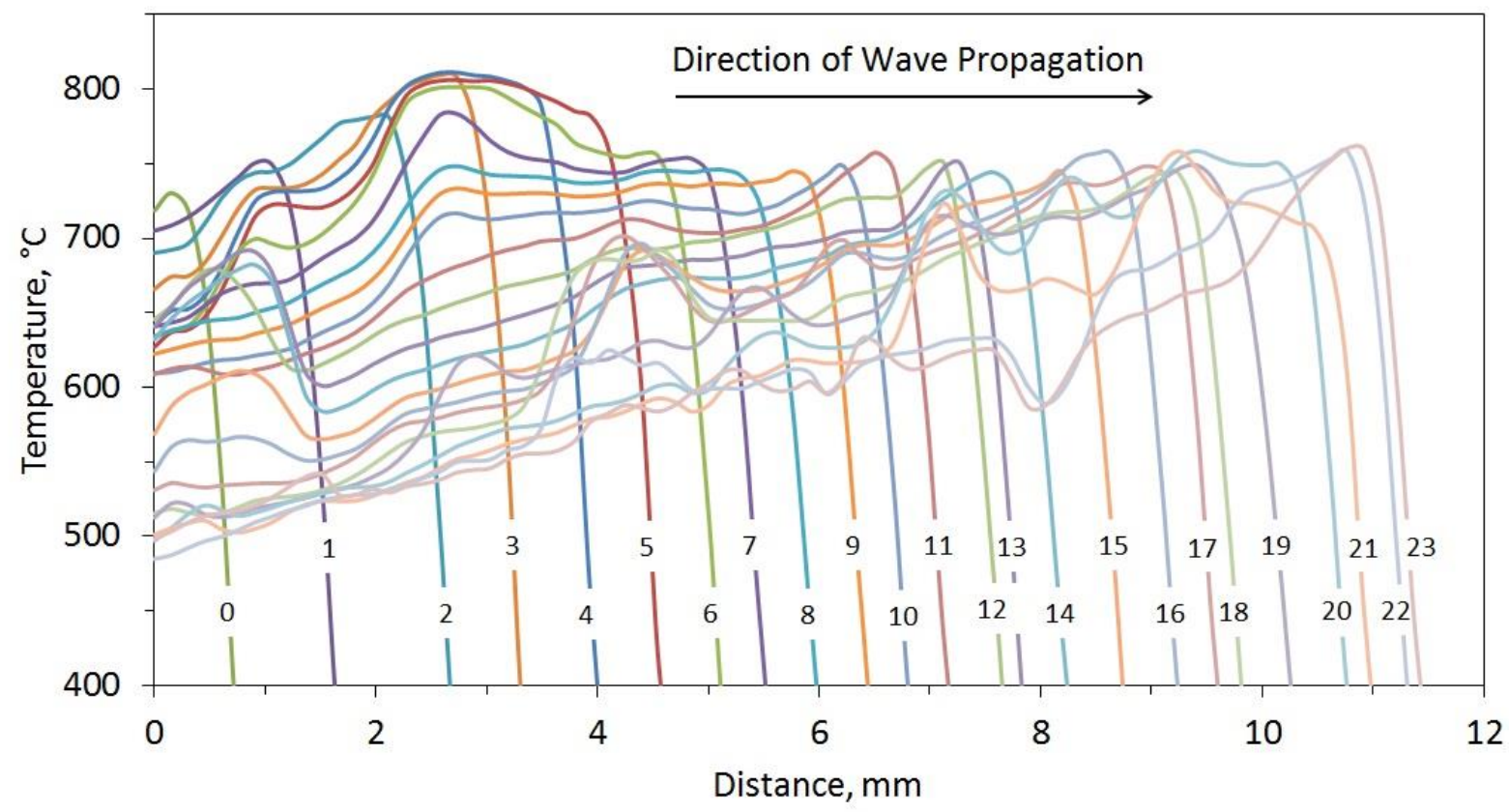




\section{$3.24 \mathrm{wt} \% \mathrm{Al} / \mathrm{Mg}(4.7: 5.3)$}

\subsubsection{Temperature vs Time}

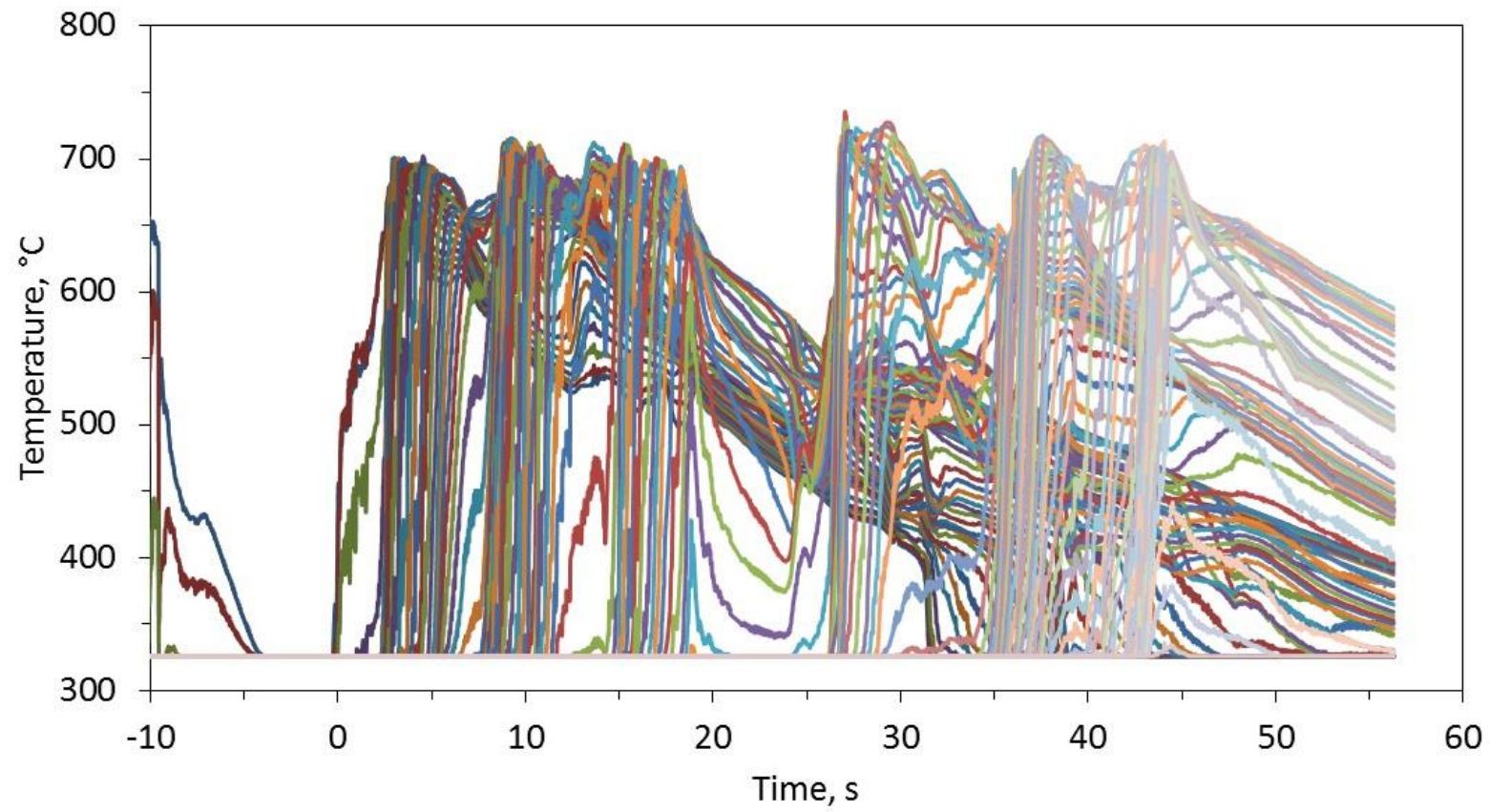

\subsubsection{Temperature vs. Distance}

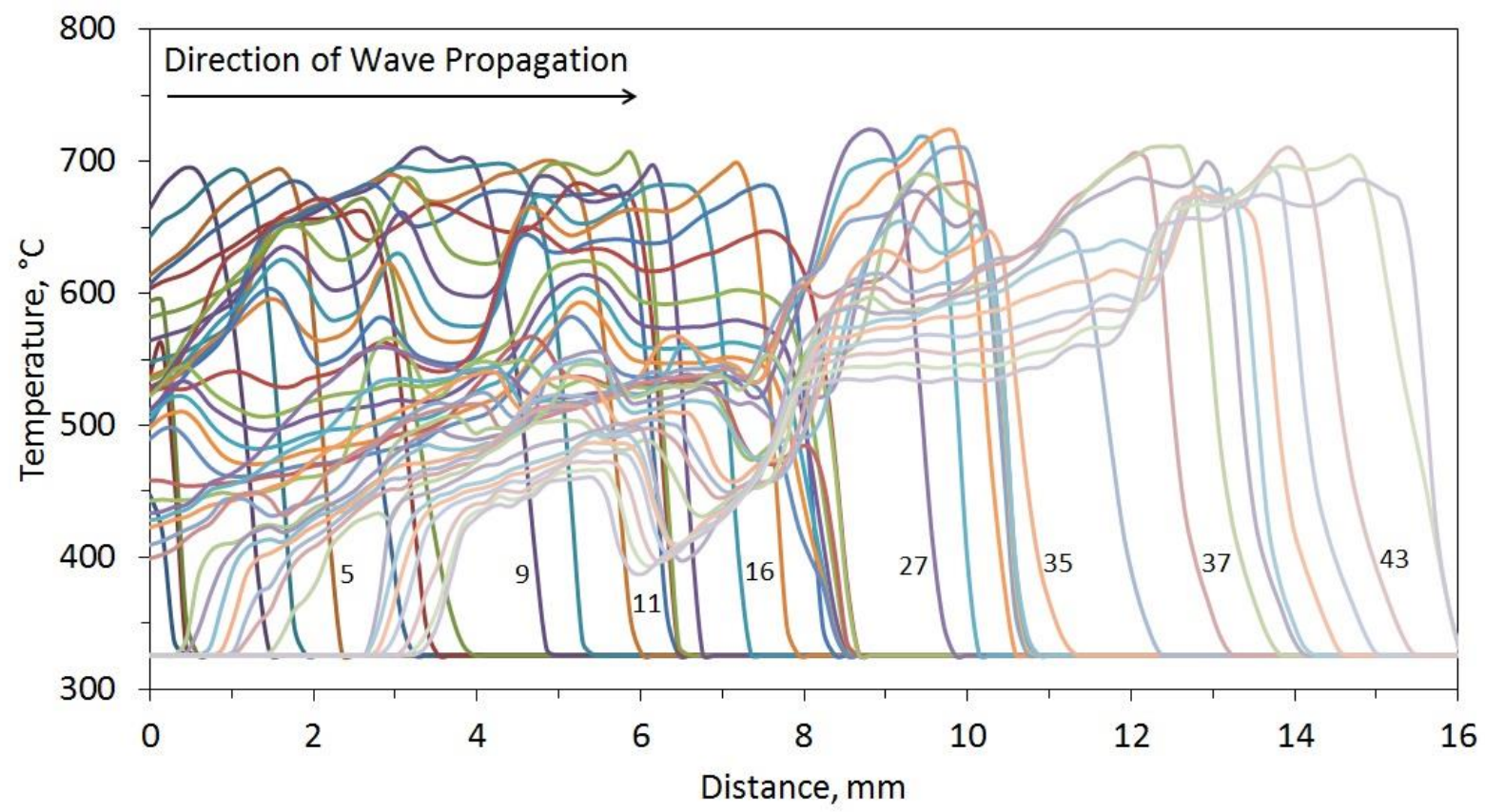




\subsubsection{Maximum Temperature and Combustion Front vs. Time}

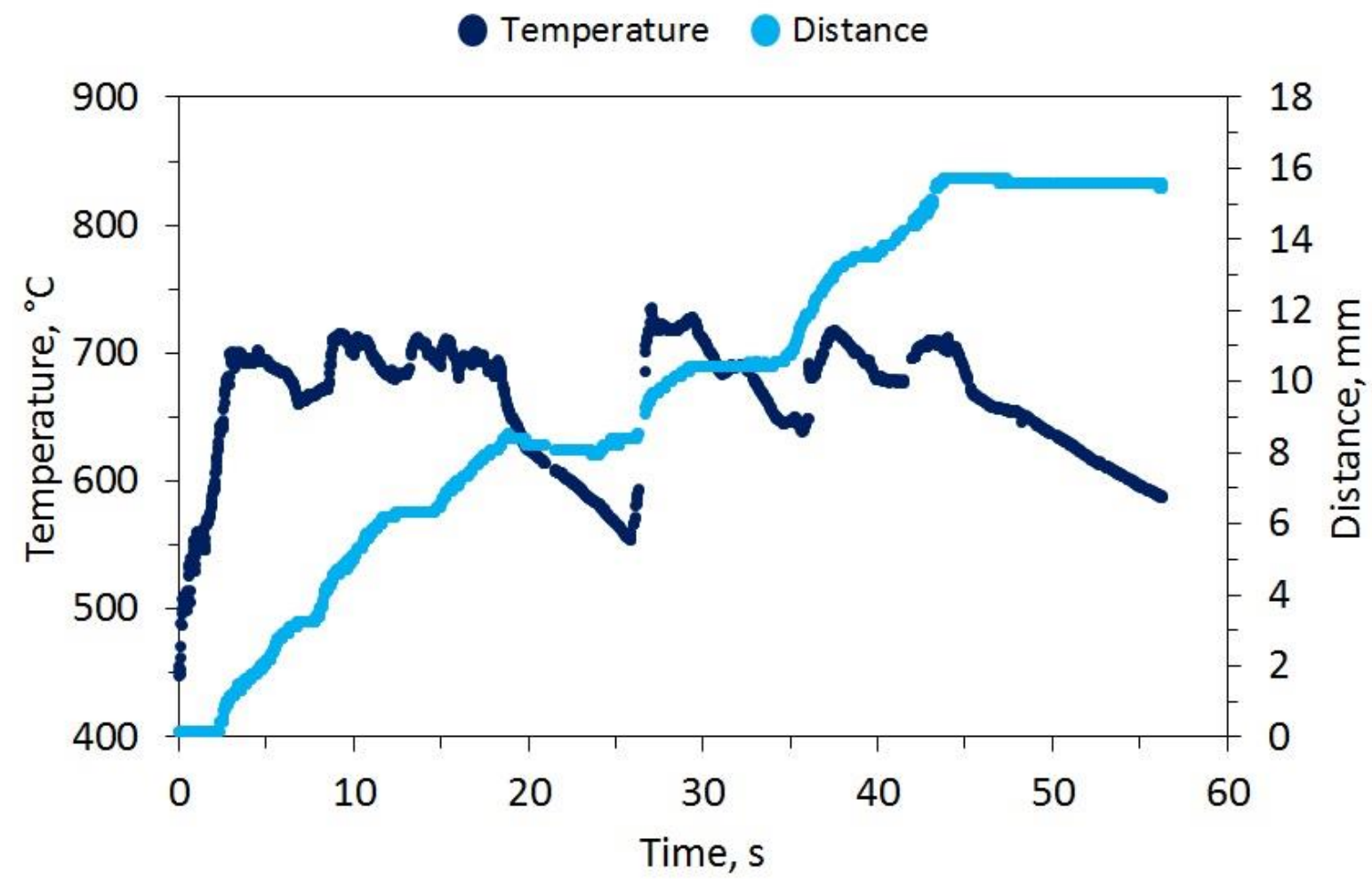

\section{$3.3 \quad 3 \mathrm{wt} \% \mathrm{Al} / \mathrm{Mg}(4.7: 5.3)$}

\subsubsection{Temperature vs. Time}

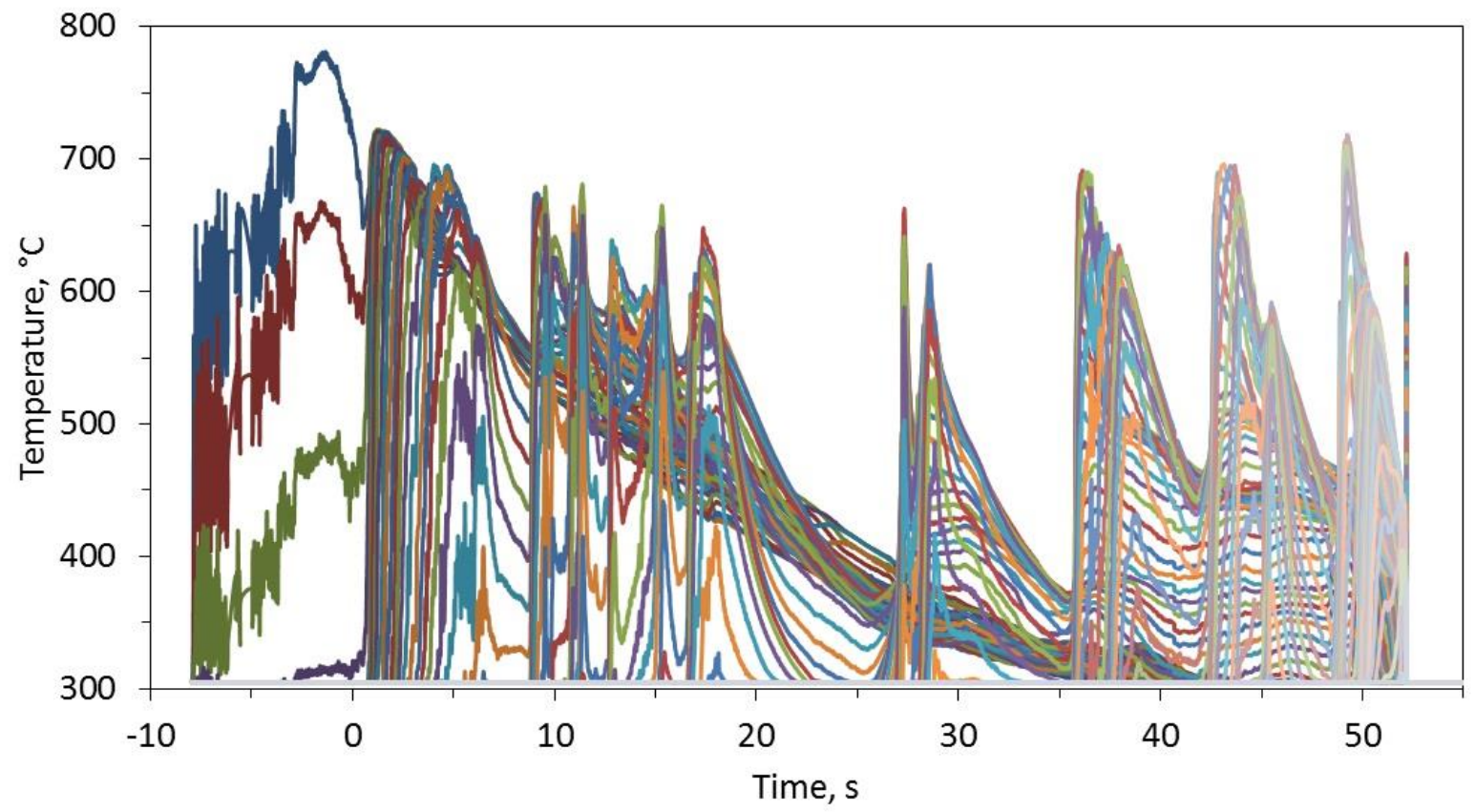




\subsubsection{Temperature vs. Distance}

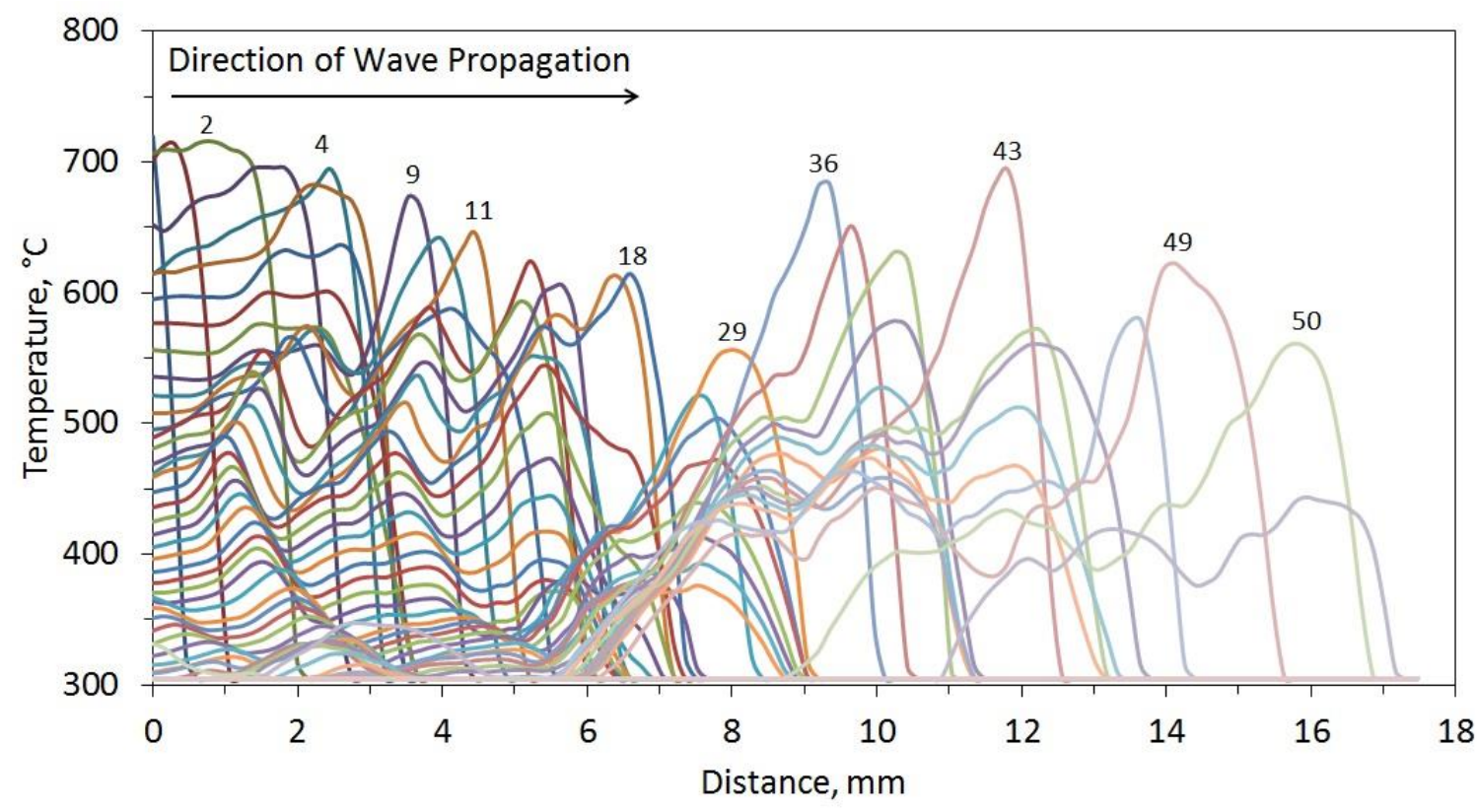




\section{Aluminum/Magnesium (7:3)}

\section{$4.15 \mathrm{wt} \%$ Al/Mg (7:3)}

\subsubsection{Temperature vs. Time}

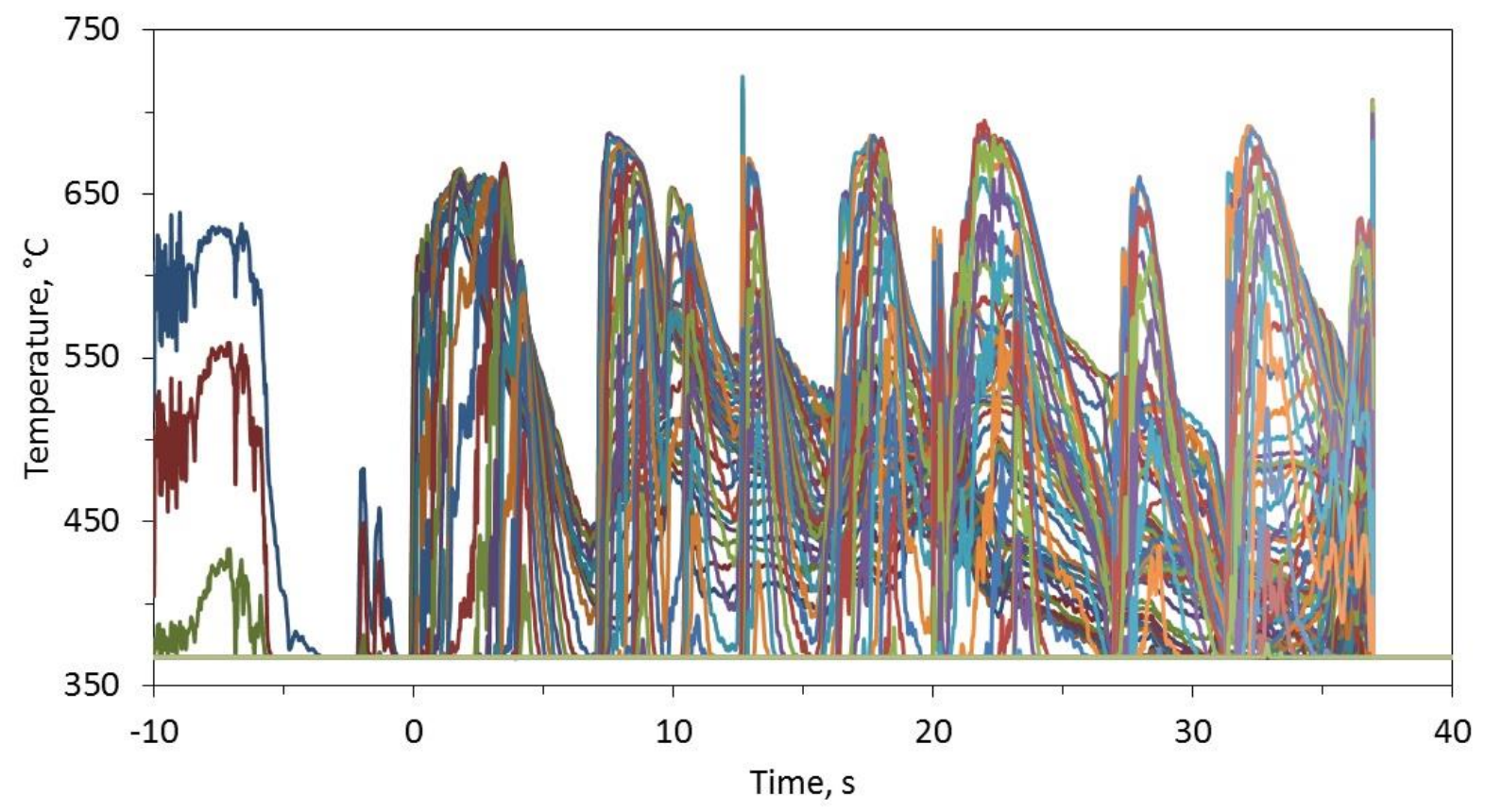

\subsubsection{Temperature vs. Distance}

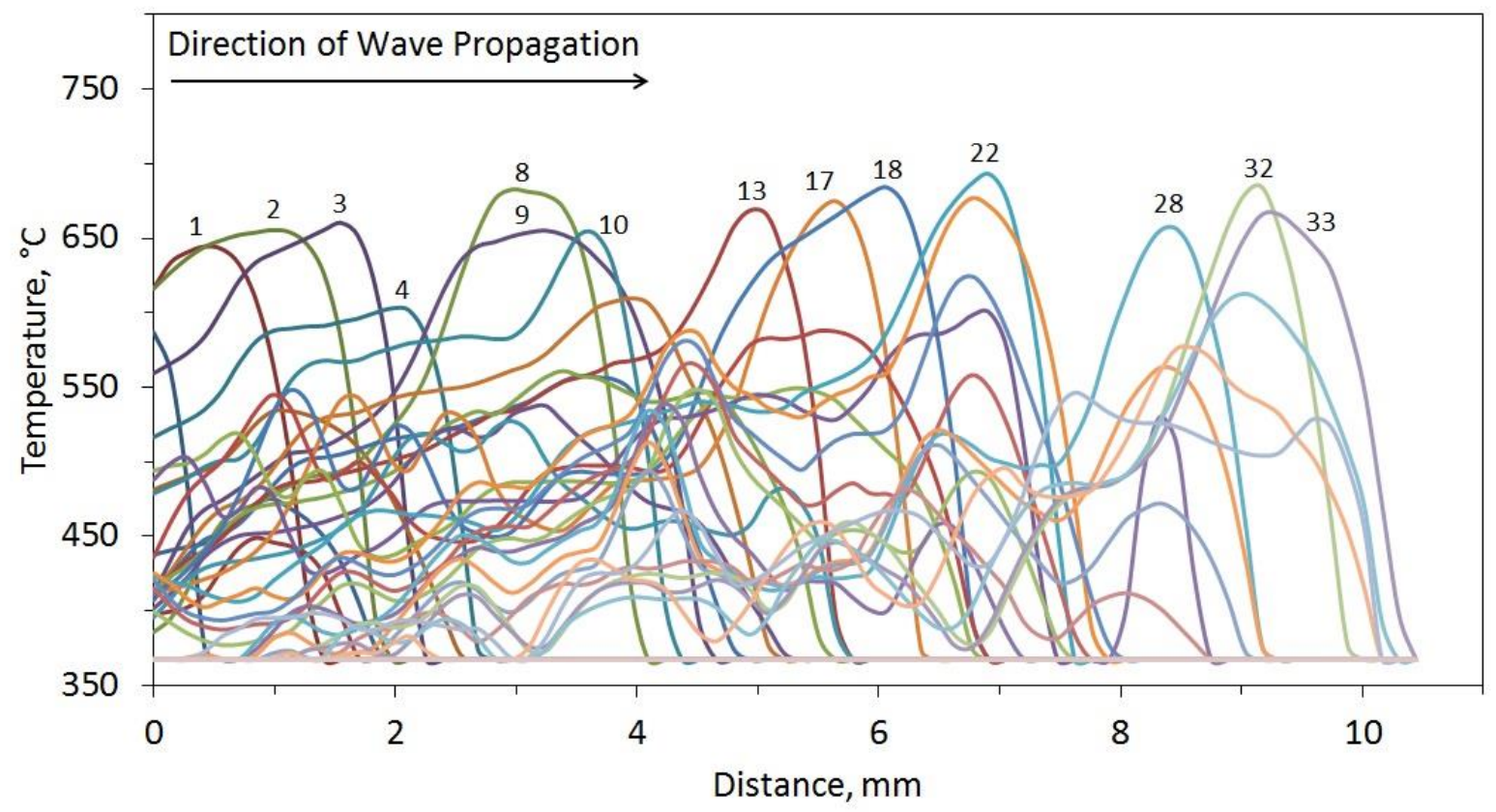




\section{IRON/MAGNESIUM (3:1)}

\section{$5.15 \mathrm{wt} \% \mathrm{Fe} / \mathrm{Mg}(3: 1)$}

\subsubsection{Temperature vs. Time}

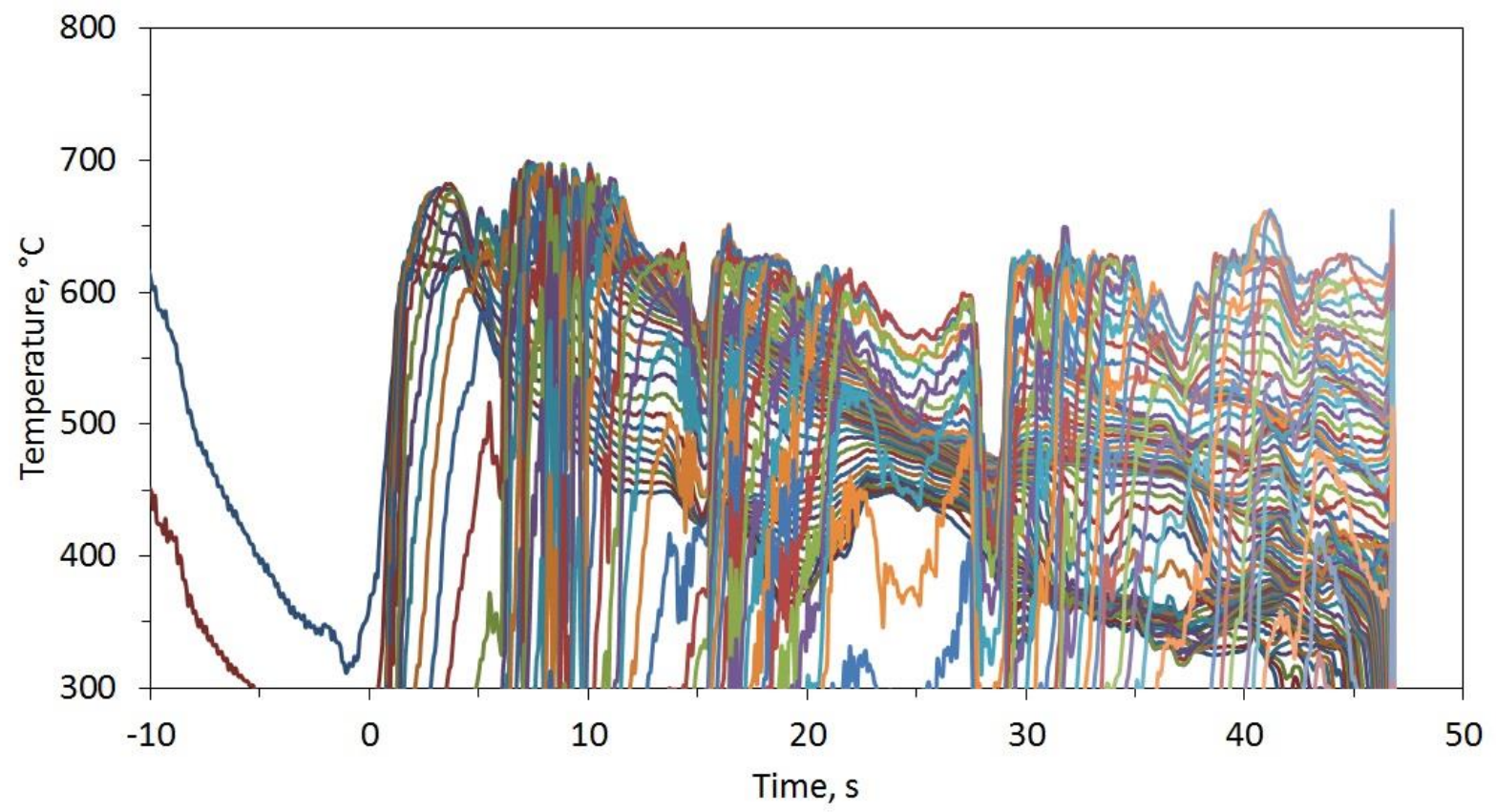

\subsubsection{Temperature vs. Distance}

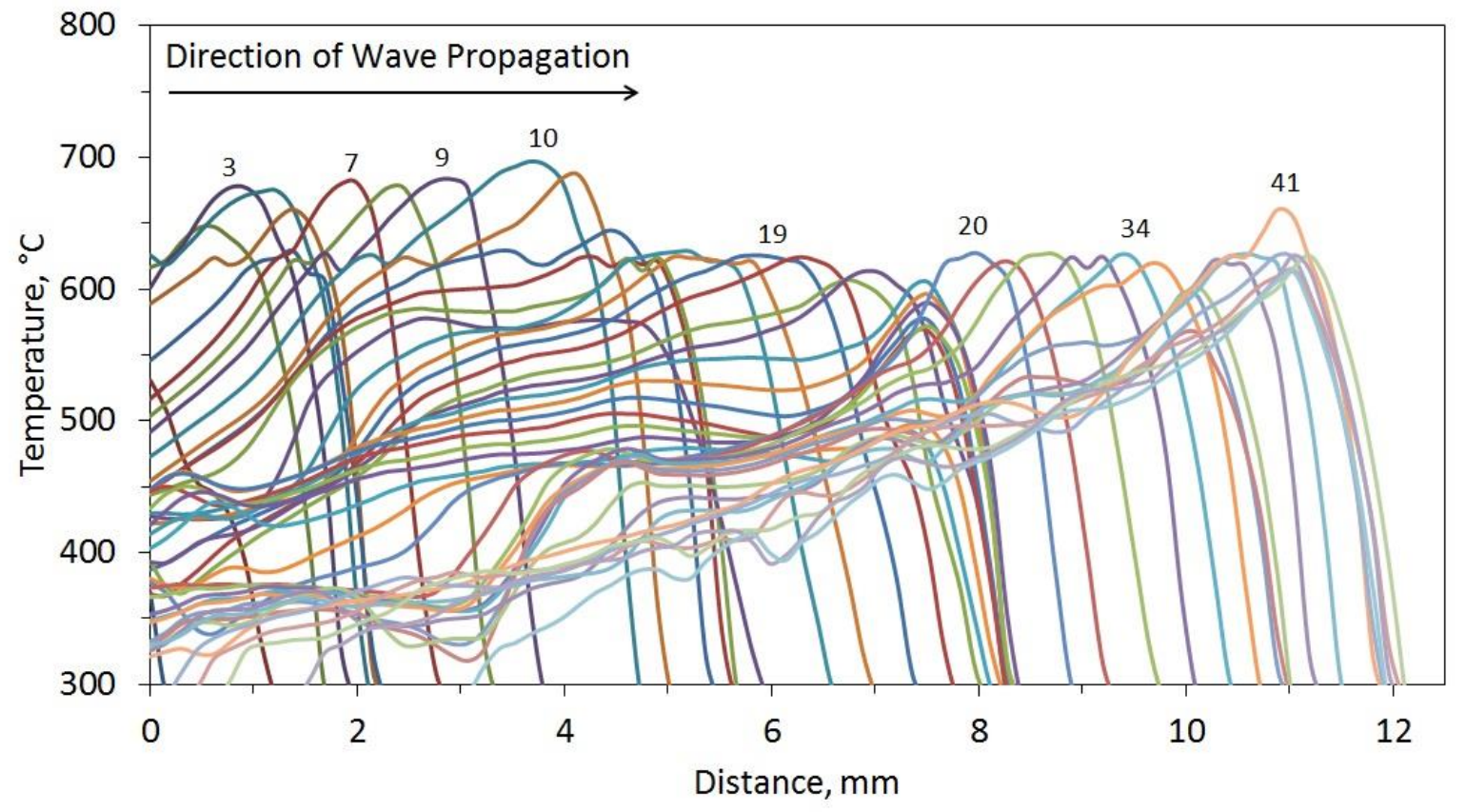




\section{BORON/TITANIUM $(2: 1)$}

\subsection{5 wt $\%$ B/Ti (2:1)}

\subsubsection{Temperature vs. Time}

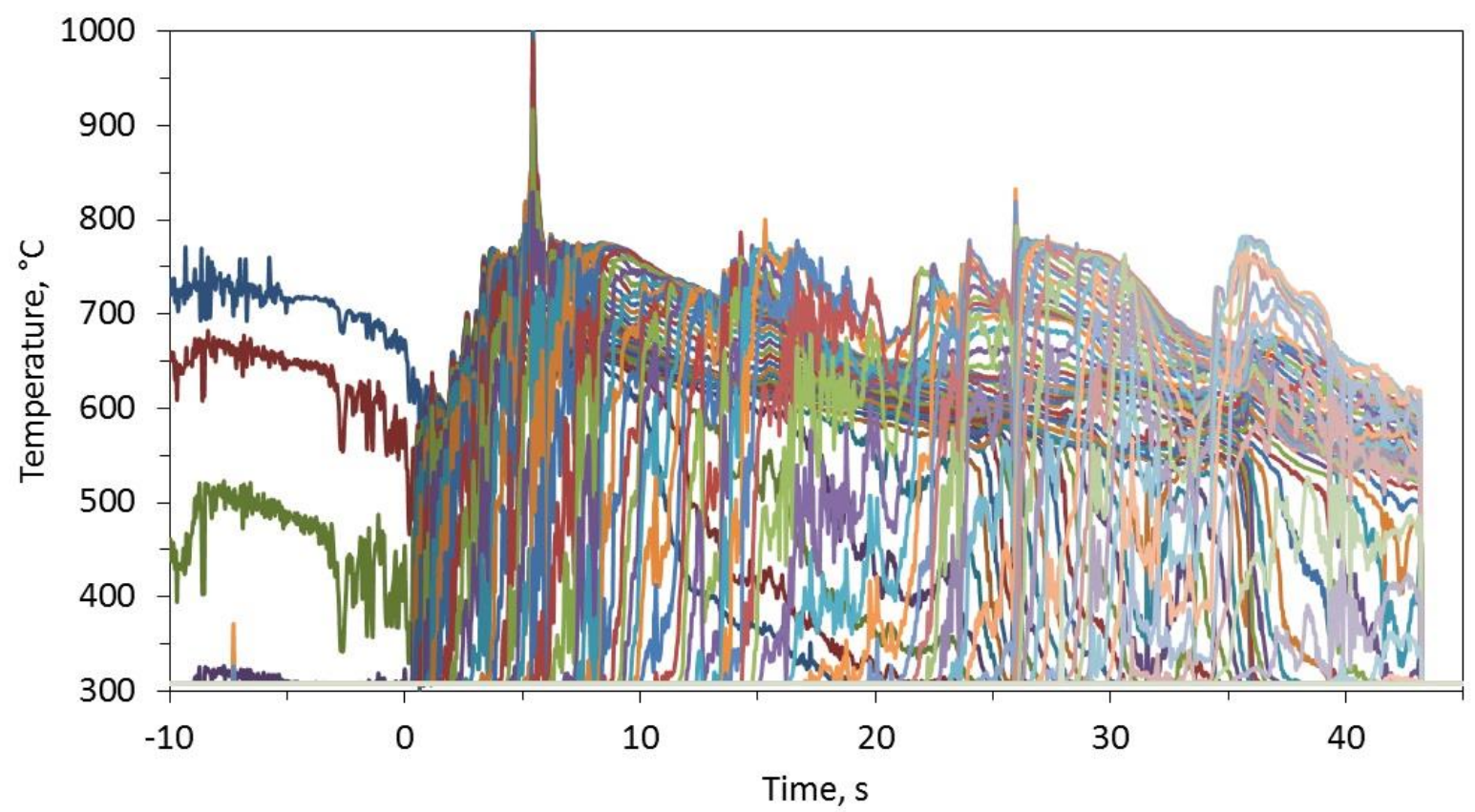

\subsubsection{Temperature vs. Distance}

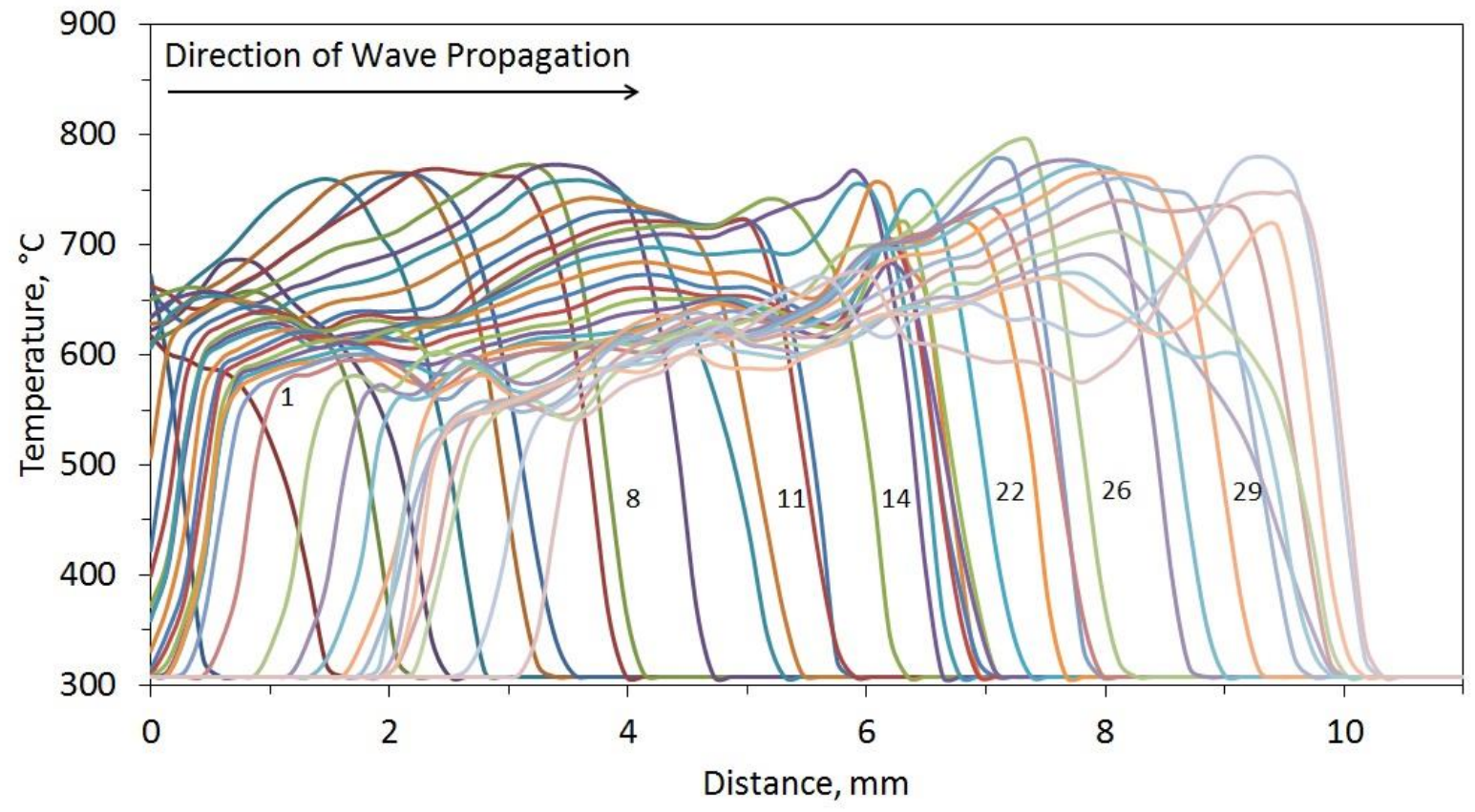




\section{VITA}

Marco Antonio Machado was born in El Paso, Texas in 1988. He is son of Federico Machado and Camerina Chavez. He grew up in Ciudad Juarez, Chihuahua, Mexico and moved to El Paso after finishing middle school. Marco attended Del Valle High School for two years and graduated from Parkland High School. In August 2007, Marco began his undergraduate studies at the University of Texas at El Paso. In summer 2010, Marco worked in the Lawrence Livermore National Laboratory (LLNL) under supervision by Dr. Evgeny Shafirovich. The results of that summer work were published in the LLNL internal report "A Review of Underground Coal Gasification Field Tests Sponsored by the U.S. Department of Energy.” In December 2011, Marco received his B.S. degree in Mechanical Engineering. In January 2012, Marco started his M.S. studies at UTEP and became a member of Dr. Shafirovich's research team in the Center for Space Exploration Technology Research, where he worked for the DoD-sponsored project on gas generators. In June 2012, Marco attended the Summer Combustion School at Princeton University. Marco presented his research results at the $51^{\text {st }}$ AIAA Aerospace Sciences Meeting in January 2013 and at the XII International Symposium on Selfpropagating High-temperature Synthesis in October 2013. A full-length article, titled "Nanocomposite

and Mechanically Alloyed Reactive Materials as Energetic Additives for Oxygen Generators," was submitted to a peer-reviewed journal (Combustion and Flame) in November 2013.

Permanent address: 11667 Caballo Lake Dr.

El Paso, TX 79936

This thesis/dissertation was typed by Marco Antonio Machado. 